\title{
APLICAÇÃO DE UM MODELO BASEADO EM ATIVIDADES PARA ANÁLISE DA RELAÇÃO USO DO SOLO E TRANSPORTES NO CONTEXTO BRASILEIRO
}

Tese apresentada à Escola de Engenharia de São Carlos da Universidade de São Paulo, como parte dos requisitos para obtenção do Título de Doutor em Engenharia Civil - Transportes.

Orientador: Prof. Associado Antônio Nélson Rodrigues da Silva

São Carlos 
Ficha catalográfica preparada pela Seção de Tratamento da Informação do Serviço de Biblioteca - EESC/USP

Arruda, Fabiana Serra de

Aplicação de um modelo baseado em atividades para análise da relação uso do solo e transportes no contexto brasileiro / Fabiana Serra de Arruda. -- São Carlos, 2005 .

Tese (Doutorado) -- Escola de Engenharia de São Carlos-Universidade de São Paulo, 2005.

Área: Transportes.

Orientador: Prof. Associado Antônio Nélson Rodrigues da Silva.

1. Planejamento de transportes. 2. Demanda por transportes. 3. Modelos baseados em atividades.

4. Transportes e uso do solo. 5. Planejamento urbano.

I. Título. 
Dedico este trabalho aos meus pais, Antônio e Inalva, que sempre estiveram ao meu lado em todas as situações e que me incentivaram a iniciar e a concluir mais esta etapa de minha vida. 


\section{AGRADECIMENTOS}

A Deus, por sempre colocar as pessoas certas em meu caminho;

Ao meu orientador, professor Antônio Nélson Rodrigues da Silva, pela oportunidade de desenvolver esta pesquisa e de amadurecer tanto profissional como pessoalmente, pelas conversas, conselhos e pelo incentivo ao longo desses anos;

Ao professor Harry Timmermans, da Universidade de Eindhoven, por ter possibilitado a realização do meu estágio nessa universidade e por me proporcionar a oportunidade de compartilhar experiências com os pesquisadores de seu grupo;

Ao professor Theo Arentze, por sua ajuda imprescindível ao desenvolvimento desta pesquisa e pelo conhecimento transmitido;

Aos pesquisadores e funcionários da Universidade de Eindhoven, que me deram apoio durante os meses em que estive na Holanda: Cláudia Pelizaro, Mandy, Astrid, Aloys, Peter;

À minha avó Dalva, minhas irmãs, irmão e sobrinhos que mesmo longe me deram apoio;

À Bete, Maria Angélica e Lis, pelas palavras amigas nos momentos difíceis;

Às minhas amigas e irmãs superpoderosas Márcia e Marcela;

À Cira, Karenina, Deise, Vanessa, Alexandra, Fábio, Eduardo "Lobão", Ana Furlan, Rodrigo e Karina, Renata, Simone, Dinato, Adalberto e os demais amigos e amigas do departamento de transportes;

Aos funcionários do Departamento de Transportes em especial à Heloisa, Beth e Magali, secretárias do departamento de transportes que sempre me ajudaram nos trâmites necessários; 
Ao Marcelo Amâncio por ter colaborado com parte desta pesquisa;

À professora Suely Sanches, que foi e é a maior incentivadora;

Ao professor Eiji Kawamoto pelo auxílio em várias etapas desta pesquisa;

À minha sobrinha Flávia por ter me ajudado nos momentos difíceis e na impressão desta tese;

Ao meu grande amigo Manoranjan, que tive o prazer de conhecer e foi uma das pessoas que mais me ajudaram em momentos difíceis de minha vida;

Aos meus companheiros de república Eugenia e Jonathan, pelos momentos agradáveis que tive em Eindhoven;

Às minhas amigas Anna Carolina e Daniela.

Aos funcionários do CETEPE, em especial à Márcia;

Ao CNPq pela bolsa de doutorado no Brasil e bolsa doutorado sanduíche;

À CAPES pela bolsa de doutorado sanduíche fornecida para que grande parte desta pesquisa fosse desenvolvida; 
Sobre a Descoberta

Ninguém nos pode privar da alegria do primeiro momento de consciência, ou seja, da descoberta. Mas, se reclamamos as respectivas honras, a alegria corre grave risco de se desfazer. Porque na maior parte dos casos não somos os primeiros.

O que é a descoberta? E quem pode dizer que descobriu isto ou aquilo? Que grande loucura é afinal alardear prioridades nesta matéria. Porque não querer confessar abertamente o plágio é arrogância e inconsciência. 
Há dois sentimentos que são os mais difíceis de ultrapassar: o que resulta de descobrir uma coisa que já foi descoberta e o que decorre de se não ver descoberto aquilo que se devia ter descoberto.

Johann Wolfgang von Goethe 


\section{SUMÁRIO}

RESUMO

ABSTRACT

PARTE I - FUNDAMENTOS TEÓRICOS

1. INTRODUÇÃO

1.1 Objetivos

1.2 Relevância da Pesquisa

1.3 Estrutura do Trabalho .....

2. USO DO SOLO E TRANSPORTES

2.1 Introdução

2.2 Modelos Integrados de Transportes e Uso do Solo ........................................... 7

2.2.1 URBANSIM

2.2.2 ILUMASS (Integrated Land-Use Modelling and Transportation System Simulation $)$...................................................... 13

2.2.3 ABSOLUTE (Activity-Based System of Land Use and Transport Events) ...... 14

2.3 Uso do Solo e Comportamento de Viagem ................................ 16

2.3.1 Densidade residencial, freqüência e comprimento da viagem ......................... 16

2.3.2 Densidade residencial e uso do transporte público ..................................... 17

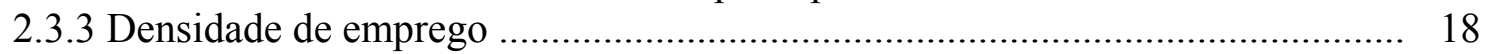

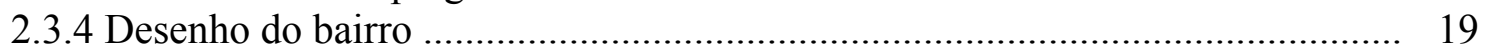

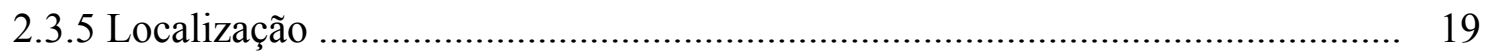

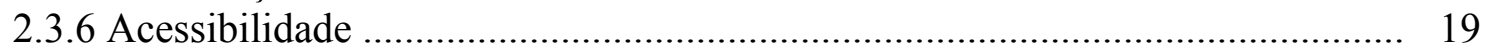

2.3.7 Fatores comportamentais e características sócio-econômicas ......................... 20

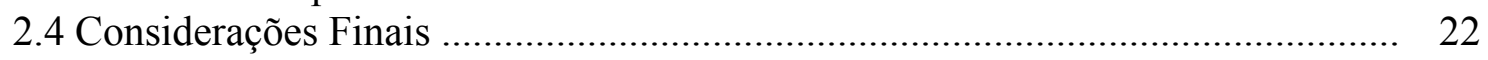

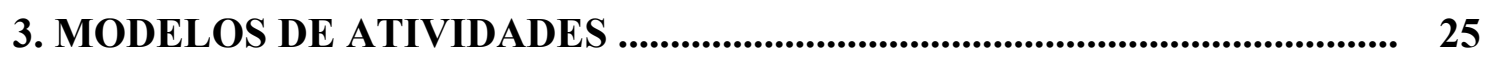

3.1 Modelos Baseados em Atividades ……....................................................... 26

3.2 Histórico ............................................................................................ 27

3.3 Considerações Referentes à Realização de Viagens e Atividades ....................... 29

3.4 Estrutura dos Modelos de Atividades ............................................................. 30

3.4.1 Modelos de atividade que utilizam a teoria da maximização da utilidade ........ 31

3.4.2 Modelos de atividades baseados em restrições .............................................. 32

3.4.3 Modelos de atividades baseados em regras lógicas ...................................... 33

3.4.4 Modelos de atividades que utilizam técnicas de microssimulação .................... 34

3.5 Dados Necessários aos Modelos de Atividades ................................................ 34

3.5.1 Metodologias para coleta de dados ........................................................ 35

3.5.2 Especificações do diário de atividades .................................................... 37

3.6 Considerações Finais ............................................................................. 41 
4. METODOLOGIA

4.1 Albatross (A Learning Based Transportation Oriented Model System) ......... 44

4.2 Arquitetura do Sistema Albatross ...................................................................... 46

4.3 Geração das Árvores de Decisão .................................................................. 58

4.4 Dados Requeridos pelo Modelo …….............................................................. 60

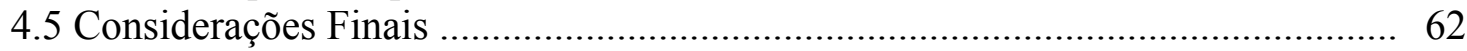

5. ESTUDO DE CASO .........................................................................................63

5.1 Estrutura do Questionário de do Diário de Atividades ................................... 67

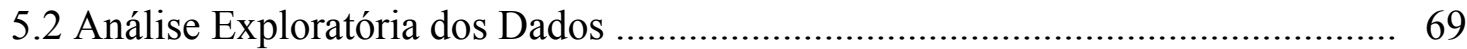

5.2.1 Características dos padrões de viagens e atividades .................................... 77

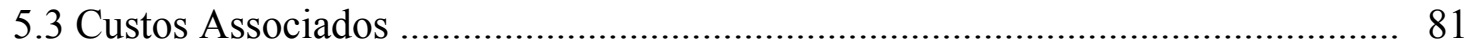

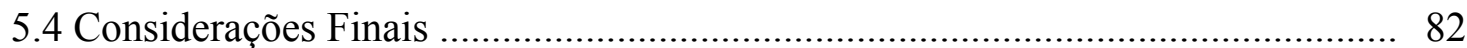

\section{PARTE II - RESULTADOS}

6. PADRÕES DE ATIVIDADES OBSERVADOS .............................................. 83

6.1 Estrutura dos Dados Usados na Calibração do Modelo .................................... 84

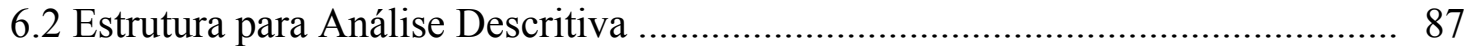

6.3 Resultados dos Padrões de Atividades Observados ........................................ 89

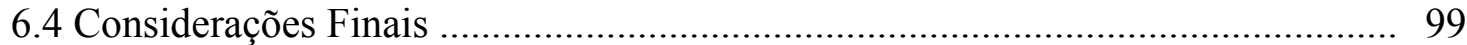

7. ÁRVORES DE DECISÃO

7.1 Conjunto de Variáveis Explicativas .............................................................. 102

7.1.1 Variáveis relacionadas às atividades e viagens ............................................ 102

7.1.2 Variáveis referentes ao uso do solo ................................................................. 103

7.2 Escolha do Modo de Transporte para a Atividade de Trabalho .......................... 105

7.3 Seleção das Atividades e Com Quem a Atividade será Realizada ....................... 108

7.4 Escolha do Horário de Início das Atividades e Decisões de Encadeamento das

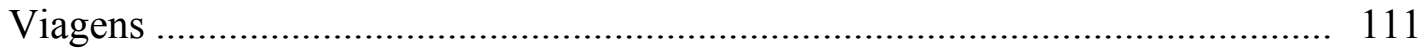

7.5 Escolha do Modo de Transporte para cada Encadeamento de Viagem e da Localização da Realização da Viagem ................................................................. 117

7.6 Considerações Finais ................................................................................... 125

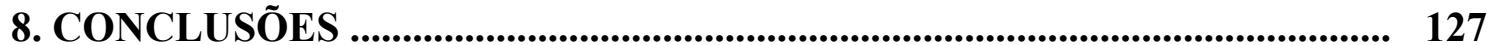

9. REFERÊNCIAS BIBLIOGRÁFICAS .............................................................. 134

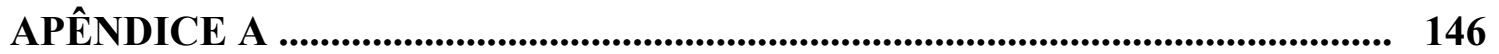




\section{LISTA DE FIGURAS}

Figura 2.1: Ciclo de realimentação transportes e uso do solo .................................. 6

Figura 2.2: Evolução da modelagem de transportes e uso do solo ............................ 8

Figura 2.3: Distribuição geográfica dos modelos integrados de transportes e uso

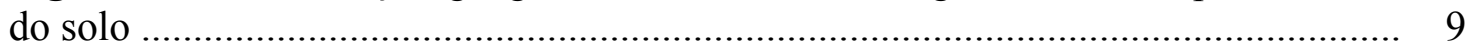

Figura 2.4: Distribuição dos modelos na matriz evolutiva de Wegener e Fürst ....... 12

Figura 3.1: Prisma espaço-tempo ............................................................... 28

Figura 4.1: Arquitetura do Sistema ............................................................... 46

Figura 4.2: Etapas de geração dos padrões de atividades fixas ............................. 55

Figura 4.3: Processo de previsão da localização das atividades fixas e flexíveis ..... 56

Figura 4.4: Processo de programação das atividades flexíveis ............................. 57

Figura 5.1: Distribuição geográfica dos 2000 domicílios selecionados para

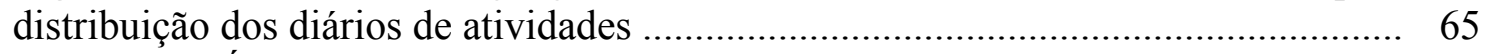

Figura 5.2: Área coberta na coleta de dados ..................................................... 66

Figura 5.3: Distribuição geográfica dos domicílios da amostra ............................ 67

Figura 5.4: Exemplo da página principal do diário de atividades aplicado em São

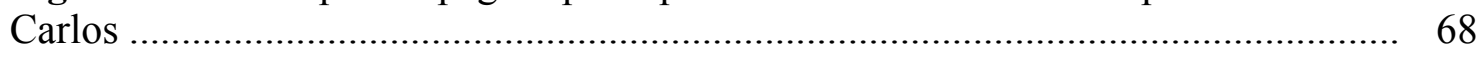

Figura 5.5: Distribuição da faixa etária na amostra avaliada ............................... 71

Figura 5.6: Grau de instrução da amostra avaliada ............................................... 72

Figura 5.7: Ocupação principal dos indivíduos na amostra ................................. 73

Figura 5.8: Posição no domicílio na amostra avaliada ......................................... 75

Figura 5.9: Faixa de renda domiciliar ................................................................ 75

Figura 5.10: Porcentagem do número de automóveis na amostra avaliada .............. 76

Figura 5.11: Porcentagem de utilização de cada modo de transporte na amostra

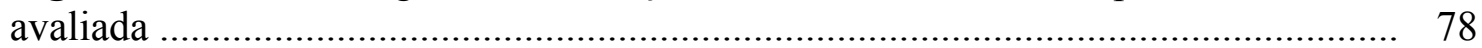

Figura 5.12: Porcentagem de viagens na amostra por faixas de distância ............... 78 


\section{LISTA DE TABELAS}

Tabela 4.1: Etapas do processo de programação de atividades 47

Tabela 4.2: Alternativas de escolha para cada etapa no processo de programação .. 48

Tabela 4.3: Resumo das atividades dos modelos no sistema de inferência

Tabela 4.4: Variáveis referentes às atividades/viagens utilizadas pelo modelo Albatross

Tabela 4.5: Variáveis referentes ao uso do solo utilizadas pelo modelo Albatross .. $\quad 61$

Tabela 5.1: Índice de aproveitamento do material de coleta de dados .................... 70

Tabela 5.2: Características básicas da variável faixa etária .................................. 71

Tabela 5.3: Freqüência de uso do automóvel por semana .................................... 76

Tabela 5.4: Duração das viagens por modo de transporte (em minutos) ................. 77

Tabela 5.5: Porcentagem de uso dos modos de transporte por faixas de distância ... 79

Tabela 5.6: Porcentagem dos motivos de viagem por faixas de distância ............... 80

Tabela 5.7: Porcentagem de realização das atividades ........................................... 80

Tabela 5.8: Duração média das atividades (em minutos) ...................................... 81

Tabela 5.9: Porcentagem de uso dos modos de transporte por motivos das atividades

Tabela 6.1: Freqüência do padrão de atividades antes da primeira viagem de trabalho, considerando o tempo necessário para a realização de atividades de trabalho/escola,para dias da semana

Tabela 6.2: Freqüência do padrão de atividades durante a primeira viagem de trabalho, em relação ao tempo empregado em atividades de trabalho/escola

Tabela 6.3: Freqüência do padrão de atividades entre dois episódios de trabalho ....

Tabela 6.4: Freqüência do padrão de atividades durante a última viagem de trabalho (viagem de volta do trabalho para o domicílio)

Tabela 6.5: Freqüência do padrão de atividades após a última viagem de trabalho . 
Tabela 6.6: Freqüência do padrão de atividades durante o período da manhã .......... 92

Tabela 6.7: Freqüência do padrão de atividades durante o período da tarde ............ 93

Tabela 6.8: Freqüência do padrão de atividades durante o período da noite ............ 93

Tabela 6.9: Freqüência média das atividades realizadas fora de casa com base na composição domiciliar

Tabela 6.10: Freqüência do padrão de atividades por número de encadeamento e por gênero

Tabela 6.11: Freqüência das atividades realizadas fora de casa por tipo de atividade e com quem a atividade foi realizada

Tabela 6.12: Duração das atividades por seus diferentes tipos 96

Tabela 6.13: Horário de início das atividades

Tabela 6.14: Freqüência das atividades realizadas fora de casa por tipo de atividade e tipo de viagem

Tabela 6.15: Freqüência das atividades realizadas fora de casa por tipo de atividade e modo de transporte

Tabela 7.1: Descrição das variáveis usadas na primeira etapa do processo de decisão

Tabela 7.2: Resultado da árvore de decisão para escolha do modo de transporte para a atividade de trabalho

Tabela 7.3: Descrição das variáveis usadas na segunda etapa do processo de decisão - seleção da atividade

Tabela 7.4: Resultado da árvore de decisão para a seleção da atividade flexível ....

Tabela 7.5: Descrição das variáveis usadas na segunda etapa do processo de decisão - com quem

Tabela 7.6: Resultado da árvore de decisão para a seleção da atividade com quem . 111

Tabela 7.7: Descrição das variáveis usadas na terceira etapa do processo de decisão - horário de início das atividades

Tabela 7.8: Resultado da árvore de decisão para a seleção da dimensão horário de início da atividade

Tabela 7.9: Descrição das variáveis usadas na terceira etapa do processo de decisão - encadeamento de viagens 
Tabela 7.10: Resultado da árvore de decisão para a seleção da dimensão encadeamento de viagem

Tabela 7.11: Descrição das variáveis usadas na quarta etapa do processo de decisão - modo de transporte para o encadeamento de viagem

Tabela 7.12: Resultado da árvore de decisão para a seleção da dimensão escolha do modo de transporte para o encadeamento de viagem

Tabela 7.13: Descrição das variáveis usadas na quarta etapa do processo de decisão - escolha da localização - parte 1

Tabela 7.14: Resultado da árvore de decisão para a seleção da dimensão escolha da localização - parte 1

Tabela 7.15: Descrição das variáveis usadas na quarta etapa do processo de decisão - escolha da localização - parte 2

Tabela 7.16: Resultado da árvore de decisão para a seleção da dimensão escolha da localização - parte 2 


\section{RESUMO}

ARRUDA, F. S. Aplicação de um modelo de atividades para análise da relação uso do solo e transportes no contexto brasileiro. Tese (Doutorado). Escola de Engenharia de São Carlos, Universidade de São Paulo, 2005.

Esta tese está voltada para dois temas que vêm sendo, embora raramente juntos, objeto de freqüentes estudos por pesquisadores de todo o mundo: os modelos baseados em atividades para análise da demanda por transportes, e as complexas inter-relações entre características do uso do solo e transportes. De forma geral, o objetivo principal deste estudo é, a partir da aplicação de um modelo baseado em atividades, caracterizar a influência das características do uso do solo nas decisões individuais sobre quais atividades e viagens realizar. $\mathrm{O}$ esforço para tal estudo se justifica por alguns motivos. Primeiro, pelo fato da modelagem baseada em atividades ser apontada como metodologia promissora na análise de demanda por transportes, o que conduz à expectativa de que a mesma seja capaz de fornecer resultados que permitam alcançar o objetivo principal desta tese. Segundo, por não existirem, até os dias de hoje, registros de aplicação dessa nova metodologia em cidades brasileiras, este estudo irá permitir que alguns objetivos secundários sejam alcançados. São eles: verificar tanto a viabilidade de aplicação dessa metodologia nas cidades brasileiras de médio porte, bem como buscar a metodologia mais adequada para a coleta dos dados necessários para a calibração desses modelos. Este estudo exploratório torna possível ainda a divulgação no meio acadêmico de uma experiência do uso desses modelos no contexto brasileiro, o que poderá auxiliar e incentivar outros pesquisadores a desenvolverem novos estudos sobre o tema. Em termos concretos, esta pesquisa tornou possível identificar os custos e dificuldades associados à coleta de dados, bem como avaliar o desempenho do modelo, tanto em termos gerais, como em relação aos resultados direcionados para o objetivo geral proposto. No tocante a este último aspecto, os resultados do modelo não permitiram a realização de análises conclusivas sobre a inter-relação uso do solo e transportes, ao que tudo indica em virtude da quantidade de dados coletados não sido suficiente para caracterizar as variáveis de uso do solo de modo claro. Ainda assim, esta tese cumpre um importante papel do ponto de vista acadêmico, na medida em que inova nos campos conceitual, metodológico e tecnológico, além de servir como guia e incentivo para que outros pesquisadores aprofundem o estudo dos modelos baseados em atividades para modelagem da demanda por transportes.

Palavras-chave: planejamento de transportes, demanda por transportes, modelos baseados em atividades, transportes e uso do solo, planejamento urbano. 


\section{ABSTRACT}

ARRUDA, F. S. Analysis of the land use-transportation relationship with an activitybased model in the context of Brazil. Thesis (Doctorate). São Carlos School of Engineering, University of São Paulo, 2005.

This study is directed to two themes that frequently are, although rarely together, the subject of research projects in many parts of the world: the use of activity based models for the analysis of transportation demand and the complex relationships among land use characteristics and transportation. The main aim of this work is to verify the influence of land use characteristics on individual activities and travel decisions, by means of an activity based model. The motivation for it comes from two aspects. First, activity based models are pointed by many authors as the most promising approach currently available for transportation demand analysis. As a consequence, it may be able to produce results that contribute for reaching the main objective of this study. Second, given that the search in the literature has shown no records of activity-based models applied to Brazilian cities, this study also contributes to the some secondary objectives, as follows. It helps to test the viability of the modeling approach in Brazilian medium-sized cities and it is also useful for seeking the most appropriate method for the collection of data needed for model calibration. In addition, exploratory studies such as this one are important to disseminate the possibilities offered by the models in the Brazilian context, what can encourage other researchers to direct efforts to the topic. In concrete terms, the application carried out in this investigation made possible not only to identify the costs and difficulties associated to data collection, but also to evaluate the model performance. Its performance was assessed in two ways: in general terms, and concerning the results specifically associated with the main objective of the study. With regard to the latter, the model results did not allow conclusive analyses about the land use-transportation relationship, apparently because the data sample was not comprehensive enough to clearly characterize land use variables. Even though, this investigation plays an important role from an academic standpoint, given that it brings innovation to the country in conceptual, methodological, and technological fields. As a consequence, its main merit is certainly to serve as a guide and an incentive to other Brazilian researchers interested in the development of new studies about activity based models and their application to transportation demand modeling.

Key words: transportation planning, transportation demand, activity based models, transportation and land use, urban planning. 


\section{INTRODUÇÃO}

Não existem dúvidas que o sistema de transportes e o planejamento do uso do solo estão intrinsecamente ligados. Essa afirmação se baseia no reconhecimento que a distribuição do uso do solo afeta a demanda de viagem, e investimentos no sistema de transportes afetam as decisões de uso do solo (Waddell, 2000).

A complexidade da inter-relação entre as características do uso do solo e transportes é uma das questões que tem sido muito estudada por vários pesquisadores. $\mathrm{O}$ entendimento de como estas podem afetar o conjunto de decisões individuais de realização de viagens é tema de vários estudos.

Apesar de muitos trabalhos terem sido realizados, ainda nos dias de hoje existem divergências quanto às respostas encontradas (Zegras, 2004). Enquanto alguns autores afirmam existir forte relação entre características do uso do solo e comportamento de viagem (Wee, 2002), outros afirmam que essa relação, quando existente, é fraca, e que outras características (por exemplo, as socioeconômicas) moldam o comportamento de viagem individual (Boarnet e Sarmiento, 1996, Kitamura et al., 1997; Crane e Crepeau, 1998).

A demanda de viagem é derivada da necessidade individual de realização de atividades espacialmente dispersas no meio urbano. Além de ser influenciado pelas alterações que ocorrem na estrutura espacial das cidades, o comportamento de viagem pode também ser determinado em função de aspectos da estrutura domiciliar. Desta forma, os indivíduos necessitam adaptar sua programação diária de realização de atividades às necessidades domiciliares. Alterações como maior participação feminina no mercado de trabalho, presença de crianças, novas tecnologias (teletrabalho) e novas 
opções de rotas entre dois locais, trazem a necessidade de reorganização das agendas de atividades, atribuindo a elas graus de prioridade, de tal forma que a cada indivíduo cabe $\mathrm{a}(\mathrm{s}) \operatorname{tarefa}(\mathrm{s})$ que deve realizar, na seqüência relacionada com sua prioridade.

O conjunto de possíveis padrões de atividades e viagens é amplo e sujeito a vários fatores externos (como alterações no ambiente de viagem, por exemplo) que podem alterar a rotina diária individual. Os modelos de demanda por transportes tradicionalmente usados não são capazes de modelar alternativas de viagem que incorporem novas tendências de comportamento (Moeckel et al. 2003), como a não consideração do fato de que algumas viagens são planejadas em função daquelas realizadas anteriormente ou posteriormente. As viagens encadeadas, estudadas por Pitombo (2003) e Ichikawa (2002), por exemplo, são apenas um dos exemplos de tendência de comportamento de viagem individual que devem ser investigados para melhor compreensão das relações entre uso do solo e transportes.

Por serem capazes de captar as variações que ocorrem no processo de programação de atividades individual e domiciliar, considerando principalmente o tempo disponível para a realização das mesmas, os modelos baseados em atividades se apresentam como metodologia mais adequada para análise da demanda por transportes. Por extensão, a hipótese central deste trabalho é que esta metodologia seria também a mais adequada para avaliar a relação entre uso do solo e transportes.

\subsection{Objetivos}

O objetivo principal desta pesquisa é explorar a viabilidade de aplicação de um modelo baseado em atividades no contexto das cidades brasileiras. Paralelamente, seus objetivos secundários são:

- Identificar a viabilidade de aplicação de uma nova metodologia de coleta de dados em uma cidade brasileira, em termos de qualidade dos dados, tempo e custo;

- Divulgar, no meio acadêmico, os conceitos teóricos que envolvem o desenvolvimento de um modelo baseado em atividades e os obstáculos que podem ser encontrados na tentativa de aplicação do mesmo no contexto brasileiro. 
De modo a alcançar os objetivos propostos, será feito um estudo de caso, que consiste em identificar a relação entre as características do uso do solo e transportes (padrão de viagens individual e domiciliar) a partir de um modelo baseado em atividades, através de sua aplicação a uma cidade brasileira de médio porte.

\subsection{Relevância da Pesquisa}

De acordo com a literatura, o desenvolvimento de modelos baseados em atividades tem sido estimulado por vários grupos de pesquisadores (Bhat e Lawton, 2000; Marshment, 2000). Ao mesmo tempo, a maior complexidade do conjunto de opções disponíveis ao indivíduo para programar sua agenda diária de atividades e viagens traz a necessidade de investigação sobre quais os fatores do uso do solo que efetivamente afetam o processo de tomada de decisão neste caso. Grande parte dos trabalhos realizados para verificação da influência das características de uso do solo no comportamento de viagem individual analisa cada viagem independentemente do contexto diário sobre quais atividades realizar, desconsiderando, muitas vezes, as restrições impostas aos indivíduos (institucionais, individuais e temporais). De modo a preencher essa lacuna, pesquisas vêm sendo desenvolvidas para testar a nova geração de modelos de demanda por transportes, cujas especificações são mais avançadas e com as quais se espera substituir os modelos tradicionalmente usados (Snellen, 2000; Arentze e Timmermans, 2000).

Nesse contexto, esta pesquisa pretende usar a nova geração de modelos de demanda para avaliar as possíveis relações entre uso do solo e transportes, de modo a verificar a viabilidade de aplicação desses modelos em uma cidade brasileira de porte médio.. Certamente o desenvolvimento desta pesquisa irá contribuir para o aumento do conhecimento científico, no Brasil, na área da modelagem baseada em atividades, já que até a conclusão deste trabalho não foram encontrados registros de aplicação direta de um modelo baseado em atividades em cidades brasileiras.

Espera-se que este trabalho possa contribuir, se não com a geração de resultados práticos, mas como instrumento de exploração de novas técnicas e metodologias na área de transportes, e ainda como estímulo a outros pesquisadores da área de planejamento de transportes para que novas pesquisas venham a ser realizadas para o desenvolvimento e aplicação de um modelo baseado em atividades nacional. 


\subsection{Estrutura do Trabalho}

O presente trabalho é composto por 9 capítulos, divididos em duas partes a partir desta introdução. A primeira parte se destina aos aspectos teóricos e metodológicos da pesquisa e compreende os capítulos de 2 a 4 . O capítulo 2 se refere aos fundamentos teóricos sobre a relação entre uso do solo e transportes. O tema é abordado em dois tópicos principais: o primeiro descreve os modelos integrados de transportes e uso do solo; o segundo relaciona os trabalhos pontuais desenvolvidos e as variáveis freqüentemente empregadas pelos pesquisadores da área. Este capítulo tem como objetivo fornecer a base teórica ao desenvolvimento deste trabalho. No capítulo 3 são apresentados os fundamentos dos modelos baseados em atividades. A metodologia usada é descrita no capítulo 4.

A segunda parte se destina à exploração dos resultados obtidos a partir da aplicação, tanto da metodologia de coleta de dados como dos resultados gerados pelo modelo aqui usado. No capítulo 5 são apresentados, além da metodologia usada para a coleta dos dados, o estudo de caso e a análise exploratória dos dados. O capítulo 6 é destinado aos resultados obtidos a partir da inclusão no modelo do conjunto de dados coletados. Nesse capítulo são apresentados os padrões de atividades observados na amostra analisada, gerados pelo modelo empregado. O capítulo 7 se destina à apresentação dos resultados gerados a partir da aplicação de um algoritmo de escolhas inerente ao próprio modelo, que fornece quais as possíveis escolhas individuais dentro de um conjunto mais amplo de alternativas.

O capítulo 8 relata as conclusões do trabalho juntamente com sugestões de melhorias e de trabalhos futuros e o capítulo final se destina às referências bibliográficas que serviram como base ao desenvolvimento desta pesquisa. 


\section{USO DO SOLO E TRANSPORTES}

O objetivo deste capítulo é apresentar alguns trabalhos desenvolvidos para análise da relação entre uso do solo e transportes, de modo a formar a base teórica para o desenvolvimento desta pesquisa. Após o item introdutório, a análise da relação entre uso do solo e transportes será abordada em dois tópicos principais. O primeiro diz respeito aos modelos integrados de transportes e uso do solo, no qual será feita uma breve apresentação sobre o processo evolutivo desses modelos. A título de exemplo, serão apresentados três dos modelos mais atuais, que empregam em sua estrutura abordagens mais sofisticadas. O segundo tópico apresenta trabalhos pontuais, desenvolvidos para a verificação da influência de características diversas do uso do solo sobre o comportamento de viagem individual. Os trabalhos relacionados fornecem evidências de como essas características afetam (ou não) o comportamento de viagem individual, e também as hipóteses comumente testadas pelos diversos autores. Esses trabalhos servem como referencial teórico para a escolha do conjunto de variáveis e das hipóteses relacionadas ao uso do solo e transportes a serem investigadas nesta pesquisa.

\subsection{Introdução}

A necessidade de participação em atividades dispersas no espaço urbano determina o padrão de viagem a ser adotado pelo indivíduo, dentro de um conjunto de opções a ele disponíveis e restrições encontradas: tempo para realização da viagem e da atividade, disponibilidade de modos de transporte, local, composição domiciliar etc. Nesse contexto, a disposição dos locais das atividades no meio urbano determina a maior ou menor facilidade com que o indivíduo pode cumpri-las diariamente. 
De acordo com Wegener e Fürst (1999), a interrelação entre uso do solo e transportes, ou seja, como as decisões de viagem e a distribuição das atividades influenciam uns aos outros, pode ser representada pelo "ciclo de realimentação uso do solo-transportes" (Figura 2.1), que os autores definem como:

- A distribuição dos tipos de uso do solo (como o residencial, industrial ou comercial) em áreas urbanas determina a localização das atividades humanas, como moradia, trabalho, compras, educação ou lazer;

- A distribuição espacial das atividades humanas requer interações espaciais (ou viagens) nos sistemas de transportes para vencer as distâncias entre as localizações das atividades;

- A distribuição da infra-estrutura do sistema de transportes cria oportunidades para a interação espacial e pode ser medida em termos de acessibilidade;

- A distribuição da acessibilidade no espaço determina as decisões de localização, o que resulta em alterações no sistema de uso do solo.

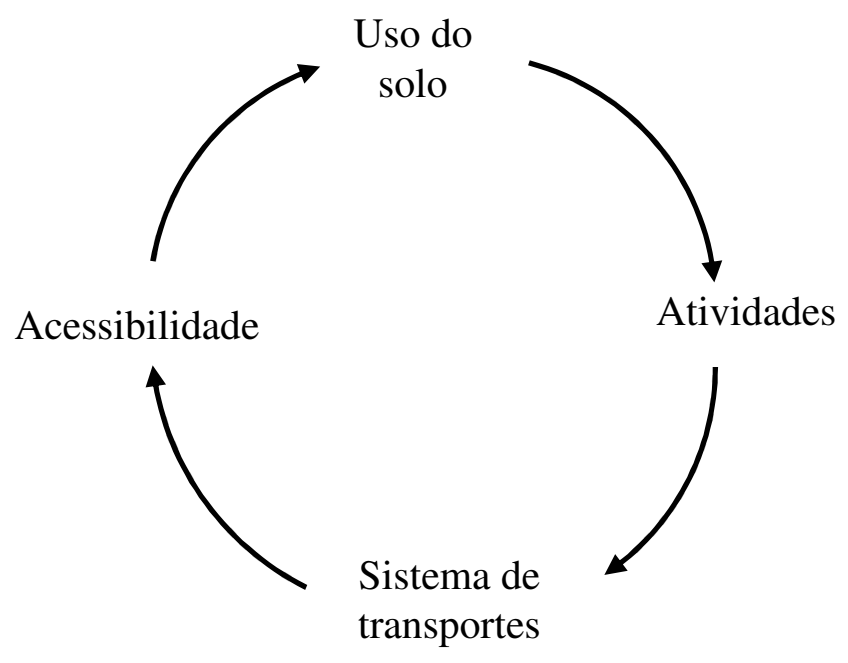

Figura 2.1: Ciclo de realimentação transportes e uso do solo (Wegener e Fürst, 1999).

Entre as metodologias utilizadas para avaliar de forma sistemática a interrelação entre os sistemas de uso do solo e transportes estão os modelos integrados de 
transportes e uso do solo. De acordo com Wegener (2003), esses modelos incorporam o processo mais essencial de desenvolvimento espacial: eles incluem o uso do solo urbano (quantidade de solo ocupado por usos residencial, industrial, comercial etc.) e o sistema de transportes (que pode ser modelado tanto pelo mesmo modelo, como por modelos exógenos de demanda de transportes).

\subsection{Modelos Integrados de Transportes e Uso do Solo}

Vários modelos que integram o sistema de transportes e os usos do solo foram e vêm sendo desenvolvidos, de modo a prever os padrões de desenvolvimento do solo urbano e dos sistemas de transportes (Wegener, 2003). Pesquisadores de diversas partes do mundo têm buscado o aprimoramento de modelos tradicionalmente usados para a quantificação da demanda por transportes a partir da inclusão da modelagem, com uso de técnicas de microsimulação, por exemplo, dos aspectos do uso do solo (Abraham et al, 2004). Um dos desafios nesta área é desenvolver modelos que sirvam como ferramentas adequadas para representar os problemas de transportes e uso do solo, considerando qualquer política relevante relacionada a um desses sistemas (ou a ambos), com maior variedade de indicadores de desempenho (Kim et al., 2003).

Um dos primeiros modelos a integrar os aspectos dos sistemas de transportes e uso do solo foi desenvolvido por Lowry na década de 60. O objetivo era "explicar a conformação urbana das áreas residenciais e dos centros de atividades a elas associadas, sob o ponto de vista de concentração demográfica" (Novaes, 1981). A partir do modelo gravitacional originalmente desenvolvido, vários outros modelos foram surgindo.

De acordo com Waddell (199?) os modelos surgidos nos Estados Unidos entre as décadas de 60 e 80 tinham como objetivo solucionar os problemas relacionados à capacidade viária. $\mathrm{O}$ desafio era acomodar o aumento do número de viagens resultantes da maior distribuição espacial dos domicílios e locais de emprego na área metropolitana. Esses modelos, inicialmente voltados principalmente à modelagem das viagens por automóvel, passaram a integrar, gradualmente, modos de transporte alternativos, como o transporte coletivo e os modos não motorizados e algumas características do uso do solo.

A Figura 2.2 apresenta a matriz evolutiva dos modelos de transportes e uso do solo (Wegener e Fürst, 1999), na qual as linhas correspondem aos diferentes níveis de modelagem de uso do solo e as colunas aos níveis de modelos de demanda de 
transportes. De acordo com essa lógica, os modelos evoluem do canto superior esquerdo (L1/T1) para o canto inferior direito (L6/T4). Dessa forma fica fácil observar a transição da modelagem voltada apenas ao automóvel (T1) para a análise multimodal (T4).

O processo de modelagem mais complexo, com incorporação da inter-relação entre os sistemas de transportes e uso do solo, apontou a necessidade de desenvolvimento de modelos capazes de englobar o maior número possível de aspectos desses sistemas de forma clara, e que facilitasse o teste e a avaliação dos impactos da aplicação de políticas de transportes e uso do solo (Waddell, 199?) sobre a demanda de viagem.

Nesse contexto, Wegener e Fürst (1999) evidenciam o uso da abordagem baseada em atividades para o desenvolvimento de modelos mais sofisticados, como pode ser observado pela Figura 2.2 (canto inferior direito).

\begin{tabular}{|c|c|c|c|c|c|}
\hline \multirow{2}{*}{\multicolumn{2}{|c|}{ Modelos de uso do solo }} & T1 & $\mathbf{T 2}$ & T3 & T4 \\
\hline & & $\begin{array}{l}\text { Não considera } \\
\text { transporte } \\
\text { público e } \\
\text { escolha modal }\end{array}$ & $\begin{array}{l}\text { Considera o } \\
\text { transporte } \\
\text { público, não } \\
\text { utiliza } \\
\text { modelos } \\
\text { Logit, adota } \\
\text { período de } \\
\text { análise de } 24 \mathrm{~h} \\
\end{array}$ & $\begin{array}{c}\text { Considera o } \\
\text { transporte } \\
\text { público, uso } \\
\text { de modelos } \\
\text { Logit, análise } \\
\text { do horário de } \\
\text { pico }\end{array}$ & $\begin{array}{c}\text { Análise } \\
\text { multimodal, } \\
\text { baseada em } \\
\text { atividades }\end{array}$ \\
\hline L1 & Nenhum & & & & 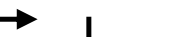 \\
\hline $\mathbf{L} 2$ & Atividade & & & & \\
\hline $\mathbf{L 3}$ & $\begin{array}{l}\text { Alocação de usos do solo } \\
\text { não segue regras de mercado }\end{array}$ & & & & $\downarrow$ \\
\hline $\mathbf{L 4}$ & $\begin{array}{c}\text { Alocação tipo Logit com } \\
\text { inclusão de preços do solo } \\
\text { urbano }\end{array}$ & & & & \\
\hline L5 & $\begin{array}{l}\text { Modelo de uso do solo de } \\
\text { acordo com regras de } \\
\text { mercado }\end{array}$ & & & & \\
\hline L6 & $\begin{array}{l}\text { Modelo de uso do solo } \\
\text { baseado em atividades }\end{array}$ & & & & \\
\hline
\end{tabular}

Figura 2.2: Evolução da modelagem de transportes e uso do solo.

Fonte: Wegener e Fürst (1999)

O desenvolvimento de modelos de transportes e uso do solo baseados em 
atividades é também defendido por Waddell (199?) e Wegener (2003), uma vez que essa abordagem envolve toda a complexidade das viagens individuais, bem como a influência de políticas de transporte e uso do solo sobre o comportamento de viagem.

De modo a apresentar um panorama geral dos modelos integrados já desenvolvidos e em desenvolvimento até os dias de hoje, são apresentados nas Figuras 2.3 e 2.4 a distribuição geográfica desses modelos e sua respectiva localização na matriz evolutiva de Wegener e Fürst, de acordo com a estrutura de cada um deles. Vale ressaltar a inclusão do modelo integrado de transportes e uso do solo desenvolvido por Arentze e Timmermans (ABSOLUTE) (2004), posterior à publicação da matriz originalmente proposta por Wegener e Fürst.

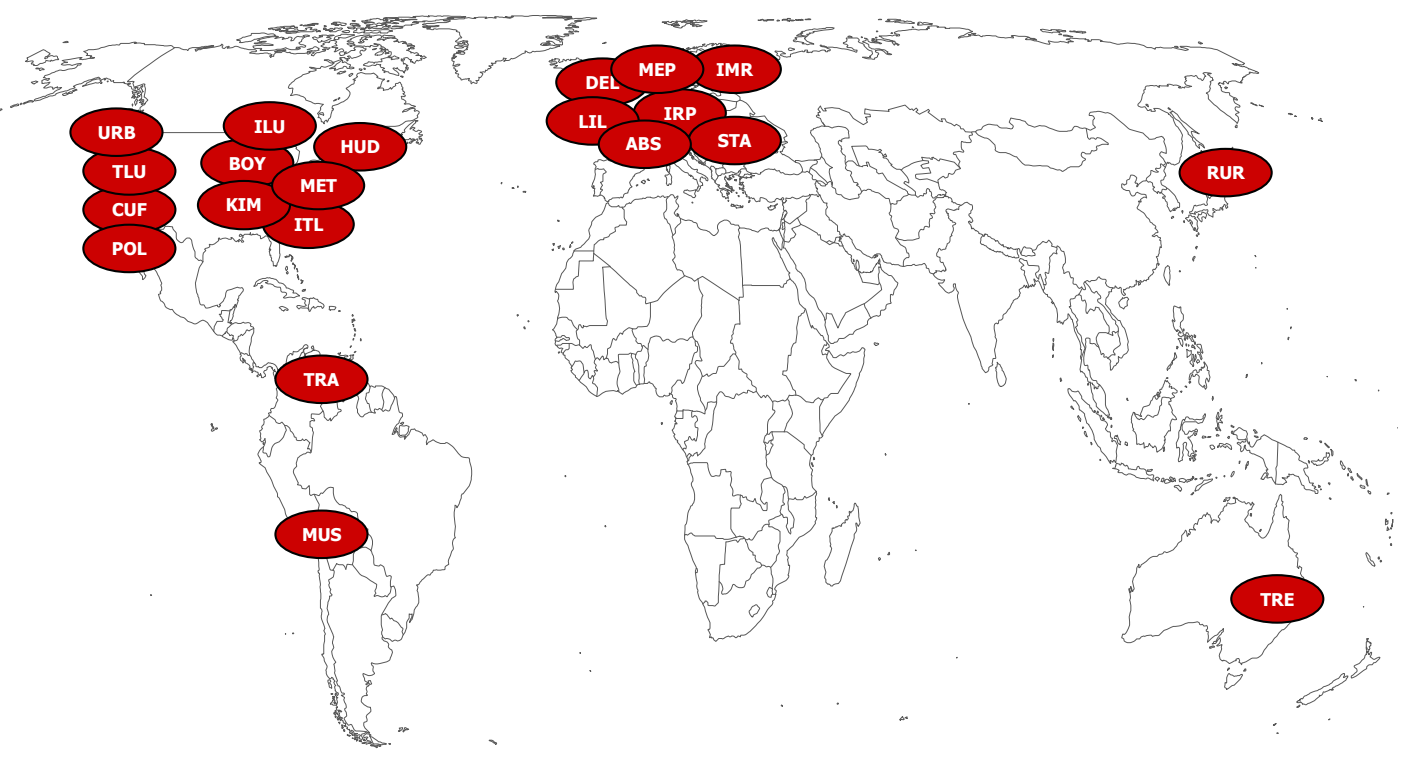

Figura 2.3: Distribuição geográfica dos modelos integrados de transportes e uso do solo (Wegener, 2003) (Modificada).

Os modelos mostrados na Figura 2.3 foram selecionados por Wegener (2003) para uma análise da qualidade das informações que podem ser obtidas, bem como de sua estrutura, conceitos teóricos envolvidos, capacidade de compreensão do sistema, 
técnicas utilizadas, dinâmica de simulação, dados requeridos, processo de calibração e validação, operacionalidade e viabilidade de aplicação. Foram selecionados vinte modelos e, aquí, foi incluído ainda o modelo ABSOLUTE. São eles:

Quadro 2.1: Modelos integrados de transportes e uso do solo

\begin{tabular}{|c|c|}
\hline BOYCE & $\begin{array}{l}\text { Combinação de modelos de localização e escolha de viagem. Desenvolvido por Boyce } \\
\text { (Boyce } \text { et al. 1983; Boyce, 1986; Boyce } \text { et al., 1992). }\end{array}$ \\
\hline CUFM & $\begin{array}{l}\text { Califórnia Urban Futures Model, desenvolvido na Universidade da Califórnia, } \\
\text { Berkeley (Landis, 1992, 1993, 1994; Landis e Zhang, 1998a, 1998b). }\end{array}$ \\
\hline DELTA & $\begin{array}{l}\text { Integração do modelo de uso do solo DELTA, de Davis Simmond Consultancy, } \\
\text { Cambridge, Inglaterra, com o modelo de transportes START desenvolvido por MVA } \\
\text { Consultants e o Institute of Transport Studies (ITS) da Universidade de Leeds } \\
\text { (Simmonds e Still, 1998; Simmonds, 1990) }\end{array}$ \\
\hline HUDS & Harvard Urban Development Simulation, desenvolvido por Kain e Apgar (1985) \\
\hline ILUTE & $\begin{array}{l}\text { Modelo integrado em desenvolvimento em universidades canadenses; Miller e Salvini, } \\
2001 .\end{array}$ \\
\hline IMREL & $\begin{array}{l}\text { Integrated Model of Residencial and Employment Location, de Anderstig e Mattsson } \\
(1991,1998) .\end{array}$ \\
\hline IRPUD & $\begin{array}{l}\text { Modelo da região de Dortmund desenvolvido por Wegener (1982a, 1982b, 1985, } \\
\text { 1986a, Wegener } \text { et al., 1991, Wegener, 1996, 1998b). }\end{array}$ \\
\hline ITLUP & $\begin{array}{l}\text { Integrated Transportation and Land Use Package, desenvolvido por Putman (1983, } \\
\text { 1991, 1998). }\end{array}$ \\
\hline KIM & $\begin{array}{l}\text { Esse modelo é a versão não linear do modelo de equilíbrio urbano desenvolvido por } \\
\text { Kim (1989) e Rho e Kim (1989). }\end{array}$ \\
\hline LILT & $\begin{array}{l}\text { Leeds Integrated Land-use/Transport Model desenvolvido por Mackett (1983; 1990c, } \\
\text { 1991a, 1991b). }\end{array}$ \\
\hline MEPLAN & $\begin{array}{l}\text { Modelo integrado desenvolvido por Marcial Echenique \& Partners (Echenique et al., } \\
\text { 1969; Echenique e Williams, 1980; Echenique, 1985; Echenique, 1994; Hunt, 1994). }\end{array}$ \\
\hline METROSIM & $\begin{array}{l}\text { Modelo microeconômico de transportes e uso do solo desenvolvido por Anas (Anas e } \\
\text { Moses, 1978; Anas, 1982; Anas, 1994, 1995, 1998). }\end{array}$ \\
\hline MUSSA & $\begin{array}{l}\text { 5-Stage Land-Use Transport Model, desenvolvido por Martinez para Santiago do Chile } \\
\text { (1991; 1992a, 1992b; Martinez e Donoso, 1995; Martinez, 1996, 1997a, 1997b). }\end{array}$ \\
\hline POLIS & $\begin{array}{l}\text { Projective Optimization Land Use Information System, desenvolvido por Prastacos } \\
\text { para Association of Bay Area Governments (Prastacos, 1986; Caindec e Prastacos, } \\
\text { 1995). }\end{array}$ \\
\hline RURBAN & $\begin{array}{l}\text { Random-Utility Urban - modelo desenvolvido por Miyamoto (Miyamoto et al., 1986; } \\
\text { Miyamoto e Kitazume, 1989). }\end{array}$ \\
\hline STASA & Modelo integrado desenvolvido por Haag (1990). \\
\hline TLUMIP & $\begin{array}{l}\text { Modelo de transportes e uso do solo do estado de Oregon, Estados Unidos - } \\
\text { ODOT,2002. }\end{array}$ \\
\hline TRANUS & $\begin{array}{l}\text { Modelo integrado desenvolvido por de la Barra (de la Barra, 1982; de la Barra et al., } \\
\text { 1984; de la Barra 1989, 1998). }\end{array}$ \\
\hline TRESIS & Simulador de impactos de transportes e meio ambiente, de Hensher e Ton (2001). \\
\hline URBANSIM & $\begin{array}{l}\text { Modelo de escolha de localização domiciliar e de firmas, desenvolvido por Waddell } \\
\text { (1998a; 1998b, 1998c, 1998d; Waddell } \text { et al., 1998) }\end{array}$ \\
\hline ABSOLUTE & Modelo integrado desenvolvido por Arentze e Timmermans (2004) \\
\hline
\end{tabular}

**Nota: todas as referências listadas nesse quadro constam na fonte.

Fonte: Wegener, 2003

A título de exemplo, três modelos integrados de transportes e uso do solo serão aqui descritos brevemente: o URBANSIM, o ILUMASS e o modelo ABSOLUTE. Esses modelos foram escolhidos por se apresentarem como os mais sofisticados já 
desenvolvidos até os dias de hoje e por se enquadrarem na categoria mais evoluída desse tipo de modelagem, como pode ser observado por sua localização no canto inferior direito da Figura 2.4. Esses modelos procuram incorporar em sua estrutura a dinâmica da inter-relação entre os sistemas de transportes e uso do solo, como se poderá depreender de seus aspectos descritivos, apresentados a seguir.

\subsubsection{URBANSIM}

URBANSIM é um sistema que simula o desenvolvimento de áreas urbanas, incluindo uso do solo e transportes, por períodos de 20 anos ou mais (Noth et al., 2001). Ele consiste de modelos que representam os diferentes componentes envolvidos (população residente, empregos, malha viária e uso do solo), e módulos responsáveis pelo armazenamento de dados. Foi aplicado inicialmente em Eugene-Springfiels, Oregon, e posteriormente em Salt Lake City, Utah e Honolulu, Hawaii.

Os modelos que compõem o URBANSIM codificam o comportamento dos componentes envolvidos na simulação. São eles:

- Modelo de transição demográfica;

- Modelo de mobilidade domiciliar;

- Modelo de escolha da localização residencial;

- Modelo de transição econômica;

- Modelo de mobilidade de emprego;

- Modelo de escolha da localização do emprego;

- Modelo de acessibilidade;

- Modelo de desenvolvimento do uso do solo, e

- Modelo de preço do solo.

Esses modelos não são interligados. A “comunicação” entre eles é feita com o auxílio dos seguintes módulos, que compõem o sistema:

- Módulo de coordenação: programa a execução dos modelos e notifica quando os dados usados são modificados;

- Módulo de armazenamento: armazena as representações compartilhadas por 
agentes e outras entidades no ambiente de simulação e,

- Módulo de transição e agregação: realiza conversão de dados para a “comunicação" entre o módulo anterior e os modelos.

\begin{tabular}{|c|c|c|c|c|c|}
\hline \multicolumn{2}{|c|}{ Modelos de transportes } & T1 & $\mathbf{T 2}$ & T3 & T4 \\
\hline \multicolumn{2}{|c|}{ Modelos de uso do solo } & $\begin{array}{l}\text { Não considera } \\
\text { transporte } \\
\text { público e } \\
\text { escolha modal }\end{array}$ & $\begin{array}{c}\text { Considera o } \\
\text { transporte } \\
\text { público, não } \\
\text { utiliza } \\
\text { modelos } \\
\text { Logit, adota } \\
\text { período de } \\
\text { análise de 24h }\end{array}$ & $\begin{array}{l}\text { Considera o } \\
\text { transporte } \\
\text { público, uso } \\
\text { de modelos } \\
\text { Logit, análise } \\
\text { do horário de } \\
\text { pico }\end{array}$ & $\begin{array}{c}\text { Análise } \\
\text { multimodal, } \\
\text { baseada em } \\
\text { atividades }\end{array}$ \\
\hline L1 & Nenhum & & & & \\
\hline L2 & Atividade & & & & \\
\hline $\mathbf{L 3}$ & $\begin{array}{l}\text { Alocação de usos do solo } \\
\text { não segue regras de mercado }\end{array}$ & & & & \\
\hline $\mathbf{L 4}$ & $\begin{array}{c}\text { Alocação tipo Logit com } \\
\text { inclusão de preços do solo } \\
\text { urbano }\end{array}$ & & & & \\
\hline $\mathbf{L 5}$ & $\begin{array}{c}\text { Modelo de uso do solo de } \\
\text { acordo com regras de } \\
\text { mercado }\end{array}$ & & & & \\
\hline L6 & $\begin{array}{l}\text { Modelo de uso do solo } \\
\text { baseado em atividades }\end{array}$ & & & & \\
\hline
\end{tabular}

Figura 2.4: Distribuição dos modelos na matriz evolutiva de Wegener e Fürst

(Adaptada de Wegener, 2003).

Os modelos utilizam os dados disponíveis no módulo de armazenamento, com o auxílio do módulo de transição. A vantagem da arquitetura modular é que esta suporta a evolução do sistema, o que possibilita a substituição dos modelos por outros mais atualizados.

O sistema requer, como dados de entrada, grande quantidade de informações para simulação da área urbana, tais como: população, empregos e malha viária. Os arquivos com resultados armazenados no segundo módulo são exportados para outros 
sistemas (como SIG, programas estatísticos e modelos exógenos de demanda de viagens) para análises e representação gráfica.

Maiores informações sobre o modelo podem ser encontradas on-line, no endereço http://www.urbansim.org da Internet.

\subsubsection{ILUMASS (Integrated Land-Use Modelling And Transportation System Simulation)}

Este projeto, desenvolvido por uma equipe de pesquisadores das universidades de Aachen, Bamberg, Dortmund, Cologne e Wuppertal, inclui um modelo de simulação dinâmico de fluxo de tráfego urbano em escala microscópica, incorporando alterações no uso do solo e na demanda por transportes. O componente de uso do solo utiliza técnicas de microsimulação para modelar as alterações de uso do solo e fluxos de tráfego. As interações entre padrões de atividades e padrões de mobilidade são modeladas em nível individual (Moeckel et al., 2003).

Módulos de microsimulação incluem modelos de desenvolvimento demográfico, formação domiciliar, ciclos de vida de empresas, construção residencial e comercial, mobilidade do mercado de trabalho e domiciliar. Esses módulos são ligados a modelos de demanda por transportes, que fornecem os padrões diários de atividades e viagens e movimento de mercadorias. Pelo fato de considerar dados associados a domicílios, o modelo de uso do solo trabalha com dados sintéticos, que podem ser derivados a partir de dados agregados.

Os principais dados de entrada do projeto são a população sintética de domicílios, construções industriais e comerciais, empresas e número de veículos em um ano base, bem como as informações da malha viária. Esses dados são processados nos módulos de microsimulação e a previsão é feita para vários anos. Para cada ano, as distribuições dos domicílios, pessoas, empresas e trabalhadores são transferidas para os módulos de microsimulação de previsão de viagem e demanda por transporte de carga e alocação de tráfego. Os fluxos de tráfego, o tempo e o custo das viagens geradas são alimentados novamente pelo modelo de uso do solo onde, através de um índice de acessibilidade, afetam o comportamento de empreendedores, domicílios e empresas (ciclo de realimentação uso do solo e transportes). Adicionalmente, esses dados servem para alimentar outros módulos, que calculam impactos ambientais, tais como poluição 
do ar e nível de ruído. Esses dados podem realimentar, em um fluxo inverso, modelos de uso do solo e afetar as decisões de localização de domicílios e empresas.

O modelo é calibrado com dados de pesquisas sobre atividades e viagens domiciliares e validado usando dados temporais agregados da população, moradias e empregos, bem como dados sobre o tráfego na região em estudo. Ele pode ser usado para avaliar os impactos de várias alternativas de políticas de uso do solo e transportes, tais como: desenvolvimento de áreas com alta densidade, desenvolvimento polinucleado, limites de velocidade, políticas monetárias etc.

\subsubsection{ABSOLUTE (Activity-Based System of Land Use and Transport Events)}

ABSOLUTE (Arentze e Timmermans, 2004a) é o resultado da integração de um modelo de demanda por transportes baseado em atividades (Arentze e Timmermans, 2000) a um modelo de uso do solo (Arentze e Timmermans, 2004b). Essa integração é parte de um sistema multi-agentes de maior escala, que simula como agências de planejamento e planejadores decidem sobre o tipo de uso e ocupação do solo. Dada a alocação inicial do tipo de uso do solo, o sistema simula o elo entre alterações no uso do solo e os padrões de uso, com base em um modelo de padrões de viagens e atividades. A estrutura do sistema multi-agentes permite representar uma vasta variedade de locais de realização e tipos de atividades no sistema e simular, em escala microscópica, seu comportamento sob condições de informações limitadas.

Apesar do objetivo final do modelo ABSOLUTE ser a modelagem das decisões de localização por parte de firmas, planejadores e domicílios, o presente estudo se focaliza apenas na categoria atividade de consumo (lojas, parques, escolas etc). Assim, para uma determinada área de estudo, são admitidos como conhecidos os locais de residência e de atividades de produção e é feita a modelagem da dinâmica de escolha ao nível das atividades de consumo.

A demanda por realização dessas atividades é determinada pela programação diária das atividades individuais, bem como a execução das mesmas. Essa programação determina qual atividade será realizada, onde, com quem, por quanto tempo e qual modo de transporte será usado. Por outro lado, a oferta dessas atividades é feita por firmas e autoridades planejadoras que decidem onde desenvolver as quantidades suficientes de atividades de consumo capazes de atender a toda a demanda existente. Oferta e demanda interagem: o padrão de atividades existente determina o conjunto de 
oportunidades para que os indivíduos realizem suas atividades e o padrão de uso do solo determina a viabilidade econômica das implantação de novos postos de atividade e os níveis de congestionamento no sistema.

$\mathrm{Na}$ abordagem multi-agentes, para a modelagem e simulação de toda essa dinâmica, todos os atores da demanda e da oferta são representados individualmente como agentes capazes de comportamento autônomo no sistema. A vantagem desse sistema é um alto grau de desagregação das atividades que podem ser realizadas e, assim, maior heterogeneidade no comportamento pode ser obtida, quando comparada às abordagens tradicionais. Uma das especificações dessa versão do modelo ABSOLUTE é que ele simula a localização das atividades não como uma decisão individual de firmas e planejadores (uma vez que cada um desses atores tem objetivos próprios), mas como um comportamento agregado de grupos. Como conseqüência, as regras heurísticas usadas para tomada de decisão pelos agentes não representam, necessariamente, os objetivos de cada ator individualmente envolvido. $\mathrm{O}$ objetivo final do sistema integrado é prever a necessidade de localização das atividades e padrões de uso do solo que sejam consistentes com o comportamento de todos os atores envolvidos.

Cada indivíduo da população em estudo é representado por um agente no modelo. O comportamento de cada agente consiste na programação das atividades e sua execução. Foi usado o modelo baseado em atividades Albatross (Arentze e Timmermans, 2000) como ferramenta para previsão das atividades geradas. Para um determinado dia, o modelo determina quais atividades serão realizadas, onde, por quanto tempo, quando e, se existe viagem envolvida, o modo de transporte usado. Do mesmo modo, são consideradas restrições temporais, variáveis socioeconômicas, dia da semana e localização residencial.

Os agentes escolhem os locais de realização das atividades de acordo com a seqüência em que estas ocorrem na programação. O conjunto das possíveis localizações em que as atividades poderão ser realizadas será definido em função da combinação do local em que a viagem se origina, do modo de transporte utilizado e do tempo disponível ao indivíduo para a realização da viagem e da atividade.

Os modelos descritos anteriormente ainda se encontram em fase de desenvolvimento por grupos de pesquisadores de diversas áreas, com o objetivo de aprimorar cada vez mais o desempenho dos mesmos. O modelo URBANSIM, por exemplo, começou a ser desenvolvido no começo da década de 1990. Como pôde ser 
observado, eles constituem sistemas modulares operacionais que incorporam em sua estrutura ferramentas capazes de analisar a relação entre uso do solo e transportes em escala microscópica. São hoje o que há de mais avançado no que se refere aos modelos integrados de transportes e uso do solo.

O tópico a seguir relaciona trabalhos pontuais desenvolvidos por vários pesquisadores da área para a verificação de como as características do uso do solo afetam o comportamento de viagem individual. Em sua maioria, esses trabalhos foram desenvolvidos com o auxílio de técnicas estatísticas e modelos do tipo Logit.

\subsection{Uso do Solo e Comportamento de Viagem}

O modo como as características do uso do solo afetam o comportamento de viagem individual ainda é muito discutido por vários pesquisadores. Apesar disso, não existe até então consenso se as decisões individuais são afetadas pelas características de uso do solo, pelo conjunto de fatores que envolvem cada uma delas (por exemplo, em regiões compactas é mais prático o uso dos modos não motorizados), por fatores socioeconômicos, ou pela combinação entre todos estes aspectos. Dada a variedade de possibilidades, foram aqui selecionadas algumas variáveis relacionadas direta ou indiretamente ao uso do solo, de modo a constituir um referencial teórico para o desenvolvimento deste trabalho.

\subsubsection{Densidade residencial, freqüência e comprimento da viagem}

Uma das hipóteses testadas em diversas pesquisas é se a densidade residencial e o desenvolvimento compacto do uso do solo resultam em viagens mais curtas e em menor número. Essa hipótese se baseia no fato de que regiões compactas apresentam maior proximidade espacial entre locais de realização de atividades, com maior propensão ao uso dos modos não motorizados.

Steiner (1994) concluiu que residentes em bairros de alta densidade viajam menores distâncias e usam o transporte público ou caminham mais freqüentemente que residentes em regiões de baixa densidade. Cervero (1996) e Cervero e Kockelman (1997) verificaram também que altas densidades, em combinação com certa configuração de desenho do bairro e uso misto do solo, reduzem os níveis de propriedade do automóvel, distâncias de viagem e incentivam o uso dos modos não 
motorizados.

Por outro lado, Miller e Ibrahim (1998) verificaram que a densidade residencial não afeta diretamente as distâncias de viagem por motivo trabalho. Com o auxílio de regressão linear simples, os autores testaram a relação entre forma urbana e maior eficiência das viagens para trabalho. Não foram encontradas evidências de que uma distribuição espacial mais equilibrada entre empregos e moradias seria uma opção que ajudasse a reduzir a distância viajada pelos trabalhadores.

Para Wegener e Fürst (1999) a densidade residencial é apenas uma variável intermediária, ou seja, a causa real por trás do alto nível de mobilidade, comprimento de viagem e consumo de energia é o baixo custo do combustível usado em modos de transporte motorizados.

\subsubsection{Densidade residencial e uso do transporte público}

A hipótese testada neste caso é se a densidade residencial está positivamente relacionada à maior utilização do transporte público e negativamente correlacionada com a propriedade e uso do automóvel.

Dunphy e Fisher (1996), Messenger e Ewing (1996), Schimek (1996b), Cervero (1996) e Cervero e Kockelman (1997) verificaram que regiões urbanas com altas densidades têm menor uso do automóvel, mais viagens por transporte público e menores distâncias viajadas. Limtanakool et al. (2004) verificaram que maior densidade na origem e no destino aumentam significativamente o uso do trem em viagens de longa distância.

Dunphy e Fisher (1996), por exemplo, investigaram a relação entre densidade residencial e viagens individuais e verificaram a ocorrência de altos índices de uso do transporte público e menor uso do automóvel em comunidades com altas densidades. Entretanto, o alto número de viagens por transporte coletivo pode ter ocorrido pelo fato de que os domicílios em regiões de altas densidades residenciais tendem a ser aqueles com menor dependência do automóvel.

Em outro estudo, Kitamura et al. (1997) verificaram que a densidade populacional está ligada à maior proporção de viagens por transporte público, mesmo quando existem diferenças na escolha modal de grupos socioeconômicos. Foram usados modelos de regressão linear e análise estatística multivariada para avaliação dos efeitos do uso do solo na demanda de viagem. 
Já Kockelman (1997) não encontrou relação significativa entre densidade residencial e uso do transporte público. A autora investigou ainda se a intensidade, o equilíbrio e a diversidade de uso do solo são relevantes na explicação do comportamento de viagem, e se cada uma dessas dimensões contribui para a redução do uso do automóvel. Esse e outros estudos sugerem que o fator determinante no uso do transporte público pode ser o nível de serviço deste - freqüência, velocidade, conforto dos veículos e o número de destinos que podem ser alcançados através de sua utilização.

\subsubsection{Densidade de emprego}

A proximidade entre locais de residência e emprego pode ser um fator que leve à redução no número de viagens motorizadas. Parece óbvio que pessoas que morem perto do local de emprego viajem menores distâncias e por modos não motorizados. Entretanto, locais de emprego em uma determinada região podem não atender aos moradores locais devido ao tipo de qualificação exigida (ou seja, os trabalhadores da região não estariam qualificados ao tipo de trabalho disponível). Nesse caso específico, promover o uso misto do solo nos bairros com equilíbrio entre moradias e empregos pode não levar à redução das viagens de trabalho, já que os moradores necessitarão trabalhar em outras regiões.

Sob a hipótese de que trabalhadores em regiões mais densas, com diversidade de atividades não relacionadas ao trabalho, podem realizar suas viagens pelo modo a pé ou por transporte coletivo, Chatman (2002) investigou a influência da densidade de usos comerciais (lojas, prestadoras de serviço etc) do local de trabalho sobre as "milhas viajadas por veículo - VMT" para acesso às atividades. Para o autor, existe a possibilidade dos indivíduos escolherem o local de residência com base em suas características físicas, mas essa possibilidade é reduzida quando se trata do local de trabalho. Dessa forma, qualquer relação encontrada nesta análise pode ser interpretada como conseqüência dos efeitos de cada característica do uso do solo isoladamente. Foram encontradas relações positivas entre densidade comercial e menor utilização do automóvel, o que mostra que características do uso do solo nas regiões de trabalho podem afetar o processo de escolha modal de trabalhadores. 


\subsubsection{Desenho do bairro}

Existem vários estudos sobre espalhamento urbano e desenvolvimento urbano compacto, nos quais o conceito de desenvolvimento de bairros neo-tradicionais está ligado à caminhada e ao uso da bicicleta.

Nesse sentido, Friedman et al. (1994), Cervero (1996), Kockelman (1997) e Cervero e Kockelman (1997) verificaram relação positiva do desenho do bairro com uso de modos de transporte alternativos ao automóvel. Kockelman (1997), por exemplo, em pesquisa realizada em uma área de São Francisco, concluiu que a integração do uso do solo e desenvolvimento compacto reduz o uso do automóvel.

Por outro lado, outros estudos verificaram que o desenho do bairro não é significativo na explicação do comportamento de viagem quando fatores socioeconômicos são conjuntamente considerados (McNally e Kulkarni, 1997). Além disso, Snellen (2000) verificou que a forma urbana não afeta os padrões de atividades individuais. Os resultados de sua pesquisa mostraram que indivíduos e domicílios tendem a organizar seu padrão diário de atividades e viagens de acordo com suas preferências pessoais e que a forma urbana não é fator significativo na estruturação desses padrões comportamentais.

\subsubsection{Localização}

A localização geográfica do bairro dentro da região urbana e sua proximidade à malha viária principal também devem ser consideradas, juntamente com a estrutura interna do bairro. É possível que bairros centrais estejam positivamente correlacionados com viagens por transporte público ou modos não motorizados. Frank e Pivo (1994), Ewing (1995), Kockelman (1997) e Kitamura et al. (1997) confirmaram essa hipótese. Neste último trabalho verificou-se que a distância do domicílio ao ponto de ônibus afeta a escolha modal: quanto mais próximo o domicílio do ponto de ônibus, menor o número de viagens por automóvel.

\subsubsection{Acessibilidade}

A acessibilidade é um dos conceitos chave na análise da relação entre o uso do solo e transportes. Uma grande variedade de indicadores é freqüentemente usada para 
sua quantificação. Seu conceito pode ser interpretado como a facilidade com que as atividades podem ser alcançadas, dada a sua localização e o modo de transporte a ser usado. A acessibilidade integra, em suas diversas formulações, aspectos relacionados à distribuição do uso do solo (distribuição espacial das atividades) e aqueles relacionados ao sistema de transportes. De acordo com Black e Cheung (2003), a acessibilidade é um conceito que combina a distribuição geográfica do uso do solo e o sistema de transportes que serve a esses usos do solo. Diferentes localizações não apresentam o mesmo nível de acessibilidade, uma vez que nem a distribuição das atividades nem a cobertura e qualidade do sistema de transportes são uniformes.

Um dos primeiros trabalhos de impacto nessa temática foi desenvolvido por Hansen (1959), que demonstrou que locais com boa acessibilidade apresentam altas chances de serem ocupadas com altas densidades. Após o trabalho de Hansen, importantes conceitos de acessibilidade também foram desenvolvidos por Ingram (1971), Pirie (1979), Handy e Niemeier (1997), incluindo conceitos envolvendo abordagens recentes, como o trabalho desenvolvido por Dong et al. (2002).

Dong et al. (2002) trabalharam com uma medida de acessibilidade baseada no conceito de utilidade, gerada a partir de um modelo baseado em atividades - o Day Activity Schedule, ou DAS. O DAS modela todas as programações diárias de um indivíduo, considerando a possibilidade de realização de múltiplas atividades e viagens. Esses padrões são, posteriormente, agrupados para a identificação de um padrão particular. Os autores fizeram a comparação entre o índice de acessibilidade baseado em atividades e os índices tradicionais (estes calculados apenas considerando as viagens realizadas), e concluíram que o primeiro se mostrou superior aos outros. Uma explicação para isto está no fato do índice considerar a importância dos vários fatores que afetam a acessibilidade no contexto da programação individual de atividades diárias.

\subsubsection{Fatores comportamentais e características socioeconômicas}

Segundo alguns autores (Kitamura et al., 1997; Boarnet e Sarmiento, 1996; Crane e Crepeau, 1998), moradores em determinada região irão realizar maior número de viagens a pé por terem escolhido residir em um bairro onde a caminhada é uma alternativa viável. Nesse caso, os autores defendem que a escolha da localização residencial é feita, em parte, pelo desejo individual de comportamento de viagem. 
McNally e Kulkarni (1997) também concluíram que o comportamento de viagem ocorre em função do estilo de vida de cada indivíduo (comportamento usual do indivíduo, socioeconômicas e demográficas), e não apenas em função dos sistemas de transportes e uso do solo. Esses fatores podem ter influência significativa sobre o comportamento de viagem. Essa suposição foi a base do trabalho de Krizek (2000), que se concentrou em verificar se realmente as características do uso do solo, isoladamente, podem afetar o comportamento de viagem dos residentes que já apresentam a preferência por viagens não dependentes do automóvel.

O trabalho de Kitamura et al. (1997) confirmou a hipótese de que as características do bairro adicionam maior poder explicativo aos modelos quando as variáveis de controle são as diferenças socioeconômicas. Por outro lado, apesar desse aumento na explicação do modelo, as variáveis relacionadas ao comportamento usual dos indivíduos obtiveram o mais alto poder de explicação nas variações encontradas nos dados. O fato de que as variáveis que medem o comportamento usual do indivíduo estão mais fortemente associadas às viagens do que o uso do solo sugere que políticas que promovam altas densidades e uso misto do solo não irão alterar sozinhas a demanda de viagem a menos que as atitudes dos residentes sejam alteradas.

Características como renda, propriedade de automóvel e idade são freqüentemente avaliadas em estudos relacionados na literatura. Por exemplo, domicílios de baixa renda (abaixo de US\$30.000,00/ano) fazem em média 6,5 viagens/dia contra 12,5 dos domicílios de renda alta (mais de US\$75.000,00/ano) (McNally e Kulkarni, 1997). Os resultados encontrados pelos pesquisadores mostraram ainda que a renda é mais importante que o desenho do bairro no que diz respeito ao número de viagens realizadas por domicílio. A renda tem maior poder explicativo naquilo que concerne à variação na geração de viagens entre os bairros.

De acordo com o trabalho realizado por Schwanen et al. (2004), membros de domicílio de baixa renda consomem menos tempo em viagens para trabalho. Os autores realizaram o estudo verificando como diferentes segmentos da população (em função da composição domiciliar e faixas de renda) alteram seu comportamento de viagem em função de características socioeconômicas e de uso do solo.

De acordo com o trabalho desenvolvido por Limtanakool et al. (2004), que avalia a escolha modal para viagens de longa distância, os fatores socioeconômicos (particularmente a disponibilidade do automóvel) têm forte influência na escolha modal para cada propósito de viagem. Alto nível de educação está associado a maior número 
de viagens por trem (no caso, o estudo foi realizado na Holanda, onde as linhas ferroviárias são bem desenvolvidas). A presença de crianças não apresentou resultados significativos na escolha modal nesse estudo. Segundo os autores isto pode ter ocorrido pelo fato da alocação de tarefas e do automóvel em domicílios cujos membros viajam longas distâncias ocorrer de maneira diferente do que nos casos das viagens curtas.

A forte influência das características socioeconômicas também pode ser verificada no trabalho de Boarnet et al. (2004). Os autores desenvolveram um estudo para avaliar a influência das características de uso do solo sobre distâncias de viagens que não por motivo trabalho e sobre a geração de viagens individuais. Os autores concluíram que as variáveis de uso do solo, quando avaliadas sem a consideração da renda domiciliar, têm impacto semelhante sobre ambas as variáveis dependentes. Porém, quando avaliadas juntamente com a variável renda, estas não foram tão significativas.

\subsection{Considerações Finais}

Há indícios, com base na literatura, de que os modelos integrados de transportes e uso do solo constituem a metodologia mais adequada para a verificação da inter-relação entre os sistemas de transportes e uso do solo. Esses modelos vêm sendo desenvolvidos por grupos multi-profissionais, com o auxílio de ferramentas computacionais avançadas, incorporando em sua estrutura abordagens que permitem a verificação em escala microscópica dos efeitos mútuos dos sistemas de transportes e uso do solo.

Com base nos trabalhos pontuais relacionados neste capítulo, verifica-se que os pesquisadores da área não chegaram a um consenso sobre a influência das características do uso do solo sobre a demanda de viagens. Entre as variáveis diretamente relacionadas ao uso do solo freqüentemente avaliadas estão a densidade residencial e de empregos, o desenho do bairro, a localização geográfica do bairro e a acessibilidade. São avaliados ainda os fatores comportamentais e socioeconômicos.

De acordo com Boarnet e Sarmiento (1996), trabalhos empíricos para análise da relação uso do solo e comportamento de viagem devem ser desenvolvidos no contexto de modelos de demanda; a localização das atividades deve ser modelada como uma escolha endógena; e as medidas de uso do solo devem ser refinadas tanto para medir os conceitos do desenho urbano como para medir a relação entre as características 
do bairro e acessibilidade.

Apesar dos modelos integrados serem uma opção passível de consideração para o desenvolvimento desta pesquisa, optou-se por utilizar um modelo de demanda de viagens baseado em atividades para a análise da relação entre as características do uso do solo e transportes. Como evidenciado anteriormente, essa abordagem é indicada por um grande número de pesquisadores como sendo a mais adequada para a análise da demanda de viagens e, por extensão, da relação entre uso do solo e transportes. Esse fato pode ser facilmente constatado na matriz evolutiva dos modelos de transportes e uso do solo apresentado por Wegener e Fürst (1999) (Figura 2.2).

Além dos modelos baseados em atividades serem os mais sofisticados para análise da demanda de viagens, eles também são adequados para responder a um conjunto de requisitos que Waddell (199?) destaca como sendo primordiais aos modelos de transportes e uso do solo. Alguns desses requisitos são apresentados a seguir:

- Os modelos devem ser capazes de captar os efeitos de políticas voltadas ao custo do transporte sobre o comportamento de viagem e uso do solo;

- Os modelos devem permitir a comparação entre diferentes modos de transporte e representar as viagens realizadas por modos não motorizados;

- Devem reconhecer o impacto dos padrões de uso do solo na demanda de transportes;

- Os modelos precisam considerar os efeitos de novas políticas de controle de gestão da demanda para redução do número de viagens motorizadas (como a comparação entre horários flexíveis de trabalho versus horários fixos, teletrabalho etc.);

- Os efeitos dos elementos do desenho urbano (como uso misto do solo, densidade, configuração viária e amenidades para pedestres) devem ser considerados no processo de escolha individual da localização residencial e de local de emprego, bem como sobre o comportamento de viagem;

- Os modelos devem ser capazes de reproduzir as escolhas domiciliares de propriedade de automóvel, participação no mercado de trabalho, e realização e programação de atividades e viagens. 
Outro fator relevante na escolha dos modelos baseados em atividades (que são abordados em maior nível de detalhes no próximo capítulo) para o desenvolvimento desta pesquisa é o fato de não existirem referências de aplicação sistemática desses modelos no contexto das cidades brasileiras. 


\section{MODELOS BASEADOS EM ATIVIDADES}

Este capítulo tem por objetivo apresentar os conceitos que envolvem os modelos de demanda por transportes baseados em atividade, que constituem a base metodológica desta pesquisa. De forma resumida, são apresentados o histórico de desenvolvimento desses modelos e algumas considerações referentes à realização de viagens e atividades no contexto da metodologia em questão. Dois tópicos são de fundamental importância ao desenvolvimento deste trabalho. O primeiro trata da estrutura dos modelos de atividades, onde são apresentadas as técnicas comumente utilizadas para o desenvolvimento desses modelos; o segundo está direcionado à especificação dos dados necessários para sua calibração, bem como a metodologia mais adequada para que esses dados sejam obtidos.

O desenvolvimento de ferramentas analíticas capazes de avaliar os padrões de viagens urbanas ocorreu na década de 50, nos Estados Unidos, em uma época em que vários fatores impulsionaram o desenvolvimento do processo de planejamento de transporte urbano: o crescimento populacional, um maior número de usuários do automóvel e um aumento da movimentação entre áreas urbanas (Pas, 1995). Os estudos de transporte urbano com aplicação dessas ferramentas foram inicialmente utilizados com o objetivo de planejar o sistema viário, de modo que este fosse capaz de acomodar o aumento de viagens motorizadas nas áreas urbanas.

O modelo tradicionalmente utilizado - o modelo de quatro etapas - separa a demanda por transportes em quatro submodelos (ou etapas): geração de viagens, distribuição de viagens, escolha modal e alocação das viagens às rotas. Esses modelos se caracterizam por seu aspecto não comportamental; ou seja, eles apenas reproduzem 
os resultados de condições existentes no momento da pesquisa e fornecem poucas informações sobre possíveis efeitos de políticas de transportes sobre decisões de viagens. Os dados de viagem e as características sociodemográficas são agregados por zonas de tráfego (o que oculta informações que podem ser relevantes ao estudo). Além disso, a falta da estrutura comportamental torna difícil a generalização do modelo (transferabilidade) (Domencich e McFadden, 1975).

De modo a suprir as falhas dos modelos tradicionais, uma nova estrutura de modelos de demanda começou a ser desenvolvida nos anos 70: os modelos de demanda desagregados, com base na teoria econômica e no comportamento de escolha individual. Esses modelos têm a vantagem de incorporar um maior número de variáveis explicativas, e podem fornecer, de forma mais explícita, respostas à implementação de políticas de transportes (Ettema, 1996).

Embora baseados nos princípios do comportamento humano, os modelos desagregados desconsideram alguns fatores que podem afetar o processo de escolha individual sobre as viagens a serem realizadas. Eles também falham por considerarem as decisões de viagem separadamente. Por exemplo, as viagens encadeadas (ou as diferentes viagens com base domiciliar) são modeladas independentemente umas das outras.

O uso de ferramentas tecnológicas (por exemplo, telecomunicações) na realização de determinadas atividades diárias e as conseqüentes alterações no comportamento individual (por exemplo, horários flexíveis de trabalho), tornaram amplo o número de fatores que podem ocasionar determinado padrão de viagem individual. De modo a se possibilitar a modelagem desse novo padrão de viagens e atividades, tornou-se necessário o uso de modelos de demanda de transportes capazes de incorporar, em sua estrutura, grande parte das variáveis que envolvem o processo de decisão individual. Os modelos de atividades parecem ser, então, uma das metodologias apontadas como mais adequada a essa avaliação.

\subsection{Modelos Baseados em Atividades}

Um dos princípios básicos dos modelos baseados em atividades é que a demanda por transporte é derivada da necessidade que as pessoas têm em realizar suas atividades diárias distribuídas no tempo e no espaço. Esses modelos procuram simular como os indivíduos em um domicílio organizam suas programações de atividades 
diárias no tempo e no espaço e, a partir daí, avaliam quais as viagens necessárias para que esta programação de atividades possa ser cumprida.

Esta abordagem reconhece as complexas interações entre a participação em atividades e o comportamento de viagem individual. Assim sendo, as atividades geradoras da demanda de transportes, e não as viagens, são o foco para o entendimento do comportamento de viagem individual, dentro das quais as relações de causa e efeito que determinam as decisões de viagem podem ser modeladas (Pendyala et al., 1998). Esses modelos verificam os mecanismos que os indivíduos usam para decidir sobre quais atividades irão realizar e as viagens necessárias para a composição de sua agenda diária de atividades (Ettema, 1996).

No processo de simulação podem ser consideradas, em conjunto, as interações entre os membros do domicílio, o tipo de atividade que cada um deve realizar, os padrões de uso do solo e as restrições que cada membro do domicílio pode encontrar (como a estrutura familiar, os recursos financeiros disponíveis no domicílio, as restrições de tempo do indivíduo, o período de funcionamento dos estabelecimentos e a disponibilidade de automóvel) (Bhat e Lawton, 2000; Marshment, 2000). Estes fatores podem ser determinantes na opção do indivíduo por um ou outro modo de transporte, de acordo com as tarefas que ele precisa cumprir (Kitamura, 1996; Kurani e Lee-Gosselin, 1996).

Com ênfase dada principalmente à participação em atividades e focalizando na seqüência ou nos padrões de realização dessas atividades (utilizando como unidades de análise um longo período de tempo ou um dia completo), essa abordagem pode fornecer informações sobre o modo pelo qual os indivíduos e os domicílios modificam suas participações em atividades, em resposta à aplicação de determinadas políticas de transportes e de uso do solo, e como esse processo afeta a dinâmica urbana em uma cidade (Misra e Bhat, 2000).

\subsection{Histórico}

Os primeiros trabalhos realizados por Hägerstrand (1970), Chapin (1971) e Cullen e Godson (1975) formam a base das pesquisas sobre análise de atividades. Chapin (1971) propôs uma estrutura na qual as restrições sociais e as motivações inerentes ao indivíduo interagem para moldar os padrões de comportamento de realização de atividades. Hägerstrand (1970), por outro lado, enfatizou as restrições 
impostas a um indivíduo para sua participação em atividades dispersas no tempo e no espaço, formalizando o conceito de prisma espaço-tempo.

Um prisma espaço-tempo pode ser utilizado para definir quais as regiões de tempo e espaço que podem ser alcançadas por um indivíduo, dado um conjunto de restrições a ele imposto (restrições de capacidade, restrições de acoplamento e restrições de autoridade) e o modo de transporte utilizado. A Figura 3.1 representa o prisma espaço-tempo de Hägerstrand.

As propriedades de acessibilidade da malha viária e a intensidade de padrões de uso do solo afetam diretamente a disposição do prisma (Timmermans, 2000). Por exemplo, pessoas que trabalham necessitam estar em um local pré-determinado em horários fixos; dessa forma, parte do seu prisma é fixa em virtude das restrições de autoridade, tornando necessária a utilização de modos de transporte que atendam a essa necessidade individual (considerando o tempo de viagem até o local).

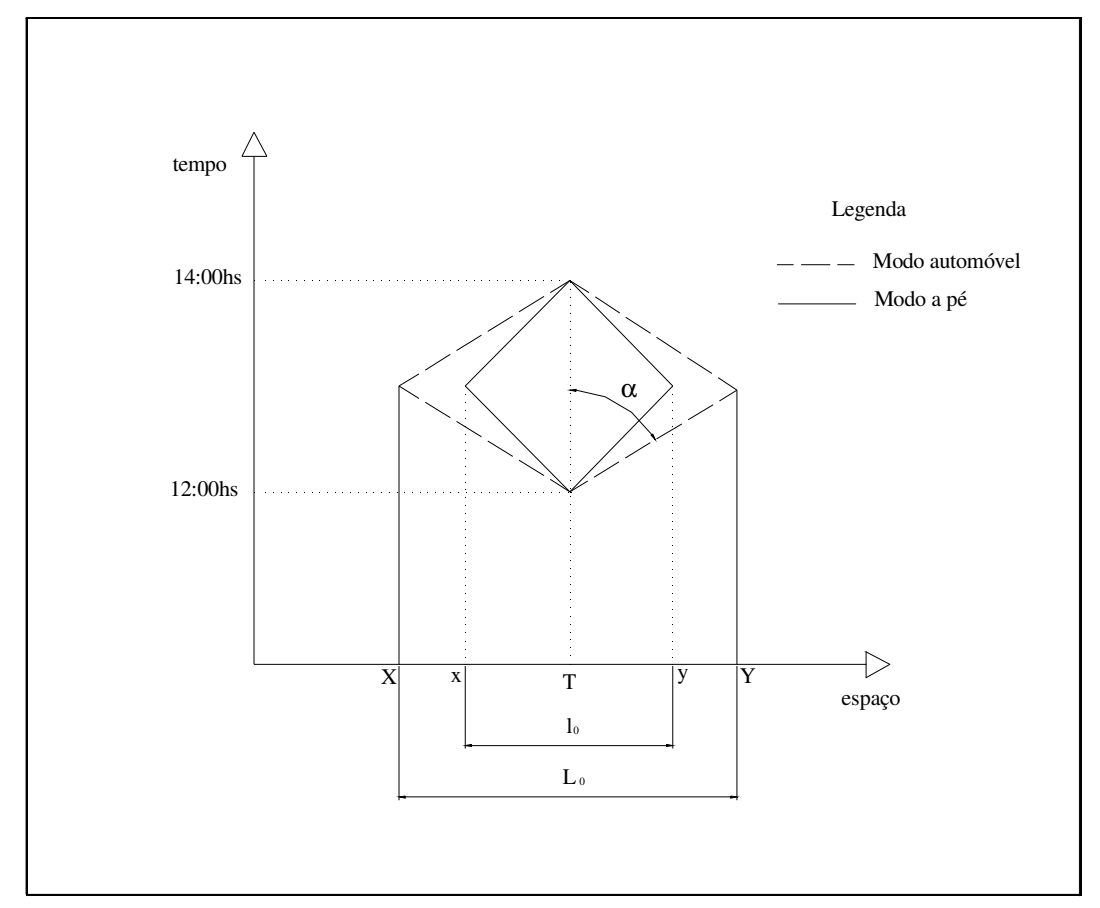

Figura 3.1: Prisma espaço-tempo (Arruda, 2000). 
Cullen e Godson (1975) argumentam que as restrições espaço-temporais identificadas por Hägerstrand são fundamentalmente caracterizadas por graus de rigidez. Os autores realizaram uma análise empírica mostrando que as restrições temporais são mais rígidas que as restrições espaciais, e que a rigidez das restrições temporais está relacionada ao tipo de participação em atividades (com maior rigidez associada a atividades relacionadas ao trabalho do que a atividades de lazer, por exemplo).

Chapin se concentrou nas motivações que levam os indivíduos a participarem em várias atividades; a importância de seu trabalho está no entendimento dos fatores que envolvem os padrões de atividades nos quais a viagem é necessária. Hägerstrand enfatiza os fatores que limitam as opções individuais para realizar atividades; oferece o conceito dos espaços de atividades que podem ser diretamente incorporados em modelos de transporte (Ettema, 1996).

\subsection{Considerações Referentes à Realização de Viagens e Atividades}

Resumidamente, de acordo com Ettema (1996), algumas considerações relevantes podem ser feitas no contexto da participação em atividades e realização de viagens:

a) A viagem é uma demanda derivada - ela é realizada de modo a satisfazer a necessidade ou desejo individual de realização de atividades em diferentes locais. Nesse sentido, as características dessas atividades afetam diretamente o comportamento de viagem. Outras características que podem influenciar a programação domiciliar de atividades são a ordem de prioridade das atividades, a situação domiciliar, as restrições de custo e as opções de modos de transporte;

b) A realização das atividades depende da disponibilidade de localizações específicas, que formam um conjunto de limitações à possibilidade de realização das mesmas. Algumas atividades só podem ser realizadas em locais específicos. Por exemplo, atividades de trabalho têm locais e horários fixos, enquanto que atividades de compras são essencialmente dependentes de locais, que pode ser limitada em função do horário de funcionamento dos estabelecimentos. Outras restrições podem ocorrer devido à própria 
estrutura familiar, como a necessidade de um determinado indivíduo de tomar conta de crianças. Como as viagens são necessárias para satisfazer ao conjunto de atividades a serem realizadas dispersas espacialmente, a posição das localidades e a conseqüente quantidade de viagens podem impor restrições à participação individual nestas. Esse conjunto de limitações é denominado de "restrições espaço-temporais";

c) Ênfase no domicílio como unidade de decisão. A inter-relação entre os membros do domicílio determina a agenda de atividades de cada um. As restrições que limitam a realização de atividades de um determinado indivíduo podem afetar a agenda de atividades de outros membros do domicílio. A distribuição dos recursos dentro do domicílio também é um fator importante de ser analisado pois afeta diretamente as opções individuais por quais atividades realizar e qual modo de transporte utilizar;

d) A viagem deve estar inserida no contexto de padrões de atividades, consistindo de múltiplas atividades e viagens. Devem ser observadas as interdependências entre os diferentes eventos que ocorrem durante o dia: se mais tempo é gasto em uma atividade, menos tempo haverá para as outras atividades a serem realizadas em locais diferentes.

A estrutura de tomada de decisão sobre viagens e atividades a realizar é obtida no contexto do processo de programação de atividades e padrões de atividades. Essa estrutura permite fornecer respostas a uma vasta gama de políticas de transportes e uso do solo, como possíveis alterações no ambiente de viagem. Como conseqüência, esses modelos, que descrevem a programação e/ou a execução de atividades, são ferramentas poderosas para a previsão de demanda de viagens (Ettema, 1996).

\subsection{Estrutura dos Modelos de Atividades}

Diferentes abordagens têm sido utilizadas no desenvolvimento dos modelos de atividades. Os primeiros modelos foram desenvolvidos com base na teoria de Hägerstrand (por exemplo, o modelo PESASP - Lenntorp, 1978). Com base nessa abordagem, esses modelos identificam o conjunto de padrões de atividades possíveis dados os padrões de uso do solo, restrições temporais e opções de transporte. Essa abordagem é útil para a avaliação de possibilidades de implementação de programas de 
atividades específicos em conjuntos espaço-temporais a eles referentes.

A estrutura dos modelos de atividades é bastante complexa e o desenvolvimento desses modelos se tornou possível a partir da utilização das avançadas técnicas computacionais existentes nos dias de hoje. Em uma revisão bibliográfica preliminar, pôde-se identificar que os modelos de atividades utilizam em sua estrutura ferramentas como, por exemplo, a teoria da máxima utilidade (Recker et al. 1986a, 1986b) e técnicas de microsimulação (McNally, 1997). Alguns modelos utilizam a combinação dessas técnicas - os chamados modelos híbridos. Por exemplo, o modelo Merlin (Middelkoop et al., 2004) é um modelo baseado em atividades direcionado às atividades de lazer e viagens de férias. É um sistema composto por modelos de escolha discreta e modelos baseados em regras lógicas (usados para previsão das viagens) e microsimulação (usada para prever padrões agregados de viagens). Como uma forma de evidenciar as técnicas usadas no processo de modelagem, a seguir são descritas essas categorias, apesar de alguns dos modelos citados poderem ser, também, considerados como híbridos Timmermans (2000).

\subsubsection{Modelos de atividade que utilizam a teoria da maximização da utilidade}

Os modelos de escolha discreta, ou modelos do tipo Logit, têm sido a abordagem mais utilizada na área de transportes. Estes modelos fundamentam-se na hipótese básica de que "a probabilidade de um indivíduo escolher uma determinada alternativa é função da atratividade da alternativa escolhida em relação à atratividade das outras alternativas disponíveis" (Ortúzar e Willumsem, 1994). Para representar a atratividade de uma alternativa utiliza-se o conceito de "utilidade", geralmente definida como uma combinação de variáveis que representam as características da alternativa ou mesmo do indivíduo (tais como: idade, sexo, faixa de renda etc).

No caso específico dos modelos baseados em atividades, como a análise do comportamento de escolha de um padrão de atividades é um processo complexo (no que diz respeito ao amplo conjunto de escolhas alternativas), os pesquisadores têm utilizado a estrutura dos modelos do tipo Logit aninhado. Os modelos do tipo Logit aninhado avaliam a probabilidade de escolha entre alternativas similares ou correlacionadas, que são agrupadas em um ninho, na árvore de decisão. Por exemplo, esses modelos são utilizados, geralmente, para prever a escolha entre o uso do transporte coletivo e do automóvel em um nível superior. Em um nível inferior são então agrupadas as 
alternativas similares como, por exemplo, o metrô e o ônibus (ambos como parte do transporte coletivo). O número de ninhos incluídos na árvore de decisão tem aumentado freqüentemente, o que reflete que cada vez mais números maiores de conjuntos de escolhas são incluídos no modelo.

Entre os modelos que se encontram nessa categoria pode-se citar, por exemplo, o modelo STARCHILD (Recker et al., 1986a, 1986b), o modelo PETRA (Fosgerau, 1998, apud Arentze e Timmermans, 2000) e o modelo COBRA (Wang e Timmermans, 1999).

\subsubsection{Modelos de atividades baseados em restrições}

O conceito de geografia temporal de Hägerstrand tem direcionado o desenvolvimento de uma série de modelos que têm como objetivo comum identificar as possíveis programações de atividades diárias a serem realizadas por um indivíduo, em função de um conjunto de restrições (restrições de capacidade, de acoplamento e de autoridade).

Esses modelos verificam se um determinado padrão de atividades pode ser realizado em um específico ambiente de espaço e tempo. Um ambiente espaço-tempo pode ser definido em termos de localização da realização da atividade, dos atributos das atividades, dos modos de transporte disponíveis e do tempo de viagem (entre os locais de realização das atividades) por cada modo de transporte. Para se verificar a viabilidade de uma determinada programação de atividades, um algoritmo combinatorial é freqüentemente utilizado, de modo a gerar todas as possíveis seqüências de atividades. A viabilidade de cada seqüência de realização de atividades é testada das seguintes formas:

- Verificação se o intervalo entre o horário de término da atividade anterior e o horário de início da próxima atividade é suficiente para a realização da atividade mais o tempo associado à viagem e,

- Verificação se as condições das sequiências de atividades não são violadas.

Entre os modelos que se enquadram nessa categoria, podemos citar o modelo CARLA e os modelos holandeses BSP e MASTIC (Arentze e Timmermans, 2000). A aplicação desses modelos é particularmente importante em situações onde se deseja 
avaliar o impacto da aplicação de uma determinada política de transporte no ambiente espaço-tempo e, consequientemente, nos padrões de atividades individuais e domiciliares.

\subsubsection{Modelos de atividades baseados em regras lógicas}

A terceira categoria de modelos compreende aqueles que utilizam, em sua estrutura, regras lógicas para simular o comportamento individual e domiciliar de realização de atividades. Esses modelos incorporam os conjuntos de restrições e as alternativas de escolhas de um modo mais equilibrado. O objetivo é avaliar como os indivíduos, dentro de um domicílio, tomam suas decisões de realização de atividades, dadas as condições do ambiente de viagem (sistemas de transportes disponíveis e padrões de uso do solo) e das restrições que podem ser encontradas.

De modo similar aos modelos da categoria anterior, estes são baseados em heurísticas de escolhas, representadas pelo uso de regras SE <condição> ENTÃO <ação> (ou sistema de produção - conjunto de pares “condição-ação"), que especificam quais decisões irão ser tomadas em função de um conjunto de condições. As regras SE ... ENTÃO podem se referir, por exemplo, à prioridade de uma determinada atividade ou à proximidade espacial entre atividades.

Esses modelos simulam o comportamento de viagens individuais e domiciliares através de escolhas de programações diárias de atividades sujeitas a conjuntos de regras como, por exemplo, a não violação de uma seqüência de atividades. Da mesma forma, esses modelos simulam o processo de adaptação do comportamento de viagem individual e domiciliar em virtude de uma modificação no ambiente de viagem.

Os modelos que se encontram nessa categoria são o modelo SCHEDULER (Gärling et al., 1989), o modelo AMOS (RDC Inc., 1995; Pendyala et al., 1998), o modelo SMASH (Ettema et al., 1996), o modelo ALBATROSS (Arentze e Timmermans, 2000; Arentze et al., 2000) e o modelo CHASE (Doherty e Miller, 1997; Doherty, 2000). 
3.4.4 Modelos de atividades que utilizam técnicas de microsimulação

A última categoria constitui os modelos de análise de atividades que utilizam técnicas de microsimulação, onde o comportamento de realização de atividades de cada indivíduo da população seja simulado.

Os modelos de microsimulação simulam os padrões de atividades através de distribuições de probabilidades, que são definidas para os vários conjuntos de escolha que caracterizam um padrão de atividade.

As técnicas de microsimulação são utilizadas há muito tempo na análise por atividades. Originalmente, eram usados os modelos Markov e semi-Markov para simular atividades e encadeamentos de viagens. Talvez o projeto TRANSIMS seja o modelo mais completo até então desenvolvido (Barrett et al., 1995). Outros modelos que utilizam técnicas de microsimulação são o modelo SMART (Stopher e Hartgen, 1993 apud Arentze e Timmermans, 2000) e o modelo RAMBLAS (Veldhuisen et al., 2000).

O modelo CEMDAP (Bhat et al., 2004) é um microsimulador desenvolvido para modelar os padrões individuais de atividades e viagens diárias. O simulador implementa um sistema de modelos econométricos pré-definidos para representar o comportamento de escolha. É uma ferramenta flexível que pode ser usada em qualquer estudo em que os dados de entrada e os parâmetros do modelo estejam disponíveis.

O uso de técnicas de microsimulação é o mais indicado para fornecer os dados de entrada necessários aos modelos desagregados, fornecendo informações sobre o comportamento individual e domiciliar de programação de atividades diárias (Miller, 1996).

\subsection{Dados Necessários aos Modelos de Atividades}

Segundo Ettema (1996), os dados necessários para os modelos de atividades superam aqueles coletados para os modelos tradicionais de duas formas. Primeiro, em relação às variáveis dependentes, a calibração do modelo de atividades requer que sejam observadas as etapas consecutivas da programação de atividades, bem como os atributos que afetam a programação das decisões. Segundo, em relação às variáveis relacionadas à implementação de novas políticas de transportes e uso do solo, esses modelos incluem variáveis que são freqüentemente rejeitadas em pesquisas convencionais como o tempo 
disponível para a realização de uma determinada atividade (em função de restrições institucionais) e a priorização das atividades para os indivíduos.

Os modelos baseados em atividades utilizam como dados de entrada informações geográficas, informações sociodemográficas individuais (idade, gênero, situação do emprego, ocupação etc), informações sobre recursos disponíveis ao domicílio (propriedade de automóvel, características do domicílio, renda etc), dados espaciais e não espaciais sobre os locais de realização das atividades (localização, horário de funcionamento dos estabelecimentos, nível de acessibilidade etc) e dados referentes à malha viária. Dados socioeconômicos e de uso do solo são utilizados, por exemplo, para criar programações de atividades a serem utilizadas pelas pessoas, fornecendo como resultado uma lista de todas as possíveis atividades, o tempo que será gasto em cada uma e as viagens necessárias para movimentação entre os locais de realização de atividades.

Para Arentze et al. (2000), três principais considerações são importantes no processo de coleta de dados: (a) apenas dados relevantes aos objetivos do projeto devem ser coletados; (b) a qualidade dos dados requer consideração cuidadosa, uma vez que terá efeito direto nos resultados do modelo, e (c) coletas de dados de viagens e atividades produzem baixa taxa de respostas. Da mesma forma, com o objetivo de garantir a maior e melhor qualidade dos dados coletados devem ser cuidadosamente avaliadas decisões operacionais tais como a utilização de questionários ou diários e a forma de aplicação dos mesmos (envio pelo correio ou entrevistas pessoais).

O modo como são coletados os dados necessários à calibração de um modelo de atividades depende, basicamente, do propósito da pesquisa que se pretende realizar. Definido o objetivo principal, segue-se para determinação da metodologia mais aplicável à coleta, selecionando-se a forma mais viável e prática de obtenção desses dados (em função do tempo e recursos disponíveis). A seguir são descritas algumas das formas que têm sido utilizadas para coleta desses dados.

\subsubsection{Metodologias para Coleta de dados}

Existem várias formas de se realizar uma coleta de dados em planejamento de transportes. Esta pode ser feita através de pesquisas por telefone, questionários ou diários, programas de computador (Kalfs e Saris, 1997; Doherty e Miller, 2000), 
internet (Raub, 2003; Ruiz, 2004), GPS (Stopher et al., 2003; Marca et al., 2003; Doherty e Papinski, 2004) e sistemas de realidade virtual (Tan e Timmermans, 2004).

Para obtenção dos dados necessários à calibração de um modelo de demanda por transportes frequientemente são aplicados questionários e/ou diários. No caso de diários de viagem, os entrevistados devem descrever os vários aspectos das viagens anteriormente realizadas. Entretanto, o uso dessa metodologia dificulta a exploração da dinâmica da programação de atividades individual e domiciliar (escolha dos atributos das atividades e das viagens, dado o conjunto de necessidades que devem ser satisfeitas), uma vez que nestes diários são fornecidas apenas informações sobre o resultado do processo de tomada de decisão, e não sobre o processo em si mesmo (Axhausen, 1997).

Por outro lado, os diários de atividades são capazes de fornecer as informações necessárias e em maior nível de detalhes sobre os padrões de atividades individuais e domiciliares, os quais serão utilizados para verificar as potenciais relações entre viagens e atividades (Richardson et al., 1995). Esse método requer que as pessoas descrevam todas as atividades e viagens realizadas em um determinado dia. Segundo alguns pesquisadores (Ettema, 1996; Stopher, 1992; Timmermans, 2000), os diários de atividades apresentam melhor desempenho que os diários de viagem, uma vez que as viagens curtas e não baseadas no domicílio também são descritas.

Segundo Stopher (1992), a evolução de diários de viagem para diários de atividades ocorreu, principalmente, para evitar confusões em relação a alguns termos freqüentemente utilizados como, por exemplo, o termo "viagem" (responsável por dúvidas por parte dos entrevistados). Para os entrevistados, é mais fácil recordar que atividades realizaram, em qual local, por qual modo de transporte etc. Verifica-se que a viagem em si é apenas um meio para alcançar determinado destino, onde se deseja realizar alguma atividade. Assim, as viagens, principalmente aquelas mais curtas, são freqüentemente esquecidas ou ignoradas. Por outro lado, as atividades que as pessoas realizaram são muito mais facilmente lembradas e serão, também, mais facilmente descritas completa e detalhadamente. As questões existentes nos dois tipos de diários são as mesmas, alterando-se apenas a ordem como são feitas, o que já possibilita o fornecimento de dados mais ricos em detalhes e de melhor qualidade (Stopher, 1998).

Clarke et al. (1981) e Stopher (1992) recomendam o uso de diários de atividades quando houver necessidade de se conhecer viagens curtas e não baseadas no 
domicílio. Para Ettema (1996) se os dados serão utilizados para a estimação de um modelo de atividades, o uso de diários de atividades é, por definição, uma necessidade.

A estrutura dos diários de atividades, quando comparada à dos diários tradicionais, é muito mais complexa no que se refere à quantidade de informações exigidas do entrevistado, o que acaba por ocasionar baixo nível de respostas ou dados inconsistentes. Uma das formas utilizadas para se tentar contornar esse fato é através do oferecimento de incentivos que podem estimular a participação individual e domiciliar na coleta de dados. Freqüentemente, são oferecidas gratificações, tais como a participação em sorteios ou até mesmo certa quantidade em dinheiro, para que os indivíduos sejam motivados a preencherem os diários de atividades (Axhausen et al., 2002; Vaughn, 2003; Tan e Timmermans, 2004).

Apesar de existirem diversas maneiras de se coletar dados para a calibração de modelos de demanda por transportes em geral, não existem dúvidas que o uso de diários de atividades é o método mais eficiente para se coletar os dados necessários à calibração de um modelo baseado em atividades (Ettema, 1996). Entretanto, é essencial que o pesquisador fique atento à estrutura do diário a ser aplicado, uma vez que a esta está diretamente relacionada a qualidade dos resultados obtidos (Arentze et al., 2000). A seguir são destacadas algumas considerações que devem ser analisadas pelo pesquisador, de modo a garantir que a aplicação dos diários de atividades forneça informações de qualidade para o fim a que se destinam.

\subsubsection{Especificações do Diário de Atividades}

Na aplicação de diários para coleta de dados é importante identificar quais informações serão realmente relevantes no processo de definição do conjunto de escolha de atividades e viagens individuais. Por isto, mesmo antes da finalização da estrutura do diário é importante que o pesquisador verifique alguns aspectos que precisam ser avaliados no processo de coleta de dados. Primeiramente deve ser feita a escolha do formato de diário mais apropriado, de acordo com os dados que se deseja obter e o tipo de análise que se quer realizar. Por exemplo, informações relacionadas às atividades realizadas dentro do domicílio podem ser importantes quando se pretende avaliar a inter-relação entre estas e aquelas realizadas fora dele, ou a substituição de atividades que necessitam de viagem por aquelas que podem ser realizadas no próprio domicílio. 
As atividades devem ser classificadas de acordo com o nível de detalhes que se deseja obter. Classificações muito detalhadas podem ser mais ricas e apropriadas na definição do conjunto de escolha e das restrições espaço-temporais. Disponibilizar ao entrevistado uma lista com várias categorias de atividades pode tornar o processo de preenchimento do diário uma tarefa cansativa. Deve-se avaliar ainda a possibilidade do entrevistado descrever suas atividades com as próprias palavras.

No que se refere à data em que as atividades e viagens foram realizadas, o pesquisador pode optar por registrar as viagens ocorridas no dia anterior, ou solicitar ao entrevistado que relate as atividades que serão realizadas em data futura. No primeiro caso, pode acontecer do entrevistado não se recordar de todas as informações necessárias, como os horários de realização das atividades.

Outro aspecto importante na implementação desses diários é a escolha do(s) dia(s) da semana em que as informações devem ser coletadas. Como o conjunto de atividades realizadas por um indivíduo pode sofrer alterações durante os dias da semana, deve-se tentar garantir que os diários sejam distribuídos de forma balanceada nos dias da semana, de forma a tentar capturar essas eventuais mudanças de programação de atividades. O pesquisador, nesse sentido, dispõe de duas formas de aplicação dos diários: o(s) dia(s) de preenchimento pode(m) ser designado(s) pelo entrevistador ou escolhido(s) pelo entrevistado, de acordo com sua conveniência.

A dimensão temporal é uma das principais variáveis incluídas nesses modelos, dado que ela fornece a possível programação de atividades individual, em função da disponibilidade de tempo de cada pessoa. Assim, devem ser coletados dados sobre horários de início e término das atividades e viagens. Nesse caso, o pesquisador deve estar atento à precisão que deseja obter em relação a essa variável. Podem ser usados intervalos de tempo abertos - em que o entrevistado descreve os horários de início e término de suas atividades - ou intervalos de tempo fixos - em que o entrevistado deve descrever as atividades em intervalos de tempo pré-definidos. Intervalos fixos, quando muito longos, podem levar à omissão de atividades curtas realizadas no período. Essa escolha deve ser feita com o objetivo de minimizar inconsistências no relato dos horários de início e término das atividades.

O tempo de aplicação dos diários deve ser de, no máximo, dois dias (Timmermans, 2000). Após esse período os entrevistados não se sentem estimulados a preencherem os diários, dando margem a um maior número de falta de respostas e/ou dados inconsistentes. Certamente o ideal seria um período maior, em dias diferentes e 
até mesmo durante os finais de semana (Lockwood et al., 2004), de modo a se obter o padrão de atividades e viagens mais próximo à realidade, já que muitas vezes o preenchimento do diário por apenas dois dias pode não captar eventuais atividades que ocorram em dias diferentes daqueles.

Em conseqüência da especificação de com quem a atividade é realizada existe, ainda, a necessidade de se coletar dados sobre quem está participando das várias atividades juntamente com o entrevistado. Se essa dimensão envolve outros membros do domicílio, devem ser coletadas, preferencialmente, informações de todos os outros membros, ainda que alguns sejam utilizados apenas para o esclarecimento do processo de tomada de decisão. Entretanto, quando atividades são realizadas juntamente com outros indivíduos que não fazem parte do domicílio, a coleta desses diários fica comprometida.

Os diários podem ser administrados por correio, entrevistas domiciliares ou telefone. Entretanto, a pesquisa por telefone, neste caso, não é a mais indicada, em virtude da grande quantidade de informações necessárias. Como os diários requerem uma certa quantidade de tempo para que todas as informações sejam obtidas, o mais indicado é a visita domiciliar. Inicialmente pode ser feito o contato via telefone ou correio para verificar a disponibilidade do entrevistado e em seguida conduzir a visita domiciliar.

Uma das desvantagens do uso dos diários de atividades é o fato de eles poderem apresentar baixo nível de respostas. Freqüentemente, os indivíduos que não encontram tempo para preencher diários são aqueles que realizam maior número de viagens. Dessa forma, incentivos podem estimular a participação individual e domiciliar na coleta de dados e, assim, evitar altas taxas de respostas inconsistentes ou a falta destas. Uma das formas de se reduzir o excesso de esforço envolvido nas várias etapas da coleta de dados (estruturação, entrega, recolhimento, digitalização, verificação de inconsistências etc), é o uso de ferramentas computacionais. Nesse caso, um programa de entrevistas apresenta as questões na tela e registra as respostas. Assim, são descartadas algumas das etapas anteriores, o que torna a coleta mais rápida e barata (Kalfs e Saris, 1997). Outra vantagem do uso da coleta de dados por computador (denominada CADAC - Computer-Assisted Data Collection) é o fato de, automaticamente, as informações serem codificadas e sua consistência verificada.

O processo de coleta de dados por computador tem sido usado por alguns pesquisadores. Doherty e Miller (2000) desenvolveram o programa CHASE 


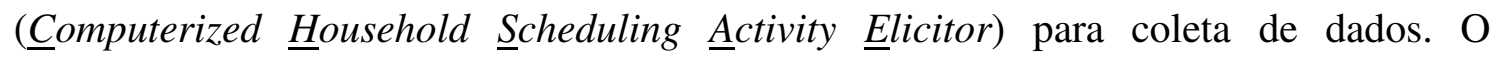
programa foi instalado em computadores portáteis e estes distribuídos em domicílios para que os moradores semanalmente descrevessem suas programações de atividades. $\mathrm{O}$ principal objetivo do CHASE era de explorar a agenda domiciliar de atividades para verificar todo o processo de decisão sobre quando e como as atividades foram adicionadas e/ou modificadas ao longo da semana. Outras informações eram obtidas através de entrevistas no domicílio (para obter informações de características sociodemográficas e da residência). Com base na agenda de atividades, os indivíduos deveriam especificar quais delas iriam realizar e seus atributos, como freqüência, localização e pessoa envolvida. O programa se apresentou eficiente e com baixas taxas de respostas inconsistentes ou em branco. Posteriormente, foi desenvolvido o $i$ CHASE

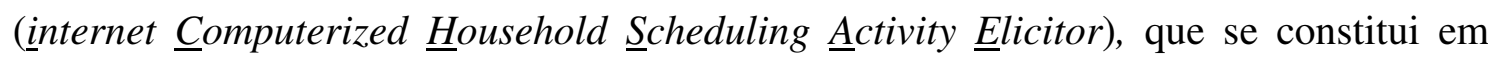
uma versão mais sofisticada do CHASE, a qual permite aos respondentes utilizar seus próprios computadores para inserir informações e atualizá-las quando necessário (Lee et al., 2000).

A internet como ferramenta de coleta de dados foi utilizada por Raub (2003), na cidade de Chicago, com o propósito de verificar como os trabalhadores consultavam informações sobre rotas de viagem. O autor constatou que o uso da internet forneceu respostas em nível satisfatório (cerca de 30\%, contra $23 \%$ das pesquisas por correio). Uma das desvantagens dessa metodologia é a exclusão de potenciais viajantes que não têm ou não fazem uso da internet. Entre as vantagens está o fato de os dados serem automaticamente codificados e as pessoas poderem responder em horários que lhes sejam mais convenientes, não correndo o risco de esquecimento de devolução do formulário ou mesmo de perdê-lo.

O uso de ferramentas computacionais para coleta de dados pode realmente ser mais eficiente (em termos de tempo empregado na coleta dos dados) que o uso de técnicas convencionais (diários impressos). Entretanto, diários e questionários ainda são muito utilizados em pesquisas de demanda de viagens.

Alguns autores (Kalfs e Saris, 1997) realizaram trabalhos comparando resultados obtidos com coleta de dados convencional (aplicação de diários) e técnicas convencionais. A comparação foi feita quanto à precisão na descrição das atividades e dos horários de realização das mesmas, e o tempo envolvido na pesquisa. Os autores concluíram que nos diários convencionais (impressos) os indivíduos descrevem suas atividades e os horários de realização de forma mais precisa. 


\subsection{Considerações Finais}

A importância do desenvolvimento de novos métodos para a previsão da demanda de viagens é consenso por parte dos pesquisadores. Vários trabalhos relacionados ao tema vêm sendo publicados, ressaltando a necessidade do uso de uma nova abordagem (por exemplo, Bhat e Lawton, 2000; Marshment, 2000). Nesse sentido, a abordagem baseada em atividades vem sendo amplamente defendida por diversos pesquisadores, o que pode ser verificado pelo alto número de trabalhos publicados em revistas e congressos internacionais.

Como pode ser observado, a estrutura desses modelos é bastante complexa, uma vez que envolve vários aspectos relacionados às viagens e atividades realizadas. Outro fator relevante no que se refere aos modelos de atividades é a quantidade e a qualidade dos dados necessários ao seu desenvolvimento e aplicação.

Vários modelos foram e vêm sendo desenvolvidos e aplicados (item 3.4) em diversos países. Alguns pesquisadores vêm usando a metodologia para análises dos fatores que afetam o comportamento individual de programação de atividades, tal como a possibilidade do indivíduo receber informações sobre o ambiente de viagem antes mesmo deste iniciar suas viagens e reorganizar sua agenda diária de atividades (Arentze et al., 2004). Todo esse panorama evidencia a maior potencialidade dessa abordagem em fornecer informações ricas em relação àquelas tradicionalmente utilizadas.

A metodologia de coleta de dados com aplicação de diários de atividades está sendo usada por vários pesquisadores em várias partes do mundo com o objetivo de coletar dados detalhados em relação às atividades e viagens realizadas pelos indivíduos. No Brasil, pode ser encontrado apenas um registro desse tipo de aplicação (Arruda e Silva, 2004). Dessa forma, a aplicação dos diários de atividades em um contexto de cidades brasileiras permitirá a análise da viabilidade de aplicação desses diários, tanto em termos de custos como de qualidade dos dados obtidos. 
Espera-se que a aplicação de um modelo baseado em uma cidade brasileira seja viável e que traga resultados satisfatórios. Neste trabalho, a viabilidade de aplicação desses modelos será verificada de acordo com os resultados alcançados para análise da relação entre as características do uso do solo e transportes, no âmbito de uma cidade brasileira de médio porte. No próximo capítulo será discutida a metodologia a ser usada nesta pesquisa, com uma explanação teórica do modelo de atividades a ser utilizado. 


\section{METODOLOGIA}

O objetivo deste capítulo é apresentar a metodologia adotada para o desenvolvimento desta pesquisa. Serão apresentados os fundamentos teóricos do modelo Albatross, que se constitui em um modelo de demanda por transportes baseado em atividades, sua estrutura e dos dados necessários à sua calibração e validação.

A metodologia adotada para o desenvolvimento desta pesquisa consiste na utilização do modelo de atividades Albatross (Arentze e Timmermans, 2000). O modelo será aplicado para verificação da influência das características do uso do solo sobre o processo individual de programação de atividades e viagens. Nesse processo incluemse, entre outras informações, a determinação de quais atividades realizar, em que local, os horários de início e término e o modo de transporte.

A escolha pelo modelo Albatross foi feita durante uma primeira fase do estágio de Doutorado Sanduíche realizado na Universidade de Eindhoven, Holanda, no período de agosto de 2002 a janeiro de 2003. Um fator que motivou o uso desse modelo foi o fato de que o desenvolvimento de um modelo baseado em atividades requer o uso de ferramentas complexas e alto nível de conhecimento computacional, o que consumiria muito tempo para que esse modelo pudesse ser desenvolvido, calibrado e validado no Brasil.

É importante salientar que este é um modelo de demanda por transportes, e não um modelo integrado de uso do solo e transportes. Entretanto, ele é capaz de fornecer resultados referentes à inter-relação entre as variáveis de uso do solo e o comportamento de viagem, em todas as etapas do processo de tomada de decisão sobre quais atividades e viagens realizar (Figuras 4.2 a 4.4 do Apêndice A). 
O Albatross, desenvolvido e aplicado às condições das cidades holandesas, será devidamente calibrado de acordo com os dados coletados na cidade de São Carlos, estado de São Paulo.

\subsection{Albatross (A Learning Based Transportation Oriented Model System)}

O modelo Albatross foi desenvolvido por pesquisadores da Universidade de Eindhoven, Holanda, para o Ministério dos Transportes daquele país. A primeira versão do modelo foi aplicada apenas a algumas cidades holandesas no ano de 1997. O Albatross é portanto um modelo operacional, voltado a aplicações práticas. A primeira versão do modelo, inicialmente usada em nível regional na Holanda, foi ampliada com inclusão de novas variáveis para aplicação em nível nacional, obtendo resultados satisfatórios. Trata-se de um modelo de atividades baseado em regras lógicas, que representam heurísticas de escolha a partir de um conjunto de dados. O modelo incorpora grande parte dos conjuntos de escolha que envolvem os padrões de atividades e apresenta um ambiente que possibilita a geração de cenários e ferramentas de avaliação.

A demanda de viagem é considerada como derivada do processo pelo qual os indivíduos programam suas atividades e viagens em um período de tempo. As decisões são tomadas em nível domiciliar, sendo consideradas restrições espaço-temporais e institucionais no processo de programação das atividades diárias.

No modelo, as atividades são classificadas em fixas e flexíveis. Atividades fixas são aquelas consideradas obrigatórias, com local e horários pré-definidos (como atividades de trabalho). Atividades flexíveis são aquelas cuja decisão de realização é tomada durante o dia, e não apresentam local nem horários fixos. O modelo considera que a geração de programações de atividades depende da natureza destas (fixas ou flexíveis) e da urgência em se realizar uma determinada atividade em um dia específico.

O processo de programação de atividades é conceitualizado como aquele no qual o indivíduo busca realizar objetivos particulares, dada uma variedade de restrições que limitam o número de padrões de atividades possíveis. Um padrão de atividades é a ordenação destas e suas respectivas viagens com local, tempo de início, duração e modo de transporte definidos. Muitas vezes esse padrão é coordenado com padrões de atividades de outros indivíduos no domicílio (ou fora dele).

O uso do tempo e do espaço é condicionado pelos locais onde o individuo 
realiza suas atividades (denominados "bases"), sejam estes o domicílio, o local de trabalho etc. (Dijst e Vidakovic, 1997). O prisma espaço-tempo (Capítulo 3, Figura 3.1) compreende o conjunto de posições no espaço e no tempo que o indivíduo pode visitar. De acordo com Dijst e Vidakovic (1997) a projeção do prisma no eixo do espaço fornece o espaço de ação potencial. Dessa forma, espaço de ação potencial é definido como a área contendo todos os locais de atividade que são alcançáveis, sujeito a um conjunto de condições espaço-temporais. Esse conjunto de condições inclui os tipos e as localizações das bases de atividades, intervalo de tempo disponível, velocidade de viagem e a proporção do tempo disponível gasto na viagem.

A programação de atividades individual é feita com base no contexto domiciliar. Decisões relacionadas aos modos de transporte definem o espaço de ação dentro do qual os indivíduos podem escolher as localizações para a realização de suas atividades. A organização das viagens em "elos" (viagens encadeadas) permite aos indivíduos realizar um maior número de atividades em um intervalo de tempo específico.

Identificadas as restrições que definem o espaço de ação dos indivíduos, a próxima etapa é a definição de como os indivíduos escolhem um entre os possíveis padrões de atividades. O modelo Albatross admite que os padrões de atividades irão ser construídos a partir de "mecanismos de aprendizado", onde o indivíduo determina um padrão de atividades de acordo com sua experiência (ou conhecimento). Esse padrão pode não ser o ótimo, uma vez que o indivíduo, baseado apenas em seus conhecimentos, pode desconsiderar outras opções viáveis.

O processo de aprendizagem transforma gradualmente padrões de busca em preferências individuais por determinadas localizações, tempo e modo de transporte para a realização de atividades. Essas preferências guiam o processo de tomada de decisão na construção de programações de atividades possíveis de serem realizadas. Rejeita-se então a noção de que indivíduos estão envolvidos em uma comparação sistemática de todos os possíveis padrões de atividades. O resultado desse aprendizado é um conjunto de regras que guiam o processo de solução do problema, o que permite aos indivíduos se adaptarem às condições de mudança. 


\subsection{Arquitetura do Sistema Albatross}

O modelo é composto por vários componentes que realizam determinadas funções no processo de programação e execução das atividades. A arquitetura do sistema é representada na Figura 4.1.

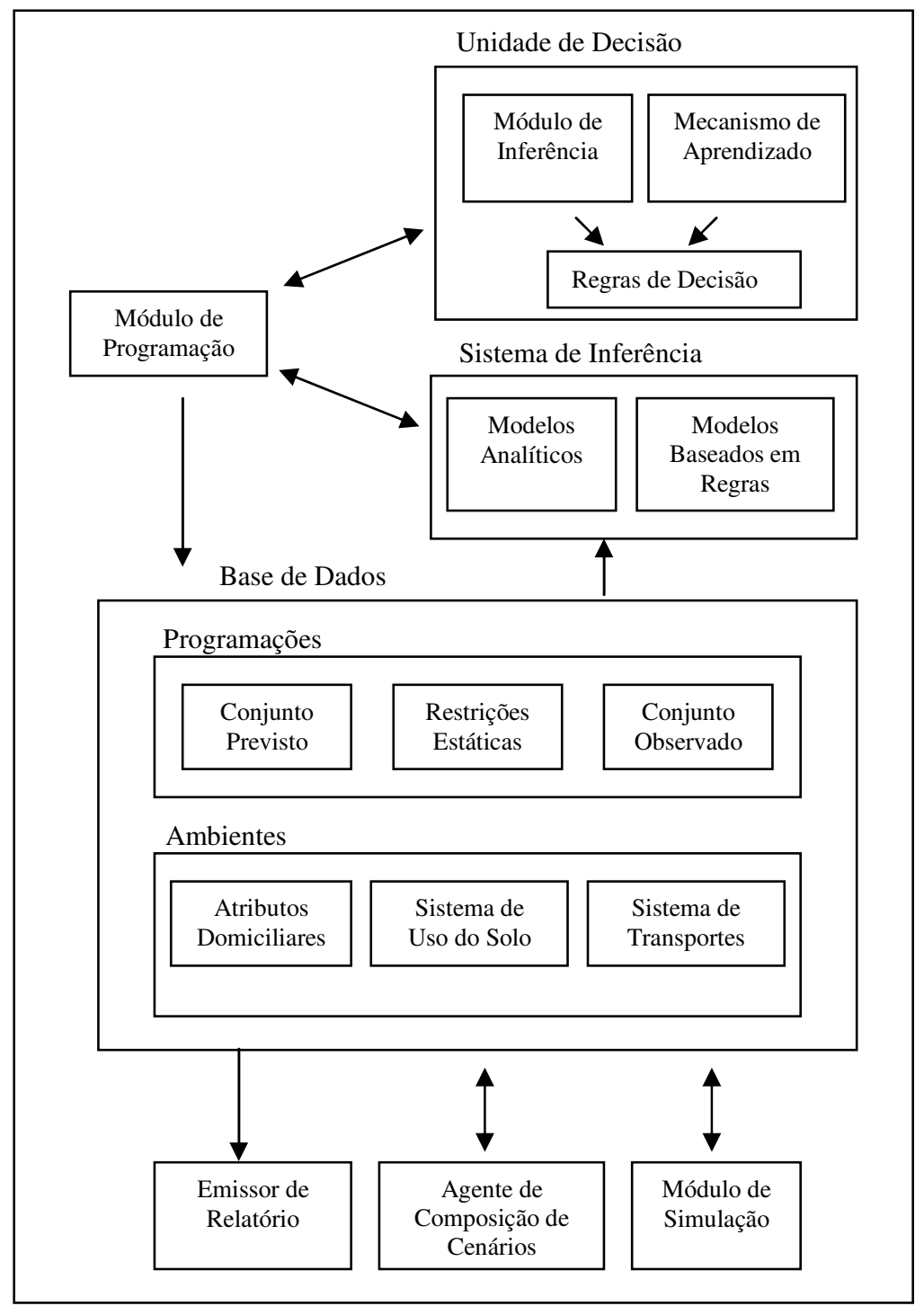

Figura 4.1: Arquitetura do Sistema (Arentze e Timmermans, 2000)

A seguir é feita uma breve descrição em relação aos componentes do modelo. 
a) Módulo de Programação

Esse é o componente central do sistema, que controla todo o processo de programação de atividades para os membros adultos de um determinado domicílio em um determinado dia. Nele são identificadas informações que serão usadas no próximo componente (Unidade de Decisão).

Esse módulo denomina como estrutura básica do modelo o conjunto de atividades fixas que devem ser realizadas por um determinado indivíduo. O método de programação envolve a complementação da estrutura, com a adição de atividades flexíveis nos intervalos de tempo disponíveis. Em vários momentos no processo de programação, a prioridade de classificação das atividades flexíveis é requerida para determinar a sequiência na qual as decisões serão tomadas.

A Tabela 4.1 apresenta de forma sucinta as principais etapas do processo de programação das atividades fixas e flexíveis, enquanto que na Tabela 4.2 são apresentadas as alternativas de escolha para cada etapa no processo de programação.

Tabela 4.1: Etapas do processo de programação de atividades

(Arentze e Timmermans, 2000).

\begin{tabular}{cl}
\hline Etapas & \multicolumn{1}{c}{ Ação } \\
\hline 0 & $\begin{array}{l}\text { Dado o conjunto de atividades fixas, é iniciado o processo de programação de atividades } \\
\text { Seleção do modo de transporte para cada atividade principal de trabalho }\end{array}$ \\
2 & $\begin{array}{l}\text { Seleção e adição de atividades flexíveis à programação, e especificação de atributos (com } \\
\text { quem a atividade será realizada e a duração para cada atividade adicionada) }\end{array}$ \\
3 & $\begin{array}{l}\text { Para cada atividade flexível, determinação da hora do dia em que a atividade deverá iniciar e } \\
\text { sua posição adequada na programação }\end{array}$ \\
4 & $\begin{array}{l}\text { Para cada atividade, determinação de sua posição na programação e o encadeamento de } \\
\text { viagem com atividades anteriores e posteriores, ou inserção de atividades no domicílio, se } \\
\text { necessário }\end{array}$ \\
5 & $\begin{array}{l}\text { Para cada encadeamento de viagem resultante na programação, determinação do modo de } \\
\text { transporte } \\
\text { Para cada atividade flexível, determinação da localização e tempo de viagem }\end{array}$ \\
\hline
\end{tabular}

Esse módulo usa especificações funcionais tanto do Sistema de Inferência como da Unidade de Decisão, mas não precisa saber como a relação entre as decisões é definida. Nesse sentido, o Módulo de Programação incorpora apenas o conhecimento de controle. 
Tabela 4.2: Alternativas de escolha para cada etapa no processo de programação (Arentze e Timmermans, 2000).

\begin{tabular}{|c|c|c|}
\hline Etapas & Dimensão & Alternativas \\
\hline \multirow[t]{2}{*}{1} & $\begin{array}{l}\text { Principal atividade de trabalho, } \\
\text { modo de transporte }\end{array}$ & $\begin{array}{c}\text { Modos não motorizados, carro (motorista), transporte } \\
\text { público, carro (passageiro) }\end{array}$ \\
\hline & Seleção da atividade & Sim, não \\
\hline \multirow[t]{2}{*}{2} & Atividade (com quem) & $\begin{array}{l}\text { Sozinho, com outros membros do domicílio, com membros } \\
\text { de fora do domicílio }\end{array}$ \\
\hline & Duração da atividade & Curta, média, longa \\
\hline 3 & Horário de início da atividade & $\begin{array}{l}\text { Antes das } 10 \text { horas, entre } 10-12 \text { horas, entre } 12-14 \text { horas, } \\
\text { entre } 14-16 \text { horas, entre } 16-18 \text { horas, após } 18 \text { horas }\end{array}$ \\
\hline 4 & $\begin{array}{l}\text { Padrão de viagem para cada } \\
\text { atividade }\end{array}$ & $\begin{array}{l}\text { Antes de uma parada, após uma parada, entre paradas, } \\
\text { parada simples }\end{array}$ \\
\hline 5 & $\begin{array}{l}\text { Encadeamentos de viagem, modo } \\
\text { de transporte }\end{array}$ & $\begin{array}{l}\text { Modos não motorizados, carro (motorista), transporte } \\
\text { público, carro (passageiro) }\end{array}$ \\
\hline \multirow{2}{*}{6} & Atividade, localização (1) & Escolhas heurísticas (1) \\
\hline & Atividade, localização (2) & Escolhas heurísticas (2) \\
\hline
\end{tabular}

b) Unidade de Decisão

Esse componente incorpora, para cada etapa no processo de programação, um conjunto de regras de decisão representando preferências individuais e restrições relacionadas às opções. Este é composto por dois elementos:

- Módulo de Inferência: responsável pela seleção e aplicação de regras apropriadas para se alcançar uma decisão quando o Módulo de Programação elabora uma pergunta. Apenas as variáveis de condição mais relevantes e as opções de decisão são definidas no código do programa do sistema. As regras que conectam as variáveis de condição e opções de decisão são externas a este e "carregadas" a partir de arquivos de dados.

- Mecanismo de Aprendizado: fornece como resultado as regras de decisão. Este componente determina as regras a partir de dados baseados em princípios de aprendizado induzido.

Em vários momentos do processo de programação no primeiro módulo (Tabela 4.1), a Unidade de Decisão é consultada para a tomada de decisão. Esse módulo é complementado pelo Sistema de Inferência descrito a seguir. 
c) Sistema de Inferência

O Sistema de Inferência consiste em um conjunto de modelos analíticos e baseados em regras que fornecem informações necessárias para o processo de programação a partir dos dados disponíveis. Os modelos incorporados implementam restrições dinâmicas para determinar a disponibilidade de opções de decisão em cada etapa do processo, como quando ou não uma atividade se ajusta em um intervalo de tempo dado o tempo de viagem necessário, duração mínima da atividade, possíveis localizações, horário de funcionamento dos estabelecimentos etc. O mesmo modelo também serve para calcular indicadores de desempenho como medidas de prisma espaço-tempo e o nível de acessibilidade das localizações. Com essas informações, a Unidade de Decisão é capaz de articular preferências para opções.

As informações entre o Sistema de Inferência e a Unidade de Decisão são transmitidas e controladas pelo Módulo de Programação. Esses dois sistemas não necessitam, para seu funcionamento, do conhecimento do processo de programação, agindo apenas como fornecedores de informações ao Módulo de Programação de atividades. A Tabela 4.3 apresenta o resumo das atividades realizadas pelos modelos no Sistema de Inferência.

d) Base de Dados

A Base de Dados armazena conhecimento do conjunto de arquivos de dados gerados pelo Módulo de Programação. Como mostrado na Figura 4.1, a base de dados é formada por duas camadas de informações. A primeira camada armazena informações das programações de atividades por domicílio e dia da semana, formada por três conjuntos de dados:

- O primeiro conjunto armazena as programações geradas pelo Módulo de Programação.

- O segundo conjunto de dados fornece as restrições específicas a cada domicílio, que são dados de entrada ao Módulo de Programação. As restrições incluem conjuntos de escolha, intervalos de tempo etc., definindo as opções de escolha para decisões de programação;

- O terceiro conjunto observado permite ao sistema avaliar o ajuste das 
programações geradas pelo Módulo de Programação em condições iniciais (sem simulação de cenários).

Tabela 4.3: Resumo das atividades dos modelos no sistema de inferência (Arentze e Timmermans, 2000).

\begin{tabular}{|c|c|}
\hline \multicolumn{2}{|r|}{ Sistema de Inferência } \\
\hline 1 & Análise do domicílio: classifica os atributos domiciliares e individuais \\
\hline 2 & $\begin{array}{l}\text { Análise do programa de atividade: computa, para um dado conjunto de atividades, o } \\
\text { engajamento de cada uma em categorias de atividades pré-definidas em termos de tempo total e } \\
\text { freqüência }\end{array}$ \\
\hline 3 & $\begin{array}{l}\text { Análise da disponibilidade de automóvel: determina para uma dada pessoa e um determinado } \\
\text { intervalo de tempo, a disponibilidade do automóvel no domicílio considerando atividades de } \\
\text { trabalho do cônjuge ou outra pessoa no domicílio }\end{array}$ \\
\hline 4 & $\begin{array}{l}\text { Análise da disponibilidade de tempo: para um dado conjunto de atividades, computa o tempo } \\
\text { disponível em cada posição na programação para completar uma atividade com restrições no } \\
\text { horário de início, considerando os tempos de viagem }\end{array}$ \\
\hline 5 & $\begin{array}{l}\text { Análise de oportunidade de encadeamento de viagem (1): computa para um determinado } \\
\text { conjunto de atividades fixas } \mathrm{S} \text {, uma atividade flexível A e a localização do domicílio } \mathrm{H} \text {, a } \\
\text { existência de atividades fora de casa } \mathrm{O} \text {, a máxima redução na distância de viagem possível entre } \\
\text { localizações para a atividade flexível, encadeando as viagens } \mathrm{H}-\mathrm{O}-\mathrm{A}-\mathrm{H} \text { comparada com H-O-A- } \\
\mathrm{H} \text { para cada } \mathrm{O} \in \mathrm{S}\end{array}$ \\
\hline 6 & $\begin{array}{l}\text { Análise de oportunidade de encadeamento de viagem (2): como em } 5 \text {, o horário de início de A é } \\
\text { restrito por um dado intervalo de tempo }(\mathrm{T} 1, \mathrm{~T} 2)\end{array}$ \\
\hline 7 & Análise da possibilidade de encadeamento de viagem (1): retorna para uma dada programação \\
\hline & $\begin{array}{l}\mathrm{S} \text {, o intervalo de tempo (T1, T2) e atividade flexível A, o subconjunto de } S_{x} \subseteq S \text { para o qual } \\
\text { o elo A-O, O } \in \mathrm{S} \text { são possíveis, dadas restrições espaço-temporais. }\end{array}$ \\
\hline 8 & Análise da possibilidade de encadeamento de viagem (2): como em 7, para elos O-A \\
\hline 9 & $\begin{array}{l}\text { Análise do encadeamento de viagem: analisa um determinado encadeamento em termos de } \\
\text { programas de atividade, duração, distância de viagem etc. }\end{array}$ \\
\hline 10 & $\begin{array}{l}\text { Análise do modo de viagem: determina para um determinado encadeamento de viagem } S, 1) \text { o } \\
\text { tempo mínimo de viagem por modo de transporte entre localizações para a atividade flexível } \\
A \in S \text {, se existente, e 2) tempo extra de viagem por modo de transporte requerido para } \\
\text { alcançar a localização de mais alta ordem para uma atividade flexível } A \in S \text {, se existente. }\end{array}$ \\
\hline 11 & $\begin{array}{l}\text { Análise da localização: determina, para uma determinada atividade flexível } \mathrm{A} \text {, a janela de } \\
\text { tempo (T1, T2) para A, característica da localização do conjunto de escolha para } \mathrm{A}\end{array}$ \\
\hline
\end{tabular}

A segunda camada inclui informações sobre a área de estudo, em termos de atributos da população e dos domicílios, o padrão de uso do solo e sistema de transportes. O sistema de uso do solo é descrito em termos de horário de funcionamento dos estabelecimentos para atividades a serem realizadas fora de casa. O sistema de transportes é representado por um conjunto de matrizes de tempos de viagem por modo de transporte. O tempo de viagem é determinado sob condições de fluxo livre e de menor caminho físico. 
e) Emissor de Relatório

Os módulos finais do sistema realizam determinadas tarefas em relação à necessidade de informações dos usuários ou aspectos dinâmicos do sistema. O Emissor de Relatório atua em três níveis:

- Primeiro, para análise de freqüência e contingência, os usuários são capazes de definir as dimensões para uma tabulação cruzada em três dimensões;

- Segundo, para análise de desempenho, o emissor de relatório calcula e apresenta indicadores de desempenho selecionado pelo usuário. Para contingência, bem como para análise de desempenho, o usuário pode escolher um conjunto de dados a ser analisado: previsto, observado ou a diferença entre os dois, e,

- Em um terceiro nível, gera um conjunto de medidas de ajuste entre as programações observadas e geradas.

Este módulo fornece facilidade para gerar a estatística requerida para análise de impacto em várias "rodadas" do Módulo de Programação.

\section{f) Agente de Composição de Cenário}

Esse componente é útil para a realização de previsões, pois permite ao usuário alterar os atributos do sistema de uso do solo e transportes, as características domiciliares e restrições estáticas da programação (ou seja, a estrutura). Esse agente pode ser ativado em três modos: composição da população, alterações de comportamento e alterações de variáveis exógenas ao sistema.

Ele fornece a interface e assiste usuários na definição e aplicação de múltiplos cenários em combinação. Para fornecer máxima flexibilidade, todas as entradas de dados podem ser manipuladas e simuladas por técnicas de Monte Carlo.

g) Módulo de Simulação

Enquanto o módulo anterior está relacionado a possíveis políticas a serem aplicadas, o Módulo de Simulação controla a dimensão tempo do sistema. Simula 
assim, em tempo real, a dinâmica do ambiente na qual o indivíduo interage no estágio de execução da programação. A função principal consiste na simulação de fluxos de tráfego nas vias e no ajuste dos dados de tempo de viagem com base na capacidade viária. O Módulo de Simulação atualiza informações de restrições em nível domiciliar, fornecendo informações ao Módulo de Programação sobre a urgência de atividades ou previsão de eventos durante a execução das programações.

\section{Extensão do Modelo}

Após implantação em nível regional, com obtenção de resultados satisfatórios, o modelo foi ampliado, de modo a torná-lo operacional para aplicações nacionais. Esse processo envolveu (Arentze et al., 2003):

- Geração das estruturas básicas de atividades (originalmente eram consideradas fornecidas);

- Re-indução do agente de programação de atividades do modelo para nível nacional (opostos, portanto, às características regionais de uso do solo), sistema de transportes e conjunto de dados de diários de atividades;

- Adição de variáveis de custo ao conjunto de variáveis independentes em cada componente do modelo, e,

- Reavaliação dos componentes de escolha de localização.

A nova versão do modelo apresenta a possibilidade de geração da estrutura de atividades (fixas), e seus respectivos horários de início e duração. Com a estrutura gerada pelo próprio modelo, um outro componente introduzido no sistema determina a parte da programação relacionada às atividades flexíveis a serem realizadas naquele dia, com quem, duração, hora do dia e características das viagens. Esses novos componentes supõem um processo de escolha seqüencial e regras pré-definidas delineiam o conjunto de escolha e implementam as escolhas feitas na programação atual.

A estrutura do processo de decisão em relação às atividades flexíveis é a mesma da versão inicial. O componente de localização das atividades foi reestruturado. As etapas da programação são apresentadas pelas Figuras 4.2 a 4.4. Cada retângulo corresponde a uma árvore de decisão. Os índices usados são definidos como: 
- $\mathrm{i}$ : índice da atividade em ordem de prioridade, $\mathrm{i}=1, \ldots, \mathrm{I}$;

- j é o índice do "episódio" da atividade i em ordem de horário de início, $\mathrm{j}=1 \ldots \mathrm{J}$

- $\mathrm{k}$ é o índice do ciclo de viagens em ordem de horário de início, $\mathrm{k}=1 \ldots \mathrm{K}$.

Aqui é importante definir dois termos que serão usados neste trabalho: episódio e ciclos de viagens. Episódio é definido como sendo o "tempo entre o início e o término de uma atividade"; ou seja, são períodos de realização de atividade (atividade trabalho tem dois episódios: diurno e vespertino). Ciclo de viagem é definido como a "sequiência de viagens, com início e término no mesmo local".

A estrutura compreende as etapas de 1 a 13 (Figura 4.2), o componente de localização usado tanto para as atividades fixas como flexíveis de 14 a 20 (Figura 4.3) e o componente das atividades flexíveis de 21 a 27 (Figura 4.4).

O componente de geração da estrutura determina os padrões de atividade em escala de tempo contínuo (Figuras 4.2 e 4.3). Ele consiste de vários sub-processos, incluindo: determinação do padrão de atividades de dormir (retângulos 1-2), determinação do padrão de atividades de trabalho/escola (retângulos 3-8); determinação de padrões secundários, atividades fixas (retângulos 9-13) e determinação da localização de cada episódio de atividade fixa (retângulos 14-20).

O modelo escolhe o horário de término da atividade dormir e o horário de início da atividade dormir a noite. A atividade trabalho/escola tem no máximo dois episódios e uma duração mínima de 1 hora por episódio. O padrão é definido por decisões sobre o número de episódios, horário de início, duração e tempo interepisódios. Atividades trabalho/escola com duração curta são tratadas como categoria separada das atividades fixas secundárias na próxima etapa.

O componente de localização escolhe os locais de realização de atividades em ordem decrescente de prioridade das atividades fixas. O processo será descrito da forma como o modelo foi aplicado às regiões holandesas. No caso da aplicação em nível nacional, foram estabelecidos dois níveis de localização: primeiro em nível de municípios e, em segundo nível, por divisões com base em códigos postais. Inicialmente o modelo escolhe a cidade e depois a área postal dentro da cidade. Em ambos os níveis o modelo determina a escolha delimitando ao máximo o conjunto de escolhas em um número de etapas. Para a escolha da cidade, a primeira árvore de decisão determina 
onde a atividade é realizada (dentro ou fora da cidade do domicílio do indivíduo). Se a última opção for selecionada, a escolha da cidade segue a escolha de uma ordem e faixas de distância. As ordens são diferenciadas com base na população e depois se dá a escolha da faixa de distância.

A combinação de ordem e faixa de distância tende a reduzir o conjunto de escolhas. Se ainda restarem múltiplas alternativas, o modelo seleciona a cidade semialeatoriamente. Mais precisamente, a seleção da probabilidade é função da distância relativa, definida como:

$$
P(j \mid \mathbf{J})=\frac{\alpha^{r(j)}}{\sum_{j^{\prime} \in J} \alpha^{r\left(j^{\prime}\right)}}
$$

onde:

$P(j \mid \mathbf{J})=$ probabilidade de selecionar $j$ do conjunto de escolha $J$;

$r(j)$ é a classificação de $j$ onde os elementos de $J$ são ordenados em ordem crescente de distância;

$0<\alpha \leq 1$ é um parâmetro a ser estimado.

A idéia é que localizações menos distantes (dentro de uma determinada faixa de distância) apresentem maior probabilidade de serem selecionadas. Quanto mais baixo o valor de alfa, mais sensível o modelo em relação à distância relativa. $\mathrm{O}$ valor 1 corresponde a uma completa indiferença.

Para a escolha da zona postal dentro da cidade escolhida, uma lógica similar é adotada. As localizações são classificadas em 4 categorias. Agora, ordens são definidas em termos de tamanho relativo do setor de empregos dentro da cidade escolhida. Tamanhos relativos implicam que zonas da mesma ordem podem diferir em tamanho de empregos entre cidades. Dado o critério de escolha, zonas de primeira ordem pertencem ao centro da cidade, segunda ordem à faixa em volta do centro e assim sucessivamente, até a última ordem, que corresponde à faixa mais periférica. A escolha da zona é então o resultado da escolha da ordem e da faixa de distância do mesmo modo anterior. Novamente, se ainda permanecerem conjuntos de escolhas, a equação acima é usada para determinar a escolha final com o parâmetro alfa estimado especificamente para a escolha das zonas. 


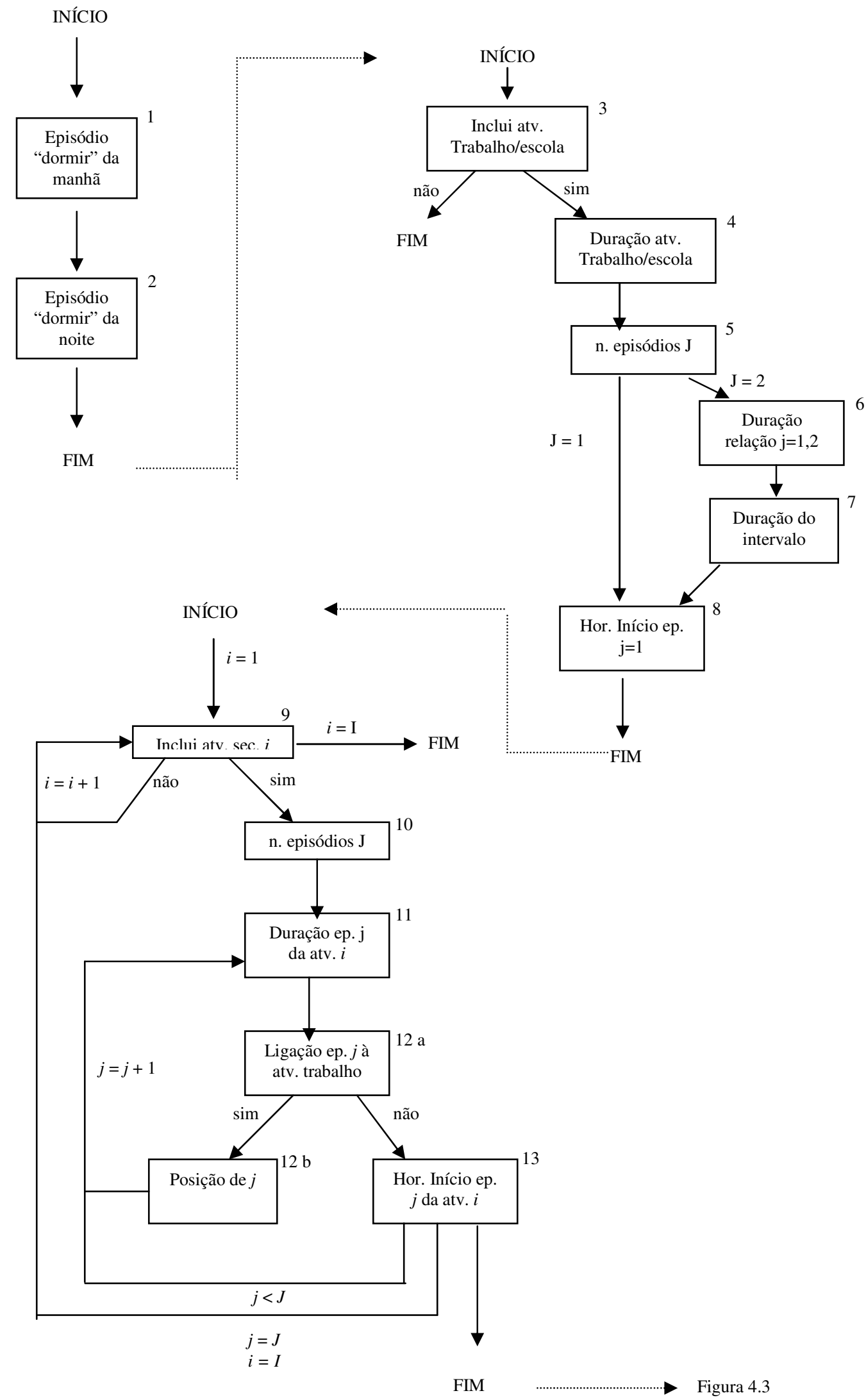

Figura 4.2: Etapas de geração dos padrões de atividades fixas. 


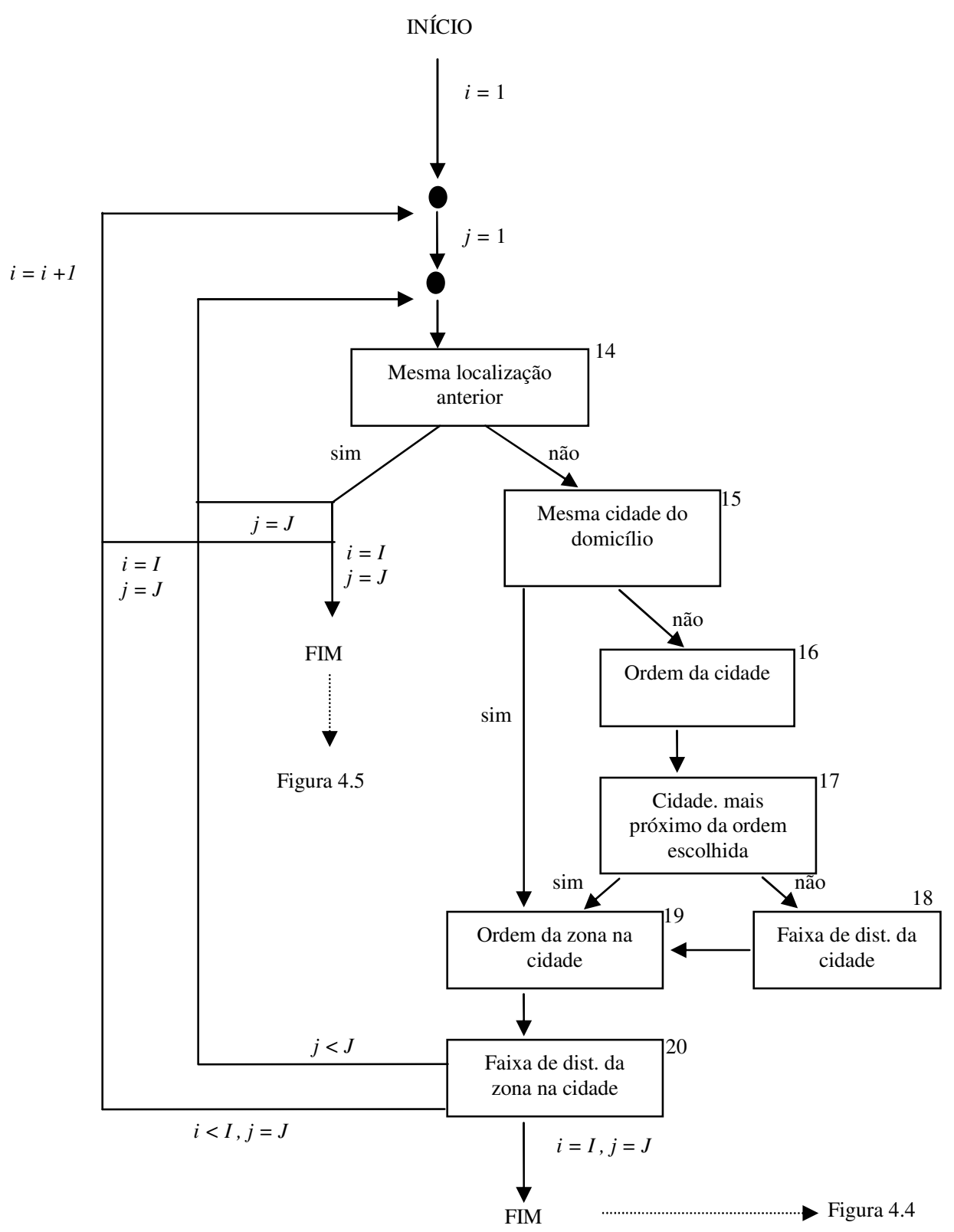

Figura 4.3: Processo de previsão da localização das atividades fixas e flexíveis.

A Figura 4.4 representa a última parte do modelo e lida com a escolha do modo de transporte para atividades principais de trabalho (21), determinação da seleção, da companhia e da duração das atividades flexíveis (22-24), determinação do horário de início e encadeamento de atividades e viagens (25-26), determinação do modo de transporte para cada ciclo de viagens na programação (27) determinação da localização de cada atividade flexível (14-20). 

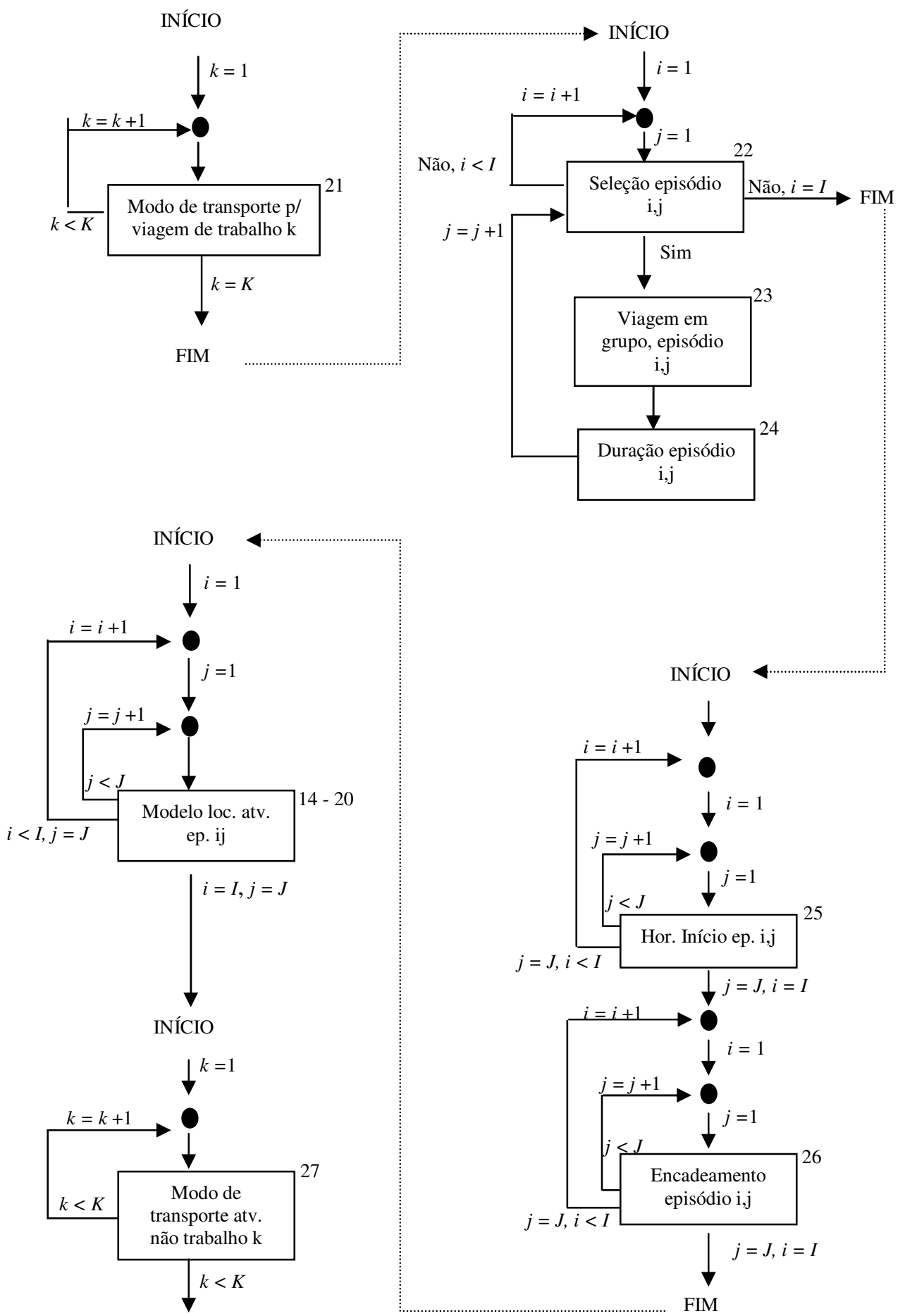

FIM

Figura 4.4: Processo de programação das atividades flexíveis. 


\subsection{Geração das Árvores de Decisão}

Como já dito anteriormente, o modelo Albatross é um sistema baseado em regras lógicas, que procuram simular as várias escolhas que devem ser feitas em uma programação de atividades. Para cada etapa de decisão o modelo gera uma árvore de decisão. Essas árvores consistem em algumas variáveis de condição (que podem ser as variáveis socioeconômicas, atributos individuais, e informações sobre as atividades, entre outras) e variáveis de ação (que representam as alternativas disponíveis para escolha) que podem ser formuladas como uma heurística de escolha. Essas variáveis são pré-definidas, mas a estrutura da árvore de decisão é gerada com base em dados empíricos.

Uma árvore de decisão pode ser definida como uma tabela que representa um conjunto de variáveis que interagem umas com as outras, dentro de um tópico especifico a ser analisado.

A indução de uma árvore de decisão foi definida da seguinte forma pelos autores do modelo. Seja $C_{i}$ um conjunto de variáveis de condição para $i=1, \ldots c ; C T_{i}$ um conjunto pré-definido de condições para cada variável $i$; e $A$ uma variável de ação com $k=1, \ldots, a$, com categorias de resposta mutuamente exclusivas. É admitido um conjunto de observações em termos de $C_{i p}, A_{p}$ para $p=1, \ldots N$ casos. O problema é encontrar o local de particionamento da variável de condição da árvore de decisão que maximize a homogeneidade das respostas na variável de ação $A$ nas colunas da tabela. Assim, a tabela é iniciada com uma única coluna (a variável não é particionada). A distribuição de frequiências dos casos nas categorias de ação representa a heterogeneidade das respostas na amostra. De modo a reduzir essa heterogeneidade nas colunas, deve-se identificar a melhor variável de condição para ramificar a variável em análsie em duas ou mais colunas. Se a variável é dividida em $r$ situações, uma tabela de freqüência $a \times r$ deve mostrar as diferenças nas distribuições das respostas nas colunas (ou seja, o grau de homogeneidade nas colunas). Esse processo continua até que a máxima homogeneidade ou mínimo número de respostas dentro de cada coluna seja alcançado. Com base nesse processo seqüencial, o problema a ser resolvido é como identificar, em cada etapa, a melhor variável de condição e o melhor particionamento da variável de condição. 
O algoritmo usado para gerar as árvores de decisão no modelo Albatross foi o CHAID (Chi-square Automatic Interaction Detection).

O algoritmo CHAID constrói árvores não-binárias (ou seja, árvores em que mais de duas ramificações podem ser anexadas a um único nó), com base em um algoritmo adequado a análises de amplos bancos de dados. Ele permite ainda a elaboração de várias tabelas de freqüência em múltiplas ramificações.

- Preparação dos estimadores - o primeiro passo é criar estimadores em categorias, dividindo a respectiva distribuição continua em um número de categorias com aproximadamente igual número de observações. Para estimadores discretos, as classes são naturalmente definidas.

- Combinação das categorias - o próximo passo é determinar para cada estimador o par de categorias menos significativas com relação à variável dependente; para problemas de classificação (onde a variável dependente é discreta), será realizado o teste do Qui-quadrado; para problemas de regressão (em que a variável dependente é contínua), é usado o teste F. O teste do Qui-quadrado (geralmente usado para medir a independência entre duas categorias de variáveis) é usado para determinar o grau de significância em cada particionamento, usando o valor de alfa de 0,05 . Se o teste para um dado par de estimadores não for estatisticamente significativo (definido pelo valor de alfa), ele será combinado com o respectivo estimador e será repetido o processo (ou seja, encontrar o próximo par de categorias, que agora inclui categorias previamente combinadas). Se o teste estatístico ainda não for significativo, será então realizado (opcionalmente) um ajuste pelo teste de Bonferroni para o conjunto de categorias para o respectivo estimador.

- Seleção da variável de ramificação - O próximo passo é escolher a ramificação do estimador com o menor p-valor; ou seja, o estimador (variável) que irá gerar a divisão mais significativa. Se o menor p-valor para qualquer estimador for maior que o valor de algum alfa na divisão, então nenhuma divisão será feita, e o respectivo nó será o final. 
Definido o melhor local do particionamento como resultado desse processo seqüencial, o próximo passo é identificar, para cada coluna, a variável de ação apropriada.

Uma das vantagens do uso do Qui-quadrado é encontrar o particionamento da variável em análise que maximize a diferença nas distribuições das respostas nas colunas. Esse critério é apropriado na relação à ação probabilística das regras usadas. Ao contrário do critério Teta (algoritmos THAID), o Qui-quadrado é sensível não apenas às mudanças nas categorias das respostas, mas no conjunto total das distribuições das respostas entre as categorias.

Por outro lado não há garantias que o particionamento produzido seja o ótimo. Ramificações são consideradas individualmente para cada uma das variáveis de condição e não é considerada a interação ou dependência de decisões anteriores. $\mathrm{O}$ ajuste do teste de Bonferroni garante a busca por melhores opções de ramificações, mas não considera que múltiplas variáveis de condição possam ser testadas.

O coeficiente estatístico $c$ (contingency coefficient) é calculado como medida de grau de associação entre variáveis. Esse indicador varia entre 0 e 1 (melhor resultado pois indica maior interdependência entre variáveis), com base na distribuição do Quiquadrado. Esse processo continua até que nenhuma outra ramificação possa ser realizada.

\subsection{Dados Requeridos pelo Modelo}

O Albatross requer uma grande quantidade de dados referentes ao sistema de transportes, uso do solo e dados individuais para a realização do processo de programação de atividades, como pode ser observado nas Tabelas 4.4 e 4.5 .

Tabela 4.4: Variáveis referentes às atividades/viagens utilizadas pelo modelo Albatross.

\begin{tabular}{|l|}
\hline DADOS REFERENTES ÀS ATIVIDADES/VIAGENS \\
\hline Atributos socioeconômicos domiciliares e individuais \\
\hline Dia da semana em que as atividades são realizadas \\
\hline Atributos espaço-temporais e institucionais do endereço do domicílio \\
\hline Atributos da programação de atividades atual do indivíduo e cônjuge (se existente) \\
\hline Atributos das atividades à qual a decisão está relacionada \\
\hline Atributos das escolhas alternativas (modo de transporte, atividades flexíveis etc) \\
\hline
\end{tabular}


Tabela 4.5: Variáveis referentes ao uso do solo utilizadas pelo modelo Albatross.

\begin{tabular}{|l|}
\hline DADOS REFERENTES AO USO DO SOLO \\
\hline Distribuição da população - atividades sociais fora de casa \\
\hline Distribuição do número total de empregos - atividades de trabalho \\
\hline Distribuição do número de escolas para crianças - atividades de leva/traz \\
\hline Distribuição de empregos em estabelecimentos comerciais - compras diárias \\
\hline Distribuição de empregos em estabelecimentos comerciais - compras não diárias \\
\hline $\begin{array}{l}\text { Distribuição de emprego em bancos e correios - relacionado às atividades de } \\
\text { serviço }\end{array}$ \\
\hline $\begin{array}{l}\text { Distribuição de empregos em restaurantes e cafés - atividades relacionadas a lazer } \\
\text { fora de casa }\end{array}$ \\
\hline
\end{tabular}

As atividades de serviço e lazer são diversas em termos dos possíveis locais em que podem se basear. Para essas atividades, o setor de emprego foi escolhido como sendo o indicador disponível para as oportunidades para a categoria como um todo.

As variáveis relacionadas ao sistema de transportes merecem especial atenção. $\mathrm{Na}$ aplicação feita em cidades holandesas, o custo de viagem foi calculado e usado como indicador de custo relativo de se viajar por um determinado modo. Um número de suposições envolveu a equação usada. Por exemplo, adotou-se a hipótese de que custos fixos não têm papel na escolha do modo para uma dada viagem, ou seja, apenas custos variáveis foram considerados. No caso do automóvel, os custos variáveis foram calculados em função do valor do combustível e da distância da viagem. No caso do transporte público, foram consideradas reduções em relação às estações do ano e cartões de desconto com redução no valor das passagens (cartões comuns à população residente no país). Assume-se que o custo do modo mais favorável (ônibus, bonde, metrô ou trem) e a escolha do tipo de passagem são indicativos da escolha a ser feita pelos indivíduos por um ou outro modo de transporte.

A relação entre o tempo de viagem em fluxo livre e congestionado serve como indicador da extensão em que as viagens por carro para pares origem-destino específicos são sujeitas a atraso devido ao incremento de volume de tráfego nas horas de pico. A variável espaço-temporal chave é a janela de tempo disponível para a realização da atividade, levando em consideração vários momentos do processo de decisão com base em: 
- Locais disponíveis para a realização da atividade;

- Horário de funcionamento dos estabelecimentos para a realização da atividade;

- Duração mínima da atividade;

- Menor tempo de viagem;

- Horário mais cedo de início da atividade, incluindo a viagem de todas as atividades precedentes na agenda de atividades;

- Horário mais tarde de término da atividade, incluindo a viagem para todas as atividades sucessivas na agenda de atividades.

A disponibilidade das localizações é feita com base no tamanho do setor de emprego na cidade ou em zonas, dependendo da escolha em consideração.

\subsection{Considerações Finais}

O modelo de atividades Albatross foi desenvolvido por pesquisadores holandeses para previsão da demanda por transportes nas cidades daquele país. A implementação do modelo resultou em resultados satisfatórios, o que possibilitou a adoção de algumas políticas de transportes e uso do solo nas cidades analisadas.

A escolha pelo modelo Albatross foi feita durante a primeira etapa do Programa de Doutorado Sanduíche realizado pela autora no ano de 2002/2003 na Universidade de Eindhoven, Holanda. Na ocasião, definiu-se pela utilização do Albatross pelo fato de, primeiro, ele ter apresentado bons resultados em sua implementação nas cidades holandesas e, segundo, pela necessidade de verificação do desempenho do modelo em um contexto diferente do inicialmente avaliado.

Pelo fato do modelo ter sido desenvolvido com base em padrões holandeses de viagem e atividades, alguns parâmetros deverão ser adaptados às condições das cidades brasileiras. Dessa forma, a partir de uma coleta de dados realizada na cidade de São Carlos, será feita a adequação do modelo bem como sua calibração com os dados obtidos.

Nos capítulos que seguem é detalhado o processo de coleta de dados e é apresentada uma análise exploratória dos dados obtidos. Em seguida, o processo de adequação do modelo às condições de uma cidade brasileira e os resultados obtidos com a calibração do modelo é apresentado. 


\section{ESTUDO DE CASO}

O objetivo deste capítulo é apresentar o estudo de caso desta pesquisa, realizada em uma cidade brasileira de médio porte, no interior do estado de São Paulo. Aqui é apresentado o processo de coleta dos dados, bem como a estrutura do material usado e o procedimento adotado. É apresentada, também, uma análise exploratória dos dados obtidos.

Com base nas referências bibliográficas analisadas e em modelos de diários de atividades utilizados em coletas de dados por pesquisadores da Universidade de Eindhoven, Holanda (fornecidos diretamente ao orientador desta pesquisa), procedeu-se à elaboração do material necessário à coleta de dados que melhor se aplicasse às condições brasileiras. Cabe aqui esclarecer que o material utilizado para a coleta de dados é composto por um questionário e um diário de atividades. O questionário se destina a obter informações socioeconômicas sobre o respondente e seu domicílio. No diário de atividades são descritas as atividades realizadas pelo entrevistado, bem como os vários aspectos a elas relacionados (viagens, horários, locais etc). Ainda nesse material o entrevistado dispõe de instruções sobre o preenchimento do questionário e do diário, bem como um exemplo de diário já preenchido.

Inicialmente foi realizada uma pesquisa piloto para verificar a viabilidade de aplicação prática do questionário e do diário desenvolvidos. Esse teste serviu para a verificação de possíveis aspectos que pudessem gerar dúvidas para os respondentes e o grau de dificuldade por eles encontrados no ato do preenchimento. Com base nos resultados obtidos foram feitas algumas modificações, principalmente na estrutura do diário de atividades, para que este pudesse ser aplicado a uma amostra mais ampla. 
Os diários de atividades já modificados foram então distribuídos na cidade de São Carlos, interior do estado de São Paulo, que se caracteriza como uma cidade de médio porte, com cerca de 200.000 habitantes. Foram selecionados, aleatoriamente, dois mil domicílios na cidade, utilizando uma base de dados de endereços fornecida pelo SAAE (Serviço Autônomo de Água e Esgoto), que contém as coordenadas geográficas de todos os pontos com fornecimento de água da cidade - cerca de 52.000 pontos. Foi adotada a hipótese de que a maior parte dos pontos georeferenciados representa um domicílio, uma vez que cerca de $99,5 \%$ da população da cidade de São Carlos é atendida pela rede de água (Lima, 2003). A distribuição geográfica dos 2000 domicílios selecionados pode ser verificada na Figura 5.1.

Os diários foram distribuídos entre os dias 24 de novembro e 10 de dezembro de 2003, por um grupo de dez pesquisadores devidamente instruídos, de modo a abordarem de forma correta os entrevistados. Apesar de não ter sido o período mais adequado à coleta de dados por se tratar de início das férias escolares (o que altera a programação diária de atividades em um domicílio), em virtude de atrasos tanto na elaboração do material usado como na obtenção dos recursos necessários à coleta, optou-se por realizá-la nesta época, de modo a garantir um conjunto de dados que possibilitasse o uso do modelo baseado em atividades para a realização de algumas investigações.

A coleta dos dados ocorreu da seguinte maneira. Com base nos domicílios selecionados, cada grupo de cinco pesquisadores foi alocado em diferentes regiões da cidade, com o intuito de cobrir o maior número possível de domicílios naquelas áreas. Cada domicílio selecionado foi visitado por um pesquisador que explicava, da forma mais clara possível, o porquê da realização da pesquisa e como o questionário e o diário deveriam ser preenchidos. Quando no domicílio selecionado não havia nenhum morador, escolhia-se o domicílio da esquerda; caso neste também não fosse encontrado o morador, escolhia-se o da direita, e assim sucessivamente.

Aos entrevistados foi pedido que preenchessem o questionário e o diário de atividades por dois dias úteis (entre terça-feira e quinta-feira), de modo que fosse possível a identificação do comportamento de realização de atividades mais representativo do cotidiano destes indivíduos. Neste caso, optou-se por não designar os dias em que o entrevistado deveria reportar suas atividades, pois foi constatado na pesquisa piloto que, deixando o entrevistado à vontade, este se disponibilizava mais facilmente a participar na pesquisa. Sempre que possível foi entrevistada mais de uma 
pessoa no mesmo domicílio, com o propósito de caracterizar o comportamento de viagem domiciliar. O material era deixado em cada domicílio para posterior preenchimento e após dois dias era recolhido.

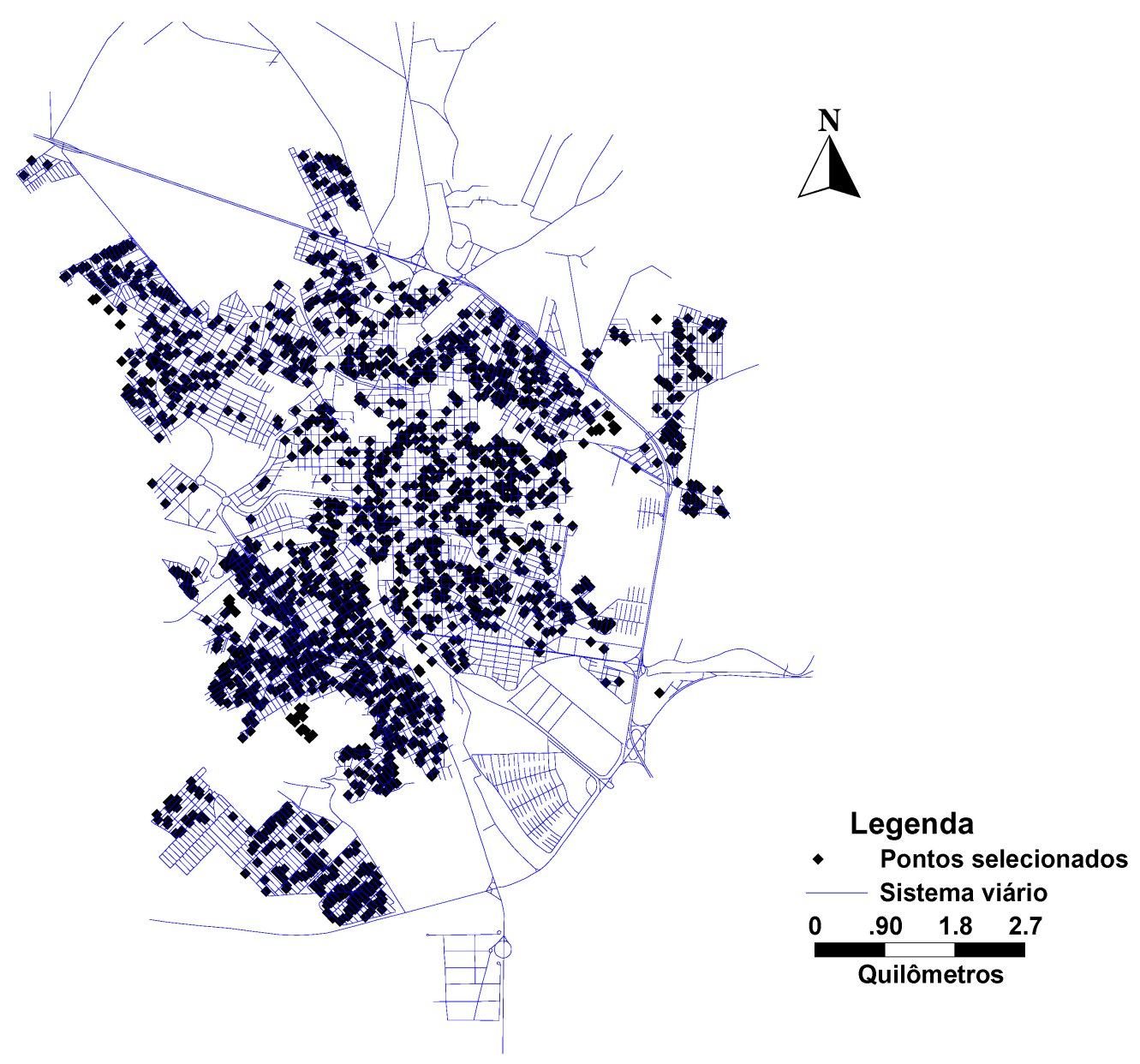

Figura 5.1: Distribuição geográfica dos 2000 domicílios selecionados para distribuição dos diários de atividades.

Apesar de terem sido selecionados 2000 domicílios em toda a cidade, apenas uma parte destes foi coberta pela pesquisa. Não foi possível a distribuição dos diários em todos os domicílios selecionados devido a alguns fatores. Primeiramente, o tempo gasto por cada pesquisador para entrar em contato com o entrevistado e a explicação de como preencher o material a ele entregue foi maior do que aquele inicialmente previsto. Outro fator negativo foram as condições climáticas não favoráveis (forte ocorrência de chuvas). Por isso, a coleta não pode ser realizada em alguns dias da semana. Os entrevistados também foram instruídos a não preencherem os diários de atividades em dias chuvosos, 
pois esse fator poderia causar alterações no comportamento de viagem individual e domiciliar. A área da cidade coberta pela pesquisa é apresentada na Figura 5.2.

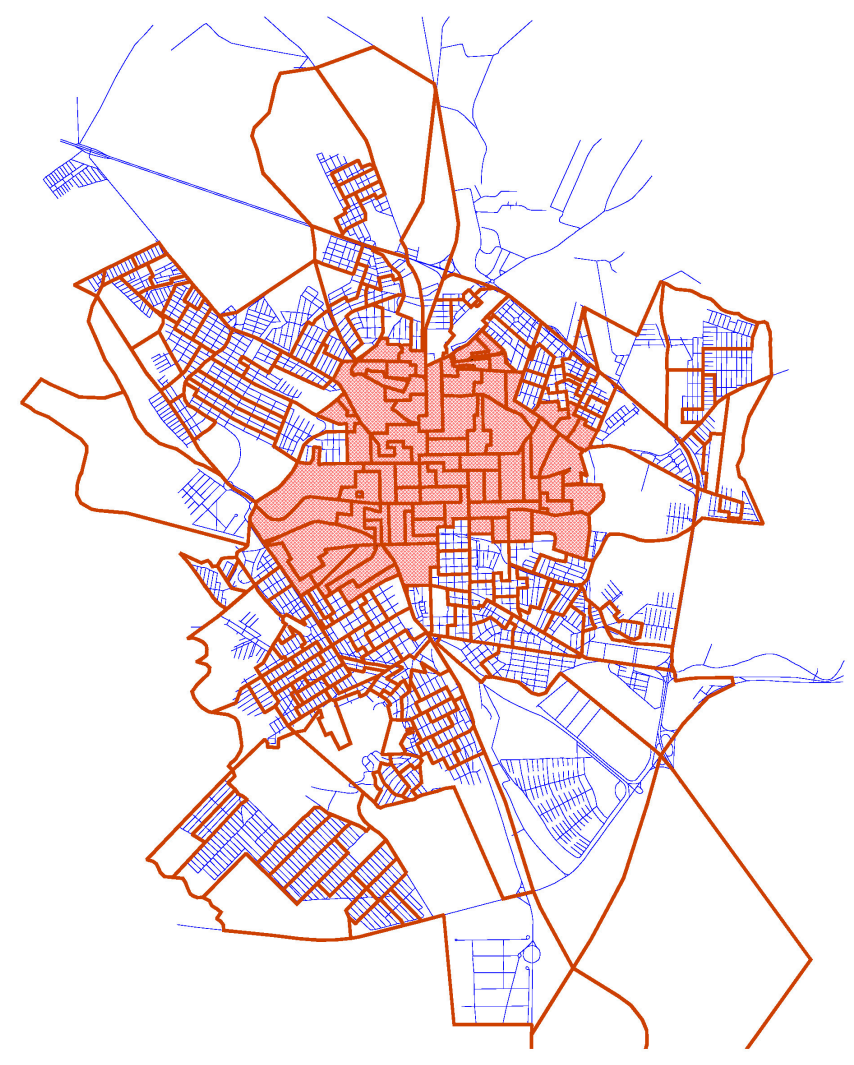

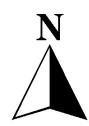

Camadas do mapa

Sistema viário

Setores censitários 2000

Conjuntos de seleção

Setores selecionados

$\stackrel{0}{0} \mathbf{1}_{\text {Quilômetros }}^{2} 3$

Figura 5.2: Área coberta na coleta de dados.

Embora a área coberta na coleta de dados tenha sido a região central da cidade (como pode ser verificado na Figura 5.2), a Figura 5.3 mostra que a real localização dos domicílios dos entrevistados se encontra dispersa por várias outras áreas da cidade. Esse fato é perfeitamente compreensível, visto que na região central existe grande concentração de estabelecimentos comerciais e ainda uma das universidades da cidade a Universidade de São Paulo. Ou seja, é uma região com grande concentração de locais de atividades - pólos de atração de viagem. 


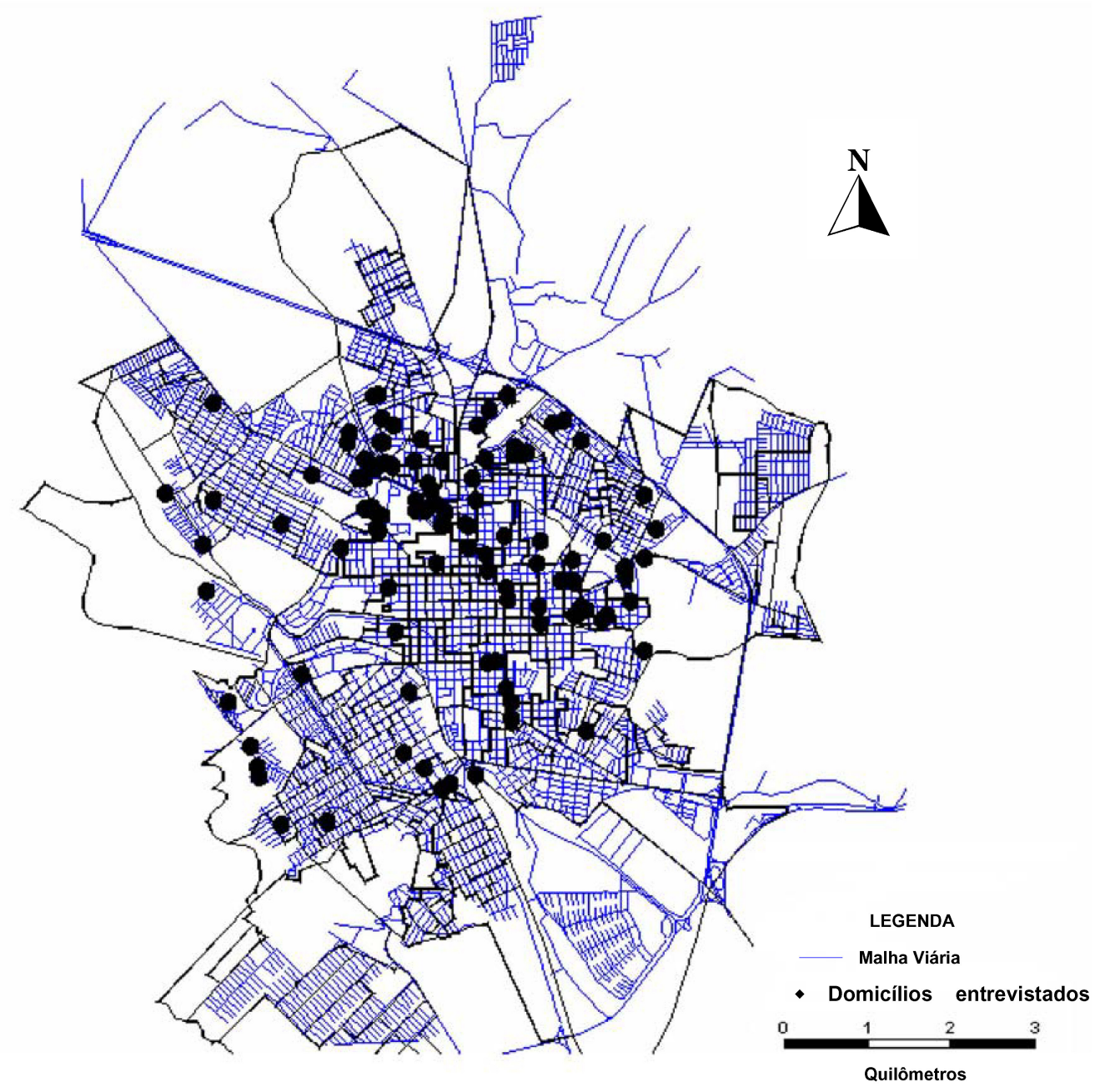

Figura 5.3: Distribuição geográfica dos domicílios da amostra.

\subsection{Estrutura do questionário e do diário de atividades}

No questionário, o entrevistado deveria descrever suas características pessoais e domiciliares. Foram requeridas informações como endereço do domicílio, número de automóveis no domicílio, faixa de renda domiciliar, se o entrevistado possuía algum tipo de deficiência física e a freqüência de utilização do automóvel. Adicionalmente, eram requeridas informações sobre idade, sexo, posição no domicílio, posse de carteira de habilitação, ocupação principal, grau de instrução e desconto para uso do transporte público.

No que se refere ao diário de atividades, algumas questões não diferem daquelas encontradas nos diários de viagem - apenas o modo como são feitas é que muda. Apenas para exemplificar, a Figura 5.4 mostra uma das páginas do diário de 
atividades utilizado (o diário completo se encontra no Anexo I), que pode ser dividido em três partes. A primeira delas se destina às informações referentes aos locais de origem e destino das viagens, os horários de saída e chegada, com quem a viagem foi realizada, o motivo da viagem (neste caso particular, o entrevistado dispunha, no final do diário, de uma lista codificada com todos os motivos de viagem) e o modo de transporte utilizado.

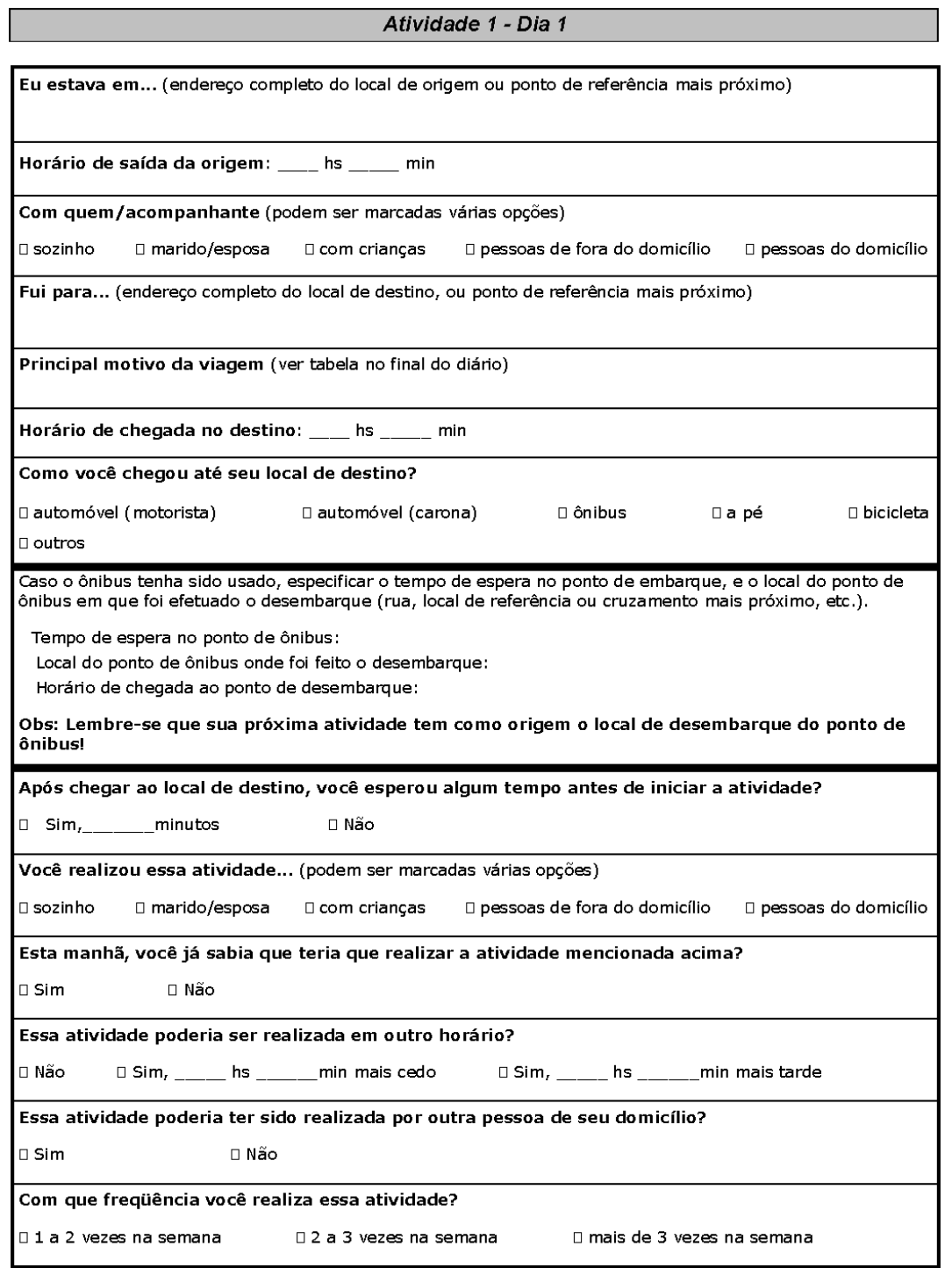

Figura 5.4: Exemplo da página principal do diário de atividades aplicado em São Carlos.

Foram usados intervalos de tempo abertos e, em relação aos locais de origem e destino das viagens, caso o entrevistado não soubesse o endereço exato do local, este poderia indicar um ponto de referência ou cruzamento entre ruas mais próximo. 
$\mathrm{Na}$ segunda parte (parte central) do diário de atividades foram colocadas algumas questões que o entrevistado deveria preencher caso utilizasse o transporte público. Nesse campo deveriam ser reportados os tempos de espera nas paradas de ônibus, bem como os locais de embarque e desembarque.

A parte final do diário corresponde às informações referentes às atividades e inclui: a identificação de com quem a atividade está sendo realizada, se o indivíduo espera algum tempo antes de iniciá-la, se a atividade era planejada ou não, se poderia ser realizada em outro horário e por outra pessoa do domicílio e a freqüência com que o indivíduo a realiza. Essas informações são importantes por fornecerem, por exemplo, dados em relação às restrições que podem ser encontradas pelo indivíduo, e a possibilidade de uma reestruturação da agenda de atividades diária em função de alterações nos horários de realização destas.

Em sua totalidade, o material de coleta de dados entregue a cada participante continha 41 folhas, com as seguintes partes: apresentação e explicação da importância da pesquisa, instruções de preenchimento, modelo, questionário e diário de atividades para dois dias (cada um contendo dez atividades).

A aplicação destes diários em São Carlos permitiu obter algumas informações interessantes acerca do método aplicado e dos dados, como se pode constatar pela análise exploratória apresentada na seqüência.

\subsection{Análise exploratória dos dados}

Inicialmente cabe comentar a respeito do índice de aproveitamento do material distribuído, com base nos dados apresentados na Tabela 5.1. Material válido é aquele em que tanto o questionário como o diário de atividades estão preenchidos corretamente, com todas as informações necessárias. Nulos são aqueles que não puderam ser utilizados, em virtude de dados inconsistentes ou ausência de informações. Material em branco diz respeito ao material entregue e posteriormente recolhido, mas devolvido não preenchido.

Do material não utilizado, cerca de $59 \%$ apresentaram falta de informações apenas no diário de atividades. Por exemplo, ou não foi informado o número do edifício onde determinada atividade foi realizada - impossibilitando sua localização completa ou mesmo os horários de início e término das atividades. Cerca de $18 \%$ dos entrevistados preencheram apenas o questionário - o diário foi iniciado, mas 
abandonado a partir da segunda atividade. Cerca de $10 \%$ responderam apenas parte do questionário e não completaram o diário. O restante do material não utilizado foi devido a motivos como o entrevistado ter realizado uma viagem para fora da cidade ou trabalhar em cidades próximas. Como conseqüência, apenas um pequeno número de diários pôde ser efetivamente utilizado para a elaboração do banco de dados desta pesquisa.

Tabela 5.1: Índice de aproveitamento do material de coleta de dados.

\begin{tabular}{lr}
\hline \multicolumn{1}{c}{ CARACTERÍSTICAS DO MATERIAL } & QUANTIDADES \\
\hline Material distribuído & $343(100,00 \%)$ \\
Material válido & $155(45,19 \%)$ \\
Material não devolvido & $37(10,79 \%)$ \\
Material nulo & $96(27,99 \%)$ \\
Material em branco & $55(16,03 \%)$ \\
\hline
\end{tabular}

A divisão por sexo é equilibrada no grupo que preencheu de forma correta o material, sendo $55,10 \%$ de homens. Já entre aqueles que forneceram informações incompletas, a maioria é do sexo feminino (58,62 \%). Apenas 5,75\% não informaram o sexo. Cerca de $15 \%$ dos domicílios têm presença de crianças - indivíduos com idade inferior a 12 anos de idade.

$\mathrm{Na}$ Figura 5.5 observa-se que a faixa etária predominante dos entrevistados que entregaram o material válido se encontra entre 18 e 30 anos e a grande maioria apresenta nível superior (variando de incompleto a pós-graduado) (Figura 5.6). No que se refere ao material nulo, a grande maioria se encontra entre 18 e 50 anos, com segundo grau e superior completos. Essa tendência pode ser melhor verificada quando percebe-se que a maior parte do material válido foi entregue por estudantes, enquanto que, do material nulo, a maioria dos respondentes é de trabalhadores (empregados e autônomos) (Figura 5.7).

Verifica-se ainda que a idade média dos entrevistados que entregaram o material válido é de 30 anos e de aproximadamente 35 anos para aqueles que entregaram material nulo (Tabela 5.2). 


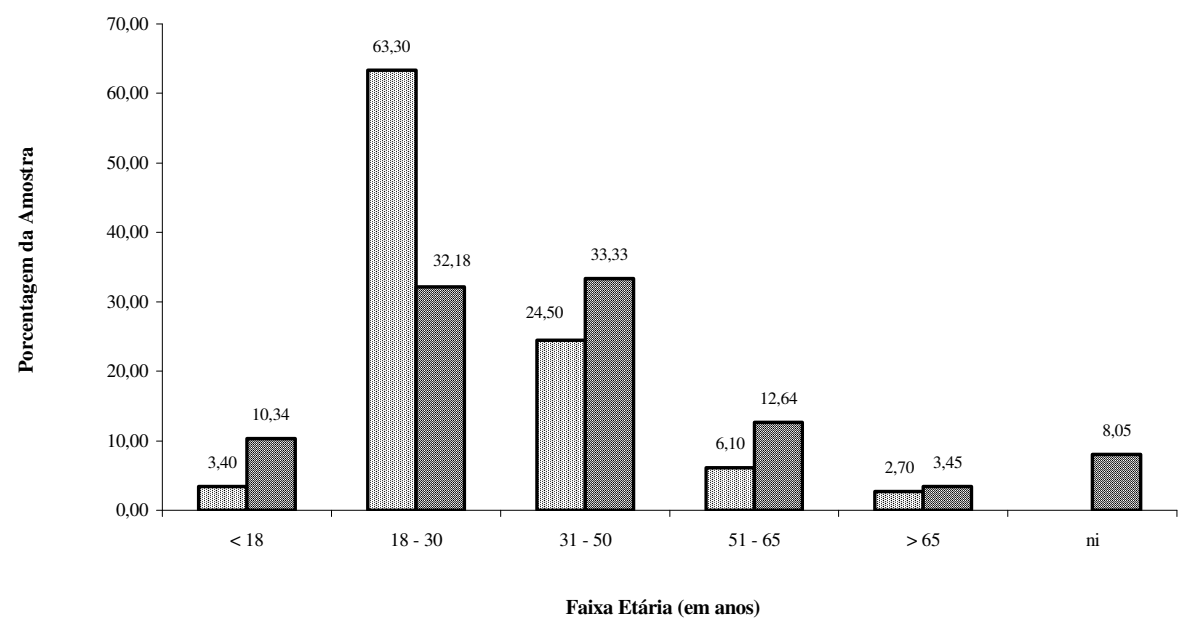

$\square$ Válidos $\square$ Nulos

* ni = não informou

Figura 5.5: Distribuição da faixa etária na amostra avaliada.

Tabela 5.2: Características básicas da variável faixa etária.

\begin{tabular}{lcc}
\hline $\begin{array}{c}\text { VALORES RELATIVOS À } \\
\text { IDADE (EM ANOS) }\end{array}$ & MATERIAL VÁLIDO & MATERIAL NULO \\
\hline Média & 30,28 & 34,95 \\
Desvio padrão & 12,52 & 15,94 \\
Mínimo & 13 & 13 \\
Máximo & 74 & 82 \\
\hline
\end{tabular}




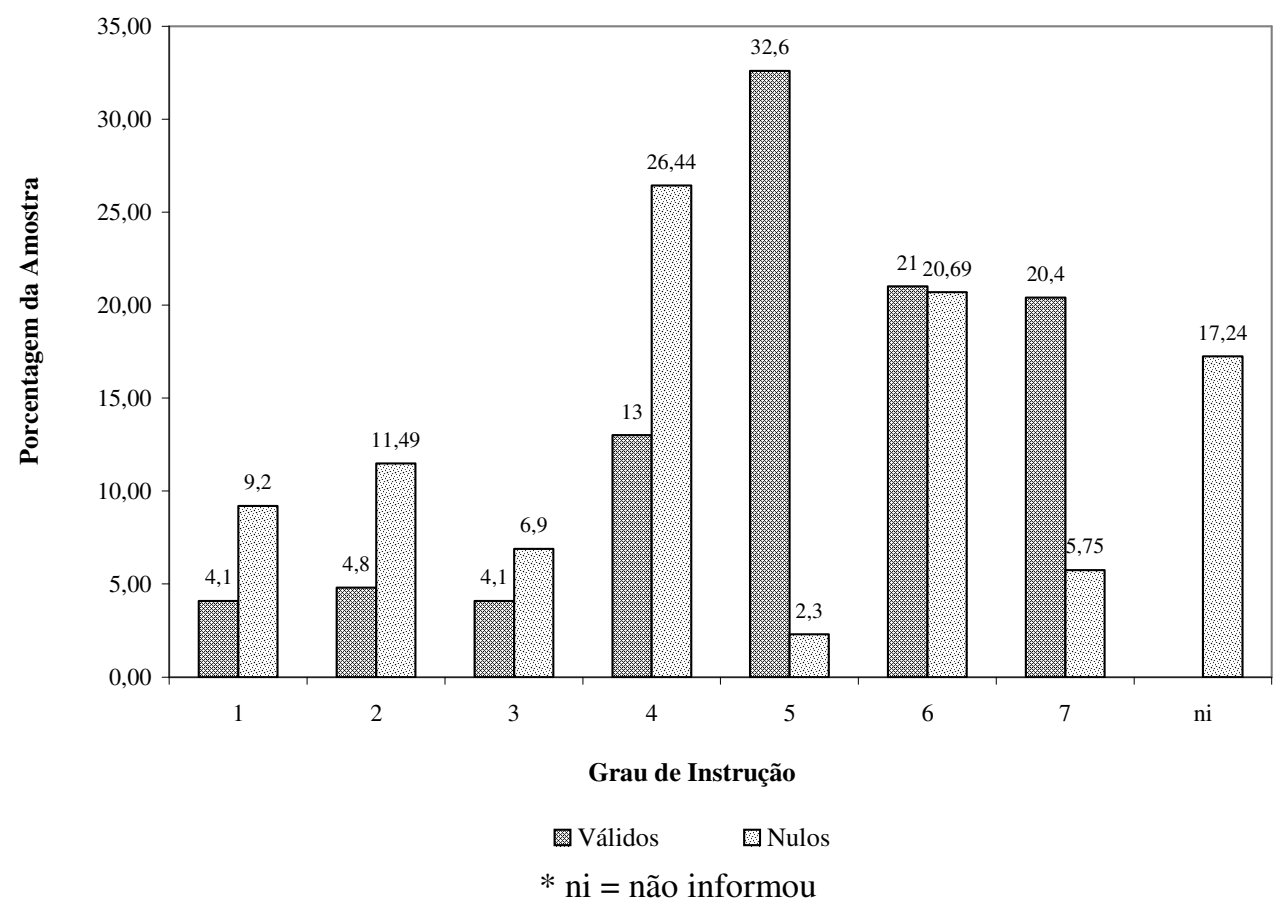

Figura 5.6: Grau de instrução da amostra avaliada.

Legenda

\begin{tabular}{cl}
\hline CÓDIGO & \multicolumn{1}{c}{ DESCRIÇÃo } \\
\hline 1 & Primeiro grau incompleto \\
2 & Primeiro grau completo \\
3 & Segundo grau incompleto \\
4 & Segundo grau completo \\
5 & Superior incompleto \\
6 & Superior completo \\
7 & Pós-graduado \\
\hline
\end{tabular}




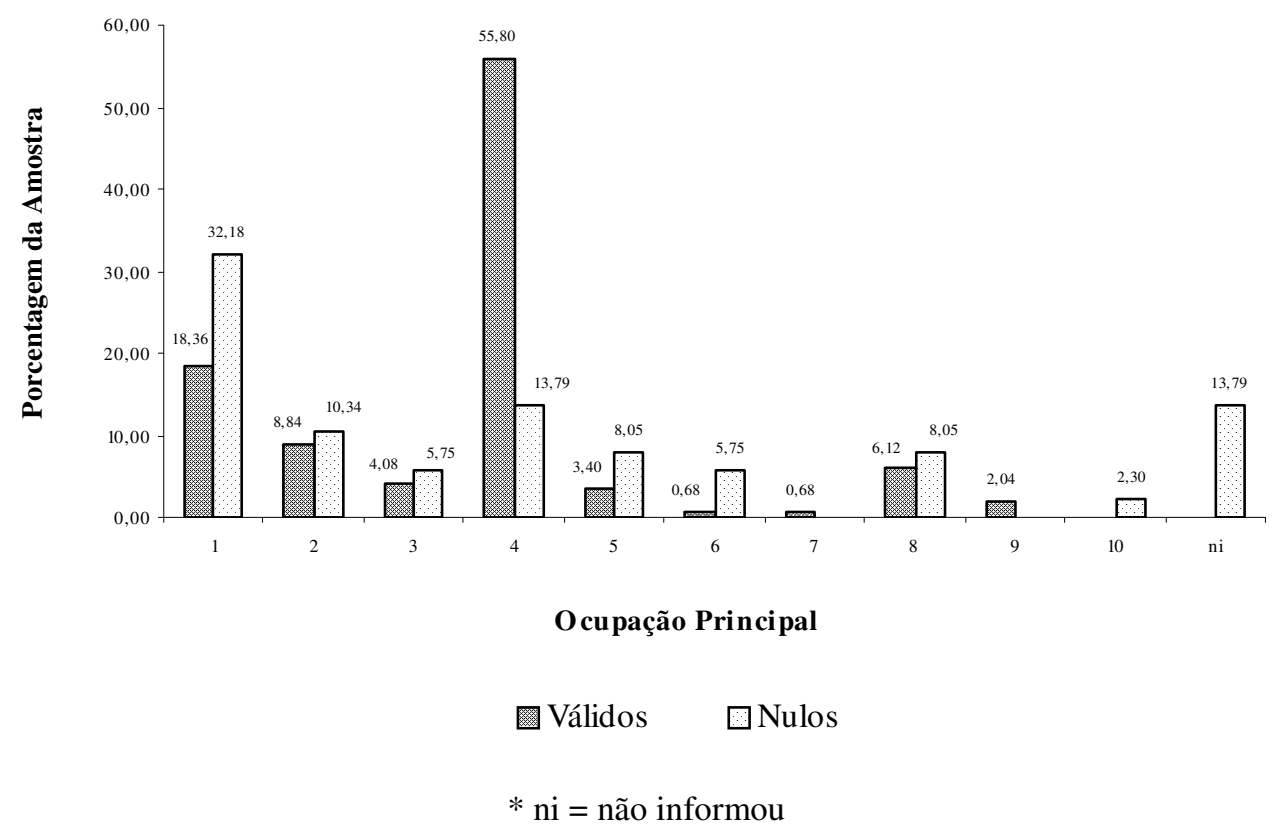

Figura 5.7: Ocupação principal dos indivíduos na amostra.

\section{Legenda}

\begin{tabular}{cl}
\hline CóDIGO & \multicolumn{1}{c}{ DESCRIÇÃo } \\
\hline 1 & Empregado \\
2 & Autônomo \\
3 & Prendas domésticas \\
4 & Estudante \\
5 & Aposentado \\
6 & Desempregado \\
7 & Outros \\
8 & Empregado e estudante \\
9 & Licença/afastado \\
10 & Sem ocupação/nunca trabalhou \\
\hline
\end{tabular}

Isso reforça uma suposição inicial de que estudantes (tanto de pós-graduação como de graduação) estão entre aqueles que mais se dispõem a participar em pesquisas, enquanto que trabalhadores evitam esse tipo de atividade. Este último fato é perfeitamente justificável, visto que após a jornada diária de trabalho poucos estão dispostos a participarem em uma coleta de dados. Obviamente isso acaba por tornar os dados coletados mais pobres, uma vez que trabalhadores podem eventualmente realizar 
um maior e mais diversificado número de viagens e atividades. Freqüentemente, aqueles que mais realizam atividades são os que menos se interessam em participar da pesquisa.

Uma característica interessante que pode ser verificada diz respeito à posição no domicílio (Figura 5.8). A categoria “outro" apresenta um grande número de entrevistados, o que reflete, mais uma vez, a presença de grande número de estudantes na amostra. Essa categoria se explica pelo alto número de pessoas que dividem a mesma residência (as chamadas "repúblicas"). Já no material nulo, a maior parte dos indivíduos pertence às categorias que formam um domicílio: chefe de família/cônjuge/filho. Essa característica tende a tornar difícil a caracterização do padrão de atividades e viagens domiciliar.

Como pôde ser observado anteriormente na Figura 5.6, e ao contrário do que se esperava, a grande maioria dos entrevistados que não entregaram material válido, apresenta segundo grau incompleto ou superior. Era esperado que a maior parte dos não respondentes se encontrasse em níveis de instrução mais baixos, o que justificaria o não preenchimento principalmente do diário de atividades, devido à sua complexidade. Talvez isso tenha ocorrido em virtude das áreas da cidade onde se encontra a população de mais baixa renda e nível de instrução não terem sido adequadamente cobertas pela pesquisa. A Figura 5.9 mostra que, em relação à faixa de renda, os entrevistados que preencheram de forma correta o material possuem, na sua maioria, renda acima de $\mathrm{R} \$$ 2.000,00 por mês. Já entre aqueles que não preencheram de forma correta o material, a grande maioria se encontra nas faixas até 1.500,00/mês. Esse fato pode ser um indicativo que, como esperado, a população de baixa renda e baixo nível de instrução encontre maiores dificuldades para preencher o material da coleta de dados. 


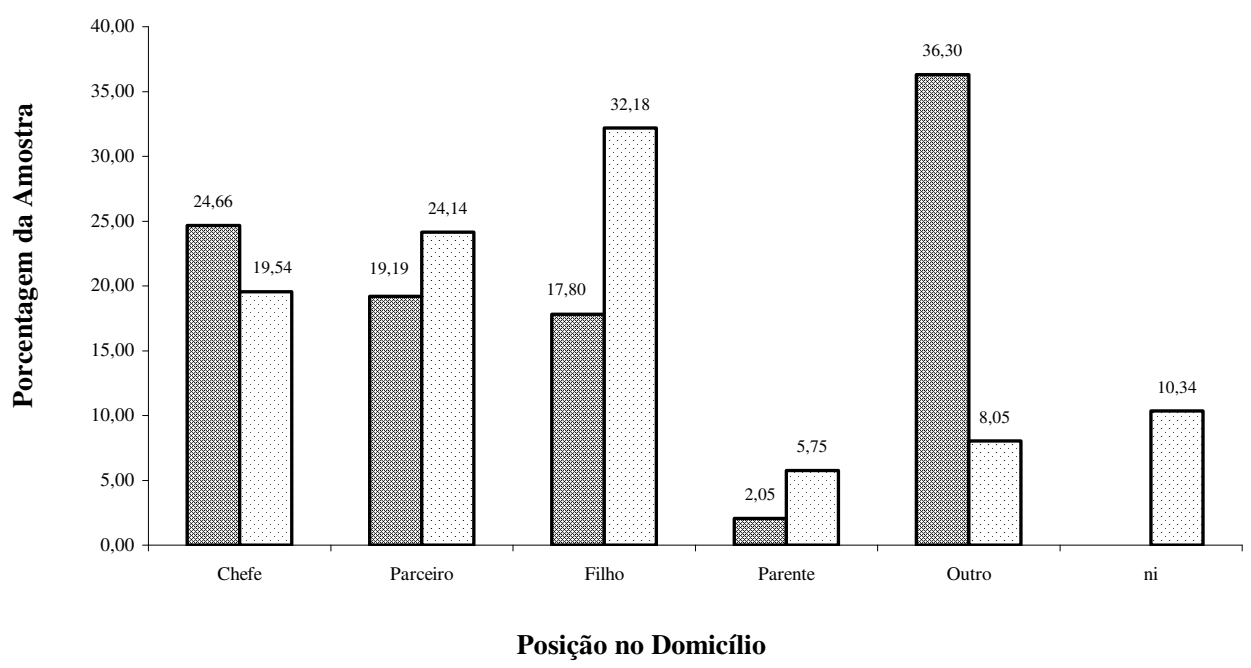

$\square$ Válidos $\quad \square$ Nulos

* ni = não informou

Figura 5.8: Posição no domicílio na amostra avaliada.

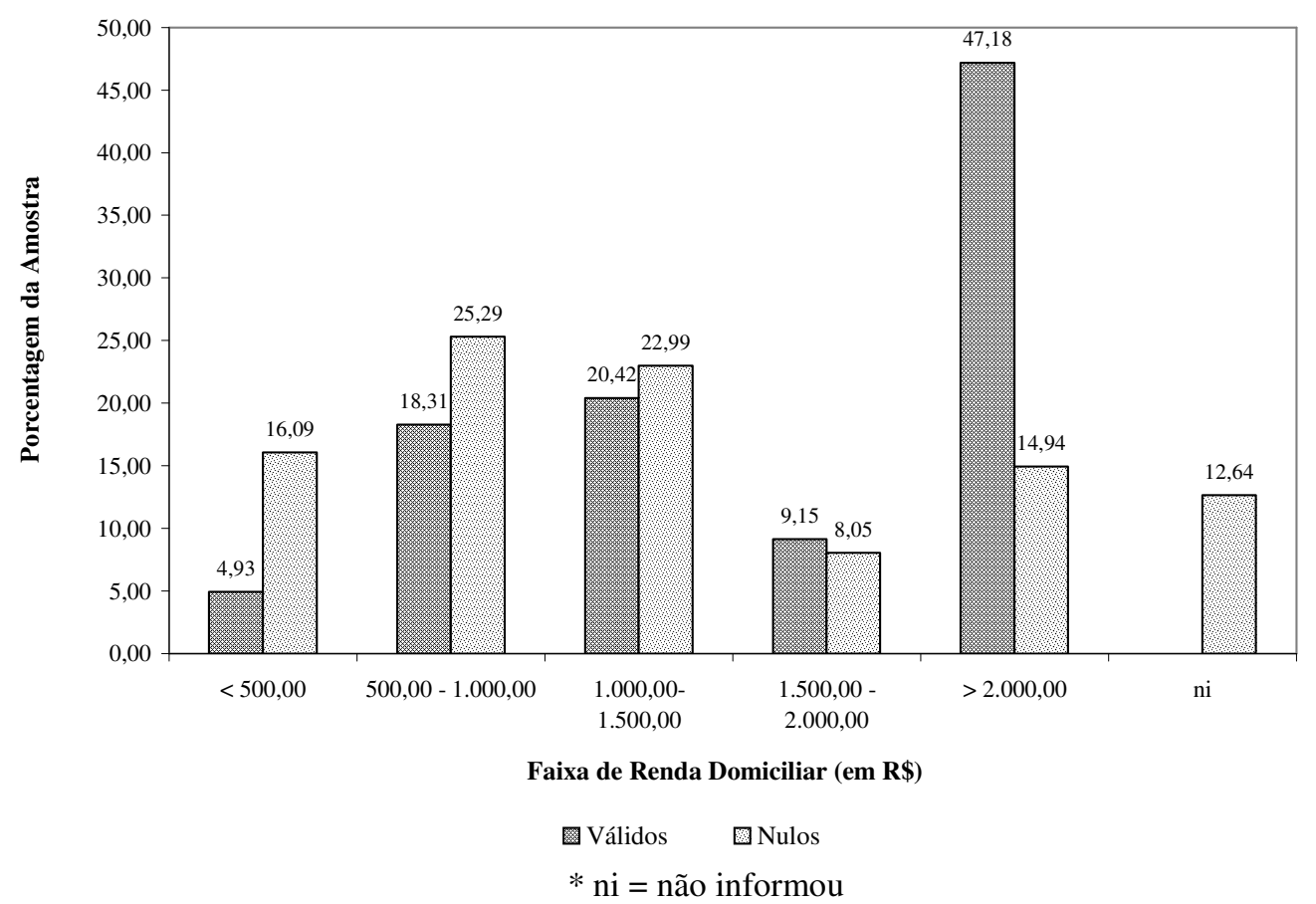

Figura 5.9: Faixa de renda domiciliar. 
Em relação apenas ao material válido, observa-se na Figura 5.10 que a maior parte dos domicílios entrevistados possui pelo menos um automóvel. Esse fato pode revelar, ao final da pesquisa, um alto número de viagens realizadas por esse modo de transporte. Outro fator constatado é que $84,50 \%$ dos indivíduos entrevistados possuem carteira de habilitação. Entretanto, como existe grande quantidade de domicílios formados por indivíduos sem vínculo familiar (categoria "outros", Figura 5.8), a existência de um automóvel no domicílio não significa que todos os indivíduos com carteira de habilitação tenham possibilidade e/ou autonomia para usá-lo. Ainda em relação ao uso do automóvel como modo de transporte, verifica-se na amostra que a maior parte dos entrevistados utiliza este modo mais de três vezes na semana (Tabela $5.3)$.

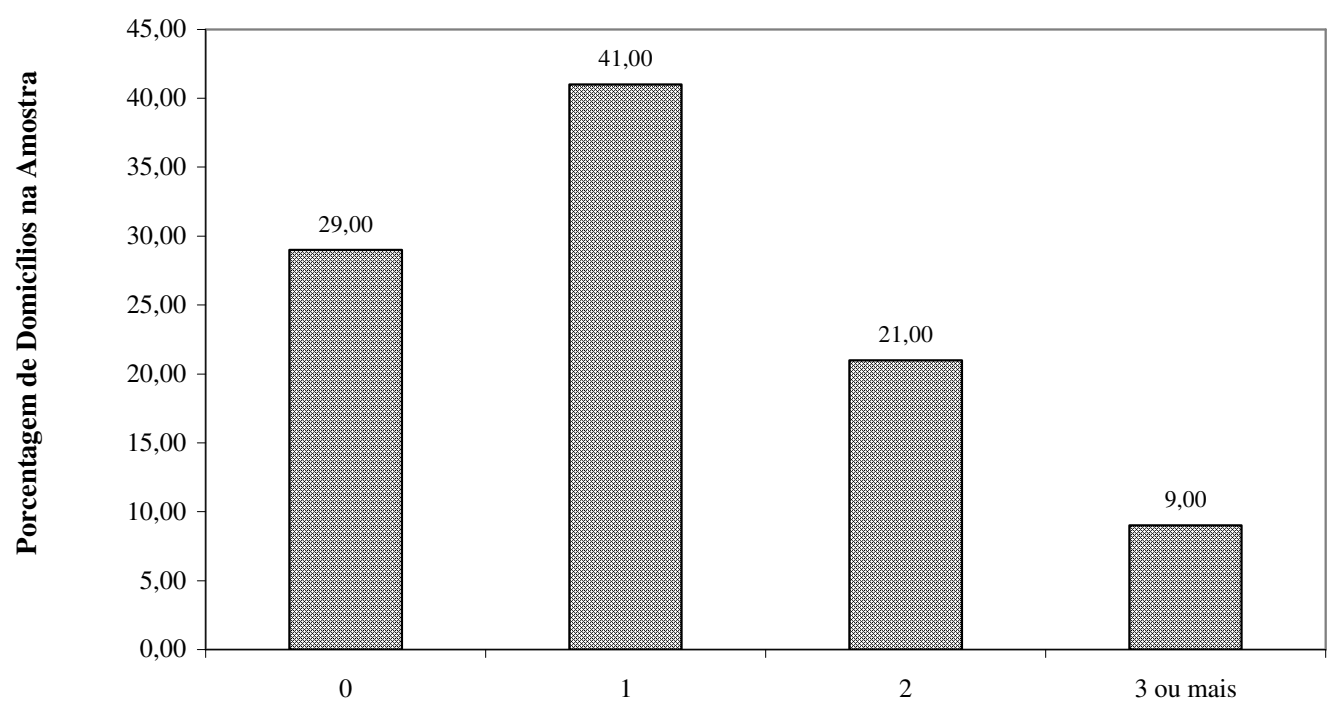

Número de Automóveis

Figura 5.10: Porcentagem do número de automóveis na amostra avaliada.

Tabela 5.3: Freqüência de uso do automóvel por semana.

\begin{tabular}{ccc}
\hline FREQÜÊNCIA & PORCENTAGEM & PORCENTAGEM ACUMULADA \\
\hline 0 & 28,90 & 28,90 \\
1 & 10,00 & 38,90 \\
2 & 4,70 & 43,60 \\
3 & 56,40 & 100,00 \\
Total & 100,00 & 100,00 \\
\hline
\end{tabular}


5.2.1 Características dos padrões de viagens e atividades

Como antecipado no item anterior, os resultados confirmam que um grande número de viagens foi realizado por automóvel (Figura 5.11). Cerca de $52 \%$ das viagens foram realizadas por esse modo de transporte (considerando-se ainda o grupo carona) e 39,10\% foram realizadas pelo modo a pé. Os outros modos de transporte juntos somam apenas $8,50 \%$. É preciso ressaltar, no entanto, que o número de diários de atividades obtidos não caracteriza uma amostra estatisticamente representativa dos moradores da cidade. Verifica-se, por exemplo, que a porcentagem de utilização do transporte coletivo é bastante inferior ao esperado para uma cidade de porte médio, que seria de, aproximadamente, 28,00 \% do total de viagens (Raia Jr., 2000). Por outro lado, o baixo número de viagens por bicicleta é aceitável, uma vez que a cidade de São Carlos apresenta uma topografia muito acidentada (Figura 5.11).

$\mathrm{Na}$ Tabela 5.4 verifica-se que a duração média das viagens é de aproximadamente 13 minutos por automóvel e 14 minutos por transporte coletivo. Os valores são relativamente baixos para viagens motorizadas de modo geral, visto que São Carlos ainda não apresenta altos índices de congestionamento nas vias. Outro fator que também contribui para a baixa duração encontrada é o fato das viagens realizadas não serem muito longas. Pode se verificar pela Figura 5.12 que a maior parte das viagens realizadas são relativamente curtas. Apenas $17,80 \%$ foram realizadas em distâncias maiores que $3,00 \mathrm{~km}$.

Tabela 5.4: Duração das viagens por modo de transporte (em minutos).

\begin{tabular}{lcccc}
\hline \multicolumn{1}{c}{ Modo de } & \multicolumn{4}{c}{ Duração } \\
\cline { 2 - 5 } Transporte & Mínima & Máxima & Média & Desvio padrão \\
\hline Automóvel & 1,0 & 53,5 & 13,47 & 36,14 \\
Automóvel (carona) & 3,0 & 35,0 & 10,7 & 5,93 \\
A pé & 1,0 & 24,5 & 10,82 & 12,93 \\
Bicicleta & 3,0 & 30,0 & 15,35 & 9,89 \\
Transporte Coletivo & 5,0 & 80,0 & 14,29 & 8,68 \\
Outros & 10,0 & 15,0 & 11,67 & 2,50 \\
\hline
\end{tabular}




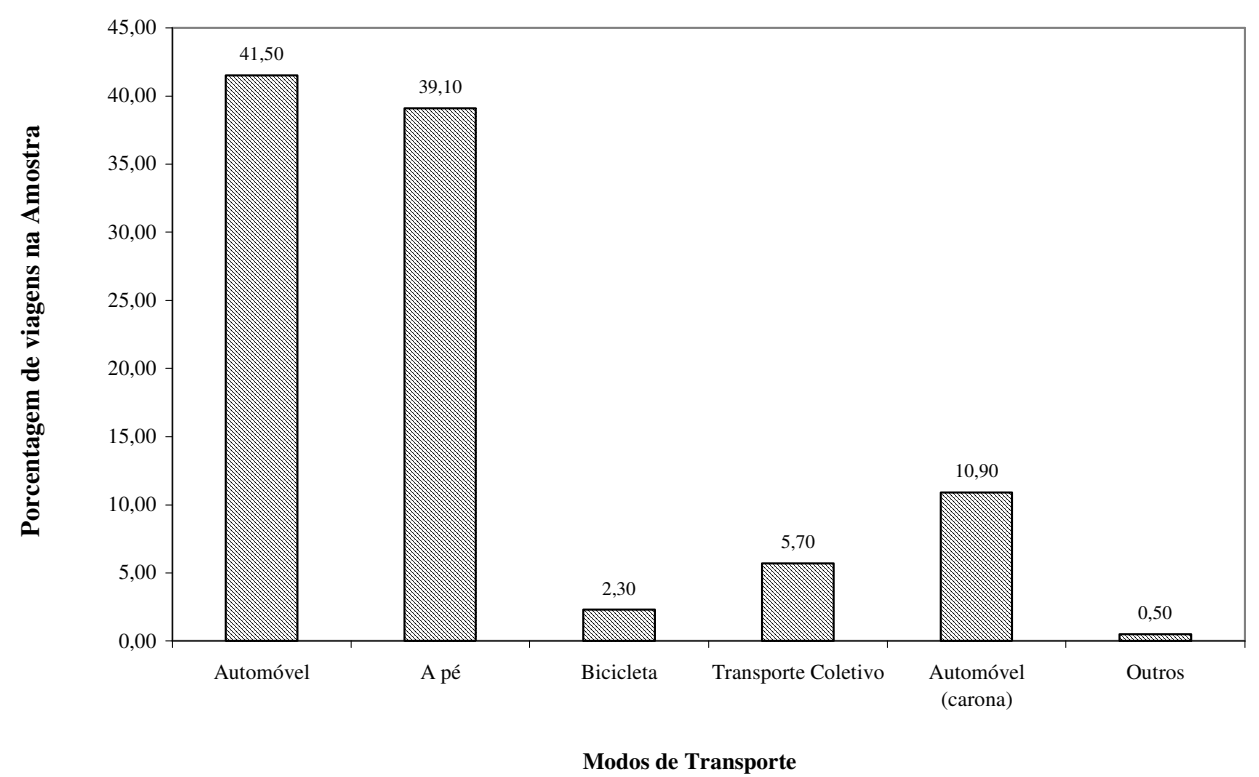

Figura 5.11: Porcentagem de utilização de cada modo de transporte na amostra avaliada.

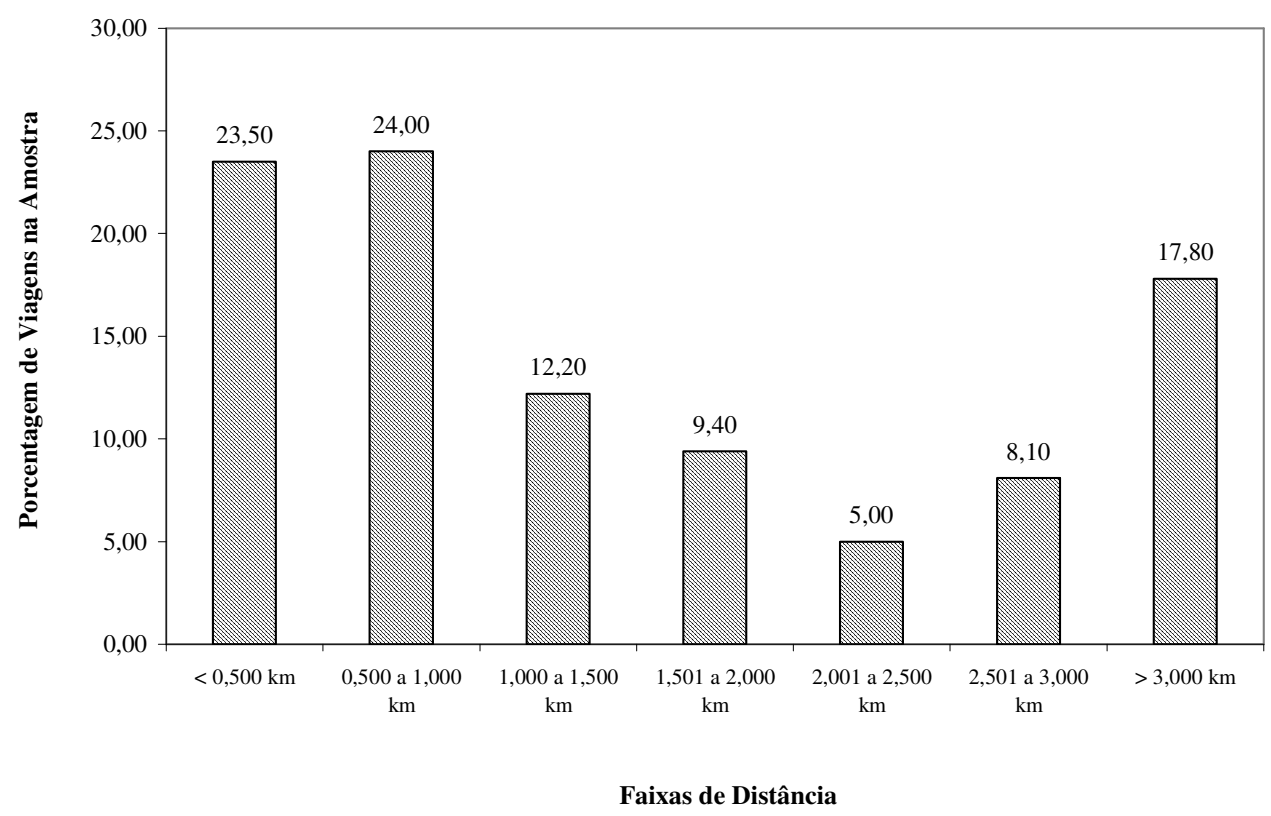

Figura 5.12: Porcentagem de viagens na amostra por faixas de distância.

A Tabela 5.5 apresenta como varia a utilização dos modos de transporte em relação às faixas de distância. Pode-se verificar que o modo a pé é o mais usado para viagens curtas - de até $1,50 \mathrm{~km}$ - e que $25,00 \%$ das viagens por transporte coletivo são realizadas para distâncias entre 2,50 a 3,00 km. 
Tabela 5.5: Porcentagem de uso dos modos de transporte por faixas de distância.

\begin{tabular}{lcccccc}
\hline & \multicolumn{5}{c}{ Modos de Transporte } \\
\cline { 2 - 7 } Faixas de & Automóvel & B pé (\%) & $\begin{array}{c}\text { Bicicleta } \\
(\%)\end{array}$ & $\begin{array}{c}\text { Transporte } \\
\text { Coletivo }\end{array}$ & $\begin{array}{c}\text { Automóvel } \\
(\text { carona) }\end{array}$ & Outros (\%) \\
& $(\%)$ & & & $(\%)$ & $(\%)$ & \\
\hline Até 0,500 & 7,10 & 51,10 & 3,00 & & 5,50 & \\
0,501 a 1,000 & 21,10 & 32,90 & 25,00 & 3,40 & 17,20 & \\
1,001 a 1,500 & 15,20 & 6,10 & 12,50 & 2,30 & 18,40 & \\
1,501 a 2,000 & 13,40 & 4,60 & 6,30 & 8,00 & 14,10 & \\
2,001 a 2,500 & 5,80 & 1,60 & 9,40 & 13,60 & 8,60 & 11,10 \\
2,501 a 3,000 & 13,10 & 0,80 & 6,30 & 25,00 & 8,60 & \\
Mais de 3,000 & 24,30 & 2,90 & 37,50 & 47,70 & 27,60 & 88,90 \\
& & & & & & \\
Total (\%) & 100,00 & 100,00 & 100,00 & 100,00 & 100,00 & 100,00 \\
\hline
\end{tabular}

A Tabela 5.6 mostra que as viagens curtas são realizadas sobretudo por motivo de trabalho e estudo. Esse dado pode revelar em futuras análises que parte da amostra avaliada reside em locais próximos àqueles em que realizam suas atividades diárias. Entretanto, caso essa hipótese seja verdadeira, de acordo com a Tabela 5.5 esse fator não atua de forma significativa na redução de viagens motorizadas, já que cerca de $42 \%$ das viagens até $1 \mathrm{~km}$ ainda são realizadas ou por automóvel (como motorista ou passageiro, respectivamente, $21,1 \%$ e $17,20 \%)$ ou por transporte coletivo $(3,4 \%)$. A existência de altos valores para o motivo "volta para casa" está associado ao fato de que, como São Carlos se caracteriza como uma cidade média e as distâncias entre locais de realização de atividade são relativamente curtas, os indivíduos têm a possibilidade de voltar para casa para realizar determinadas atividades que eventualmente seriam realizadas fora de casa (almoço, por exemplo).

Em relação à participação em atividades, várias análises puderam ser feitas. As atividades foram inicialmente classificadas como "em casa" e "outro", significando as atividades que são realizadas fora do domicílio. Os dados mostram que 51,60\% das atividades são realizadas fora do domicílio. Como já esperado, a Tabela 5.7 confirma que grande parte das atividades é por motivo "estudo" (28,30\%). 
Tabela 5.6: Porcentagem dos motivos de viagem por faixas de distância.

\begin{tabular}{|c|c|c|c|c|c|c|c|}
\hline \multirow{2}{*}{$\begin{array}{l}\text { Motivos de } \\
\text { Viagem }\end{array}$} & \multicolumn{7}{|c|}{ Faixas de Distância } \\
\hline & $\begin{array}{c}\text { Até } 500 \\
\text { m }\end{array}$ & $\begin{array}{c}501 \mathrm{a} \\
1000 \mathrm{~m}\end{array}$ & $\begin{array}{l}1001 \mathrm{a} \\
1500 \mathrm{~m}\end{array}$ & $\begin{array}{c}1501 \mathrm{a} \\
2000 \mathrm{~m}\end{array}$ & $\begin{array}{l}2001 \mathrm{a} \\
2500 \mathrm{~m}\end{array}$ & $\begin{array}{l}2501 \mathrm{a} \\
3000 \mathrm{~m}\end{array}$ & $\begin{array}{l}\text { Mais de } \\
3000 \mathrm{~m}\end{array}$ \\
\hline Trabalho & 19,40 & 11,00 & 9,80 & 13,40 & 16,70 & 31,80 & 24,10 \\
\hline Estudo & 15,10 & 23,50 & 22,80 & 17,40 & 9,00 & 6,20 & 14,50 \\
\hline Lazer & 5,60 & 4,50 & 3,10 & 3,40 & 5,10 & 6,20 & 6,00 \\
\hline Compras & 11,60 & 7,40 & 6,70 & 8,10 & 7,70 & 3,10 & 4,30 \\
\hline Volta para casa & 40,00 & 41,20 & 45,10 & 33,60 & 44,90 & 37,20 & 39,40 \\
\hline Assuntos pessoais & 7,50 & 9,80 & 7,80 & 14,70 & 5,10 & 7,00 & 6,00 \\
\hline Leva e traz & 0,80 & 2,60 & 4,70 & 9,40 & 11,50 & 8,50 & 5,70 \\
\hline
\end{tabular}

Tabela 5.7: Porcentagem de realização das atividades.

\begin{tabular}{lc}
\hline \multicolumn{1}{c}{ Atividades } & Porcentagem \\
\hline Trabalho & 22,40 \\
Estudo & 28,30 \\
Lazer & 8,70 \\
Compras & 12,30 \\
Volta para casa & 0,30 \\
Espera & 12,50 \\
Assuntos pessoais & 14,20 \\
Leva e traz & 1,20 \\
Total & 100,00 \\
\hline
\end{tabular}

A Tabela 5.8 apresenta a duração média de cada atividade. As atividades de “compras" consumiram em torno de 20 minutos e as atividades relacionadas a "assuntos pessoais" aproximadamente 70 minutos. As atividades de compras incluem tanto compras diárias como não diárias. 
Tabela 5.8: Duração média das atividades (em minutos).

\begin{tabular}{lcccc}
\hline \multirow{2}{*}{ Atividades } & \multicolumn{4}{c}{ Duração (em minutos) } \\
\cline { 2 - 5 } & Mínimo & Máximo & Média & $\begin{array}{c}\text { Desvio } \\
\text { padrão }\end{array}$ \\
\hline Trabalho & 5,00 & 875,00 & 264,00 & 154,00 \\
Estudo & 5,00 & 670,00 & 220,42 & 165,49 \\
Lazer & 5,00 & 315,00 & 88,93 & 63,26 \\
Compras & 1,00 & 110,00 & 23,49 & 21,53 \\
Volta para casa & 5,00 & 15,00 & 11,67 & 5,77 \\
Espera & 1,00 & 150,00 & 10,72 & 18,99 \\
Assuntos pessoais & 2,00 & 620,00 & 69,67 & 91,21 \\
Leva e traz & 5,00 & 100,00 & 24,81 & 29,31 \\
Em casa & 0,00 & 1180,00 & 313,21 & 204,43 \\
\hline
\end{tabular}

Em relação ao modo de transporte usado para a realização das atividades para todas as categorias, os modos mais usados são o automóvel e o modo a pé (Tabela 5.9).

Tabela 5.9: Porcentagem de uso dos modos de transporte por motivos das atividades

\begin{tabular}{lcccccc}
\hline \multicolumn{1}{c}{ Modo } & & & & & & \\
Motivo & Automóvel & A pé & Bicicleta & $\begin{array}{c}\text { Transporte } \\
\text { coletivo }\end{array}$ & $\begin{array}{c}\text { Automóvel } \\
\text { (carona) }\end{array}$ & Outros \\
\hline Trabalho & 44,50 & 35,20 & 1,80 & 11,00 & 6,00 & 1,40 \\
Estudo & 33,60 & 43,20 & 1,40 & 6,20 & 13,00 & 2,70 \\
Lazer & 23,80 & 46,40 & 9,50 & 1,20 & 17,90 & 1,20 \\
Compras & 43,30 & 42,50 & 0,80 & 1,70 & 10,80 & 0,80 \\
Volta para casa & 39,50 & 40,00 & 2,40 & 5,50 & 10,80 & 1,80 \\
Assuntos & 40,30 & 41,00 & 2,10 & 3,50 & 13,20 & \\
pessoais & 89,00 & & & & 8,20 & 2,70 \\
Leva e traz & & & & & & \\
\hline
\end{tabular}

\subsection{Custos associados}

Os custos monetários associados a esta pesquisa foram da ordem de $\mathrm{R} \$ 18,00$ (cerca de seis dólares americanos) por domicílio entrevistado. Neste valor estão inclusos gastos com material necessário à coleta e com os pesquisadores. Neste último incluemse gastos com o pagamento de horas trabalhadas ( $\mathrm{R} \$ 1,50$ por hora) e os custos com 
transporte coletivo ( $\mathrm{R} \$ 2,30$ por dia) para que estes pudessem se deslocar entre as áreas da cidade. Vale mencionar que o custo observado não chega a inviabilizar a realização deste tipo de coleta de dados em cidades brasileiras, por ser relativamente baixo. $\mathrm{O}$ único problema é que a taxa de resposta foi muito aquém do esperado, o que exigiria uma ampliação do número de domicílios visitados para se atingir o nível de resposta almejado, com conseqüente aumento nos custos.

\subsection{Considerações Finais}

Os diários de atividades estão sendo usados por vários pesquisadores em várias partes do mundo com o objetivo de coletar dados detalhados em relação às atividades e viagens realizadas pelos indivíduos.

Embora o número de diários de atividades efetivamente utilizado nessa pesquisa ter sido baixo, os resultados mostraram que sua aplicação é viável, tanto em termos de custos monetários, como em termos de qualidade das informações obtidas. Algumas modificações na estrutura do diário aplicado precisam ser melhoradas, de modo a tentar evitar o grande número de respostas inconsistentes. Outro aspecto que também precisa ser considerado é a possibilidade de, em aplicações futuras, usar o artifício da oferta de incentivos aos participantes da pesquisa.

Uma das características da amostra que chama atenção é a predominância da população estudantil. Esse fato é perfeitamente justificado pelo fato da cidade de São Carlos ter duas grandes universidades públicas e outras faculdades particulares.

O conjunto de dados de viagens e atividades e o conjunto de dados referentes ao uso do solo serão usados para a calibração do modelo de atividades Albatross. Apesar do número ideal de informações coletadas para se calibrar um modelo de atividades estar muito além do que foi aqui obtido (no caso holandês foram distruídos cerca de 3000 diários), espera-se que essas informações possam ser úteis, se não na geração de resultados práticos, mas na alimentação do modelo e geração dos resultados que possam ser discutidos em nível acadêmico.

O processo de adequação do modelo em função das características de uma cidade brasileira, a calibração e os resultados obtidos com o modelo serão descritos no capítulo a seguir. 


\section{PADRÕES DE ATIVIDADES OBSERVADOS}

O objetivo deste capítulo é apresentar os resultados obtidos com a calibração do modelo Albatross com dados de São Carlos. As análises que serão apresentadas são referentes ao padrão de atividades realizadas pelos indivíduos da amostra pesquisada. Serão apresentados aqui os padrões observados na amostra avaliada em função de variáveis relevantes ao processo de modelagem.

O uso de diários de atividades para obtenção dos dados necessários ao modelo pode resultar em um grande número de informações inconsistentes. Pela necessidade de obtenção de grande quantidade de informações relacionadas às atividades, erros podem ocorrer nesse tipo de coleta, como a omissão de algumas atividades na programação ou dos horários de início e término das mesmas. Isto é um problema, dado que os modelos baseados em atividades são muito sensíveis à específicas interdependências entre dimensões de escolha sobre uma determinada atividade, o que faz com que qualquer tipo de erro ou omissão de informações da base de dados usada prejudique o desempenho do mesmo.

Uma das formas de minimizar o impacto de informações inconsistentes é a aplicação de programas computacionais que sejam capazes de verificar e testar a lógica dos dados coletados. No caso do modelo Albatross, foi desenvolvido um sistema em liguagem C++ (SYLVIA - A System for the Logical Verification and Inference of Activity Diaries) para verificar a consistência dos dados, que permite ao usuário aplicar qualquer regra incluída no sistema e selecionar uma entre várias opções para "corrigir" os erros encontrados. 
Entretanto, por sugestão dos próprios autores do modelo (Prof. Theo Arentze e Prof. Harry Timmermans), o sistema Sylvia não foi usado nos dados coletados para essa pesquisa. Uma das razões foi o fato do sistema, após algumas modificações do modelo, não estar apropriado a esse tipo de análise. Nesse caso específico, foi utilizado um programa desenvolvido no software estatístico SPSS por um dos estudantes de pósgraduação da Universidade de Eindhoven. Em linhas gerais, os programas que verificam a consistência dos dados seguem um conjunto de regras lógicas (heurísticas) que testam e corrigem as programações de atividades.

O modelo Albatross gera, como parte dos resultados, uma série de análises descritivas do padrão de atividades observado na amostra, que descrevem alguns aspectos importantes e as interdependências nos padrões de atividades observados. Essas análises são baseadas nos vários conjuntos de escolha intrínsecos aos padrões de atividades, que descrevem quais atividades foram realizadas em qual local, quando, por quanto tempo, com quem e o modo de transporte usado.

Para que esses resultados fossem gerados, o modelo foi calibrado com o conjunto de dados coletados na cidade de São Carlos. Nessa etapa foram feitas algumas modificações no modelo original, de modo que este fosse adaptado, em partes, à realidade dessa cidade. Inicialmente, neste capítulo, serão apresentadas essas modificações, seguidas de um tópico específico relativo às análises dos padrões de atividades observados.

\subsection{Estrutura dos dados usados na calibração do modelo}

O modelo Albatross foi desenvolvido com o intuito de capturar o comportamento de viagem e atividades ao nível dos domicílios. O enfoque é basicamente nas agendas de atividades do casal - chefe e cônjuge (indivíduos adultos). No modelo original, foi adotada a hipótese que os indivíduos, quando alcançam uma determinada idade (por exemplo, aos 18 anos), eles saem da casa dos pais e passam a constituir outro domicílio. Vale salientar que essa é uma característica cultural do país, em que a partir de determinada idade, os filhos deixam de morar com os pais.

No caso de São Carlos os dados foram coletados nos domicílios qualquer que fosse o membro. Não foi colocada a restrição de que o diário deveria ser preenchido apenas pelo casal. Essa posição foi adotada em conseqüência da dificuldade encontrada em fazer com que todas as pessoas do domicílio participassem da pesquisa. Dessa 
forma, a variável posição no domicílio precisou ser adaptada às condições aqui encontradas. Por exemplo, em virtude da grande quantidade de estudantes na amostra e de domicílios compostos por membros sem ligação familiar, estes foram tratados como indivíduos isolados - domicílio simples, sem trabalhador.

Cabe aqui uma explicação acerca das considerações do modelo, que distingue apenas entre as opções "trabalha" e "não trabalha", não existindo a categoria "estudante". Dessa forma, como nos dados coletados para a realização desta pesquisa existe um grande número de estudantes, todos os indivíduos dessa categoria foram inseridos na classe "não trabalha". No caso de um indivíduo estudar e trabalhar, a escolha de sua atividade principal será feita em função do número de horas dedicadas a cada uma dessas atividades. Caso a maior parte do tempo seja dedicada à atividade estudo, ele será inserido na categoria "não trabalha; caso contrário, na categoria "trabalha".

Em relação à disponibilidade de automóvel, como dito anteriormente, a amostra é composta por vários domicílios referidos como "repúblicas". Como cada indivíduo foi tratado isoladamente, pode ocorrer deste possuir um automóvel nas características domiciliares, mas não ser o proprietário e não ter a autonomia para usálo. Como o modelo considera o formato "família", todo domicílio que contém pelo menos um automóvel tem a disponibilidade do modo. No caso de São Carlos, adotou-se a seguinte hipótese: mesmo que o domicílio apresente um automóvel, o indivíduo só será considerado habilitado para utilizá-lo se: possuir carteira de habilitação e ter realizado pelo menos uma viagem de automóvel como motorista e com frequiência de mais de 2 vezes por semana. Ainda quando o indivíduo usou o carro apenas em algumas viagens, mas era parte de um domicílio "família", ele foi tratado como apto a usar o carro.

Em relação ao horário de funcionamento dos estabelecimentos foi adotado, de modo geral, o horário comercial de 8 da manhã até às 18 da tarde. Esses horários foram alterados em regiões com presença de grandes supermercados e do shopping center. $\mathrm{Na}$ região do shopping center na cidade de São Carlos adotou-se o horário de funcionamento deste: das 10 às 22 horas. No setor onde estão alguns grandes supermercados na cidade foi adotado o período das 8 às 20 horas.

A matriz tempo de viagem foi estimada de acordo com a velocidade média nas vias. Para o automóvel, $40 \mathrm{~km} / \mathrm{h}$; para viagens a pé, $4,5 \mathrm{~km} / \mathrm{h}$, para o ônibus, $18 \mathrm{~km} / \mathrm{h}$. No caso do transporte público, onde para cada viagem de ônibus existem 2 viagens a pé, 
foi considerado o ônibus como modo principal: ou seja, tanto a distância como o tempo foram estimados como parte da viagem por ônibus. No caso do modo a pé e da bicicleta, no Albatross eles são considerados como uma única categoria: modos lentos. Como as viagens por bicicleta são dominantes no banco de dados original (outra característica inerente à cultura local da Holanda), até mesmo para as viagens a pé as variáveis são estimadas com base na velocidade da bicicleta. Como no caso de São Carlos existem poucas viagens por bicicleta, foi adotada a velocidade do modo a pé, como sendo o modo principal. O tempo de viagem foi estimado de cada quadra (origem) para as outras quadras (destinos). Para a distância foram adotados os mesmos princípios acima.

Todas as informações de viagens, atividades e de uso do solo que alimentam o modelo foram calculadas em nível de quadras. O modelo original usa como características de uso do solo as informações que constam na Tabela 4.5, no Capítulo 4. Entretanto, aqui não foram usadas todas as informações. Algumas informações disponíveis no banco de dados de uso do solo para a cidade de São Carlos não foram usadas pelo fato da versão usada do modelo Albatross não permitir sua inclusão. A proposta original de inserir novos indicadores de uso do solo no modelo não pôde ser realizada, uma vez que, por sugestão dos autores, foi usada a primeira versão do modelo e pelo fato do modelo Albatross estar em fase de integração com um modelo de uso do solo.

No caso da variável disponibilidade de automóvel, o modelo considera que todos os domicílios tinham pelo menos um automóvel (caso verificado na amostra) e a disponibilidade de uso ou não para a primeira atividade era prevista considerando a programação de atividades do parceiro. Nesta aplicação do modelo, foi adotado que nem todos os domicílios possuem automóvel ( o que foi detectado na amostra de São Carlos) e a disponibilidade deste seria função da posse de carteira de habilitação, uma vez que nem sempre foram obtidas informações sobre todos os membros adultos do domicílio (chefe e cônjuge).

Uma das informações que não pôde ser usada neste caso é o número de tipos de atividades em cada região da cidade - variável usada originalmente. No estudo de caso holandês, essas informações estão disponíveis, bem como informações sobre número de empregados por região, número de escolas, número de locais de realização de serviços etc. Assim, as atividades relacionadas a compras, serviços, lazer e atividades sociais são previstas em função do número de opções de locais disponíveis aos indivíduos para realização desses tipos de atividades. Por exemplo, o número de 
atividades de lazer é quantificado em função do número de locais em que é possível a realização dessa atividade, considerando uma faixa de distância aceitável em relação ao domicílio. Dessa forma, neste trabalho foi admitida a hipótese que as pessoas poderiam realizar suas atividades em qualquer lugar da cidade. As classes de duração das atividades (mínima, média e máxima) também foram alteradas de modo a ficar consistentes com os dados coletados em São Carlos.

No item a seguir é apresentada a estrutura usada para análise dos padrões de atividades.Algumas das variáveis usadas na alimentação do modelo podem ser inclusive diferentes daquelas usadas na análise exploratória dos dados apresentada no capítulo anterior. Isso porque, quando os dados foram inseridos no modelo Albatross, houve a necessidade de padronização destes ao formato exigido pelo modelo. Estas serão devidamente descritas quando necessário.

\subsection{Estrutura para análise descritiva}

O modelo Albatross segue a estrutura de análise dos padrões de realização de atividades e viagens desenvolvida por Bhat (1999, apud Arentze e Timmermans, 2000), que serve para fornecer o modo de apresentação dos resultados da análise descritiva. A estrutura é fundamentalmente baseada no padrão de viagens de um trabalhador em um dia típico, e se baseia em sua regularidade e na localização fixa do local da atividade de trabalho e do domicílio. Ela não é válida para todos os casos, mas é útil para desenvolver o esqueleto ${ }^{(1)}$ dos padrões de atividade.

São identificados cinco diferentes tipos de subpadrões em um padrão de atividades de um dia típico de trabalho:

- Atividades e viagens realizadas antes da primeira viagem para trabalho (tendo como base o domicílio);

- Atividades e viagens realizadas durante a viagem a partir do domicílio para o local de trabalho no período da manhã;

- Atividades e viagens realizadas entre o período de trabalho da manhã e da tarde, tendo como base o local de trabalho (período intermediário);

- Atividades e viagens realizadas durante a vigem de volta do local de trabalho para o domicílio, no final da tarde; e, 
- Atividades e viagens realizadas após a volta para casa, com base no domicílio.

No primeiro caso, são representadas as atividades e as viagens realizadas antes de sair de casa para o trabalho no período da manhã. Em alguns casos esse padrão envolve apenas atividades realizadas em casa (que, apesar de serem originalmente incluídas no modelo, aqui não são representadas), mas também pode incluir atividades e viagens realizadas fora de casa antes de ir para o local trabalho. O segundo caso compreende as atividades e viagens realizadas durante o período da manhã. $\mathrm{O}$ padrão intermediário inclui todas as atividades e viagens realizadas a partir do local de trabalho, geralmente no horário de almoço. O padrão da tarde relaciona as atividades e viagens realizadas no caminho de volta do local trabalho para casa e a última categoria compreende todas as atividades realizadas após chegar em casa, ao final do dia de trabalho. Vale ressaltar que as atividades realizadas podem ou não necessitar de viagens, dependendo do local em que estas deverão ser realizadas.

Cada um desses padrões pode conter vários encadeamentos, definidos como viagens que começam e terminam em casa para os padrões antes e depois do trabalho, e circuitos que começam e terminam no trabalho no padrão intermediário. Da mesma forma, cada encadeamento pode compreender várias paradas para realização de outras atividades.

Os padrões de atividades observados serão analisados em função de alguns indicadores, que podem ser subdivididos em dois níveis: de padrões de realização de atividades ou de encadeamentos (ou até mesmo associados às paradas simples realizadas durante o dia). Para exemplificar, a estrutura final pode resultar no seguinte conjunto de indicadores:

- Indicadores do nível de programação diária completa - participação nas atividades e número de atividades realizadas fora de casa;

- Indicadores do nível de encadeamento de viagens - número de atividades fora de casa e padrão de encadeamento de modos de transporte e tempo de viagem;

- Indicadores do nível de paradas - tipo de encadeamento feito, acompanhamento da atividade (com quem), duração da atividade e sua 
relação com o tempo da viagem, horário de início da atividade, padrão de viagem (conforme descrito anteriormente) e modo de transporte.

Esses indicadores podem ainda ser desmembrados em variáveis sóciodemográficas como tipo do domicílio, tipo de emprego, número de crianças, nível de educação e gênero. Essas variáveis serão discriminadas no texto que segue, quando necessário.

Vale aqui ressaltar que uma das características inerentes ao modelo é a consideração, durante o processo de modelagem, das atividades realizadas dentro de casa (como dormir, assistir televisão, higiene pessoal, entre outras). Essas atividades são relevantes principalmente na quantificação do tempo total disponível para a realização de outras atividades, fora do domicílio. Assim, algumas variáveis são discriminadas com o termo "fora de casa", o que significa que o modelo está apenas diferenciando as atividades usuais dos indivíduos (realizadas no domicílio) das atividades que necessitam ser realizadas em outro local. Nesta pesquisa não foram consideradas as atividades realizadas dentro do domicílio. Pelo fato do processo de coleta dos dados não ter sido simples, optou-se por desconsiderar essas variáveis, de modo a simplificar o formato do diário de atividades para os entrevistados.

\subsection{Resultados dos padrões de atividades observados}

Os resultados que serão apresentados a seguir foram derivados da amostra composta por 296 casos analisados em nível de padrão diário de atividades. Ou seja, do total de indivíduos entrevistados na amostra, foram retirados 296 programas de atividades diárias. As Tabelas de 6.1 a 6.8 mostram as frequiências de realização de determinado padrão de atividade em função dos períodos de tempo definidos na estrutura proposta por Bhat (1999, apud Arentze e Timmermans, 2000). Vale lembrar que esses períodos não correspondem aos períodos do dia (manhã, tarde e noite), mas a uma subdivisão criada pelo autor e usada aqui como ferramenta de análise.

Todas as análises que se seguem foram realizadas apenas para as atividades realizadas durante a semana, uma vez que não foram coletadas essas informações para o final de semana. A terminologia usada em todas as Tabelas abaixo está descrita no Quadro 6.1. 
Quadro 6.1: Terminologia usada nas análises de freqüência.

\begin{tabular}{ll}
\hline Código & \multicolumn{1}{c}{ Descrição } \\
\hline & \\
Dom & Atividade com base domiciliar \\
LT & Atividade de leva e traz (pessoas ou mercadorias \\
CSe & Atividades de compras ou relacionadas a serviços \\
SLz & Atividades sociais ou de lazer realizadas fora do domicílio \\
Outras & Outras atividades fora de casa \\
NDom & Atividades realizadas sem base domiciliar \\
T & Atividades de trabalho \\
\hline
\end{tabular}

Tabela 6.1: Frequiência do padrão de atividades antes da primeira viagem de trabalho, considerando o tempo necessário para a realização de atividades de trabalho/escola, para dias da semana.

\begin{tabular}{lc}
\hline Padrão de Atividades & Freqüências \\
\hline Nenhum caso & 0,105 \\
Apenas Dom & 0,834 \\
Dom-LT-Dom & 0,003 \\
Dom-CSe-Dom & 0,024 \\
Dom-SLz-Dom & 0,007 \\
Dom-Outras-Dom & 0,020 \\
NDom & 0,007 \\
& \\
Total & $\mathbf{1 , 0 0 0}(\mathbf{n}=\mathbf{2 9 6})$ \\
\hline
\end{tabular}

Como pode ser observado nas Tabelas 6.1 e 6.2, mais de $80 \%$ das atividades realizadas antes da primeira viagem para o trabalho (que não é necessariamente feita no período da manhã) e durante a viagem para o trabalho, são realizadas no próprio domicílio. Ou seja, a maior parte da amostra avaliada não realiza um número significativo de atividades e viagens antes e durante a viagem para o trabalho.

Já no período intermediário (entre episódios de trabalho), o padrão encontrado na amostra é que cerca de $48 \%$ dos indivíduos da amostra não realizou nenhum tipo de atividade ou viagem, ou são realizadas atividades no mesmo local de trabalho (almoço, por exemplo). Cerca de $32 \%$ das atividades são baseadas no domicílio e outras atividades e viagens realizadas, com base no local de trabalho, somam $20 \%$ do total. 
Tabela 6.2: Freqüência do padrão de atividades durante a primeira viagem de trabalho, em relação ao tempo empregado em atividades de trabalho/escola.

\begin{tabular}{lc}
\hline \multicolumn{1}{c}{ Padrão de Atividades } & Freqüências \\
\hline Nenhum caso & 0,105 \\
A partir do Dom & 0,821 \\
Dom-LT-Dom & 0,007 \\
Dom-CSe-Dom & 0,003 \\
Dom-SLz-Dom & 0,010 \\
Dom-Outras-Dom & 0,041 \\
NDom & 0,014 \\
& \\
Total & $\mathbf{1 , 0 0 0}(\mathbf{n}=\mathbf{2 9 6})$ \\
\hline
\end{tabular}

Tabela 6.3: Freqüência do padrão de atividades entre dois episódios de trabalho.

\begin{tabular}{lc}
\hline Padrão de Atividades & Freqüências \\
\hline Nenhum caso & 0,483 \\
Nenhuma viagem & 0,000 \\
Apenas Dom & 0,324 \\
T-LT-T & 0,000 \\
T-CSe-T & 0,007 \\
T-SLz-T & 0,007 \\
T-Outras-T & 0,044 \\
T-NDom/NDom-T & 0,014 \\
T-NDom/Dom-T & 0,122 \\
& \\
Total & $\mathbf{1 , 0 0 0}(\mathbf{n}=\mathbf{2 9 6})$ \\
\hline
\end{tabular}

As Tabelas 6.4 e 6.5 mostram que a volta para o domicílio após a jornada de trabalho é predominante na amostra e que cerca de $68 \%$ dos respondentes considerados não realiza outras atividades no final do dia.

Tabela 6.4: Freqüência do padrão de atividades durante a última viagem de trabalho (viagem de volta do trabalho para o domicílio).

\begin{tabular}{lc}
\hline Padrão de Atividades & Freqüiências \\
\hline Nenhum caso & 0,105 \\
para o Dom & 0,706 \\
T-LT-Dom & 0,007 \\
T-CSe-Dom & 0,051 \\
T-SLz-Dom & 0,030 \\
T-Outra-Dom & 0,057 \\
NDom & 0,044 \\
& \\
Total & $\mathbf{1 , 0 0 0}(\mathbf{n}=\mathbf{2 9 6})$ \\
\hline
\end{tabular}


Tabela 6.5: Frequiência do padrão de atividades após a última viagem de trabalho.

\begin{tabular}{lc}
\hline Padrão de Atividades & Freqüências \\
\hline Nenhum caso & 0,105 \\
Apenas Dom & 0,686 \\
Dom-LT-Dom & 0,000 \\
Dom-CSe-Dom & 0,030 \\
Dom-SLz-Dom & 0,084 \\
Dom-Outras-Dom & 0,057 \\
NDom & 0,037 \\
& \\
Total & $\mathbf{1 , 0 0 0}(\mathbf{n}=\mathbf{2 9 6})$ \\
\hline
\end{tabular}

As Tabelas de 6.6 a 6.8 mostram o padrão individual de realização de atividades divididos em períodos do dia. O padrão da manhã (Tabela 6.6) é definido com um subconjunto de atividades que têm início antes do meio dia; o padrão da tarde (Tabela 6.7) compreende as atividades realizadas entre 12 e 18 horas; o padrão da noite engloba as atividades realizadas após as 18:00 horas.

Tanto no período da manhã como no período da tarde, a maior parte das atividades e viagens é realizada para o trabalho e tem base domiciliar. No período da tarde, cerca de $47 \%$ das atividades realizadas não possuem base domiciliar. Já no período da noite parte das viagens são de retorno ao domicílio, e algumas realizadas para visitas sociais e lazer.

Tabela 6.6: Frequiência do padrão de atividades durante o período da manhã.

\begin{tabular}{lc}
\hline Padrão de Atividades & Freqüências \\
\hline Nenhuma atividade & 0,000 \\
Apenas Dom & 0,091 \\
Dom-T-Dom & 0,645 \\
Dom-LT-Dom & 0,000 \\
Dom-CSe-Dom & 0,024 \\
Dom-SLz-Dom & 0,017 \\
Dom-Outras-Dom & 0,017 \\
NDom & 0,206 \\
& \\
Total & $\mathbf{1 , 0 0 0}(\mathbf{n}=\mathbf{2 9 6})$ \\
\hline
\end{tabular}


Tabela 6.7: Freqüência do padrão de atividades durante o período da tarde.

\begin{tabular}{lc}
\hline Padrão de Atividades & Freqüiencias \\
\hline Nenhuma atividade & 0,000 \\
Apenas Dom & 0,064 \\
Dom-T-Dom & 0,392 \\
Dom-LT-Dom & 0,000 \\
Dom-CSe-Dom & 0,020 \\
Dom-SLz-Dom & 0,030 \\
Dom-Outras-Dom & 0,024 \\
NDom & 0,470 \\
& \\
Total & $\mathbf{1 , 0 0 0}(\mathbf{n}=\mathbf{2 9 6})$ \\
\hline
\end{tabular}

Tabela 6.8: Freqüência do padrão de atividades durante o período da noite.

\begin{tabular}{lc}
\hline Padrão de Atividades & Freqüências \\
\hline Nenhuma atividade & 0,000 \\
Apenas Dom & 0,422 \\
Dom-T-Dom & 0,240 \\
Dom-LT-Dom & 0,003 \\
Dom-CSe-Dom & 0,017 \\
Dom-SLz-Dom & 0,081 \\
Dom-Outras-Dom & 0,064 \\
NDom & 0,172 \\
& \\
Total & $\mathbf{1 , 0 0 0}(\mathbf{n}=\mathbf{2 9 6})$ \\
\hline
\end{tabular}

A Tabela 6.9 apresenta os resultados da freqüência dos padrões de atividades realizadas fora de casa. Ao contrário dos casos anteriores, em que foram usados segmentos de tempo com base na atividade de trabalho, aqui as frequiências são quantificadas em relação à composição domiciliar. A terminologia usada para essa categoria é a seguinte:

- si, 0-t: domicílio composto por apenas um indivíduo, que não trabalha;

- si, 1-t: domicílio composto por apenas um indivíduo, que trabalha;

- do,1: domicílio composto por mais de um indivíduo, que pelo menos um trabalha;

- do,2: domicílio composto por mais de um indivíduo, em que os dois trabalham

Algumas categorias de atividades são desagregadas como categorias distintas, como atividades de lazer e sociais; e atividades de compras diárias separadas de atividades de compras que não são realizadas diariamente. Juntamente com as 
atividades de trabalho, as atividades de compras diárias e outras atividades não especificadas são as mais freqüentes no padrão observado. Em relação à composição domiciliar, um ponto deve ser destacado: a baixa frequiência de realização de atividades (mesmo para a própria atividade trabalho) em domicílios com apenas um indivíduo e que trabalha e a alta freqüência de realização da atividade trabalho em domicílios com apenas um individuo que não trabalha. Embora seja um resultado aparentemente contrário à lógica, esse fato pode ser justificável pelo fato do modelo considerar as atividades trabalho e estudo juntas. Assim, a alta freqüência da atividade trabalho no segundo caso, pode não ser efetivamente uma indicação de atividades relacionadas ao trabalho, mas sim à atividade estudo. Vale lembrar que o modelo não diferencia entre categorias de "trabalhadores" e "estudantes". Entretanto, as atividades relacionadas a trabalho e estudo são consideradas juntamente, como sendo uma das principais atividades fixas da programação diária individual. Esse fator só pode ser esclarecido a partir de uma análise mais detalhada e com maior quantidade de informações.

Tabela 6.9: Frequiência média das atividades realizadas fora de casa com base na composição domiciliar.

\begin{tabular}{|c|c|c|c|c|c|}
\hline \multirow[t]{2}{*}{ Tipo de Atividade } & \multicolumn{5}{|c|}{ Composição Domiciliar } \\
\hline & si,0-t & si,1-t & do, $1-\mathrm{t}$ & do, $2-\mathrm{t}$ & Total \\
\hline Trabalho & 0,252 & 0,020 & 0,133 & 0,154 & 0,558 \\
\hline Leva e traz & 0,007 & 0,002 & 0,001 & 0,005 & 0,015 \\
\hline Não lazer & 0,017 & 0,002 & 0,022 & 0,02 & 0,061 \\
\hline Compras diárias & 0,043 & 0,002 & 0,029 & 0,035 & 0,109 \\
\hline Serviços & 0,006 & 0,000 & 0,005 & 0,005 & 0,015 \\
\hline Compras não diárias & 0,005 & 0,000 & 0,009 & 0,003 & 0,017 \\
\hline Visitas sociais & 0,014 & 0,002 & 0,003 & 0,008 & 0,028 \\
\hline Lazer & 0,036 & 0,002 & 0,022 & 0,017 & 0,077 \\
\hline Outras & 0,076 & 0,003 & 0,020 & 0,021 & 0,120 \\
\hline Total & 0,455 & $\mathbf{0 , 0 3 5}$ & 0,244 & 0,267 & $1,000(n=866)$ \\
\hline
\end{tabular}

Como os indivíduos podem combinar diferentes atividades fora de casa em um único encadeamento, o número de encadeamentos para realizar as atividades fora de casa é uma das características mais importantes ao nível do padrão de realização de atividades. A Tabela 6.10 mostra a distribuição de freqüência entre os números de encadeamentos realizados por homens e mulheres.

Considerando juntamente homens e mulheres, cerca de $53 \%$ do padrão inclui pelo menos 2 encadeamentos de viagem. 
Tabela 6.10: Freqüência do padrão de atividades por número de encadeamento e por gênero.

\begin{tabular}{cccc}
\hline $\begin{array}{c}\text { Número de } \\
\text { encadeamentos }\end{array}$ & \multicolumn{3}{c}{ Gênero } \\
\hline & Homem & Mulher & Total \\
0 & 0 & 0 & 0 \\
1 & 0,152 & 0,118 & 0,270 \\
2 & 0,297 & 0,233 & 0,530 \\
3 & 0,091 & 0,078 & 0,169 \\
$>3$ & 0,020 & 0,011 & 0,031 \\
& & & \\
Total & $\mathbf{0 , 5 6 0}$ & $\mathbf{0 , 4 4 0}$ & $\mathbf{1 , 0 0 0}(\mathbf{n}=\mathbf{2 9 6})$ \\
\hline
\end{tabular}

As Tabelas de 6.11 a 6.15 consideram as principais dimensões das atividades que são relevantes ao modelo Albatross. A primeira delas, a dimensão com quem a atividade é realizada, diz respeito à escolha entre realizar a atividade sozinho ou com outras pessoas, que podem tanto ser pessoas do domicílio como de fora dele. Na Tabela 6.11 pode ser observado que grande parte das atividades de trabalho são realizadas apenas pelo indivíduo. Em relação às outras atividades, os valores encontrados, em todas as categorias, são relativamente pequenos. $\mathrm{O}$ valor do coeficiente de contingência, que mede o grau de interdependência entre as variáveis, é de 0,315 , mostrando que há relação entre as atividades realizadas fora de casa e a dimensão com quem possuem certa correspondência, mas não é intensa.

Tabela 6.11: Freqüência das atividades realizadas fora de casa por tipo de atividade e com quem a atividade foi realizada.

\begin{tabular}{cccccccccccc}
\hline & \multicolumn{10}{c}{ Tipo de Atividade } \\
\cline { 2 - 12 } Com quem & Trabalho & $\begin{array}{c}\text { Leva e } \\
\text { traz }\end{array}$ & Não lazer & $\begin{array}{c}\text { Compras } \\
\text { diárias }\end{array}$ & Serviços & $\begin{array}{c}\text { Compras } \\
\text { não } \\
\text { diárias }\end{array}$ & $\begin{array}{c}\text { Visitas } \\
\text { sociais }\end{array}$ & Lazer & Outras & Total \\
\hline Sozinho & 0,333 & 0,002 & 0,028 & 0,068 & 0,012 & 0,012 & 0,015 & 0,029 & 0,051 & 0,549 \\
$\begin{array}{c}\text { Outros } \\
\text { (dom) }\end{array}$ & 0,018 & 0,001 & 0,007 & 0,022 & 0,000 & 0,003 & 0,001 & 0,008 & 0,027 & 0,088 \\
$\begin{array}{c}\text { Outros } \\
\text { dom/fora) } \\
\text { Total }\end{array}$ & 0,207 & 0,012 & 0,027 & 0,018 & 0,003 & 0,002 & 0,012 & 0,040 & 0,042 & 0,363 \\
\hline
\end{tabular}

A duração média das atividades é a segunda dimensão importante para o modelo. Mais uma vez observa-se que as atividades que predominam são as de trabalho e compras diárias (Tabela 6.12). De acordo com o valor do coeficiente de contingência 
$(c=0,696)$, pode-se afirmar que o tipo de atividade está diretamente ligado à sua duração.

Tabela 6.12: Duração das atividades por seus diferentes tipos.

\begin{tabular}{llllllllll}
\hline \multicolumn{1}{c}{ Tipo de } & \multicolumn{7}{c}{ Duração da Atividade (min) } \\
\cline { 2 - 10 } Atividade & $<=10$ & $11-20$ & $21-30$ & $31-45$ & $46-60$ & $61-80$ & $81-120$ & $>120$ & Total \\
\hline Trabalho & 0,008 & 0,015 & 0,009 & 0,005 & 0,009 & 0,009 & 0,053 & 0,449 & 0,558 \\
Leva e traz & 0,007 & 0,002 & 0,003 & 0,001 & 0,001 & 0,000 & 0,000 & 0,000 & 0,015 \\
Não lazer & 0,042 & 0,012 & 0,005 & 0,000 & 0,001 & 0,000 & 0,000 & 0,002 & 0,061 \\
Compras & 0,040 & 0,027 & 0,020 & 0,010 & 0,006 & 0,002 & 0,003 & 0,000 & 0,109 \\
diárias & 0,007 & 0,003 & 0,001 & 0,001 & 0,000 & 0,001 & 0,000 & 0,001 & 0,015 \\
Serviços & & & & & & & & & \\
Compras não & 0,007 & 0,005 & 0,002 & 0,001 & 0,002 & 0,000 & 0,000 & 0,000 & 0,017 \\
diárias & & & & & & & & & \\
Visitas & 0,001 & 0,001 & 0,001 & 0,003 & 0,000 & 0,003 & 0,005 & 0,013 & 0,028 \\
sociais & 0,005 & 0,002 & 0,007 & 0,006 & 0,009 & 0,013 & 0,021 & 0,015 & 0,077 \\
Lazer & 0,016 & 0,009 & 0,027 & 0,023 & 0,017 & 0,007 & 0,009 & 0,012 & 0,120 \\
Outras & 0,133 & 0,076 & 0,075 & 0,051 & 0,046 & 0,036 & 0,091 & 0,492 & $(\mathrm{n}=866)$ \\
Total & & & & & & & &
\end{tabular}

A terceira dimensão analisada é o horário de início das atividades (Tabela 6.13). Uma vez que o horário de término da atividade é derivado da combinação do horário de início e duração da mesma, a dimensão "horário de término" não é considerada explicitamente no modelo. A Tabela 6.13 mostra a freqüência de distribuição do horário de início das atividades em função do tipo da mesma $(c=0,484)$. As atividades fixas como trabalho e estudo geralmente têm horários pré-determinados para iniciar, o que torna essa análise secundária. Apesar dos outros valores serem pequenos, vale ressaltar que a maior parte das atividades compras são realizadas antes das 10:00 horas da manhã e após as 18:00 horas da noite. As atividades de lazer também têm predominância no período da noite. 
Tabela 6.13: Horário de início das atividades.

\begin{tabular}{cccccccccccc}
\hline $\begin{array}{c}\text { Horário } \\
\text { de Início } \\
\text { (horas) }\end{array}$ & Trabalho & $\begin{array}{c}\text { Leva e } \\
\text { traz }\end{array}$ & $\begin{array}{c}\text { Não } \\
\text { lazer }\end{array}$ & $\begin{array}{c}\text { Compras } \\
\text { diárias }\end{array}$ & Serviços & $\begin{array}{c}\text { Compras } \\
\text { não } \\
\text { diárias }\end{array}$ & $\begin{array}{c}\text { Visitas } \\
\text { sociais }\end{array}$ & Lazer & Outras & Total \\
\hline $\begin{array}{c}\text { Antes das } \\
10\end{array}$ & 0,275 & 0,007 & 0,012 & 0,027 & 0,001 & 0,003 & 0,003 & 0,009 & 0,014 & 0,351 \\
$10-12$ & 0,025 & 0,001 & 0,005 & 0,012 & 0,000 & 0,002 & 0,005 & 0,002 & 0,012 & 0,064 \\
$12-14$ & 0,112 & 0,003 & 0,012 & 0,015 & 0,008 & 0,007 & 0,007 & 0,003 & 0,052 & 0,219 \\
$14-16$ & 0,072 & 0,000 & 0,008 & 0,012 & 0,002 & 0,001 & 0,003 & 0,005 & 0,013 & 0,115 \\
$16-18$ & 0,036 & 0,003 & 0,009 & 0,016 & 0,002 & 0,000 & 0,001 & 0,013 & 0,009 & 0,090 \\
Após as 18 & 0,038 & 0,000 & 0,016 & 0,028 & 0,001 & 0,003 & 0,008 & 0,045 & 0,021 & 0,161 \\
Total & 0,558 & 0,015 & 0,061 & 0,109 & 0,015 & 0,017 & 0,028 & 0,077 & 0,120 & $(\mathrm{n}=866)$ \\
\hline
\end{tabular}

A próxima dimensão é o tipo de viagem. Essa dimensão está relacionada ao tipo de encadeamento de viagens que o indivíduo escolhe realizar. São consideradas as seguintes opções:

- Viagem com parada simples: nesse caso é feita uma viagem a partir da origem diretamente ao local de destino para a realização da atividade, e com retorno ao local de origem. Por exemplo, uma viagem para compras que tenha como base o domicílio;

- Viagem encadeada para realização de uma atividade, antes que uma outra atividade seja realizada. Por exemplo, no trajeto de casa para o trabalho, usar a mesma viagem em uma parada para realização de uma atividade de compras, antes da atividade principal (trabalho);

- Viagem encadeada para realização de uma atividade, após a participação em outra atividade. Por exemplo, no trajeto de volta do trabalho para casa, usar a viagem para a realização de uma atividade de compras;

- Realizar uma atividade no espaço de tempo disponível entre a realização de duas outras atividades. Por exemplo, entre duas atividades de compras, usar a viagem para a realização de uma atividade leva e traz.

As viagens de trabalho, lazer e compras são geralmente com paradas simples, não sendo conectadas a outras atividades (Tabela 7.14). Esse fato pode ser explicado pela facilidade com que as pessoas em uma cidade média podem se deslocar a partir de um local e voltar a ele, não sendo necessário conectar a realização de outras atividades a 
uma única viagem. Entretanto, essa característica induz a um maior número de viagens realizadas diariamente. O nível de interdependência entre as variáveis é baixo $(\mathrm{c}=0,279)$

Tabela 6.14: Frequiência das atividades realizadas fora de casa por tipo de atividade e tipo de viagem.

\begin{tabular}{|c|c|c|c|c|c|c|c|c|c|c|}
\hline \multirow[b]{2}{*}{$\begin{array}{l}\text { Tipo de } \\
\text { Viagem }\end{array}$} & \multicolumn{10}{|c|}{ Tipo de Atividade } \\
\hline & Trabalho & $\begin{array}{c}\text { Leva e } \\
\text { traz }\end{array}$ & $\begin{array}{l}\text { Não } \\
\text { lazer }\end{array}$ & $\begin{array}{c}\text { Compras } \\
\text { diárias }\end{array}$ & Serviços & $\begin{array}{c}\text { Compras } \\
\text { não } \\
\text { diárias }\end{array}$ & $\begin{array}{l}\text { Visitas } \\
\text { sociais }\end{array}$ & Lazer & Outras & Total \\
\hline $\begin{array}{l}\text { Parada } \\
\text { simples }\end{array}$ & 0,396 & 0,004 & 0,018 & 0,048 & 0,011 & 0,009 & 0,008 & 0,053 & 0,029 & 0,576 \\
\hline $\begin{array}{l}\text { Após } \\
\text { parada }\end{array}$ & 0,084 & 0,004 & 0,022 & 0,024 & 0,009 & 0,006 & 0,004 & 0,013 & 0,014 & 0,180 \\
\hline $\begin{array}{l}\text { Antes } \\
\text { parada }\end{array}$ & 0,097 & 0,006 & 0,019 & 0,018 & 0,003 & 0,005 & 0,005 & 0,011 & 0,017 & 0,181 \\
\hline $\begin{array}{l}\text { Entre } \\
\text { paradas }\end{array}$ & 0,038 & 0,003 & 0,008 & 0,001 & 0,000 & 0,000 & 0,001 & 0,003 & 0,009 & 0,063 \\
\hline Total & 0,615 & 0,017 & 0,067 & 0,091 & 0,023 & 0,020 & 0,018 & 0,080 & 0,069 & $(\mathrm{n}=786)$ \\
\hline
\end{tabular}

Por ultimo, a Tabela 6.15 mostra as freqüências das atividades realizadas fora de casa com relação à escolha do modo de transporte usado na viagem $(c=2,44)$. Observa-se que a maior parte das viagens é realizada por automóvel, seguido pelos modos não motorizados. O automóvel predomina praticamente em todas as categorias de atividades, variando as faixas de valores. 
Tabela 6.15: Frequiência das atividades realizadas fora de casa por tipo de atividade e modo de transporte.

\begin{tabular}{|c|c|c|c|c|c|c|c|c|c|c|}
\hline \multirow[b]{2}{*}{$\begin{array}{l}\text { Modo de } \\
\text { Transporte }\end{array}$} & \multicolumn{10}{|c|}{ Tipo de Atividade } \\
\hline & Trabalho & $\begin{array}{c}\text { Leva e } \\
\text { traz }\end{array}$ & $\begin{array}{l}\text { Não } \\
\text { lazer }\end{array}$ & $\begin{array}{c}\text { Compras } \\
\text { diárias }\end{array}$ & Serviços & $\begin{array}{c}\text { Compras } \\
\text { não } \\
\text { diárias }\end{array}$ & $\begin{array}{l}\text { Visitas } \\
\text { sociais }\end{array}$ & Lazer & Outras & Total \\
\hline $\begin{array}{l}\text { Automóvel } \\
\text { (motorista) }\end{array}$ & 0,252 & 0,009 & 0,046 & 0,045 & 0,003 & 0,008 & 0,012 & 0,025 & 0,055 & 0,455 \\
\hline $\begin{array}{l}\text { Modos não } \\
\text { motorizados }\end{array}$ & 0,169 & 0,003 & 0,008 & 0,046 & 0,008 & 0,008 & 0,010 & 0,035 & 0,044 & 0,331 \\
\hline $\begin{array}{l}\text { Transporte } \\
\text { público }\end{array}$ & 0,056 & 0,000 & 0,002 & 0,003 & 0,001 & 0,000 & 0,001 & 0,003 & 0,002 & 0,068 \\
\hline $\begin{array}{l}\text { Automóvel } \\
\text { (passageiro) }\end{array}$ & 0,080 & 0,002 & 0,006 & 0,015 & 0,002 & 0,001 & 0,005 & 0,015 & 0,017 & 0,143 \\
\hline Outros & 0,002 & 0,000 & 0,000 & 0,000 & 0,000 & 0,000 & 0,000 & 0,000 & 0,001 & 0,003 \\
\hline Total & 0,559 & 0,014 & 0,062 & 0,109 & 0,014 & 0,017 & 0,028 & 0,078 & 0,119 & $(\mathrm{n}=866)$ \\
\hline
\end{tabular}

\subsection{Considerações Finais}

O objetivo deste capítulo foi apresentar as características dos padrões de atividades mais relevantes na cidade de São Carlos, identificados pelo modelo Albatross. Todas as análises foram baseadas naquelas originalmente realizada pelos autores do modelo para permitir futuras análises comparativas entre os resultados. $\mathrm{O}$ propósito ainda não é o de encontrar relações entre os dados, o que será feito posteriormente. As freqüências apresentadas servem apenas para revelar padrões de realização, organização e escolha das atividades.

Apesar dos resultados não revelarem o comportamento mais fiel de padrões de atividades da população de São Carlos (em função da baixa quantidade de dados considerados), algumas observações podem ser feitas. Entre as atividades que mais se destacam estão as de trabalho e escola, como já era esperado, em função da análise apresentada no capítulo anterior. Juntamente com essas atividades, aquelas realizadas para compras também aparecem com certa freqüência.

A maior parte das viagens feitas para a realização de atividades tem base domiciliar, o que é perfeitamente aceitável em uma cidade de porte médio. Esse fato também pode ser verificado pelo baixo número de encadeamentos de viagem realizados. Outro fator importante é a alta freqüência de viagens com paradas simples. 
Em relação ao horário de início das atividades verifica-se que as atividades de compras são realizadas ou no início da manhã ou à noite, assim como as atividades de lazer. Os modos de transporte mais usados são o automóvel e os modos não motorizados (no caso desta aplicação, em particular o modo a pé), que é perfeitamente ajustável ao comportamento da população, como já pôde ser observado em pesquisa realizada anteriormente por Arruda (2000).

No capítulo que segue serão derivadas as árvores de decisão que tentam reproduzir o modo como os indivíduos selecionam suas escolhas, em função de regras heurísticas. Essas árvores de decisão são geradas por um algoritmo que integra o modelo Albatross. 


\section{7. ÁRVORES DE DECISÃO}

Neste capítulo são apresentados os resultados obtidos pelas árvores de decisão, geradas com a aplicação do algoritmo CHAID. Essa ferramenta simula a probabilidade de escolha de uma determinada alternativa, considerando sua interação com outros conjuntos de variáveis.

O modelo Albatross reproduz o comportamento de escolhas individuais com aplicação do algoritmo CHAID (Chi-squared Automatic Interaction Detector). Este algoritmo é usado para extrair as árvores de decisão que representam o conjunto de heurísticas de escolhas para cada etapa no processo de tomada de decisão, como descrito no Capítulo 4. É importante destacar que heurísticas são mecanismos computacionais ou comportamentais que auxiliam no processo de tomada de decisão, mas que não resultam, necessariamente, em um resultado ótimo.

No caso do modelo Albatross, o algoritmo CHAID foi aplicado para as etapas do processo de decisão indicadas abaixo:

1. Escolha do modo de transporte para as atividades de trabalho;

2. Seleção das atividades flexíveis, e da dimensão com quem a atividade será realizada;

3. Escolha da hora do dia em que as atividades serão realizadas;

4. Decisões de encadeamento das viagens;

5. Escolha do modo de transporte para cada encadeamento de viagem e da localização de realização da atividade; 
Em cada uma das etapas acima, um grande número de variáveis foi usada, incluindo aquelas que são objeto de estudo neste trabalho (as variáveis de uso do solo). Ao gerar as árvores de decisão, o algoritmo CHAID seleciona as variáveis que são mais significativas, combinando-as com outras para que possam, juntas, fornecer informações que permitam melhor explicar o comportamento de escolha individual. Dessa forma, as variáveis que não estiverem presentes nos resultados gerados apontam não para a ausência de influência destas sobre o comportamento individual, mas que essa influência, caso ocorra, não é significativa.

Os tópicos a seguir se destinam a apresentar, primeiramente, o conjunto de variáveis usadas na geração das árvores de decisão e os resultados encontrados com a aplicação do algoritmo CHAID, a cada uma das etapas acima. Vale salientar que os testes estatísticos usados estão descritos no Capítulo 4.

\subsection{Conjunto de variáveis explicativas}

As variáveis que poderiam ser incluídas no modelo para explicar a escolha do padrão de realização de atividades individual seguiu, inicialmente, o conjunto de dados exigido pelo modelo Albatross (conforme descrito nas Tabelas 4.4 e 4.5 do Capítulo 4).

As variáveis usadas foram divididas em dois conjuntos: variáveis referentes às características individuais/domiciliares, das atividades e das viagens, e variáveis referentes ao uso do solo, conforme descrito a seguir.

\subsubsection{Variáveis referentes às atividades e viagens}

Este primeiro conjunto de variáveis é formado pelas informações obtidas com a aplicação da pesquisa de campo e que foram descritas no capítulo 5. Algumas das variáveis aqui usadas precisaram ser recodificadas, em função da exigência de padronização dos dados para entrada no modelo. A seguir os conjuntos de variáveis serão brevemente descritos, com o objetivo de identificar os dados usados.

- Atributos socioeconômicos domiciliares e individuais - idade, gênero, faixa de renda, propriedade de automóvel, ocupação, nível de escolaridade.

- Dia da semana em que as atividades são realizadas - foram consideradas as atividades realizadas entre terça e quinta-feira. 
- Atributos espaço-temporais e institucionais do endereço do domicílio localização na cidade, horário de funcionamento dos estabelecimentos.

- Atributos da programação de atividades atual do indivíduo e cônjuge (se existente) - número de atividades fixas, horário de início e duração das atividades, modo de transporte usado, localização das atividades e dimensão com quem as atividades são realizadas.

- Atributos das atividades às quais a decisão tomada nessa etapa está relacionada (horário de início e duração das atividades, modo de transporte usado, localização da atividade e dimensão com quem as atividades serão realizadas).

- Atributos das escolhas alternativas (modo de transporte, atividades flexíveis etc) - modos de transporte disponíveis, localização das atividades flexíveis, tempo disponível para a realização dessas atividades.

No que se refere aos modos de transporte, o modo automóvel (como motorista) foi considerado disponível apenas para domicílios com pelo menos um automóvel, e que o indivíduo, além de possuir carteira de habilitação, usasse esse modo de transporte mais de uma vez na semana. Essa restrição da freqüência de uso do automóvel foi feita em virtude do grande número de "repúblicas" existentes na amostra. Nesse caso, o fato do domicílio possuir um automóvel e várias pessoas habilitadas a dirigir, não significa, necessariamente, que elas têm disponibilidade de uso do mesmo (restrições de capacidade).

\subsubsection{Variáveis referentes ao uso do solo}

O conjunto de variáveis de uso do solo usado precisou ser adaptado em função das informações que foram obtidas na cidade de São Carlos. No caso do modelo Albatross, são usadas as seguintes relações para a escolha da programação de atividades a ser realizada:

- Distribuição da população - determina o número de atividades sociais realizadas fora de casa;

- Distribuição do número total de empregos - determina o número de atividades de trabalho; 
- Distribuição do número de escolas para crianças - determina o número de atividades de leva/traz;

- Distribuição de empregos em estabelecimentos comerciais - determina o número de atividades de compras diárias;

- Distribuição de empregos em estabelecimentos comerciais - determina o número de atividades de compras não diárias;

- Distribuição de emprego em bancos e correios - determina o número de atividades relacionado às atividades de serviço;

- Distribuição de empregos em restaurantes e cafés - determina o número de atividades relacionadas a lazer fora de casa.

Como o banco de dados empregado nessa pesquisa não continha a maior parte das informações acima, foi admitido que todas as atividades poderiam ser realizadas em qualquer lugar da cidade. As variáveis relacionadas ao uso do solo efetivamente usadas foram as seguintes:

- Índice de entropia - mede a diversidade de tipos de uso do solo em uma área. Este índice varia entre 0 e 1, com valores próximos de 1 indicando uma maior mistura de usos do solo;

- Densidade populacional por área total e área construída;

- Densidade de empregos por área total e área construída;

- Índice de acessibilidade.

Essas variáveis foram calculadas ao nível das quadras para todas a cidade. Dessa forma foi possível alocar esses valores a todos os locais de realização de atividades e de origem e destino das viagens. O modo como essas variáveis foram quantificadas estão descritas em Amâncio (2003).

Embora esse conjunto de variáveis de uso do solo seja pequeno e não incorpore nenhuma variável diferente das usuais, vale lembrar que houve a tentativa de inclusão de outras variáveis no modelo. Entretanto, devido a algumas restrições encontradas na modificação da estrutura computacional do modelo Albatross, optou-se por usar esse conjunto de variáveis. 


\subsection{Escolha do modo de transporte para as atividades de trabalho}

A escolha do modo de transporte para a atividade de trabalho é considerada a etapa mais importante, pois determina a disponibilidade do automóvel para um indivíduo em substancial parte do tempo, principalmente em casos em que o domicílio possui apenas um automóvel e mais de uma pessoa habilitada a dirigir. Nesta etapa, assim como nas demais, a Unidade de Decisão recebe como dados de entrada para cada caso a ser analisado, uma descrição das condições encontradas pelo indivíduo e retorna a melhor escolha entre um conjunto de alternativas de possíveis respostas. A árvore de decisão determina a probabilidade de seleção de uma alternativa em cada caso.

No que se refere à escolha das variáveis que fornecerão as condições para o processo de decisão é usada uma abordagem de busca exaustiva em um determinado conjunto de escolha e o algoritmo CHAID seleciona as variáveis que são relevantes para a formação de um conjunto final de variáveis. O resultado da árvore de decisão não apenas descreve as regras de decisão usadas pelos indivíduos, mas também define a segmentação dos casos em termos socioeconômicos, por exemplo. Isso significa que as variáveis usadas descrevem os casos nos seguintes níveis: domiciliar/individual; nível de programação das atividades (ou seja, a sequiência das atividades e o tempo disponível para a sua realização); nível de encadeamento e a atividade para a qual a decisão deverá ser tomada. As informações disponíveis ao nível da programação completa das atividades são limitadas apenas à programação das atividades fornecidas pelo esqueleto, ou seja, as atividades fixas e suas dimensões.

De acordo com o conceito usado no modelo Albatross, a escolha modal geralmente está relacionada a uma série de atividades encadeadas realizadas fora de casa, e não apenas a uma única atividade a ser realizada. Uma atividade de trabalho, por exemplo, pode consistir de vários turnos, possivelmente interrompidos por um intervalo de tempo, ou por serem realizados em diferentes localizações. Assim, outras atividades como leva e traz ou compras, podem ser realizadas durante a realização dessas viagens de trabalho: antes do trabalho, no trajeto casa-trabalho ou no trajeto de volta do trabalho para casa, ou durante os intervalos. Pelo fato das decisões de encadeamento de viagem e a seleção das atividades flexíveis serem ainda desconhecidas nesta fase, é admitido que a decisão de escolha modal é feita ao nível de um episódio de trabalho simples ou uma seqüência de episódios de trabalho que estejam relacionados no tempo. 
É admitido que a escolha modal seja a decisão de mais alto nível apenas para encadeamentos de viagens de trabalho que se estendam por parte substancial do dia. São usadas 3 horas como a duração mínima entre seções de trabalho no encadeamento. Encadeamentos de trabalho com menos de 3 horas são realizados em outra fase, na qual a escolha dos modos é feita para as viagens remanescentes.

As variáveis usadas no conjunto de escolha são definidas a seguir, na Tabela 7.1.

Tabela 7.1: Descrição das variáveis usadas na primeira etapa do processo de decisão.

\begin{tabular}{|c|c|c|}
\hline Código & Descrição & Categorias \\
\hline Csec & Classe socioeconômica do domicílio & $\begin{array}{l}\text { 1: baixa, } 2 \text { e } 3 \text { : valores intermediários; } \\
\text { 4: alta }\end{array}$ \\
\hline Gênero & Gênero do indivíduo & 1:homem, 2: mulher \\
\hline Nauto & Número de automóveis & 1: $0,2:$ um ou mais \\
\hline Twork1 & $\begin{array}{l}\text { Tempo usado para a realização da } \\
\text { atividade de trabalho/escola em } \\
\text { análise (min) }\end{array}$ & $\begin{array}{l}0: 0,1: \leq 240,2: 241-360,3: 361-480,4 \\
>480\end{array}$ \\
\hline Ttot & $\begin{array}{l}\text { Tempo total usado na realização de } \\
\text { todas as atividades (min) }\end{array}$ & $\begin{array}{l}1: \leq 240,2: 241-360,3: 361-480,4: \\
>480\end{array}$ \\
\hline Two & $\begin{array}{l}\text { Tempo total gasto em todas as } \\
\text { atividades de trabalho/escola (min) }\end{array}$ & $\begin{array}{l}0: 0,1: \leq 240,2: 241-360,3: 361-480,4 \\
>480\end{array}$ \\
\hline
\end{tabular}

A Tabela 7.2 apresenta os resultados da primeira árvore de decisão gerada pelo CHAID. As primeiras linhas correspondem às variáveis que o algoritmo selecionou como as mais significativas nesta etapa e as linhas finais à probabilidade de escolha de cada modo de transporte. Como pode ser observado, a primeira subdivisão das ramificações se refere ao número de automóveis no domicílio. Na primeira ramificação (Nauto $=1$ e Csec $=1,2)$ o resultado encontrado mostra que a escolha modal varia entre os modos não motorizados e o transporte público, que juntos atingem cerca de $52 \%$. Entretanto, o valor encontrado pelo modelo, com base nos dados usados em sua alimentação, para o modo automóvel, parece não ser consistente com as variáveis avaliadas (44\%), uma vez que indica um domicílio sem automóvel e de baixa classe socioeconômica. Na segunda ramificação (Nauto $=2$ e Csec $=1,2$ ), os resultados referentes à escolha do automóvel ainda parecem não estar apropriados. De acordo com a árvore de decisão, considerando um domicílio que possua pelo menos um automóvel e de classe econômica baixa, cerca de 46 \% dos indivíduos irão optar pelo modo automóvel (como passageiro). Os resultados começam a representar de maneira mais 
adequada as escolhas individuais a partir do momento em que um conjunto maior de variáveis é avaliado. A ramificação da variável gênero $($ Gênero $=1)$ em função tanto da classe econômica $(\mathrm{Csec}=3,4)$ como do tempo usado na realização das atividades (Ttot e Two $=1,2)$ mostra que a escolha modal é de $33 \%$ para os modos não motorizados e automóvel (como) motorista e $24 \%$ para o transporte coletivo.

$\mathrm{Na}$ ramificação referente ao tempo usado para realização das atividades de trabalho (Twork1 $=4)$, considerando as características socioeconômicas $(\mathrm{Csec}=3,4)$, tempo total empregado na realização de todas as atividades (Ttot $=3$ ), as probabilidades encontradas são de 10,3\% (modos não motorizados) e 89,7\% (automóvel como motorista). Na ramificação Gênero $=2, \operatorname{com} \mathrm{Csec}=3,4$, Ttot $=4$ e Two $=1,2$, a probabilidade de uso do automóvel é de cerca de $85 \%$.

Tabela 7.2: Resultado da árvore de decisão para a escolha do modo de transporte para a atividade de trabalho.

\begin{tabular}{lcccccccccc}
\hline Variáveis & \multicolumn{10}{c}{ Ramificações geradas pela árvore de decisão } \\
\hline Csec & 1,2 & 1,2 & 3,4 & 3,4 & 3,4 & 3,4 & 3,4 & 3,4 & 3,4 & 3,4 \\
Genero & - & - & 1 & 2 & - & - & 1 & 2 & 1 & 2 \\
Nauto & 1 & 2 & - & - & - & - & - & - & - & - \\
Twork1 & - & - & - & - & $1-3$ & 4 & - & - & - & - \\
Ttot & - & - & $1-2$ & $1-2$ & 3 & 3 & 4 & 4 & - & - \\
Two & - & - & $1-2$ & $1-2$ & $1-2$ & $1-2$ & $1-2$ & $1-2$ & $3-4$ & $3-4$ \\
& & & & & & & & & & \\
\hline Modos de & & & & & Probablidades & & & & \\
transporte & & & & & & & & & & \\
\hline mnm & 0,259 & 0,146 & 0,333 & 0,476 & 0,340 & 0,103 & 0,111 & 0,091 & 0,600 & 0,600 \\
auto (m) & 0,444 & 0,195 & 0,333 & 0,238 & 0,472 & 0,897 & 0,578 & 0,848 & 0,400 & 0,100 \\
auto (p) & 0,037 & 0,463 & 0,095 & 0,286 & 0,038 & 0,000 & 0,267 & 0,061 & 0,000 & 0,200 \\
tp & 0,259 & 0,195 & 0,238 & 0,000 & 0,151 & 0,000 & 0,044 & 0,000 & 0,000 & 0,100 \\
N & 27 & 41 & 21 & 21 & 53 & 29 & 45 & 33 & 30 & 20 \\
\hline
\end{tabular}

Número de observações: 320

Número de variáveis: 32

Número mínimo de casos por coluna: 15

Alfa: 0,05

Qui-quadrado: 158,38

Teta (1 col): 151,00

Teta $(10$ col): 183,00

Conforme discutido no Capítulo 4, no que se refere aos valores estatísticos encontrados, para um valor de alfa de $0,05 \%$, a variação ocorrida no coeficiente Teta 
mostra que houve alguma melhoria no desempenho do modelo ao serem incluídas outras variáveis e ramificações serem geradas. Vale salientar que a primeira variação do coeficiente teta corresponde à medida tradicionalmente usada na análise estatística THAID e representa a soma das freqüências na categoria em análise (modo de transporte, neste caso) entre as colunas da tabela. A segunda variação desse coeficiente representa o número esperado de casos corretamente previstos se a regra probabilística é usada para gerar os resultados.

De forma geral, os resultados apontam para a predominância de escolha entre dois modos de transporte: o automóvel (motorista e passageiro) e os modos não motorizados. Apesar do resultado estar consistente com aquele verificado no Capítulo 5 (em que esses modos de transporte são predominantes), outras ramificações poderiam ter sido geradas caso o conjunto de dados usado para alimentar a árvore de decisão possuísse um maior número de dados.

\subsection{Seleção das atividades flexíveis e da dimensão com quem a atividade será realizada}

A segunda etapa do processo de tomada de decisão é destinada à seleção das atividades flexíveis a serem incluídas na programação e à especificação da dimensão com quem a atividade será realizada. $\mathrm{O}$ conjunto das atividades fixas na programação (esqueleto) é considerado dado. São consideradas as seguintes atividades flexíveis: compras diárias, serviços, compras não diárias, visitas sociais fora de casa e atividades de lazer fora de casa.

Essa etapa é modelada como uma decisão sim/não para inserção de cada atividade flexível, em procedimento seqüencial. As atividades são consideradas de acordo com uma ordem específica: compras diárias, serviços, compras não diárias, atividades de lazer e sociais. Quando a atividade é selecionada, o sistema especifica com quem ela será realizada antes de prosseguir. Após adicionar a atividade na programação, o sistema determina quando um segundo tipo da mesma atividade deve ser inserida. Esse procedimento se repete até que nenhuma outra atividade do mesmo tipo possa ser inserida. Então, o próximo tipo de atividade é considerado pelo mesmo procedimento.

A Tabela 7.3 apresenta as variáveis usadas pela árvore de decisão. Conforme pode ser observado na Tabela 7.4, a variável que mais apresentou ramificações foi o tipo de atividade a ser incluída na programação. Inicialmente foi considerada a inclusão 
de todas as atividades (TAtv $=1$ a 5) e a seguir foi feita a ramificação para as atividades 2, 3 e 4 (definidas na Tabela 7.3). Em função do pequeno conjunto de dados usado, não foi possível a realização de uma análise mais detalhada da escolha do tipo de atividade.

Tabela 7.3: Descrição das variáveis usadas na segunda etapa do processo de decisão seleção da atividade.

\begin{tabular}{|c|c|c|}
\hline Código & Descrição & Categorias \\
\hline TAtv & Tipo de atividade & $\begin{array}{l}\text { 1: compras diárias, } 2: \text { serviço, } \\
\text { 3: compras não diárias, 4: atividades } \\
\text { sociais, 5: atividades de lazer }\end{array}$ \\
\hline TTrab & $\begin{array}{l}\text { Tempo total da atividade trabalho } \\
\text { incluindo o tempo de viagem na } \\
\text { programação de atividades (min) }\end{array}$ & $\begin{array}{l}0: 0,1: \leq 260,2: 261-360,3: 361- \\
480,4:>480\end{array}$ \\
\hline Twnlo & Tempo da atividade de trabalho (min) & $\begin{array}{l}0: 0,1: \leq 260,2: 261-360,3: 361- \\
480,4:>480\end{array}$ \\
\hline ACompras & $\begin{array}{l}\text { Existe atividades de compras na } \\
\text { programação? }\end{array}$ & 0: não, 1: sim \\
\hline DispAtv & $\begin{array}{l}\text { A seleção da atividade é possível dada a } \\
\text { programação das atividades e a duração } \\
\text { mínima necessária para esse tipo de } \\
\text { atividade? }\end{array}$ & 0: não, 1: sim \\
\hline
\end{tabular}

Tabela 7.4: Resultado da árvore de decisão para a seleção da atividade flexível.

\begin{tabular}{|c|c|c|c|c|c|c|c|c|}
\hline \multirow{2}{*}{$\begin{array}{c}\text { Variáveis } \\
\text { TAtv }\end{array}$} & \multicolumn{8}{|c|}{ Resultados gerados pela árvore de decisão } \\
\hline & 1,5 & 1,5 & 1,5 & 1,5 & 1,5 & $2,3,4$ & $2,3,4$ & $2,3,4$ \\
\hline TTrab & 0 & 0 & $1-3$ & 4 & 4 & - & - & - \\
\hline Twnlo & - & - & - & - & - & 0 & $1-4$ & $1-4$ \\
\hline ACompras & 0 & 1 & - & - & - & - & - & - \\
\hline DispAtv & - & - & - & 0 & 1 & - & 0 & 1 \\
\hline Decisão & \multicolumn{8}{|c|}{ Probabilidades } \\
\hline Não & 0,400 & 0,737 & 0,777 & 1,000 & 0,848 & 0,786 & 1,000 & 0,958 \\
\hline Sim & 0,600 & 0,263 & 0,223 & 0,000 & 0,152 & 0,214 & 0,000 & 0,042 \\
\hline $\mathrm{N}$ & 45 & 57 & 373 & 36 & 243 & 103 & 126 & 711 \\
\hline
\end{tabular}

Número de observações: 1694

Número de variáveis de condição: 40

Número mínimo de casos por coluna: 30
Alfa: 0,05
Qui-quadrado: 210,03
Teta (1 col): 1480,00
Teta (8 col): 1489,00 
De acordo com a árvore de decisão, caso haja uma atividade de compras na programação (ACompras $=1$ ), a probabilidade de inclusão de qualquer outra atividade flexível é de $26 \%$. Quando o tempo empregado nas atividades de trabalho é alto (Ttrab =4) e que não existe a disponibilidade para inclusão de qualquer outra atividade $($ DispAtv $=0)$, existe $100 \%$ de probabilidade de que nenhuma outra atividade seja escolhida.

A Tabela 7.5 descreve as variáveis usadas pela árvore de decisão para a escolha da dimensão com quem a atividade será realizada.

Tabela 7.5: Descrição das variáveis usadas na segunda etapa do processo de decisão com quem.

\begin{tabular}{|c|c|c|}
\hline Código & Descrição & Categorias \\
\hline TAtiv & Tipo da atividade & $\begin{array}{l}\text { 1: compras diárias, } 2 \text { : serviço, } 3: \text { compras } \\
\text { nao diárias, 4: atividades sociais, } 5: \\
\text { atividades de lazer }\end{array}$ \\
\hline Idade & $\begin{array}{l}\text { Idade do indivíduo mais velho no } \\
\text { domicílio }\end{array}$ & $1:<25,2: 25-44,3: 45-64,4:>64$ \\
\hline Gênero & Gênero do indivíduo & 1:homem, 2: mulher \\
\hline Tmax 4 & $\begin{array}{l}\text { Máximo tempo disponível no quarto } \\
\text { intervalo de tempo no esqueleto da } \\
\text { programação (min) }\end{array}$ & $0: 0,1: 1-30,2: 31-60,3:>60$ \\
\hline DispAtv & $\begin{array}{l}\text { A seleção da atividade é possível dada } \\
\text { a programação total e a duração } \\
\text { mínima do tipo de atividade escolhida. }\end{array}$ & 0: não, 1: sim \\
\hline
\end{tabular}

Neste ponto cabe uma explicação a respeito da variável $\operatorname{Tmax}(t)$. Ela corresponde a um período de tempo específico entre as seis categorias de intervalo prédefinidas (até as 10 horas; 10-12 horas; 12-14 horas; 14-16 horas; 16-18 horas; após 18 horas). O tempo disponível dentro de cada um desses intervalos é definido em função dos intervalos dados entre o horário de funcionamento dos estabelecimentos para cada tipo de atividade, o tempo entre atividades fixas e o período de tempo $t$.

No caso da escolha do acompanhante da atividade (Tabela 7.6), existe $80 \%$ de chance das atividades de compras diárias e não diárias, atividades de serviço, compras e atividades sociais serem realizadas apenas pela pessoa ( $\operatorname{Tatv}=1,2,3$ e 4), ao serem consideradas as faixas etárias menor que 25 anos e de 45 a 64 anos de idade (Idade $=1$, 3 e 4), gênero feminino (Gênero = 2) e disponibilidade de inclusão de atividades na programação (DispAtv $=1)$. Esse valor diminui consideravelmente (para $29 \%$ ) quando a faixa etária é entre 25 e 44 anos de idade (Idade $=2$ ), para o mesmo gênero. Nesse caso a maior probabilidade é que essas atividades sejam realizadas com outras pessoas 
do domicílio. A escolha por outros membros tem cerca de $63 \%$ de chance de ocorrer ao se considerar a atividade de lazer $($ TAtv $=5$ ), sexo feminino (Gênero $=5$ ) e a disponibilidade de inclusão de atividades (DispAtv $=1)$.

Tabela 7.6: Resultado da árvore de decisão para a seleção da dimensão com quem.

\begin{tabular}{|c|c|c|c|c|c|c|}
\hline \multirow{2}{*}{$\begin{array}{l}\text { Variáveis } \\
\text { TAtv }\end{array}$} & \multicolumn{6}{|c|}{ Resultados gerados pela árvore de decisão } \\
\hline & - & - & - & $1,3,2,4$ & $1,3,2,4$ & 5 \\
\hline Idade & - & - & - & $1,3,4$ & 2 & - \\
\hline Gênero & - & - & 1 & 2 & 2 & 2 \\
\hline $\operatorname{Tmax} 4$ & $0-2$ & 3 & - & - & - & - \\
\hline DispAtv & 0 & 0 & 1 & 1 & 1 & 1 \\
\hline $\begin{array}{c}\text { Escolha "com } \\
\text { quem" }\end{array}$ & \multicolumn{6}{|c|}{ Probabilidades } \\
\hline Sozinho & 0,333 & 0,705 & 0,707 & 0,800 & 0,294 & 0,211 \\
\hline $\begin{array}{l}\text { Outros do } \\
\text { domicílio }\end{array}$ & 0,000 & 0,000 & 0,052 & 0,120 & 0,471 & 0,158 \\
\hline $\begin{array}{l}\text { Outros fora do } \\
\text { domicílio }\end{array}$ & 0,667 & 0,295 & 0,241 & 0,080 & 0,235 & 0,632 \\
\hline $\mathrm{N}$ & 51 & 44 & 58 & 25 & 17 & 19 \\
\hline
\end{tabular}

Número de observações: 214

Número de variáveis de condição: 39

Número mínimo de casos por coluna: 15

Alfa: 0,05

Teta $(1 \mathrm{col}): 118,00$

Qui-quadrado: 85,97

Teta (6 col): 146,00

\subsection{Escolha da hora do dia em que as atividades serão realizadas e decisões de encadeamento das viagens}

O modelo Albatross admite um procedimento de seleção seqüencial para completar uma determinada programação de atividades fixas com a inclusão de atividades flexíveis nessa programação. Se a decisão é de adicionar uma atividade flexível, decisões sobre com quem ela será realizada e a classe de duração da mesma é feita como descrito no item anterior. A decisão em relação à sua posição na programação é feita quando o procedimento de seleção está completo e, como consequiência, todo o programa é conhecido. Este tópico relaciona as etapas 
subseqüentes, que resultam na alocação das atividades flexíveis às posições disponíveis na programação em função do horário de início das mesmas e a escolha dos encadeamentos de viagem.

As etapas envolvem um procedimento seqüencial no qual a decisão é feita para cada atividade, na ordem em que elas são adicionadas na programação inicial. A ordem segue: compras diárias, serviços, compras não diárias, atividades sociais e de lazer. A primeira decisão se refere à escolha do período de tempo que restringe o horário de início da atividade. As alternativas de escolha são baseadas em uma subdivisão do dia nas seguintes categorias: antes das 10 horas; 10-12 horas; 12-14 horas; 14-16 horas; 16-18 horas; após 18 horas.

A disponibilidade dessas opções é determinada por restrições institucionais e temporais (horário de funcionamento dos estabelecimentos, horários de início e término das atividades fixas). Definido o intervalo de tempo, a atividade pode se encaixar em mais de uma posição; nesse caso, o sistema seleciona a posição com o menor intervalo de tempo, de modo a otimizar as condições para as próximas atividades no programa geral de atividades.

Definidos o horário de início e a posição preliminar de cada atividade flexível na programação, o sistema escolhe o tipo de viagem para cada atividade. Os tipos de viagem são definidos em termos de existência de conexão com uma atividade anterior, posterior ou ambas (conforme explicado no Capítulo 6). A ausência dessas conexões indica que a viagem inicia no domicílio e termina no domicílio (viagem com uma única parada). O modelo admite que a viagem com apenas uma parada é uma opção sempre disponível. A disponibilidade de opções de encadeamento de viagens depende da flexibilidade dos horários de início das atividades, duração mínima das atividades e o tempo de viagem estimado.

Dado o intervalo de horário de início da atividade e a decisão do tipo de viagem para cada atividade flexível, o sistema considera as implicações dessas decisões na programação como um todo. Isso envolve: (1) o reposicionamento das atividades flexíveis, se necessário, e (2) a inserção de atividades realizadas no domicílio, se necessário. Essas alterações podem ser necessárias para garantir que a programação seja consistente com o formato escolhido, em que duas atividades adjacentes fora de casa sejam conectadas, a menos que sejam separadas por uma atividade realizada em casa. Assim, após esta etapa, cada atividade é alocada a uma posição definitiva na programação e os encadeamentos podem ser identificados em qualquer seqüência de 
atividades que se iniciem e terminem em casa. A Tabela 7.7 especifica as variáveis que foram selecionadas pelo algoritmo da árvore de decisão.

Tabela 7.7: Descrição das variáveis usadas na terceira etapa do processo de decisão horário de início das atividades.

\begin{tabular}{lll}
\hline Código & \multicolumn{1}{c}{ Descrição } & \multicolumn{1}{c}{ Categorias } \\
\hline \multirow{2}{*}{ Tmax1 } & $\begin{array}{l}\text { Máximo tempo disponível no primeiro intervalo de } \\
\text { tempo no esqueleto da programação (min) }\end{array}$ & $0: 0,1: 1-30,2: 31-60,3:$ \\
& Máximo tempo disponível no quarto intervalo de & $0: 0,1: 1-30,2: 31-60,3:$ \\
\multirow{2}{*}{ maxa 4} & tempo no esqueleto da programação (min) & $>60$ \\
& Máximo tempo disponível no sexto intervalo de & $0: 0,1: 1-30,2: 31-60,3:$ \\
\multirow{2}{*}{ max6 } & tempo no esqueleto da programação (min) & $>60$ \\
\multirow{2}{*}{ AtvSoc } & Existe atividade social na programação? & $0:$ não, 1: sim \\
\multirow{2}{*}{ AtvLz } & Existe atividade de lazer na programação? & $0:$ não, 1: sim \\
\multirow{2}{*}{ Atv(t)2 } & $\begin{array}{l}\text { Existe atividade for a de casa com horário de término } \\
\text { no intervalo de tempo 10-12 horas? }\end{array}$ & $0:$ não, 1: sim \\
\hline
\end{tabular}

Cada atividade flexível constitui um caso de análise para a árvore de decisão. Por considerar a programação completa das atividades a serem realizadas em um determinado dia, as posições das atividades flexíveis ainda são desconhecias.

De acordo com a Tabela 7.8, foram incluídas na árvore de decisão apenas as atividades sociais ou de lazer (AtvSoc e AtvLz). Os resultados obtidos não permitem uma análise mais profunda em relação à dimensão horário de início da atividade. Entretanto, pode-se perceber que no caso da inclusão de uma atividade de lazer (AtvLz =1) em que exista intervalo disponível no sexto período da programação (após as 18 horas) de mais de 60 minutos (Tmax6 =3), a probabilidade de escolha desse intervalo é de $80 \%$. Já para inclusão, separadamente, das atividades sociais e de lazer (AtvSoc $=1 \mathrm{e}$ AtvLz = 1), ainda no sexto intervalo de tempo (Tmax6 = 3), a escolha do horário de início da atividade varia entre $46 \%$ de chance de escolha que uma dessas atividades se inicie entre 16 e 18 horas, e $53 \%$ de chance que ela ocorra após as 18 horas. Para a atividade social (AtvSoc $=1$ ), ao se considerar a disponibilidade de tempo no primeiro intervalo $(\operatorname{Tmax} 1=1 \mathrm{a} 3)$, a probabilidade de que seja realizada antes das 10 horas da manhã é de $45 \%$. 
Tabela 7.8: Resultado da árvore de decisão para a seleção da dimensão horário de início da atividade.

\begin{tabular}{|c|c|c|c|c|c|c|c|c|}
\hline \multirow{2}{*}{$\begin{array}{c}\text { Variáveis } \\
\text { Tmax1 }\end{array}$} & \multicolumn{8}{|c|}{ Resultados gerados pela árvore de decisão } \\
\hline & 0 & 0 & 0 & 0 & 0 & 0 & $1-3$ & $1-3$ \\
\hline Tmax4 & $0-2$ & 3 & - & - & - & - & - & - \\
\hline Tmax6 & 0 & 0 & $1-2$ & 3 & 3 & 3 & - & - \\
\hline AtvSoc & - & - & - & - & - & - & 0 & 1 \\
\hline AtvLz & - & - & - & 0 & 1 & 1 & - & - \\
\hline $\operatorname{Atv}(t) 2$ & - & - & - & - & 0 & 1 & - & - \\
\hline $\begin{array}{l}\text { Horário de } \\
\text { início }\end{array}$ & \multicolumn{8}{|c|}{ Probabilidades } \\
\hline $\begin{array}{c}\text { Antes } 10 \\
\text { horas }\end{array}$ & 0,000 & 0,000 & 0,000 & 0,000 & 0,000 & 0,000 & 0,682 & 0,450 \\
\hline $10-12$ horas & 0,194 & 0,045 & 0,000 & 0,200 & 0,000 & 0,000 & 0,091 & 0,200 \\
\hline 12-14 horas & 0,419 & 0,318 & 0,000 & 0,400 & 0,025 & 0,000 & 0,159 & 0,050 \\
\hline $14-16$ horas & 0,000 & 0,545 & 0,000 & 0,067 & 0,100 & 0,000 & 0,023 & 0,100 \\
\hline $16-18$ horas & 0,387 & 0,091 & 0,000 & 0,067 & 0,075 & 0,467 & 0,000 & 0,150 \\
\hline $\begin{array}{c}\text { Após } 18 \\
\text { horas }\end{array}$ & 0,000 & 0,000 & 1,000 & 0,267 & 0,800 & 0,533 & 0,045 & 0,050 \\
\hline $\mathrm{N}$ & 31 & 22 & 27 & 15 & 40 & 15 & 44 & 20 \\
\hline
\end{tabular}

Número de observações: 214

Número de variáveis de condição: 63

Número mínimo de casos: 15

Alfa: 0,05

Qui-quadrado: 337,55

Teta $(1 \mathrm{col}): 74,00$

Teta $(8 \mathrm{col}): 137,00$

\section{Decisões de encadeamento de viagens}

Para cada atividade na programação, este componente do sistema determina quando é possível fazer uma conexão com uma outra atividade fora de casa que seja realizada posteriormente, anteriormente ou entre ambas. A opção de parada simples em que a localização domiciliar é tanto a origem como o destino da viagem de volta é considerada disponível em todos os casos.

O processo ocorre da seguinte forma: as atividades flexíveis já existentes em cada padrão observado são eliminadas da programação atual. Em seguida, a programação é reconstruída com a adição de atividades flexíveis uma a uma, em uma ordem determinada pelo tipo de atividade a ser realizada. Se existe mais de uma atividade do mesmo tipo, elas são ordenadas cronologicamente, da que se inicia mais cedo para a que se inicia mais tarde. 
A cada vez que uma atividade flexível é inserida, o sistema define três conjuntos que englobam também as atividades na programação atual, e verifica em que posição elas podem ser conectadas: a paradas anteriores, posteriores ou entre duas atividades. Se qualquer um dos três conjuntos incluir mais de uma atividade, o caso não é considerado para maiores análises, uma vez que a árvore de decisão pode trabalhar apenas com casos que envolvam escolhas unidimensionais. É enfatizado pelos autores do modelo Albatross que a chance de haver múltiplas possibilidades de conexões entre viagens em uma mesma amostra dentro de um determinado intervalo de tempo é geralmente muito pequena, de modo que apenas uma pequena fração de casos necessitará ser excluída por essa razão. Ao adicionar uma atividade ela será inserida na posição da programação observada. Quando as outras atividades são consideradas, a atividade já inserida atua como uma candidata a estabelecer uma possível conexão de viagem, do mesmo modo que ocorre com as atividades do esqueleto. Dessa forma, as conexões de viagem podem ser consideradas também entre atividades flexíveis.

Um encadeamento de atividades é considerado possível apenas se, com base no tempo de viagem entre as localizações, existe a possibilidade de conexão entre atividades realizadas, levando em consideração o horário de início e a duração das mesmas. Dessa forma, é possível estabelecer uma ligação da atividade escolhida com a atividade realizada anterior ou posteriormente, ou no espaço de tempo disponível entre essas duas atividades (que são atividades fixas, fornecidas pela programação de atividades).

A Tabela 7.9 apresenta as variáveis usadas pela árvore de decisão na escolha dos encadeamentos de viagem e a Tabela 7.10 apresenta os resultados gerados pela árvore de decisão.

No que se refere ao encadeamento das viagens (Tabela 7.10), as ramificações da árvore são predominantes na variável Atvapos, que é subdividida em relação ao tipo de atividade a ser realizada (Tatv $=1,2$ e 3 ) e sua duração $(1,2,3$ e 4). O tipo de viagem a ser feito mantém certo equilíbrio de probabilidade de escolha (35\%, $20 \%$, $25 \%$ e $20 \%$ ) na opção em que as atividades de compras diárias e serviços (Tatv $=1,2$ ) possam ser realizadas após outra atividade (Atvapos $=1$ ). Já uma atividade de compras não diárias (Tatv $=3$ ) que pode ser realizada após outra já inserida na programação $($ Atvapos $=1)$ e que tenha duração média (Datv $=2,3$ ), tem a chance de $78 \%$ de ser realizada com uma viagem de parada simples. Ou seja, essa atividade não será encadeada a nenhuma outra, e a viagem terá como base o domicílio. No caso de existir 
algum tipo de atividade que envolva lazer $(\operatorname{AtvLz}=1)$, a probabilidade de inclusão de uma atividade de compras não diárias $($ Tatv $=3)$ de duração longa $($ Datv $=4)$ depois de uma atividade fixa na programação é de $47 \%$ e de $53 \%$ que seja realizada com uma viagem de parada simples.

Tabela 7.9: Descrição das variáveis usadas na terceira etapa do processo de decisão encadeamento de viagens.

\begin{tabular}{|c|c|c|}
\hline Código & Descrição & Categorias \\
\hline Atvant & $\begin{array}{l}\text { A atividade pode ser realizada } \\
\text { antes de outra }\end{array}$ & 0: não; 1: sim \\
\hline Atvapos & $\begin{array}{l}\text { A atividade pode ser realizada } \\
\text { após outra }\end{array}$ & 0: não; 1: sim \\
\hline TAtiv & Tipo de atividade & $\begin{array}{l}\text { 1: compras diárias, 2: serviço, 3: compras não } \\
\text { diárias, 4: atividades sociais, 5: atividades de } \\
\text { lazer }\end{array}$ \\
\hline DAtiv & Duração da atividade (min) & $0: 0,1: \leq 260,2: 261-360,3: 361-480,4:>480$ \\
\hline AtvLz & $\begin{array}{l}\text { Existe atividade de lazer na } \\
\text { programação }\end{array}$ & $0:$ não; $1: \operatorname{sim}$ \\
\hline
\end{tabular}

Tabela 7.10: Resultado da árvore de decisão para a seleção da dimensão encadeamento de viagem.

\begin{tabular}{|c|c|c|c|c|c|c|c|}
\hline \multirow{2}{*}{$\begin{array}{c}\text { Variáveis } \\
\text { Atvant }\end{array}$} & \multicolumn{7}{|c|}{ Resultados gerados pela árvore de decisão } \\
\hline & 0 & 1 & - & - & - & - & - \\
\hline Atvapos & 0 & 0 & 1 & 1 & 1 & 1 & 1 \\
\hline TAtv & 0 & 0 & 1,2 & 3 & 3 & 3 & 3 \\
\hline DAtv & - & - & - & 1 & $2-3$ & 4 & 4 \\
\hline AtvLZ & - & - & - & - & - & 0 & 1 \\
\hline Encadeamento & \multicolumn{7}{|c|}{ Probabilidades } \\
\hline Antes Atv & 0,000 & 0,240 & 0,350 & 0,100 & 0,000 & 0,000 & 0,000 \\
\hline $\begin{array}{c}\text { Depois Atv } \\
\text { Entre Atv }\end{array}$ & $\begin{array}{l}0,000 \\
0,000\end{array}$ & $\begin{array}{l}0,000 \\
0,000\end{array}$ & $\begin{array}{l}0,200 \\
0,250\end{array}$ & $\begin{array}{l}0,650 \\
0,000\end{array}$ & $\begin{array}{l}0,222 \\
0,000\end{array}$ & $\begin{array}{l}0,840 \\
0,080\end{array}$ & $\begin{array}{l}0,467 \\
0,000\end{array}$ \\
\hline Parada simples & 1,000 & 0,760 & 0,200 & 0,250 & 0,778 & 0,080 & 0,533 \\
\hline $\mathrm{N}$ & 52 & 25 & 20 & 20 & 18 & 25 & 15 \\
\hline
\end{tabular}

Número de observações: 175

Número de variáveis de condição: 53

Número mínimo de casos: 15

Alfa: 0,05

Qui-quadrado: 159,86

Teta (1 col): 104,00

Teta (7 col): 134,00 


\subsection{Escolha do modo de transporte para cada encadeamento de viagem e da localização de realização da atividade}

Neste item são retratadas as últimas decisões de escolha que devem ser modeladas. Como visto anteriormente, o modo de transporte usado para a atividade de trabalho é escolhido na primeira etapa da programação e as localizações das atividades fixas são consideradas conhecidas..

Nesta fase, as decisões de escolha do modo de transporte são feitas ao nível de encadeamento de viagem. São consideradas as opções automóvel (como motorista), automóvel (como passageiro), transporte público e modos não motorizados. Em casos em que haja múltiplas atividades realizadas em diferentes localizações, o encadeamento terá como base as diferentes localizações. Essa versão do modelo admite que os indivíduos não alteram o modo de transporte nas viagens em um mesmo encadeamento, o que reflete a limitação de possibilidades de mudança de modos. Essa hipótese foi adotada em função da amostra usada pelos autores do modelo, em que apenas 4,4\% dos encadeamentos no banco de dados envolviam múltiplos modos de transporte.

As decisões são feitas com base em regras determinísticas para identificar o principal modo de transporte, e considera esse modo como o principal a ser usado em toda a viagem. As decisões são feitas na ordem em que elas aparecem na programação. As características do uso do solo, horário de funcionamento e tempo de viagem são usados para determinar a disponibilidade e relativa velocidade dos modos de transporte.

Após determinar o modo de transporte para cada encadeamento, as decisões em relação à localização das atividades flexível são feitas seqüencialmente. O conjunto de escolha das localizações é definido como sendo aquelas que podem ser alcançadas dadas as restrições temporais para a realização da atividade: aquelas que limitam a duração de realização da atividade, a disponibilidade da atividade, horário de funcionamento dos estabelecimentos e velocidade de viagem. As atividades sociais são uma exceção, já que essas atividades não são dependentes das instituições públicas. Assim, todas as localizações que podem ser alcançadas são consideradas possíveis. As heurísticas que os indivíduos podem usar são pré-definidas e representadas de diferentes maneiras. Como as heurísticas usadas podem não representar todas as possíveis localizações em que as atividades possam ser realizadas, uma segunda árvore de decisão é elaborada caso a opção "outros" seja selecionada. A segunda árvore então, seleciona um intervalo de tempo de viagem no qual a atividade pode ser realizada. Se existe mais 
de uma localização possível para a realização da atividade "outros" dentro desse mesmo intervalo, o modelo seleciona a localização aleatoriamente.

A escolha da localização de realização da atividade é feita em duas partes, sempre considerando o tempo de viagem necessário para se vencer a separação espacial entre duas localizações: $\mathrm{Na}$ primeira delas, os tempos de viagem calculados são considerados com base nas viagens originadas no domicílio. Já na segunda parte, os tempos de viagem são estimados a partir de viagens encadeadas, ou seja, sem base domiciliar.

Como resultado das etapas anteriores, a programação das atividades já está parcialmente completa, com as seguintes informações: seleção das atividades flexíveis, sua posição na programação, com quem elas serão realizadas, sua duração e o horário de início. Para as atividades flexíveis o horário de início e a duração são especificados em intervalos de tempo, e não como um valor exato. O horário de início e a duração das atividades de compras e de serviços são restringidos pelo horário de funcionamento dos estabelecimentos. Como o local de realização dessas atividades ainda é desconhecido, o tempo máximo de funcionamento dos estabelecimentos onde o domicílio está localizado é usado como uma medida restritiva. Para as atividades sociais não existem restrições temporais, uma vez que estas não precisam ser, necessariamente, realizadas em estabelecimentos públicos. A existência de um intervalo relativamente amplo para início das atividades permite maior liberdade de escolha para o modo de transporte e a localização.

Na Tabela 7.11 são descritas as variáveis consideradas pela árvore de decisão e na Tabela 7.12 os resultados gerados pelo modelo.

Tabela 7.11: Descrição das variáveis usadas na quarta etapa do processo de decisão modo de transporte para o encadeamento de viagem.

\begin{tabular}{cll}
\hline Código & \multicolumn{1}{c}{ Descrição } & \multicolumn{1}{c}{ Categoria } \\
\hline Com quem & $\begin{array}{l}\text { Acompanhamento na primeira } \\
\text { atividade da programação }\end{array}$ & $\begin{array}{l}\text { 0: ninguém, 1: outros de dentro do } \\
\text { domicílio, 2: outros de fora do domicílio }\end{array}$ \\
AtvCompras & $\begin{array}{l}\text { Atividades de compras como parte } \\
\text { do encadeamento }\end{array}$ & 0: não, 1: sim \\
\hline
\end{tabular}


Tabela 7.12: Resultado da árvore de decisão para a seleção da dimensão escolha do modo de transporte para o encadeamento de viagem.

\begin{tabular}{lcccc}
\hline \multicolumn{1}{c}{ Variáveis } & \multicolumn{5}{c}{ Resultados gerados pela árvore de decisão } \\
\hline Com quem & 0 & 0 & 1 & 2 \\
ACompras & 0 & 1 & - & - \\
& \multicolumn{5}{c}{ Probabilidades } \\
\hline Modos de Transporte & 0,406 & 0,700 & 0,148 & 0,403 \\
\hline Modos não motorizados & 0,536 & 0,267 & 0,667 & 0,373 \\
Automóvel (m) & 0,029 & 0,000 & 0,000 & 0,015 \\
Transporte público & 0,029 & 0,033 & 0,185 & 0,209 \\
Automóvel (p) & 69 & 30 & 27 & 67 \\
$\mathrm{~N}$ & & & & 6 \\
\hline
\end{tabular}

Número de observações: 193

Número de variáveis de condição: 35

Número mínimo de casos: 15

Alfa: $0,05 \quad$ Qui-quadrado: 31,80

Teta $(1 \mathrm{col}): 88,00 \quad$ Teta $(4 \mathrm{col}): 103,00$

Como pode ser verificado na Tabela 7.12, a árvore de decisão gerada inclui apenas duas variáveis, sem que ocorra nenhuma interação entre elas. Dessa forma, o resultado observado não deve ser considerado como uma probabilidade de escolha real. Por exemplo, no caso de uma viagem encadeada para a realização da atividade de compras (ACompras $=1$ ), de acordo com a árvore de decisão existe cerca de $70 \%$ de chance do indivíduo escolher os modos não motorizados para a realização dessa viagem. Provavelmente esse resultado seria diferente caso houvesse a inclusão de qualquer outro tipo de variável a esse conjunto de escolhas. Outro resultado mostra que a probabilidade de escolha do automóvel é de $66,7 \%$ caso a viagen seja realizada apenas pelo indivíduo (com quem $=1$ ).

\section{Escolha da localização - parte 1}

Quando a escolha do local de realização da atividade flexível é feita, todas as outras dimensões da atividade já são conhecidas: sua posição na programação, com quem ela será realizada, seu horário de inicio e sua duração, o tipo de encadeamento de 
viagem, o modo de transporte usado e a localização das atividades fixas. O procedimento usado para identificar a escolha em cada caso inclui as seguintes etapas:

- Definição do conjunto de escolha (possíveis locais de realização das atividades);

- Se a localização observada não está incluída no conjunto de escolhas, então essa localização é adicionada ao conjunto;

- Classificação da localização observada de acordo com faixas de tempo extra de viagem.

Nesse último caso, o sistema funciona do seguinte modo. Inicialmente é considerada a localização mais próxima ao domicílio em que a atividade selecionada possa ser realizada. Caso esse local não possa ser considerado no conjunto de escolhas (devido a algum tipo de restrição), o sistema busca a localização mais próxima em função do tempo extra de viagem necessário, a partir do primeiro local escolhido. Nesse caso, as faixas extras de tempo viagem variam de 5 a 30 minutos. Esse mecanismo será usado nas decisões que envolvam a escolha da localização da atividade.

Assim, o conjunto de escolhas compreende todas as localizações que podem ser alcançadas considerando-se a posição da atividade na programação, a velocidade de viagem (de acordo com o modo de transporte escolhido), a disponibilidade das facilidades na localização, o horário de funcionamento dos estabelecimentos e a duração mínima da atividade. As heurísticas de escolha usam como critério de decisão, neste caso,o tempo de viagem necessário para conectar um lugar a outro e a ordem da localização. A ordem da localização varia conforme as faixas de tempo extra de viagem, que são necessários para se chegar ao local de realização da atividade. Os valores do tempo de viagem são extraídos de uma matriz , que contém os valores tanto com base na localização do domicilio ou no encadeamento completo das viagens (que, nesse último caso, será usado na segunda escolha da localização).

A Tabela 7.13 lista as variáveis incluídas no processo de escolha da localização. 
Tabela 7.13: Descrição das variáveis usadas na quarta etapa do processo de decisão escolha da localização - parte 1 .

\begin{tabular}{|c|c|c|}
\hline Código & Descrição & Categoria \\
\hline Atv ND & $\begin{array}{l}\text { Número de atividades realizadas fora do domicílio no } \\
\text { encadeamento em análise }\end{array}$ & $1: 1,2: 2,3:>2$ \\
\hline $\operatorname{DAtv}(1)$ & $\begin{array}{l}\text { A seleção da atividade é possível, considerando a programação } \\
\text { das atividades fixas e a duração mínima do tipo de atividade } \\
\text { em análise? }\end{array}$ & $0:$ não; $1: \operatorname{sim}$ \\
\hline $\operatorname{Datv}(2)$ & $\begin{array}{l}\text { A classe da duração é adequada, considerando as atividades } \\
\text { fixas e sua a duração? }\end{array}$ & 0: não; 1: sim \\
\hline LocDom & $\begin{array}{l}\text { Existe a possibilidade de uma ocalização próxima ao } \\
\text { domicílio? }\end{array}$ & 0: não; 1: sim \\
\hline LocEnc & $\begin{array}{l}\text { A localização mais próxima está no contexto de um } \\
\text { encadeamento de viagem? }\end{array}$ & 0: não; 1: sim \\
\hline Loc5 & A localização esta dentro de 5 minutos extras de viagem? & 0: não; 1: sim \\
\hline Loc10 & A localização esta dentro de 10 minutos extras de viagem? & 0: não; 1: sim \\
\hline Loc20 & A localização esta dentro de 20 minutos extras de viagem? & 0: não; 1: sim \\
\hline Locmax & $\begin{array}{l}\text { A localização esta dentro de mais de } 20 \text { minutos extras de } \\
\text { viagem? }\end{array}$ & $0:$ não; 1: sim \\
\hline Outra & A localização está fora das faixas acima? & 0: não; 1: sim \\
\hline
\end{tabular}

De acordo com os resultados da Tabela 7.14, quando existem mais de duas atividades a serem realizadas no encadeamento de viagem (AtvND $=2,3$ ), existe cerca de $95 \%$ de chance que sejam escolhidos locais próximos ao domicílio. Quando existe disponibilidade de tempo tanto na programação das atividades (DispAtv $(1)=1)$ como no intervalo de tempo em que a atividade está inserida $(\operatorname{DispAtv}(2)=1)$ é grande a probabilidade de escolha de uma localização que esteja fora do limite de 20 minutos extras de viagem $(90 \%)$. 
Tabela 7.14: Resultado da árvore de decisão para a seleção da dimensão escolha da localização - parte 1 .

\begin{tabular}{lcccc}
\hline Variáveis & \multicolumn{4}{c}{ Resultados gerados pela árvore de decisão } \\
\hline Atv ND & 1 & 2,3 & - & - \\
DispAtv (1) & 0 & 0 & 1 & 1 \\
DispAtv(2) & - & - & 0 & 1 \\
& \multicolumn{5}{c}{ Probabilidades } \\
\hline Localização & 0,200 & 0,949 & 0,007 & 0,050 \\
\hline LocDom & 0,000 & 0,000 & 0,000 & 0,050 \\
LocEnc & 0,000 & 0,000 & 0,000 & 0,000 \\
Loc5 & 0,000 & 0,000 & 0,000 & 0,000 \\
Loc10 & 0,000 & 0,000 & 0,000 & 0,000 \\
Loc20 & 0,050 & 0,000 & 0,000 & 0,000 \\
Locmax & 0,750 & 0,051 & 0,993 & 0,900 \\
Outra & 20 & 39 & 134 & 20 \\
N & & &
\end{tabular}

Número de observações: 213

Número de variáveis de condição: 28

Número mínimo de casos: 15

Alfa: 0,05

Qui-quadrado: 188,73

Teta $(1 \mathrm{col}): 168,00$

Teta (4 col): 203,00

\section{Escolha da localização - parte 2}

Considerando agora um conjunto de escolhas mais reduzido, por levar em conta as localizações que se encontram na categoria "outras", a árvore de decisão seleciona aqui a faixa de tempo de viagem em que estão as possíveis localizações, em nível de viagens encadeadas. O procedimento é o mesmo anterior, em que os limites da viagem são definidos em termos de tempo extra de viagem, mas agora em relação ao menor tempo de viagem entre as localizações do conjunto de escolha. Os mesmos intervalos de tempo extra de viagem e classificações foram usados. Na Tabela 7.15 estao descritas as variáveis incluídas na árvore de decisão. 
Tabela 7.15: Descrição das variáveis usadas na quarta etapa do processo de decisão escolha da localização - parte 2 .

\begin{tabular}{|c|c|c|}
\hline Código & Descrição & Categoria \\
\hline Modo & Modo de transporte & $\begin{array}{l}\text { 1:automóvel (como motorista ou } \\
\text { passageiro), 2: modos não } \\
\text { motorizados , 3: transporte público }\end{array}$ \\
\hline AtvND & $\begin{array}{l}\text { Número de atividades for a de casa no } \\
\text { encadeamento considerado }\end{array}$ & $1: 1,2: 2,3:>2$ \\
\hline Tnltot & $\begin{array}{l}\text { Tempo total da atividade trabalho na } \\
\text { programação }\end{array}$ & $\begin{array}{l}0: 0,1: \leq 260,2: 261-360,3: \\
361-480,4:>480\end{array}$ \\
\hline $\operatorname{DispAtv}(5)$ & $\begin{array}{l}\text { A classe de duração mais longa (dada a } \\
\text { programação de atividades e a duração } \\
\text { mínima da atividade) está disponível? }\end{array}$ & 0: não; 1: sim \\
\hline Loc5 & $\begin{array}{l}\text { A localização está dentro de de } 5 \\
\text { minutos extras de viagem? }\end{array}$ & 0: não; 1: sim \\
\hline Loc 10 & $\begin{array}{l}\text { A localização está dentro de de } 10 \\
\text { minutos extras de viagem? }\end{array}$ & 0: não; 1: sim \\
\hline Loc 20 & $\begin{array}{l}\text { A localização está ddentro de } 20 \\
\text { minutos extras de viagem? }\end{array}$ & 0: não; 1: sim \\
\hline Loc30 & $\begin{array}{l}\text { A localização está dentro de } 30 \text { minutos } \\
\text { extras de viagem? }\end{array}$ & 0: não; 1: sim \\
\hline OutraArea & $\begin{array}{l}\text { Existem outras localizações disponíveis } \\
\text { dentro da área de estudo? }\end{array}$ & 0: não; 1: sim \\
\hline OutraNArea & $\begin{array}{l}\text { Existem outras localizações disponíveis } \\
\text { fora da área de estudo? }\end{array}$ & 0: não; 1: sim \\
\hline
\end{tabular}

Na última árvore de decisão (Tabela 7.15) gerada as ramificações foram feitas primeiramente no modo de transporte escolhido (Modo = 1, 2 e 3), seguido pelo número de atividades fora de casa realizadas no encadeamento (AtvND = 1, 2 e 3). Verifica-se que, independente do modo de transporte escolhido (Modo $=1,3$ ) e mesmo que haja apenas 1 atividade a ser realizada (AtvND $=1$ ), caso a classe de longa duração da atividade não esteja disponível (DispAtv5 =0), a chance de escolha de um local que esteja a cerca de 10 minutos de viagem no encadeamento é de 56 . Um dado curioso é o fato de, caso os modos de transporte escolhidos sejam os não motorizados (Modo $=2$ ) e exista uma atividade a ser realizada (AtvND =1), existe cerca de $43 \%$ de chance de escolha da localização em uma faixa de até 20 minutos extras de viagem. Freqüentemente espera-se que, quando os modos não motorizados são escolhidos, os locais de realização das atividades sejam próximos ao domicílio. Quando o número de atividades a serem realizadas aumenta $(A t v N D=2,3)$, existe certo equilíbrio na escolha da localização, variando de $37 \%$ para locais em uma faixa de até 5 minutos extras de viagem a $21 \%$ de escolha por locais que estejam em até 30 minutos extras de viagem. Ainda considerando mais de duas atividades no encadeamento, quando incluída a 
variável tempo total de atividade trabalho na programação de atividades (Tnltot = 1 a 4), a preferência é pelos locais mais próximos (cerca de $68 \%$ ), que estejam em até 5 minutos extras de viagem.

Tabela 7.16: Resultado da árvore de decisão para a seleção da dimensão escolha da localização (2).

\begin{tabular}{lccccc}
\hline \multicolumn{1}{c}{ Variáveis } & \multicolumn{5}{c}{ Resultados gerados pela árvore de decisão } \\
\hline Modo & 1,3 & 2 & - & - & - \\
AtvND & 1 & 1 & $2-3$ & $2-3$ & - \\
Tnltot & - & - & 0 & $1-4$ & - \\
DispAtv5 & 0 & 0 & 0 & 0 & 1 \\
& \multicolumn{5}{c}{ Probabilidades } \\
\hline Localização & 0,154 & 0,095 & 0,368 & 0,684 & 0,188 \\
\hline Loc5 & 0,564 & 0,190 & 0,158 & 0,228 & 0,156 \\
Loc10 & 0,256 & 0,429 & 0,263 & 0,070 & 0,250 \\
Loc20 & 0,026 & 0,286 & 0,211 & 0,018 & 0,125 \\
Loc30 & 0,000 & 0,000 & 0,000 & 0,000 & 0,281 \\
OutraArea & 0,000 & 0,000 & 0,000 & 0,000 & 0,000 \\
OutraNArea & 39 & 21 & 19 & 57 & 32 \\
$\mathrm{~N}$ & & \multicolumn{5}{c}{} \\
\hline
\end{tabular}

Número de observações: 168

Número de variáveis de condição: 28

Número mínimo de casos: 15

Alfa: 0,05

Qui-quadrado: 108,92

Teta ( 1 col): 60,00

Teta (5 col): 86,00 


\subsection{Considerações Finais}

Neste capítulo foram apresentados os resultados obtidos com aplicação do algoritmo CHAID para obtenção das árvores de decisão nas etapas de escolha do modelo Albatross.

Com auxílio do algoritmo, algumas heurísticas de decisão foram usadas (estas próprias do algoritmo) para simular a probabilidade de escolha dentro um conjunto possível de alternativas nas etapas importantes ao modelo. $\mathrm{O}$ algoritmo foi alimentado com um banco de dados contendo informações sobre as atividades realizadas (todas as suas dimensões incluindo as viagens necessárias) e as informações relativas às características do uso do solo.

As variáveis mais significativas foram selecionadas pelo próprio algoritmo, de modo que pudessem representar as escolhas individuais. Algumas das árvores de decisão delas produziram os resultados esperados ou coerentes, enquanto que outras previsões apresentaram resultados não confiáveis.

Entre as variáveis que mais se destacam podemos destacar entre as variáveis socioeconômicas a posse do automóvel, que indica que existe grande probabilidade de uso desse modo quando este está disponível. Outro resultado esperado é que quanto maior a faixa de renda do domicílio maior a probabilidade de uso do automóvel, seja como motorista ou passageiro. No que se refere à escolha das variáveis flexíveis, as variáveis que se destacam é o tipo de atividade a ser escolhida e o tempo usado nas atividades de trabalho (atividade principal).

A seleção do horário de início das atividades não apresenta grandes informações, mostrando que as atividades flexíveis geralmente são realizadas antes ou após as atividades principais de trabalho ou estudo. Quanto à escolha da localização da atividade, os resultados mostram que quando existe mais de uma atividade a ser realizada, a preferência de escolha é por locais próximos ao domicílio. Entretanto, quando o indivíduo dispõe de tempo tanto para a realização da atividade quanto para a viagem, as chances de escolher um lugar mais distante são maiores.

Um fator que chama atenção é o não aparecimento das variáveis de uso do solo incluídas no banco de dados. Esse fato acaba por impedir que a análise inicialmente proposta nesta pesquisa seja feita, mas não exclui a probabilidade que estas variáveis possam realmente ter alguma influência, mesmo que indireta, sobre as escolhas individuais. Por exemplo, ao se considerar a localização das atividades (parte 1), 
verifica-se que existe grande chance dos indivíduos escolherem locais que estejam mais próximos ao local do domicílio para a realização de outras atividades.

A validação do modelo não foi possível pela falta de dados. Inicialmente cogitou-se a criação de população sintética, mas a falta de um banco de dados mais amplo que servisse de base para a técnica impossibilitou que esse artifício fosse usado neste trabalho.

No capítulo a seguir serão descritas as principais conclusões deste trabalho, com sugestões de melhorias e de outras pesquisas que podem ser realizadas com base nos resultados aqui encontrados. 


\section{CONCLUSÕES}

O objetivo principal inicialmente proposto para esta pesquisa foi, a partir da aplicação de um modelo baseado em atividades, avaliar como as variáveis de uso do solo afetam o comportamento de realização de atividades individuais,. O tema, que une dois tópicos que vêm sendo estudados por vários grupos de pesquisadores em todo o mundo, foi escolhido essencialmente por dois motivos. O primeiro foi o interesse mútuo da aluna e de seu orientador em investigar a nova metodologia de análise de demanda por transportes, surgida na década de 70, mas que só a partir da década de 90 foi apontada como sendo uma metodologia promissora na área de transportes. O segundo motivo foi a possibilidade de que esta pesquisa pudesse ser realizada com o apoio de um dos mais importantes grupos de pesquisa da área de transportes do mundo, da Universidade de Eindhoven, Holanda, dirigido pelo professor Harry Timmermans. A delimitação do objeto de estudo - características do uso do solo - surgiu a parir do interesse dos dois grupos de pesquisa das universidades envolvidas, em lidar com o tema, que também é amplamente investigado nos dias de hoje.

A parceria com a Universidade de Eindhoven foi fundamental para o desenvolvimento desta tese. Primeiro, pelo fato de no Brasil o assunto ainda ser pouco explorado, existia a necessidade do aprendizado sobre o modo de funcionamento dos modelos de atividades (sua estrutura, seus fundamentos teóricos, dados necessários entre outras). Segundo, o desenvolvimento de um modelo de atividades requer a integração de um grupo de pessoas de áreas afins, trabalhando conjuntamente, de modo que os vários aspectos teóricos e estruturais que envolvem esses modelos possam ser devidamente cobertos. Dessa forma, o auxílio desses pesquisadores foi, em grande 
medida, fundamental à realização desta pesquisa. Terceiro, a experiência que pôde ser obtida no trabalho com o grupo de Eindhoven, permitiu tanto à aluna como ao orientador desta tese um maior nível de aprofundamento no tema, no que envolve, principalmente, os aspectos estruturais necessários ao desenvolvimento de um modelo de atividades. Isto permitirá, futuramente, que estes possam se empenhar em desenvolver outras pesquisa na área.

A tentativa de se investigar as relações entre características do uso do solo e comportamento de viagem a partir de um modelo de atividades levantou a hipótese de que é possível demonstrar, com o uso de modelos de demanda mais sofisticados, uma relação que até hoje não conseguiu ser evidenciada plenamente pelos modelos matemáticos. Esse tópico, que já foi e continua sendo exaustivamente investigado, ainda é foco de atenção de pesquisadores em várias partes do mundo.

Após a decisão de utilizar o modelo Albatross, a próxima etapa foi coletar os dados necessários à sua calibração. A metodologia mais indicada, nesse caso, é a aplicação de diários de atividades (Capítulo 5). Essa metodologia não foi de fácil aplicação, exigindo grande esforço para que os dados pudessem ser coletados. Efetivamente, os diários de atividades são mais complexos que os diários tradicionais, por serem necessárias várias informações sobre as atividades realizadas. Por esse motivo, muitos entrevistados reagem de forma negativa ao seu preenchimento, o que leva a baixas taxas de respostas. Entretanto, quando esses diários são válidos, isto é, são preenchidos de forma correta, as informações por ele fornecidas são mais completas e mais detalhadas do que aquelas obtidas através dos métodos tradicionais. Algumas considerações podem agora ser feitas com base na experiência adquirida na aplicação dessa metodologia de coleta de dados para esta pesquisa.

Um dos aspectos dos modelos de atividades é verificar o padrão de atividades individual ao longo de vários dias da semana, as vezes até mesmo durante o final de semana. Entretanto, verificou-se aqui que o entrevistado muitas vezes se sente desestimulado a preencher dois dias consecutivos do diário, o que causa baixo nível de respostas. Muitas vezes é preenchido o primeiro dia de forma correta, mas o segundo dia é deixado em branco ou preenchido com informações incompletas. Uma das alternativas usadas na Holanda e em outros países é o oferecimento de gratificações aos participantes. Uma sugestão a ser feita aqui é que, em trabalhos futuros, seja feito o 
primeiro contato com o entrevistado por telefone e que, somente após o consentimento deste, seja entregue o diário em visita domiciliar. Também é interessante que o pesquisador entre em contato com o entrevistado durante o período de preenchimento do diário, tanto para tirar dúvidas como para reforçar a idéia de preenchimento e participação na pesquisa. Mesmo quando o entrevistado não se dispõe a participar na pesquisa, deve-se tentar obter o maior número de informações domiciliares. Dessa forma é possível a caracterização do grupo de pessoas não participantes.

Os custos monetários associados não foram excessivos, o que viabiliza a realização deste tipo de coleta de dados inclusive em cidades de médio porte. Entretanto, o tempo necessário à realização da pesquisa é em geral longo, embora varie em função do tamanho da amostra e do tamanho da cidade em que a pesquisa será realizada.

A estrutura do diário usado nesta pesquisa ainda precisa ser melhorada, principalmente no que se refere à parte destinada às informações sobre viagens por transporte público, que foi a que gerou maior número de dúvidas por parte dos respondentes. A parte referente aos atributos das atividades também precisa ser revista, pois algumas informações acabaram sendo desconsideradas. No caso da freqüência das atividades, o diário falhou em não reconhecer que algumas atividades poderiam ser realizadas apenas uma vez por mês. Neste caso, os entrevistados foram instruídos a, sempre que houvesse necessidade, relatar a freqüência de realização da atividade.

Outro aspecto que precisa ser salientado diz respeito à terminologia usada nos diários. Os termos devem ser simples, e as questões ordenadas de forma coerente, de forma a deixar o diário o mais didático possível e fácil de ser preenchido. Mesmo após várias alterações na estrutura do diário usado nesta pesquisa, muitos entrevistados reclamaram do seu tamanho e da quantidade de informações que deveriam ser reportadas, o que significa que ainda deve ser dedicado um certo cuidado a estes aspectos em novas pesquisas.

Outra sugestão aos investigadores que decidam no futuro usar a modelagem baseada em atividades é a coleta das atividades realizadas dentro do domicílio. Essas informações são úteis principalmente para o dimensionamento do tempo que poderá ser usado na realização de outras atividades, bem como para verificar a substituição de 
atividades que necessitem ser realizadas fora de casa (e que trazem a necessidade de viagens) e que estão sendo realizadas em casa (teletrabalho, por exemplo).

Com os dados referentes às atividades e viagens coletados, o próximo passo foi a obtenção dos dados relativos ao uso do solo na cidade. O banco de dados com essas informações foi elaborado na Universidade Federal de São Carlos, e disponibilizado para o desenvolvimento desta tese. O banco de dados é composto por várias informações do uso do solo em nível de quadras, o que se adapta à unidade de análise avaliada no modelo: análise desagregada em nível individual.

Durante a segunda etapa do doutorado sanduíche, também realizado na Universidade de Eindhoven, os dados coletados foram padronizados no formato exigido pelo modelo. Foram feitas algumas análises exploratórias (Capítulo 5) e a seguir esses dados foram usados na alimentação do modelo Albatross, que gerou alguns resultados para as análises principais (Capítulos 6 e 7).

As análises realizadas no Capítulo 5 mostram, de forma geral, o comportamento de realização de atividades e viagens dos indivíduos. Um dos fatores que chama atenção é o alto número de estudantes na amostra. Isto, por um lado, prejudica a análise do comportamento da população como um todo. Mas esse fato já era esperado, tanto pela cidade de São Carlos possuir duas universidades e outras faculdades, como por esse segmento da população ser o que mais se disponibiliza a participar em pesquisas desta natureza. Embora São Carlos seja uma cidade em que os locais de realização de atividades estejam próximos, grande parte das viagens foi realizada por automóvel, mesmo para distâncias consideravelmente curtas. Por exemplo, no caso das viagens realizadas por automóvel em distâncias de até 500 metros, convém considerar a possibilidade dessa viagem ter sido para levar crianças à escola ou ir ao supermercado para compras do mês. O segundo modo de transporte mais usado foi o modo a pé. Outro fator importante é o encadeamento das viagens para realização das atividades. Essas análises devem considerar não apenas o modo de transporte envolvido, mas um conjunto de restrições espaciais, temporais e institucionais.

É importante salientar que as informações descritas acima infelizmente não caracterizam adequadamente a população da cidade de São Carlos, nem em termos de sua distribuição geográfica, nem de sua faixa etária, entre outros aspectos. É possível 
verificar que a maior parte das informações obtidas até então está relacionada a um grupo particular da população, ou seja, a uma determinada faixa etária ou nível de educação. Isto se deve parcialmente a uma das dificuldades encontradas pelos pesquisadores, que foi a recusa de um grande número de pessoas em participarem da pesquisa. Muitas alegavam falta de tempo, o fato de ser um material complexo, ou simplesmente por não estarem interessadas. Em muitas ocasiões as pessoas ficaram inicialmente com o material, mas o devolveram posteriormente em branco, afirmando que não haviam entendido ou era longo demais.

As análises mais complexas sobre o comportamento de viagem e realização de atividades dos indivíduos foram realizadas com o auxílio do modelo Albatross, na qual era esperado que os resultados gerados fossem capazes de atender ao objetivo principal deste trabalho. Entretanto, os resultados gerados pelas árvores de decisão do modelo não foram suficientes para fornecer evidências de que as características de uso do solo atuam de forma significativa no processo de tomada de decisão individual sobre quais atividades. Aliás, como se pôde perceber no Capítulo 7, essas variáveis nem sequer apareceram nas ramificações das árvores de decisão. Infelizmente, e muito provavelmente em decorrência do limitado conjunto de dados que foi usado para a calibração do modelo, essas variáveis não foram significativas a ponto de exercer qualquer influência sobre as decisões. Isso não significa que a inter-relação entre variáveis de uso do solo e comportamento de viagem não exista. O que ocorre é que, como os modelos baseados em atividades necessitam de uma grande quantidade de dados para geração e previsão de resultados, os dados aqui utilizados não foram suficientes para obtenção de resultados práticos. Outro fator que, embora menos relevante deve ser também ressaltado, é que o modelo Albatross é um modelo de análise de demanda de viagens, não um modelo integrado de transportes e suo do solo. Assim, sua estrutura não envolve, diretamente, um conjunto amplo de variáveis relacionadas ao uso do solo.

Com base nos resultados gerados pelas árvores de decisão, verificou-se mais uma vez que os modos de transporte predominantes nas escolhas individuais são o automóvel e os modos não motorizados. Em uma cidade de médio porte o número de viagens encadeadas é pequeno (2 viagens), sendo que a maior parte das viagens possuem base domiciliar. Isso é justificável uma vez que os indivíduos podem retornar ao seu domicílio antes de realizar outra atividade. Por exemplo, as atividades de 
compras não precisam, necessariamente, serem realizadas no trajeto de volta do trabalho para casa. Pelo fato da cidade ainda não apresentar congestionamentos nas vias, é possível que o indivíduo realize essa atividade após retornar à sua casa.

Além disso, algumas informações geradas mostram que, de certa forma, as informações são duvidosas. Por exemplo, de acordo com um dos padrões de atividades verificados pelo modelo (Capítulo 6, Tabela 6.15), apenas 6,8\% das viagens realizadas por diversos motivos são feitas por transporte coletivo, sendo que, para uma cidade de porte médio a porcentagem seria em torno de $28 \%$ segundo Raia Jr, 2000.

A alimentação do modelo com um pequeno número de informações não possibilita a análise mais profunda de alguns padrões de realização de atividades e viagens. As árvores geradas, muitas vezes incluíram um pequeno número de variáveis, o que na maior parte das vezes, gerou resultados de difícil interpretação. Não existem dúvidas que a falta de informações prejudicou o desempenho do modelo, o que, em partes, não possibilitou que os objetivos inicialmente almejados com esta pesquisa fossem plenamente alcançados.

No entanto, apesar da falta de elementos para melhor compreender a relação entre uso do solo e transportes (estudo de caso), os objetivos principais foram atingidos. De forma geral, a proposta aqui apresentada traz benefícios à sociedade de três formas. A primeira delas é a inovação conceitual, ao usar um novo conceito de modelos de demanda por transportes. Buscou-se evidenciar que os modelos de atividades constituem, efetivamente, uma das vertentes mais avançadas para análise da demanda por transportes. Eles são capazes de analisar o modo como indivíduos tomam suas decisões de realização de viagens e atividades em âmbito mais amplo, considerando não apenas um pequeno grupo de variáveis, mas também um conjunto de restrições que são encontradas diariamente. Assim, os tópicos conceituais aqui apresentados, tanto em relação aos modelos de atividades para análise da demanda por transportes como aos modelos integrados de transportes e uso do solo, servem para divulgação dessas abordagens no meio acadêmico, o que pode vir a estimular outros pesquisadores que estejam interessados no tema a desenvolverem pesquisas mais especificas nessa área.

Em segundo lugar, no que se refere à contribuição tecnológica, indiretamente este trabalho inovou ao aplicar um modelo baseado em atividades desenvolvido fora do 
Brasil nas condições das cidades brasileiras. Vale ressaltar que essa contribuição não está na adaptação de um modelo às condições brasileiras, uma vez que outros pesquisadores já realizaram essa experiência em outros países. O que se deve ressaltar é o fato dessa aplicação ter sido a primeira realizada no Brasil, com uso desse novo tipo de modelagem. Apesar de não ter sido possível a obtenção de resultados práticos efetivos, e das dificuldades encontradas para a calibração do modelo, ficou provado que é possível a aplicação desse tipo de modelagem nas condições nacionais, desde que sua estrutura seja desenvolvida nas condições das cidades brasileiras. Diversas universidades brasileiras já possuem hoje infra-estrutura computacional e profissionais qualificados para o desenvolvimento de um modelo baseado em atividades. Espera-se, dentro dessa perspectiva, que esta tese tenha mostrado alguns caminhos que devem ser seguidos e os pontos que merecem maior atenção para que melhorias no processo de modelagem sejam feitas.

Por último, no que se refere à inovação metodológica, esta tese apresenta duas contribuições: a exploração da metodologia dos modelos baseados em atividades e da aplicação dos diários de atividades. A utilização dessas metodologias é possível para o planejamento de transportes, apesar do grande esforço que deve ser despendido para sua aplicação prática.

Finalmente, em relação aos resultados obtidos, infelizmente não se pode dizer que foram satisfatórios para o objetivo principal proposto. Verificou-se, no entanto, que é possível a aplicação de um modelo de atividades para esse tipo de análise mas sua aplicação no contexto brasileiro precisa ser melhor estudada. Por outro lado, esta pesquisa, sem dúvida, representa um primeiro passo para exploração dessa nova metodologia, ainda que restrita ao ambiente acadêmico.

Isto leva à sugestão para trabalhos futuros, para que a metodologia aqui apresentada, seja aprofundada e testada com um conjunto maior de dados, de forma a confirmar ou rejeitar a sua superioridade em relação ao processo tradicional de modelagem da demanda por transportes. Espera-se assim que, ainda que do ponto de vista acadêmico, esta tese cumpra um papel relevante, ao incentivar novas pesquisas nessa linha para que, em breve, sejam obtidas algumas das respostas procuradas na área de planejamento urbano e de transportes. 


\section{REFERÊNCIAS BIBLIOGRÁFICAS}

ABRAHAM, J. E.; GARRY, G. R.; HUNT, J. D. e BROWNLEE, A. T. Incremental modeling developments in Sacramento: towards an advanced integrated land use and transport model. In: ANNUAL TRANSPORTATION RESEARCH BOARD MEETING, $83^{\text {rd }}$, 2004, Washington, D.C. Proceedings... Washington, D.C.: Transportation Research Board, 2004a. CD-ROM.

AMANCIO, M. A. Avaliação da caminhabilidade de zonas urbanas utilizando o método multicritério e sistema de informações geográficas. Relatório de bolsa de desenvolvimento técnico do CNPq - Projeto CT-Transpo. Universidade Federal de São Carlos (UFSCar), 2003.

ARENTZE, T. e TIMMERMANS, H. A micro-simulator of urban land use dynamics integrating a multi-agent model of land development and an activity-based model of transport demand. In: ANNUAL TRANSPORTATION RESEARCH BOARD MEETING, 83 $3^{\text {rd }}$, 2004, Washington, D.C. Proceedings... Washington, D.C.: Transportation Research Board, 2004a. CD-ROM.

ARENTZE, T. e TIMMERMANS, H. Multi-agent models of urban land development: theory and numerical simulation of retail location decisions. In: ANNUAL TRANSPORTATION RESEARCH BOARD MEETING, $83^{\text {rd }}$, 2004, Washington, D.C. Proceedings... Washington, D.C.: Transportation Research Board, 2004b. CD-ROM.

ARENTZE, T.; DIJST, M.; DUGUNDJI, E. et al. New activity diary format - design and limited empirical evidence. Transportation Research Record. n. 1768, p. 79-88. 2000. 
ARENTZE, T.; HOFMAN, F.; TIMMERMANS, H. Re-induction of Albatross' decision rules using pooled activity-travel diary data and an extended set of land use and costs-related condition states. In: ANNUAL TRANSPORTATION RESEARCH BOARD MEETING, 82 ${ }^{\text {nd }}, 2003$, Washington, D.C. Proceedings... Washington, D.C.: Transportation Research Board, 2003. CD-ROM.

ARENTZE, T.; SUN, Z.; TIMMERMANS, H. Modeling the dynamic use and impact of travel information on activity-travel (re)scheduling decisions. In: CONFERENCE ON PROGRESS IN ACTIVITY-BASED ANALYSIS, 2004, Maastricht, The Netherlands. Proceedings... 2004. CD-ROM.

ARENTZE, T.; TIMMERMANS, H. Albatross - A learning based transportation oriented simulation system. Technische Universiteit Eindhoven - European Institute of Retailing and Services Studies. 518p. 2000.

ARRUDA, F. S.; SILVA, A. N. R. Diários de atividades: uma metodologia alternativa de coleta de dados para planejamento de transportes. In: Panorama Nacional da Pesquisa em Transportes 2004, Vol I. Associação Nacional de Pesquisa e Ensino em Transportes, 675 - 686, 2004.

ARRUDA, F.S. Integração dos modos não motorizados nos modelos de planejamento dos transportes. São Carlos, 2000. 94 f. Dissertação (Mestrado em Engenharia Urbana). Universidade Federal de São Carlos.

AXHAUSEN, K. W. Data needs of activity scheduling models. In: ETTEMA, D. F.; TIMMERMANS, H. J. P. (Ed.). Activity-based approaches to travel analysis. 1997. p. 229-241.

AXHAUSEN, K. W.; ZIMMERMANN, A.; SCHÖNFELDER, S. et al. Observing the rhythms of daily life: a six-week travel diary. Transportation. n. 29, p. 95-124. 2002.

BALLING, R.; TABER, J.T.; DAY,K. et al. Land use and transportation planning for twin cities using a genetic algorithm. Transportation Research Record. n. 1722, p. 67-74. 2000.

BARRETT, C., BERKBIGLER, K., SMITH, L. et al. An operational description of TRANSIMS. LA-UR-95-2393, Los Alamos, New Mexico: Alamos National Laboratory, 1995. 
BHAT, C.; GUO, J. Y.; SRINIVASAN, S. e SIVAKUMAR, A. A comprehensive econometric micro-simulator for daily activity-travel patterns (CEMDAP). In: CONFERENCE ON PROGRESS IN ACTIVITY-BASED ANALYSIS, 2004, Maastricht, The Netherlands. Proceedings... 2004. CD-ROM.

BHAT, C.; KOPPELMAN, F. Activity-based travel demand analysis: history, results and future directions. In: ANNUAL TRANSPORTATION RESEARCH BOARD MEETING, $79^{\text {th }}$, 2000, Washington, D.C. Proceedings... Washington, D.C.: Transportation Research Board, 2000. CD-ROM.

BHAT, C.; LAWTON, K. Passenger travel demand forecasting. In: ANNUAL TRANSPORTATION RESEARCH BOARD MEETING, $79^{\text {th }}, 2000$, Washington, D.C. Proceedings... Washington, D.C.: Transportation Research Board, 2000. CD-ROM.

BLACK, J.; CHEUNG, C. Accessibility and location in the formulation of the government of New South Wales policies for sustainable cities. WORLD CONFERENCE ON TRANSPORT RESEARCH SOCIETY - Special Interest Group (SIG) 1. Sendai, Japão. 2003.

BOARNET, M. G.; CRANE, R. The influence of land use on travel behavior: specification and estimation strategies. Transportation Research A. n. 35, p. 823-845, 2001.

BOARNET, M. G.; NESAMANI, K. S. e SMITH, C. S. Comparing the influence of land use on nonwork trip generation and vehicle distance traveled: an analysis using travel diary data. In: ANNUAL TRANSPORTATION RESEARCH BOARD MEETING, 83 ${ }^{\text {rd }}, 2004$, Washington, D.C. Proceedings... Washington, D.C.: Transportation Research Board, 2004. CD-ROM.

BOARNET, M. G.; SARMIENTO, S. Can land use policy really affect travel behavior? A study of the link between non-work travel and land use characteristics. Working Paper. 1996. Capturado em 20 nov. 2002. Disponível na internet. http://repositories.cdlib.org/itsirvine/casa/UCI-ITS-AS-WP-96-5/

CERVERO, R. Mixed land-uses and commuting: evidence from the American housing survey. Transportation Research A. v. 30, n. 5, p. 361-377. 1996.

CERVERO, R.; KOCKELMAN K. Travel demand and the 3 Ds: density, diversity and design. Transportation Research D. v. 3, p.199-219. 1997.

CHAPIN, F. S. Free-time activities and the quality of urban life. Journal of the American Institute of Planners. v. 37, p. 411-417, 1971. 
CHATMAN, D. G. The influence of workplace land use and commute mode choice on mileage traveled for personal commercial purposes. In: ANNUAL TRANSPORTATION RESEARCH BOARD MEETING, $81^{\text {st }}$, 2002, Washington, D.C. Proceedings... Washington, D.C.: Transportation Research Board, 2002. CD-ROM.

CLARKE, M.; DIX, M.; JONES, P. Error and uncertainty in travel surveys. Transportation. n. 10, p. 105-126. 1981.

CRANE, R.; CREPEAU, R. Does neighborhood design influence travel? A behavioral analysis of travel diary and GIS data. Transportation Research D. v. 3, n.4, 225-238. 1998.

CULLEN, I.; GODSON, V. Urban networks: the structure of activities patterns. Progress in Planning. n. 4, p.1-96, 1975.

DIJST, M.; VIDAKOVIC, V. Individual actions space in the city. In: ETTEMA, D. F.; TIMMERMANS, H. J. P. (Ed.). Activity-based approaches to travel analysis. 1997. p. 117-113.

DOHERTY, S. T.; MILLER, E. J. A computerized household activity scheduling survey. Transportation. n. 27, p. 75-97. 2000.

DOHERTY, S. T.; MILLER, E. J. Tracing the household activity scheduling process using a one week computer-based survey. In: MEETING OF THE INTERNATIONAL ASSOCIATION FOR TRAVEL BEHAVIOUR RESEARCH, $8^{\text {th }}, 1997$, Austin, Texas. Proceedings... Austin, Texas, Set.21-25, 1997.

DOHERTY, S.T. e PAPINSKI, D. Is it possible to automatically trace activity scheduling decisions? In: CONFERENCE ON PROGRESS IN ACTIVITYBASED ANALYSIS, 2004, Maastricht, The Netherlands. Proceedings... 2004. CD-ROM.

DOMENCICH, T. A.; McFADDEN, D. Urban travel demand - a behavioral analysis. North-Holland Publishing Company - Amsterdam. 213p. 1975.

DONG, X.; BEN-AKIVA, M. E.; BOWMAN, J. L. et al. Analysis of activity-based accessibility. In: ANNUAL TRANSPORTATION RESEARCH BOARD MEETING, 81 ${ }^{\text {st }}$, 2002, Washington, D.C. Proceedings... Washington, D.C.: Transportation Research Board, 2002. CD-ROM.

DUNPHY, R. T.; FISHER K. Transportation, congestion, and density: new insights. Transportation Research Record. n. 1552, p. 89-96. 1996. 
ETTEMA, D. Activity-based travel demand modeling. Eindhoven, 1996. 280 f. Tese (Doutorado em Planejamento Urbano), Universidade de Eindhoven, Holanda.

ETTEMA, D.; BORGERS, A.; TIMMERMANS, H. SMASH (Simulation Model of Activity Scheduling Heuristics): some simulations. Transportation Research Board. n. 1551, p. 88-94, 1996.

EWING, R. Beyond density, mode choice, and single-purpose trips. Transportation Quarterly. v. 49, p. 16-23. 1995.

EWING, R.; CERVERO, R. Travel and the built environment. Transportation Research Record. n. 1780, p. 87-114, 2001.

FRANK, L. D.; PIVO, G. Impacts of mixed land use and density on utilization of three modes of travel: single-occupant vehicle, transit, and walking. Transportation Research Record, n. 1466, p. 44-52. 1994.

FRIEDMAN B.; GORDON, S. P.; PEERS, J. B. Effect of neotraditional neighborhood design on travel characteristics. Transportation Research Record. n. 1466, p. 63-70. 1994.

GÄRLING, T.; BRÄNNÄS, K; GARVILL, J. et al. Household activity scheduling. In: TRANSPORT POLICY, MANAGEMENT AND TECHNOLOGY TOWARDS 2001: SELECTED PROCEEDINGS OF THE $5^{\text {th }}$ WORLD CONFERENCE ON TRANSPORT RESEARCH, 1989. Proceedings... v. v, p. 235-248.

HAGERSTRAND, T. What about people in regional science? Papers and Proceedings of the Regional Science Association. n. 24, pp. 7-24, 1970.

HANDY, S.L.; NIEMEIER, D.A. Measuring accessibility: an exploration of issues and alternatives. Environment and Planning A. v. 29, n. 7, p. 1175-1194, 1997.

HANSEN, W. G. How accessibility shapes land use. Journal of American Institute of Planners. n. 25, p. 73-76. 1959.

HENSHER, D. A.; TON, T. TRESIS: a transportation, land use and environmental strategy impact simulator for urban areas. In: WORLD CONFERENCE ON TRANSPORT RESEARCH, $9^{\text {th }}, 2001$, Seoul. Proceedings... Seoul, 2001. CDROM.

HUNT, J. D.; ABRAHAM, J. E. Design and application of the PECAS land use modeling system. In: INTERNATIONAL CONFERENCE ON COMPUTERS IN URBAN PLANNING AND URBAN MANAGEMENT, $8^{\text {th }}, 2003$, Sendai, Japan. Proceedings... Sendai, Japan, 2003. CD-ROM. 
ICHIKAWA, S. M. Aplicação de minerador de dados na obtenção de relações entre padrões de encadeamento de viagens codificadas e características sócioeconômicas. São Carlos, 2002. 136 f. Dissertação (Mestrado em Engenharia de Transportes). Escola de Engenharia de São Carlos - Universidade de São Paulo.

INGRAM, D. R. The concept of accessibility: a search for an operational form. Regional Studies. n. 5, p. 101-107. 1971.

KALFS, N.; SARIS, W. E. New data collection methods in travel surveys. In: ETTEMA, D. F.; TIMMERMANS, H. J. P. (Ed.). Activity-based approaches to travel analysis. 1997. p. 243-261.

KAMARA, S.; PAROLIN, B. Changes in accessibility to employment in metropolitan Sydney, 1981 to 1996 In: INTERNATIONAL CONFERENCE ON COMPUTERS IN URBAN PLANNING AND URBAN MANAGEMENT, $8^{\text {th }}$, 2003, Sendai, Japan. Proceedings... Sendai, Japan, 2003. CD-ROM.

KIM, K. S.; TON, T.; HENSHER, D. Review of TRESIS as a policy advisory tool for evaluating land use and transport interaction. In: INTERNATIONAL CONFERENCE ON COMPUTERS IN URBAN PLANNING AND URBAN MANAGEMENT, $8^{\text {th }}, 2003$, Sendai, Japan. Proceedings... Sendai, Japan, 2003. CD-ROM.

KITAMURA, R. Activity-based travel forecasting: what are some issues? Applications of models of activity behavior for activity based demand forecasting. In: ACTIVITY-BASED TRAVEL FORECASTING CONFERENCE, 1996. Proceedings... Capturado em 22 out. 1998. Disponível na internet http://www.bts.gov/tmip/papers/tmip/abtf/kitamura.htm

KITAMURA, R.; MOKHTARIAN, P. L.; LAIDET, L. A micro-analysis of land use and travel in five neighborhoods in the San Francisco Bay Area. Transportation. n. 24, p. 125-158. 1997.

KOCKELMAN, K. M. Travel behavior as function of accessibility, land use mixing, and land use balance. Transportation Research Record. n. 1607, p. 116-125. 1997.

KRIZEK, K. J. The interaction between neighborhood-scale urban form and travel behavior: a new strategy with new techniques. In: ANNUAL TRANSPORTATION RESEARCH BOARD MEETING, $79^{\text {th }}, 2000$, Washington, D.C. Proceedings... Washington, D.C.: Transportation Research Board, 2000. CD-ROM. 
KURANI, K.; LEE-GOSSELIN, M. E. H. Synthesis of past activity analysis applications. In: ACTIVITY-BASED TRAVEL FORECASTING CONFERENCE, 1996. Proceedings... Capturado em 22 out. 1998. Disponível na internet $\mathrm{em} \mathrm{http://www.bts.gov/tmip/papers/tmip/abtf/kurani.htm}$

LEE, M. S.; DOHERTY, S. T.; SABETIASHRAF, R. et al. ICHASE: an internet computerized household activity scheduling elicitor survey. In ANNUAL TRANSPORTATION RESEARCH BOARD MEETING， 79 ${ }^{\text {th }} ， 2000$, Washington, D.C. Proceedings... Washington, D.C.: Transportation Research Board, 2000. CD-ROM.

LENNTORP, B. Paths in space-time environments - a time-geographic study of movement possibilities of individuals. The Royal University of Lund, Department of Geography. Lund Studies in Geography, Series B. Human Geography, 44. 1978.

LIMA, R.S. Bases para uma metodologia de apoio à decisão para serviços de educação e saúde sob a ótica dos transportes. São Carlos, 2003. 200 f. Tese (Doutorado em Transportes). Escola de Engenharia de São Carlos - Universidade de São Paulo.

LIMTANAKOOL, N.; DIJST, M. e SCHWANEN, T. The influence of socioeconomic characteristics, land use and travel time considerations on mode choice for long-distance trips. In: ANNUAL TRANSPORTATION RESEARCH BOARD MEETING, 83 ${ }^{\text {rd }}, 2004$, Washington, D.C. Proceedings... Washington, D.C.: Transportation Research Board, 2004. CD-ROM.

LOOCKWOOD, A. M.; SRINIVASAN, S. e BHAT, C. A comprehensive analysis of weekend activity patterns in the San Francisco Bay Area. In: CONFERENCE ON PROGRESS IN ACTIVITY-BASED ANALYSIS, 2004, Maastricht, The Netherlands. Proceedings... 2004. CD-ROM.

MARCA, J. E.; RINDT, C. R.; McNALLY, M. G. Collecting activity data from GPS readings. In: ANNUAL TRANSPORTATION RESEARCH BOARD MEETING, 82 ${ }^{\text {nd }}, 2003$, Washington, D.C. Proceedings... Washington, D.C.: Transportation Research Board, 2003. CD-ROM.

MARSHMENT, R. Transportation planning challenges and opportunities. In: ANNUAL TRANSPORTATION RESEARCH BOARD MEETING, $79^{\text {th }}, 2000$, Washington, D.C. Proceedings... Washington, D.C.: Transportation Research Board, 2000. CD-ROM. 
McNALLY, M. G. An activity-based micro-simulation model for travel demand forecasting. In: ETTEMA, D. F.; TIMMERMANS, H. J. P. (Ed.) ActivityBased Approaches to Travel Analysis. 1997. p. 37-54.

McNALLY, M. G.; KULKARNI, A. Assesment of the influence of land usetransportation system on travel behavior. Transportation Research Record. $\mathrm{n}$. 1607, p. 105-115. 1997.

MESSENGER, T.; EWING, R. Transit-oriented development in the Sun-belt. Transportation Research Record. n. 1552, p. 145-153. 1996.

MIDDELKOOP, M.; BORGES, A. e TIMMERMANS, H. Merlin: micro-simulation system for predicting leisure activity-travel patterns. In: ANNUAL TRANSPORTATION RESEARCH BOARD MEETING, 83 ${ }^{\text {rd }}$, 2004, Washington, D.C. Proceedings... Washington, D.C.: Transportation Research Board, 2004. CD-ROM.

MILLER, E. J.; IBRAHIM, A. Urban form and vehicular travel - some empirical findings. Transportation Research Record. n. 1617, p. 18-27. 1998.

MILLER, Eric J. Microsimulation and activity-based forecasting. In: ACTIVITYBASED TRAVEL FORECASTING CONFERENCE, 1996. Proceedings... Capturado em 22 out. 1998. Online. Disponível na internet http://www.bts.gov/tmip/papers/tmip/abtf/miller.htm

MISRA, R.; BHAT, C. Activity-travel patterns of non-workers in the San Francisco Bay Area: an exploratory analysis. In: ANNUAL TRANSPORTATION RESEARCH BOARD MEETING, 79 ${ }^{\text {th }}, 2000$, Washington, D.C. Proceedings... Washington, D.C.: Transportation Research Board, 2000. CD-ROM.

MOECKEL, R. SCHÜRMANN, R.; WEGENER, M. Microsimulation of urban land use. In: INTERNATIONAL CONFERENCE ON COMPUTERS IN URBAN PLANNING AND URBAN MANAGEMENT, $8^{\text {th }}, 2003$, Sendai, Japão. Proceedings... Sendai, Japão, 2003. CD-ROM.

NOTH, M.; BORNING, A.; WADDELL, P. An extensible, modular architecture for simulating urban development, transportation, and environmental impacts. In: INTERNATIONAL COMPUTERS IN URBAN PLANNING AND URBAN MANAGEMENT CONFERENCE, $7^{\text {th }}, 2001$, Honolulu, Hawaii. Proceedings... Honolulu, Hawaii, 2001. CD-ROM.

NOVAES, A. G. Modelos em planejamento urbano, regional e de transportes. Editora Edgard Blücher Ltda, São Paulo, SP. 290 p. 1981. 
ORTÚZAR, Juan de Dios, WILLUMSEM, Luis G. Modelling Transport. 2.ed. John Wiley and Sons, London, 1994. 439p.

PAS, E. I. The urban transportation planning process. In: HANSON, S. The Geography of Urban Transportation. $2^{\text {nd }}$ edition. Edited by Susan Hanson. 1995. p. 53-77.

PENDYALA, R. M.; KITAMURA, R.; REDDY, D.V.G.P. Application of an activitybased travel demand model incorporating a rule-based algorithm. Environment and Planning B. v.25, p. 753-772, 1998.

PIRIE, G. H. Measuring accessibility: a review and proposal. Environment and Planning A. v. 11, n. 3, p. 299-312, 1979.

PITOMBO, C. S. Análise do comportamento subjacente ao encadeamento de viagens através do uso de minerador de dados. São Carlos, 2003. $148 \mathrm{f}$. Dissertação (Mestrado em Engenharia de Transportes). Escola de Engenharia de São Carlos - Universidade de São Paulo.

RAIA Jr, A. A. Acessibilidade e Mobilidade na Estimativa de um Índice de Potencial de Viagens Utilizando Redes Neurais Artificiais. São Carlos, 2000. 202 f. Tese (Doutorado em Engenharia de Transportes). Escola de Engenharia de São Carlos - Universidade de São Paulo.

RAUB, R. A. Toward a better understanding of needs for travel information: analysis of a commuter survey. In: ANNUAL TRANSPORTATION RESEARCH BOARD MEETING, 82 nd, 2003 , Washington, D.C. Proceedings... Washington, D.C.: Transportation Research Board, 2003. CD-ROM.

RDC, Inc. Activity-based modeling system for travel demand forecasting - travel model improvement program. TMIP Project, U.S. Department of Transportation. 1995.

RECKER, W.W.; McNALLY, M.G.; ROOT, G.S. A model of complex travel behavior: part I - theoretical development. Transportation Research A. v. 20A, n. 4, p. 307-318. 1996a.

RECKER, W.W.; McNALLY, M.G.; ROOT, G.S. A model of complex travel behavior: part II - an operational model. Transportation Research A. v. 20A, n. 4, p. 319-330. $1996 \mathrm{~b}$.

RICHARDSON, A. J.; AMPT, E. S.; MEYBURG, A. H. Survey methods for transport planning. Eucalyptus Press, Parkville Australia. 476 p. 1995. 
RUIZ, T. Design of a four week activity scheduling survey using internet. In: CONFERENCE ON PROGRESS IN ACTIVITY-BASED ANALYSIS, 2004, Maastricht, The Netherlands. Proceedings... 2004. CD-ROM.

SCHIMEK, P. Household motor vehicle ownership and use: how much does residential density matter? Transportation Research Record. n. 1552, p. 120125.. 1996.

SCHWANEN, T.; DIJST, M. E DIELEMAN, F. M. Generic or context-especific? The influence of residential setting on the travel behavior of population segments in The Netherlands. In: ANNUAL TRANSPORTATION RESEARCH BOARD MEETING, 83 ${ }^{\text {rd }}$, 2004, Washington, D.C. Proceedings... Washington, D.C.: Transportation Research Board, 2004. CD-ROM.

SNELLEN, D. Urban form and activity-travel patterns - an activity-based approach to travel in a spatial context. Eindhoven, 2000. $251 \mathrm{f}$. Tese (Doutorado em Planejamento Urbano). Technische Universiteit Eindhoven, The Netherlands.

SRINIVASAN, S. Linking land use and transportation: measuring the impact of neighborhood-scale spatial patterns on travel behavior. Cambridge, MA, 2000. Tese (Doutorado em Estudos Urbanos e Planejamento). Massachusetts Institute of Technology.

STEINER, R. L. Residential density and travel patterns: review of the literature Transportation Research Record. n. 1466, p. 37-43. 1994

STOPHER, P. R. A review of separate and joint strategies for the use of data on revealed and stated choices. Transportation. n. 25, p. 187-205. 1998.

STOPHER, P. R. Use of an activity-based diary to collect household travel data. Transportation. n.19, p. 159-176. 1992.

STOPHER, P. R.; BULLOCK, P. J.; HORST, F. N. F. Conducting a GPS survey with a time-use diary. In: ANNUAL TRANSPORTATION RESEARCH BOARD MEETING, 82 nd 2003 , Washington, D.C. Proceedings... Washington, D.C.: Transportation Research Board, 2003. CD-ROM.

TAN, A. e H. TIMMERMANS. Paper-and-Pencil Retrospective Activity-Travel Diaries versus Virtual Reality Re-Enactment Sessions to Collect Activity-Travel Patterns Data: a Validation Study. In: ANNUAL TRANSPORTATION RESEARCH BOARD MEETING, 83 ${ }^{\text {rd }}$, 2004, Washington, D.C. Proceedings... Washington, D.C.: Transportation Research Board, 2004. CD-ROM. 
TIMMERMANS, H. Data requirements and data collection. In: ARENTZE, T.; TIMMERMANS, H. Albatross - a learning based transportation oriented simulation system. Technische Universiteit Eindhoven - European Institute of Retailing and Services Studies, 2000. p. 136-151.

VAUGHN, K. Bay Area travel survey 2000 - summary of a regional household survey project. In: ANNUAL TRANSPORTATION RESEARCH BOARD MEETING, $82^{\text {nd }}, 2003$, Washington, D.C. Proceedings... Washington, D.C.: Transportation Research Board, 2003. CD-ROM.

VELDHUISEN, Jan, TIMMERMANS, Harry, KAPOEN, Loek. Microsimulation of activity-travel patterns and traffic flows: validation testes and an investigation of Monte Carlo error. In: ANNUAL TRANSPORTATION RESEARCH BOARD MEETING, 79 , 2000, Washington, D.C. Proceedings... Washington, D.C.: Transportation Research Board, 2000. CD-ROM.

WADDELL, P. Introduction to urban simulation: design and development of operational models. [199?] Disponível na internet. http://www.urbansim.org

WADDELL, P. Towards a behavioral integration of land use and transportation modeling. In: $9^{\text {th }}$ INTERNATIONAL ASSOCIATION FOR TRAVEL BEHAVIOR RESEARCH CONFERENCE. Proceedings... Queensland, Australia, 2000. CD-ROM.

WANG, D.; TIMMERMANS, Harry. A conjoint-based model of activity engagement, timing, scheduling and stop pattern formation. In: ANNUAL TRANSPORTATION RESEARCH BOARD MEETING, $79^{\text {th }}$, 2000, Washington, D.C. Proceedings... Washington, D.C.: Transportation Research Board, 2000. CD-ROM.

WEE, B. van. Land use and transport: research and policy challenges. Journal of Transport Geography, v. 10, n. 4, p. 259-271. 2002.

WEGENER, M. Overview of land-use transport models. In: INTERNATIONAL CONFERENCE ON COMPUTERS IN URBAN PLANNING AND URBAN MANAGEMENT, $8^{\text {th }}, 2003$, Sendai, Japan. Proceedings... Sendai, Japão, 2003. CD-ROM.

WEGENER, M.; FÜRST, F. Land-use transport interaction: state of the art. Publicação 46 (Berichte aus dem Institut für Raumplanung 46). Institut für Raumplanung, Universität Dortmund, Dortmund. 1999. Disponível na internet: http://www.inro.tro.nl/transland/Deliverable\%202a.pdf 
ZEGRAS, P. C. The influence of land use on travel behavior: empirical evidence from Santiago de Chile. In: ANNUAL TRANSPORTATION RESEARCH BOARD MEETING, 83 ${ }^{\text {rd }}$, 2004, Washington, D.C. Proceedings... Washington, D.C.: Transportation Research Board, 2004. CD-ROM. 
APÊNDICE A 


\section{QUESTIONÁRIO}

INFORMAÇÕES GERAIS

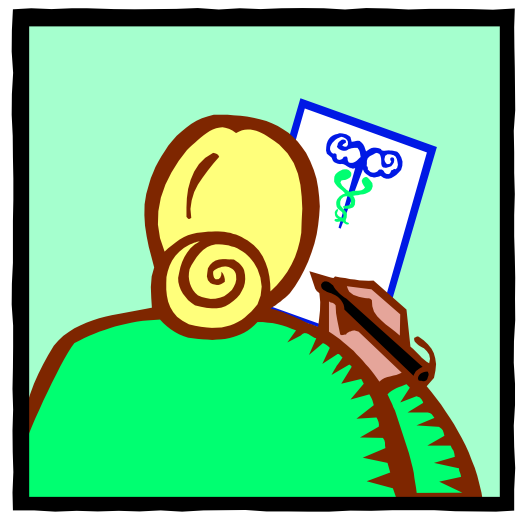




\section{INFORMAÇÕES PESSOAIS E DOMICILIARES}

1) Nome do entrevistado:

2) Endereço do domicílio (ou ponto de referência ou cruzamento entre ruas mais próximo):

3) Principal Ocupação:

4) Número de automóveis no domicílio:

5) Faixa de renda familiar mensal:

inferior a $R \$ 500,00 （ ） \quad R \$ 500,00$ a $R \$ 1000,00 \quad(\quad)$

$\mathrm{R} \$ 1000,00$ a $\mathrm{R} \$ 1.500,00$ ( ) $\mathrm{R} \$ 1.500,00$ a $\mathrm{R} \$ 2.000,00$ ( )

mais de $R \$ 2.000,00$ ( )

\section{INFORMAÇÕES ADICIONAIS}

6) Você possui alguma deficiência física que o impeça de usar algum modo de transporte:

$$
\operatorname{Sim}(\text { ) Não ( ) }
$$

Se você marcou SIM, qual o modo de transporte que você não pode utilizar?
Automóvel ( )
Ônibus ( )
Bicileta
Caminhada ( )
Outros ( )

7) Se seu domicílio possui automóvel, com que freqüência você o utiliza por semana?
1 a 2 vezes
2 a 3 vezes
mais de 3 vezes 


\section{CARACTERIZAÇÃO DO DOMICÍLIO}

\begin{tabular}{|c|c|c|c|c|c|c|c|}
\hline \multicolumn{2}{|c|}{ Moradores do domicílio } & \multirow{2}{*}{$\begin{array}{c}\begin{array}{c}1 \\
\text { (você } \\
\text { mesmo) }\end{array} \\
19\end{array}$} & \multirow{2}{*}{$\begin{array}{r}2 \\
19\end{array}$} & \multirow{2}{*}{$\begin{array}{r}3 \\
19 \\
\end{array}$} & \multirow{2}{*}{$\begin{array}{r}4 \\
19 \\
\end{array}$} & \multirow{2}{*}{$\begin{array}{r}5 \\
19\end{array}$} & \multirow{2}{*}{$\begin{array}{r}6 \\
19\end{array}$} \\
\hline $\begin{array}{l}\text { Ano de } \\
\text { nascimento }\end{array}$ & & & & & & & \\
\hline Sexo & $\begin{array}{l}\text { 1. Homem } \\
\text { 2. Mulher }\end{array}$ & $\begin{array}{l}\square \\
\square\end{array}$ & $\begin{array}{l}\square \\
\square\end{array}$ & $\begin{array}{l}\square \\
\square\end{array}$ & $\begin{array}{l}\square \\
\square\end{array}$ & $\begin{array}{l}\square \\
\square\end{array}$ & $\begin{array}{l}\square \\
\square\end{array}$ \\
\hline $\begin{array}{l}\text { Posição no } \\
\text { domicílio }\end{array}$ & $\begin{array}{l}\text { 1. Chefe de família } \\
\text { 2. Parceiro (a)/cônjuge } \\
\text { 3. Filho(a) } \\
\text { 4. Parente } \\
\text { 5. Outro }\end{array}$ & $\begin{array}{l}\square \\
\square \\
\square \\
\square \\
\square\end{array}$ & $\begin{array}{l}\square \\
\square \\
\square \\
\square \\
\square\end{array}$ & $\begin{array}{l}\square \\
\square \\
\square \\
\square \\
\square\end{array}$ & $\begin{array}{l}\square \\
\square \\
\square \\
\square \\
\square\end{array}$ & $\begin{array}{l}\square \\
\square \\
\square \\
\square \\
\square\end{array}$ & $\begin{array}{l}\square \\
\square \\
\square \\
\square \\
\square\end{array}$ \\
\hline $\begin{array}{l}\text { Possui carteira de } \\
\text { habilitação? }\end{array}$ & $\begin{array}{l}\text { 1. Sim } \\
\text { 2. Não }\end{array}$ & $\begin{array}{l}\square \\
\square\end{array}$ & $\begin{array}{l}\square \\
\square\end{array}$ & $\begin{array}{l}\square \\
\square\end{array}$ & $\begin{array}{l}\square \\
\square\end{array}$ & $\begin{array}{l}\square \\
\square\end{array}$ & $\begin{array}{l}\square \\
\square\end{array}$ \\
\hline
\end{tabular}




\begin{tabular}{|c|c|c|c|c|c|c|c|}
\hline $\begin{array}{l}\text { Ocupação } \\
\text { Principal } \\
\text { (podem ser } \\
\text { marcadas até duas } \\
\text { opções) }\end{array}$ & $\begin{array}{l}\text { 1. Empregado } \\
\text { 2. Autônomo } \\
\text { 3. Prendas domésticas } \\
\text { 4. Estudante } \\
\text { 5. Aposentado } \\
\text { 6. Desempregado } \\
\text { 7. Licença/afastado } \\
\text { 8. Sem ocupação/ nunca } \\
\quad \text { trabalhou } \\
\text { 9. Outros }\end{array}$ & $\begin{array}{l}\square \\
\square \\
\square \\
\square \\
\square \\
\square \\
\square \\
\square \\
\square \\
\square\end{array}$ & $\begin{array}{l}\square \\
\square \\
\square \\
\square \\
\square \\
\square \\
\square \\
\square \\
\square \\
\square\end{array}$ & $\begin{array}{l}\square \\
\square \\
\square \\
\square \\
\square \\
\square \\
\square \\
\square \\
\square \\
\square\end{array}$ & $\begin{array}{l}\square \\
\square \\
\square \\
\square \\
\square \\
\square \\
\square \\
\square \\
\square \\
\square\end{array}$ & $\begin{array}{l}\square \\
\square \\
\square \\
\square \\
\square \\
\square \\
\square \\
\square \\
\square \\
\square\end{array}$ & $\begin{array}{l}\square \\
\square \\
\square \\
\square \\
\square \\
\square \\
\square \\
\square \\
\square \\
\square\end{array}$ \\
\hline Grau de instrução & $\begin{array}{l}\text { 1. Primeiro grau } \\
\quad \text { incompleto } \\
\text { 2. Primeiro grau completo } \\
\text { 3. Segundo grau } \\
\quad \text { incompleto } \\
\text { 4. Segundo grau completo } \\
\text { 5. Superior incompleto } \\
\text { 6. Superior completo } \\
\text { 7. Pós-graduado }\end{array}$ & $\begin{array}{l}\square \\
\square \\
\square \\
\square \\
\square \\
\square \\
\square \\
\square\end{array}$ & $\begin{array}{l}\square \\
\square \\
\square \\
\square \\
\square \\
\square \\
\square\end{array}$ & $\begin{array}{l}\square \\
\square \\
\square \\
\square \\
\square \\
\square \\
\square \\
\square\end{array}$ & $\begin{array}{l}\square \\
\square \\
\square \\
\square \\
\square \\
\square \\
\square\end{array}$ & $\begin{array}{l}\square \\
\square \\
\square \\
\square \\
\square \\
\square \\
\square\end{array}$ & $\begin{array}{l}\square \\
\square \\
\square \\
\square \\
\square \\
\square \\
\square\end{array}$ \\
\hline $\begin{array}{l}\text { Possui algum tipo } \\
\text { de desconto para } \\
\text { uso do transporte } \\
\text { público (ônibus)? }\end{array}$ & $\begin{array}{l}\text { 1. Sim } \\
\text { 2. Não }\end{array}$ & $\begin{array}{l}\square \\
\square\end{array}$ & $\begin{array}{l}\square \\
\square\end{array}$ & $\begin{array}{l}\square \\
\square\end{array}$ & $\begin{array}{l}\square \\
\square\end{array}$ & $\begin{array}{l}\square \\
\square\end{array}$ & $\begin{array}{l}\square \\
\square\end{array}$ \\
\hline
\end{tabular}




\section{EXEMPLO}

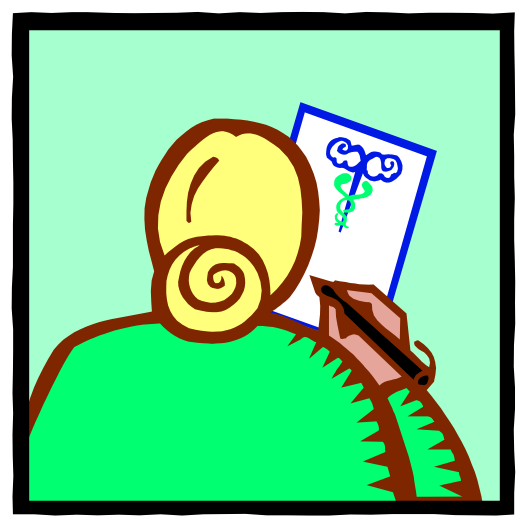




\section{INSTRUÇÕES DE PREENCHIMENTO}

Nesta pesquisa pedimos que você descreva todas as atividades realizadas durante dois dias. A pesquisa consta de um questionário a ser preenchido com informações pessoais do entrevistado, e informações do domicílio ao qual pertence. Em seguida se encontra o diário de atividades, no qual devem ser descritas TODAS as atividades realizadas, com informações sobre o local onde essa atividade é realizada, o modo de transporte usado, o tempo de início e término dessa atividade, bem como outras informações pertinentes.

É importante salientar que cada VIAGEM realizada é CONSIDERADA UMA ATIVIDADE. Assim, devem ser descritos TODOS os deslocamentos realizados para que as atividades sejam cumpridas.

Necessitamos que você mencione TODAS as atividades que realiza, SEPARADAMENTE umas das outras. Lembre-se de descrever as atividades realizadas no trajeto de um local para o outro - por exemplo, se durante o caminho de sua casa para o trabalho você deixa crianças na escola, essa atividade deve ser descrita separadamente.

Devem ser descritas APENAS as atividades que você realiza fora de casa. Atividades realizadas dentro de seu domicílio (como higiene pessoal, assistir televisão ou lavar os pratos) não precisam ser descritas.

Em anexo encontra-se um quadro com descrição detalhada de atividades, para facilitar o preenchimento do diário. A seguir você encontra um exemplo de preenchimento do diário de atividades.

Obrigada por sua participação. 


\section{EXEMPLO}

Considere uma pessoa que trabalhe fora de casa e não possua carro. Essa pessoa deve sair de casa pela manhã e pegar o ônibus para ir ao trabalho. $\mathrm{Na}$ hora do almoço ela realiza suas refeições em um local próximo ao seu trabalho, fazendo o trajeto trabalho - restaurante - trabalho pelo modo a pé. No final do dia, antes de ir para casa, ela passa na padaria. A agenda de atividades dessa pessoa é a seguinte:

6:30 h - sair de casa para o ponto de ônibus a pé

$6: 40 \mathrm{~h}$ - chegada ao ponto de ônibus (embarque)

6:45 $\mathrm{h}$ - partida do ônibus

7:00 h - chegada ao ponto de desembarque e caminhada ao local de trabalho

$7: 15 \mathrm{~h}$ - chegada ao trabalho

$12: 00 \mathrm{~h}$ - sair do trabalho e ir para o restaurante a pé

$12: 10 \mathrm{~h}$ - chegada ao restaurante

12: $45 \mathrm{~h}$ - saída do restaurante para o trabalho, a pé

12:55 h - chegada ao local do trabalho

18:00 h - sair do trabalho a pé, e ir até o ponto de ônibus

18:15 $\mathrm{h}$ - chegada ao ponto de ônibus

18: $20 \mathrm{~h}$ - partida do ônibus

18: $35 \mathrm{~h}$ - chegada ao ponto de destino e ida à padaria, a pé

18:40 $\mathrm{h}$ - chegada na padaria

18: $50 \mathrm{~h}$ - saída da padaria e volta para casa a pé

19:00 h - chegada em casa

Com base nessas informações, o diário de atividades dessa pessoa deve ser preenchido da seguinte maneira: 
Eu estava em... (endereço completo do local de origem ou ponto de referência mais próximo)

Casa-Rua José de Anchieta,34

Horário de saída da origem: 6 hs $30 \mathrm{~min}$

Com quem/acompanhante (podem ser marcadas várias opções)

X sozinho $\square$ marido/esposa $\quad \square$ com crianças $\square$ pessoas de fora do domicílio $\square$ pessoas do domicílio

Fui para... (endereço completo do local de destino, ou ponto de referência mais próximo)

Ponto de ônibus - cruzamento das ruas José de Anchieta com Júlio Hermes

Principal motivo da viagem (ver tabela no final dos diários)

Trabalho

Horário de chegada no destino: 6 hs $40 \mathrm{~min}$

Como você chegou até seu local de destino?

automóvel (motorista) $\quad \square$ automóvel (carona) $\quad \square$ ônibus $\quad$ X a pé $\quad \square$ bicicleta

outros

Caso o ônibus tenha sido usado, especificar o tempo de espera no ponto de embarque, e o local do ponto de

ônibus em que foi efetuado o desembarque (rua, local de referência ou cruzamento mais próximo, etc.).

Tempo de espera no ponto de ônibus:

Local do ponto de ônibus onde foi feito o desembarque:

Horário de chegada ao ponto de desembarque:

Obs: Lembre-se que sua próxima atividade tem como origem o local de desembarque do ponto de ônibus!

Após chegar ao local de destino, você esperou algum tempo antes de iniciar a atividade?

Sim, minutos $\quad$ X Não

Você realizou essa atividade... (podem ser marcadas várias opções)

X sozinho $\square$ marido/esposa $\square$ com crianças $\square$ pessoas de fora do domicílio $\square$ pessoas do domicílio

Esta manhã, você já sabia que teria que realizar a atividade mencionada acima?

X Sim $\square$ Não

Essa atividade poderia ser realizada em outro horário?

X Não $\square \operatorname{Sim}, \ldots$ hs __ min mais cedo $\_$Sim, _

Essa atividade poderia ter sido realizada por outra pessoa de seu domicílio?

Sim Não

Com que freqüência você realiza essa atividade?

1 a 2 vezes na semana

2 a 3 vezes na semana

$\mathbf{X}$ mais de 3 vezes na semana 
Eu estava em... (endereço completo do local de origem ou ponto de referência mais próximo)

Ponto de ônibus - cruzamento das ruas José de Anchieta com Júlio Hermes

Horário de saída da origem: 6 hs $45 \mathrm{~min}$

Com quem/acompanhante (podem ser marcadas várias opções)

X sozinho $\square$ marido/esposa $\square$ com crianças $\square$ pessoas de fora do domicílio $\square$ pessoas do domicílio

Fui para... (endereço completo do local de destino, ou ponto de referência mais próximo)

Ponto de ônibus - rua Arnaldo Jabor com Celso Cunha

Principal motivo da viagem (ver tabela no final dos diários)

Trabalho

Horário de chegada no destino: 7 hs $00 \mathrm{~min}$

Como você chegou até seu local de destino?

automóvel (motorista) $\quad \square$ automóvel (carona) $\quad$ X ônibus $\quad \square$ a pé $\quad \square$ bicicleta

outros

Caso o ônibus tenha sido usado, especificar o tempo de espera no ponto de embarque, e o local do ponto de

ônibus em que foi efetuado o desembarque (rua, local de referência ou cruzamento mais próximo, etc.).

Tempo de espera no ponto de ônibus: 5 minutos

Local do ponto de ônibus onde foi feito o desembarque: Rua Arnaldo Jabor com Celso Cunha Horário de chegada ao ponto de desembarque: 7 hs $00 \mathrm{~min}$

Obs: Lembre-se que sua próxima atividade tem como origem o local de desembarque do ponto de ônibus!

Após chegar ao local de destino, você esperou algum tempo antes de iniciar a atividade?
Sim,
minutos
X Não

Você realizou essa atividade... (podem ser marcadas várias opções)

X sozinho $\quad \square$ marido/esposa $\quad \square$ com crianças $\quad \square$ pessoas de fora do domicílio $\square$ pessoas do domicílio

Esta manhã, você já sabia que teria que realizar a atividade mencionada acima?

$\mathbf{X} \operatorname{Sim} \quad \square$ Não

Essa atividade poderia ser realizada em outro horário?

X Não $\square \mathrm{Sim}$, _ hs __ min mais cedo

Essa atividade poderia ter sido realizada por outra pessoa de seu domicílio?

Sim Não

Com que freqüência você realiza essa atividade?
1 a 2 vezes na semana
2 a 3 vezes na semana
$\mathbf{X}$ mais de 3 vezes na semana 
Eu estava em... (endereço completo do local de origem ou ponto de referência mais próximo)

Ponto de ônibus - Rua Arnaldo Jabor com Celso Cunha

Horário de saída da origem: 7 hs $00 \mathrm{~min}$

Com quem/acompanhante (podem ser marcadas várias opções)

X sozinho $\square$ marido/esposa $\square$ com crianças $\square$ pessoas de fora do domicílio $\square$ pessoas do domicílio

Fui para... (endereço completo do local de destino, ou ponto de referência mais próximo)

Trabalho - rua 15 de Novembro, 678

Principal motivo da viagem (ver tabela no final dos diários)

Trabalho

Horário de chegada no destino: 7 hs $15 \mathrm{~min}$

Como você chegou até seu local de destino?

automóvel (motorista) $\quad \square$ automóvel (carona) $\quad \square$ ônibus $\quad$ X a pé $\quad \square$ bicicleta

outros

Caso o ônibus tenha sido usado, especificar o tempo de espera no ponto de embarque, e o local do ponto de

ônibus em que foi efetuado o desembarque (rua, local de referência ou cruzamento mais próximo, etc.).

Tempo de espera no ponto de ônibus:

Local do ponto de ônibus onde foi feito o desembarque:

Horário de chegada ao ponto de desembarque:

Obs: Lembre-se que sua próxima atividade tem como origem o local de desembarque do ponto de ônibus!

Após chegar ao local de destino, você esperou algum tempo antes de iniciar a atividade?

$\mathbf{X} \operatorname{Sim}, 10$ minutos $\quad \square$ Não

Você realizou essa atividade... (podem ser marcadas várias opções)

X sozinho $\square$ marido/esposa $\square$ com crianças $\quad \mathbf{X}$ pessoas de fora do domicílio $\square$ pessoas do domicílio

Esta manhã, você já sabia que teria que realizar a atividade mencionada acima?

$\mathbf{x} \operatorname{Sim} \quad \square$ Não

Essa atividade poderia ser realizada em outro horário?

X Não $\square$ Sim, _ hs __ min mais cedo $\_$Sim __ hs ___ min mais tarde

Essa atividade poderia ter sido realizada por outra pessoa de seu domicílio?

Sim Não

Com que freqüência você realiza essa atividade?

1 a 2 vezes na semana $\quad \square 2$ a 3 vezes na semana $\quad \mathbf{X}$ mais de 3 vezes na semana 
Eu estava em... (endereço completo do local de origem ou ponto de referência mais próximo)

Trabalho - rua 15 de Novembro, 678

Horário de saída da origem: 12 hs $00 \mathrm{~min}$

Com quem/acompanhante (podem ser marcadas várias opções)

X sozinho $\square$ marido/esposa $\quad \square$ com crianças $\quad \square$ pessoas de fora do domicílio $\square$ pessoas do domicílio

Fui para... (endereço completo do local de destino, ou ponto de referência mais próximo)

Restaurante - Rua Almeida Prado, 597

Principal motivo da viagem (ver tabela no final dos diários)

Assuntos pessoais - almoço

Horário de chegada no destino: 12 hs $10 \mathrm{~min}$

Como você chegou até seu local de destino?

automóvel (motorista) $\quad \square$ automóvel (carona) $\quad \square$ ônibus $\quad$ X a pé $\quad \square$ bicicleta

outros

Caso o ônibus tenha sido usado, especificar o tempo de espera no ponto de embarque, e o local do ponto de

ônibus em que foi efetuado o desembarque (rua, local de referência ou cruzamento mais próximo, etc.).

Tempo de espera no ponto de ônibus:

Local do ponto de ônibus onde foi feito o desembarque:

Horário de chegada ao ponto de desembarque:

Obs: Lembre-se que sua próxima atividade tem como origem o local de desembarque do ponto de ônibus!

Após chegar ao local de destino, você esperou algum tempo antes de iniciar a atividade?
Sim,
minutos
X Não

Você realizou essa atividade... (podem ser marcadas várias opções)

X sozinho $\square$ marido/esposa $\square$ com crianças $\square$ pessoas de fora do domicílio $\square$ pessoas do domicílio

Esta manhã, você já sabia que teria que realizar a atividade mencionada acima?

X Sim $\quad \square$ Não

Essa atividade poderia ser realizada em outro horário?

Não $\square \operatorname{Sim}, \ldots$ hs __ min mais cedo $\_$X Sim __ hs 10 min mais tarde

Essa atividade poderia ter sido realizada por outra pessoa de seu domicílio?

Sim Não

Com que freqüência você realiza essa atividade?

1 a 2 vezes na semana $\quad \square 2$ a 3 vezes na semana $\quad \mathbf{X}$ mais de 3 vezes na semana 
Eu estava em... (endereço completo do local de origem ou ponto de referência mais próximo)

Restaurante - Rua Almeida Prado, 597

Horário de saída da origem: 12 hs $45 \mathrm{~min}$

Com quem/acompanhante (podem ser marcadas várias opções)

X sozinho $\square$ marido/esposa $\square$ com crianças $\square$ pessoas de fora do domicílio $\square$ pessoas do domicílio

Fui para... (endereço completo do local de destino, ou ponto de referência mais próximo)

Trabalho - rua 15 de Novembro, 678

Principal motivo da viagem (ver tabela no final dos diários)

Trabalho

Horário de chegada no destino: 12 hs $55 \mathrm{~min}$

Como você chegou até seu local de destino?

automóvel (motorista) $\quad \square$ automóvel (carona) $\quad \square$ ônibus $\quad$ X a pé $\quad \square$ bicicleta

outros

Caso o ônibus tenha sido usado, especificar o tempo de espera no ponto de embarque, e o local do ponto de

ônibus em que foi efetuado o desembarque (rua, local de referência ou cruzamento mais próximo, etc.).

Tempo de espera no ponto de ônibus:

Local do ponto de ônibus onde foi feito o desembarque:

Horário de chegada ao ponto de desembarque:

Obs: Lembre-se que sua próxima atividade tem como origem o local de desembarque do ponto de ônibus!

Após chegar ao local de destino, você esperou algum tempo antes de iniciar a atividade?

Sim, minutos $\quad$ X Não

Você realizou essa atividade... (podem ser marcadas várias opções)

X sozinho $\square$ marido/esposa $\square$ com crianças $\square$ pessoas de fora do domicílio $\square$ pessoas do domicílio

Esta manhã, você já sabia que teria que realizar a atividade mencionada acima?

$\mathbf{x} \operatorname{Sim} \quad \square$ Não

Essa atividade poderia ser realizada em outro horário?

X Não $\square$ Sim, _ hs ___ min mais cedo $\_$Sim __ hs ___min mais tarde

Essa atividade poderia ter sido realizada por outra pessoa de seu domicílio?

Sim Não

Com que freqüência você realiza essa atividade?

1 a 2 vezes na semana $\quad \square 2$ a 3 vezes na semana $\quad \mathbf{X}$ mais de 3 vezes na semana 
Eu estava em... (endereço completo do local de origem ou ponto de referência mais próximo)

Trabalho - rua 15 de Novembro, 678

Horário de saída da origem: 18 hs $00 \mathrm{~min}$

Com quem/acompanhante (podem ser marcadas várias opções)

X sozinho $\square$ marido/esposa $\square$ com crianças $\square$ pessoas de fora do domicílio $\square$ pessoas do domicílio

Fui para... (endereço completo do local de destino, ou ponto de referência mais próximo)

Ponto de ônibus - Rua Arnaldo Jabor com Celso Cunha

Principal motivo da viagem (ver tabela no final dos diários)

Volta para casa

Horário de chegada no destino: 18 hs $15 \mathrm{~min}$

Como você chegou até seu local de destino?

automóvel (motorista) $\quad \square$ automóvel (carona) $\quad \square$ ônibus $\quad$ X a pé $\quad \square$ bicicleta

outros

Caso o ônibus tenha sido usado, especificar o tempo de espera no ponto de embarque, e o local do ponto de

ônibus em que foi efetuado o desembarque (rua, local de referência ou cruzamento mais próximo, etc.).

Tempo de espera no ponto de ônibus: $5 \mathrm{~min}$

Local do ponto de ônibus onde foi feito o desembarque: José de Anchieta com Júlio Hermes

Horário de chegada ao ponto de desembarque: 18: $35 \mathrm{hs}$

Obs: Lembre-se que sua próxima atividade tem como origem o local de desembarque do ponto de ônibus!

Após chegar ao local de destino, você esperou algum tempo antes de iniciar a atividade?

X Sim, 5 minutos $\quad \square$ Não

Você realizou essa atividade... (podem ser marcadas várias opções)

X sozinho $\square$ marido/esposa $\square$ com crianças $\square$ pessoas de fora do domicílio $\square$ pessoas do domicílio

Esta manhã, você já sabia que teria que realizar a atividade mencionada acima?

$\mathbf{x} \operatorname{Sim} \quad \square$ Não

Essa atividade poderia ser realizada em outro horário?

$\square$ Não $\square \operatorname{Sim}, \ldots$ hs __ min mais cedo $\_$X Sim __ hs 15 min mais tarde

Essa atividade poderia ter sido realizada por outra pessoa de seu domicílio?

Sim Não

Com que freqüência você realiza essa atividade?
1 a 2 vezes na semana
2 a 3 vezes na semana
$\mathbf{X}$ mais de 3 vezes na semana 
Eu estava em... (endereço completo do local de origem ou ponto de referência mais próximo)

Ponto de ônibus - Rua Arnaldo Jabor com Celso Cunha

Horário de saída da origem: 18 hs $35 \mathrm{~min}$

Com quem/acompanhante (podem ser marcadas várias opções)

X sozinho $\square$ marido/esposa $\quad \square$ com crianças $\quad \square$ pessoas de fora do domicílio $\square$ pessoas do domicílio

Fui para... (endereço completo do local de destino, ou ponto de referência mais próximo)

Padaria - Rua José de Anchieta, 23

Principal motivo da viagem (ver tabela no final dos diários)

Compras

Horário de chegada no destino: 18 hs $40 \mathrm{~min}$

Como você chegou até seu local de destino?

automóvel (motorista) $\quad \square$ automóvel (carona) $\quad \square$ ônibus $\quad$ X a pé $\quad \square$ bicicleta

outros

Caso o ônibus tenha sido usado, especificar o tempo de espera no ponto de embarque, e o local do ponto de

ônibus em que foi efetuado o desembarque (rua, local de referência ou cruzamento mais próximo, etc.).

Tempo de espera no ponto de ônibus:

Local do ponto de ônibus onde foi feito o desembarque:

Horário de chegada ao ponto de desembarque:

Obs: Lembre-se que sua próxima atividade tem como origem o local de desembarque do ponto de ônibus!

Após chegar ao local de destino, você esperou algum tempo antes de iniciar a atividade?
$\operatorname{Sim}$
minutos
X Não

Você realizou essa atividade... (podem ser marcadas várias opções)

X sozinho $\square$ marido/esposa $\square$ com crianças $\square$ pessoas de fora do domicílio $\square$ pessoas do domicílio

Esta manhã, você já sabia que teria que realizar a atividade mencionada acima?

Sim Não

Essa atividade poderia ser realizada em outro horário?

Não $\square \operatorname{Sim}$, _ hs __ min mais cedo $\quad$ X Sim __ hs 30 min mais tarde

Essa atividade poderia ter sido realizada por outra pessoa de seu domicílio?

$\mathbf{x} \operatorname{Sim} \quad \square$ Não

Com que freqüência você realiza essa atividade?

1 a 2 vezes na semana $\quad$ X 2 a 3 vezes na semana $\square$ mais de 3 vezes na semana 
Eu estava em... (endereço completo do local de origem ou ponto de referência mais próximo)

Padaria - Rua José de Anchieta, 23

Horário de saída da origem: 18 hs $50 \mathrm{~min}$

Com quem/acompanhante (podem ser marcadas várias opções)

X sozinho $\square$ marido/esposa $\square$ com crianças $\square$ pessoas de fora do domicílio $\square$ pessoas do domicílio

Fui para... (endereço completo do local de destino, ou ponto de referência mais próximo)

Casa - Casa - Rua José de Anchieta,34

Principal motivo da viagem (ver tabela no final dos diários)

Volta para casa

Horário de chegada no destino: 19 hs $00 \mathrm{~min}$

Como você chegou até seu local de destino?

automóvel (motorista) $\quad \square$ automóvel (carona) $\quad \square$ ônibus $\quad \quad \mathbf{X}$ a pé $\quad \square$ bicicleta

outros

Caso o ônibus tenha sido usado, especificar o tempo de espera no ponto de embarque, e o local do ponto de

ônibus em que foi efetuado o desembarque (rua, local de referência ou cruzamento mais próximo, etc.).

Tempo de espera no ponto de ônibus:

Local do ponto de ônibus onde foi feito o desembarque:

Horário de chegada ao ponto de desembarque:

Obs: Lembre-se que sua próxima atividade tem como origem o local de desembarque do ponto de ônibus!

Após chegar ao local de destino, você esperou algum tempo antes de iniciar a atividade?
Sim,
minutos
X Não

Você realizou essa atividade... (podem ser marcadas várias opções)

X sozinho $\square$ marido/esposa $\square$ com crianças $\square$ pessoas de fora do domicílio $\square$ pessoas do domicílio

Esta manhã, você já sabia que teria que realizar a atividade mencionada acima?

X Sim $\quad \square$ Não

Essa atividade poderia ser realizada em outro horário?

$\square$ Não $\square \operatorname{Sim}, \ldots$ hs __ min mais cedo $\quad \mathbf{x} \operatorname{Sim} \_$hs 10 min mais tarde

Essa atividade poderia ter sido realizada por outra pessoa de seu domicílio?

Sim $\quad$ X Não

Com que freqüência você realiza essa atividade?

1 a 2 vezes na semana $\quad \square 2$ a 3 vezes na semana $\quad \mathbf{X}$ mais de 3 vezes na semana 


\title{
DIÁRIO DE ATIVIDADES
}

\author{
10 DIA
}

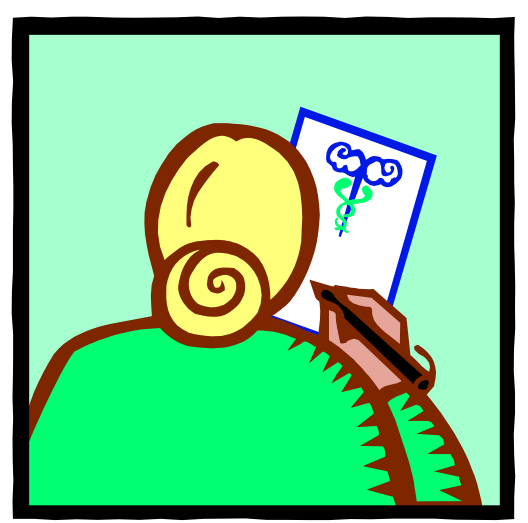

Data de preenchimento

10 Dia:

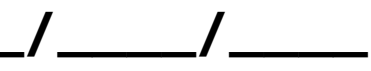


Eu estava em... (endereço completo do local de origem ou ponto de referência mais próximo)

Horário de saída da origem:

hs $\min$

Com quem/acompanhante (podem ser marcadas várias opções)

sozinho

$\square$ marido/esposa

$\checkmark$ com crianças

pessoas de fora do domicílio

pessoas do domicílio

Fui para... (endereço completo do local de destino, ou ponto de referência mais próximo)

Principal motivo da viagem (ver tabela no final do diário)

Horário de chegada no destino:

hs $\min$

Como você chegou até seu local de destino?
automóvel (motorista)
automóvel (carona)
ônibus
a pé
bicicleta

outros

Caso o ônibus tenha sido usado, especificar o tempo de espera no ponto de embarque, e o local do ponto de ônibus em que foi efetuado o desembarque (rua, local de referência ou cruzamento mais próximo, etc.).

Tempo de espera no ponto de ônibus:

Local do ponto de ônibus onde foi feito o desembarque:

Horário de chegada ao ponto de desembarque:

Obs: Lembre-se que sua próxima atividade tem como origem o local de desembarque do ponto de ônibus!

Após chegar ao local de destino, você esperou algum tempo antes de iniciar a atividade?

Sim, minutos $\checkmark$ Não

Você realizou essa atividade... (podem ser marcadas várias opções)

$\square$ sozinho $\square$ marido/esposa $\quad \square$ com crianças $\quad \square$ pessoas de fora do domicílio $\square$ pessoas do domicílio

Esta manhã, você já sabia que teria que realizar a atividade mencionada acima?

Sim $\quad \square$ Não

Essa atividade poderia ser realizada em outro horário?

$\square$ Não $\square \mathrm{Sim}$, _ hs __ min mais cedo $\quad \square \mathrm{Sim}$ ___ hs ___min mais tarde

Essa atividade poderia ter sido realizada por outra pessoa de seu domicílio?

Sim

$\square$ Não

Com que freqüência você realiza essa atividade?
1 a 2 vezes na semana
2 a 3 vezes na semana
mais de 3 vezes na semana 
Eu estava em... (endereço completo do local de origem ou ponto de referência mais próximo)

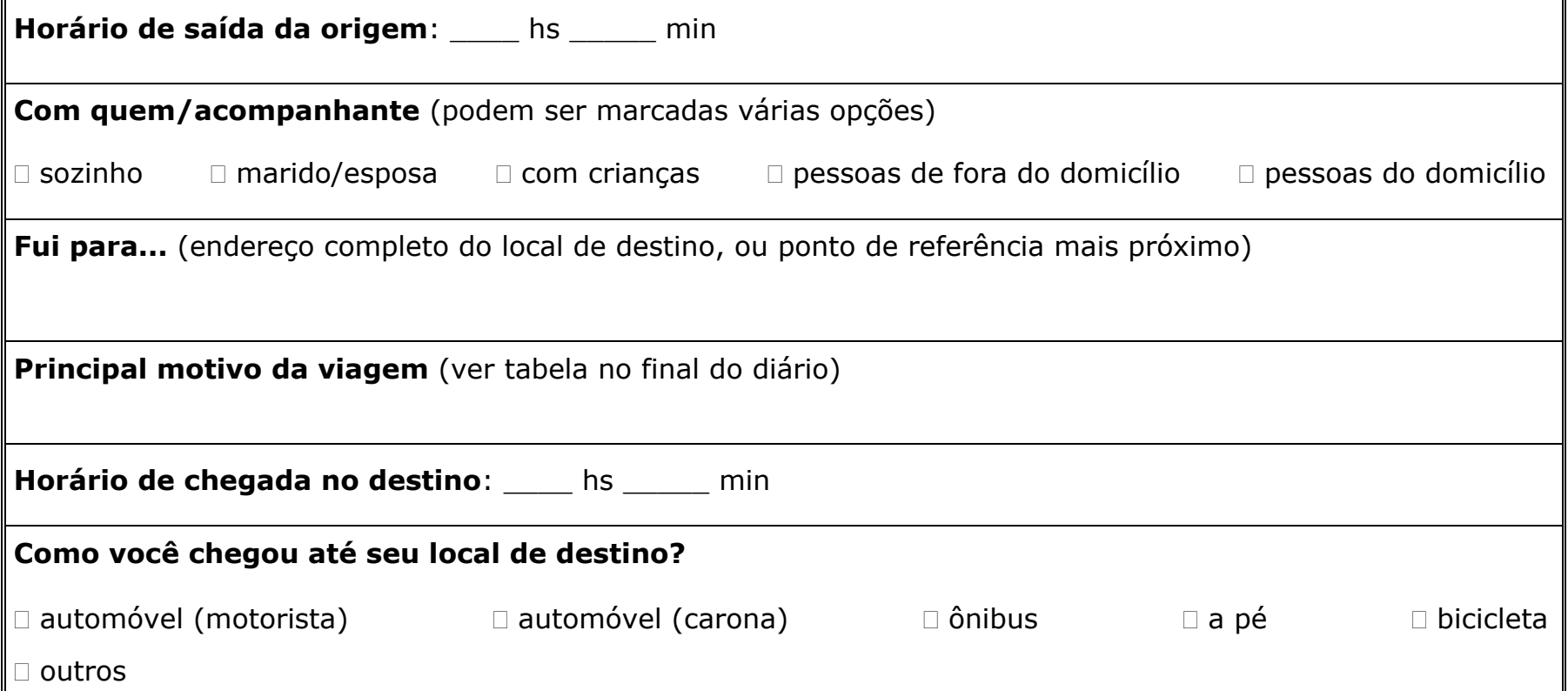

Caso o ônibus tenha sido usado, especificar o tempo de espera no ponto de embarque, e o local do ponto de ônibus em que foi efetuado o desembarque (rua, local de referência ou cruzamento mais próximo, etc.).

Tempo de espera no ponto de ônibus:

Local do ponto de ônibus onde foi feito o desembarque:

Horário de chegada ao ponto de desembarque:

Obs: Lembre-se que sua próxima atividade tem como origem o local de desembarque do ponto de ônibus!

Após chegar ao local de destino, você esperou algum tempo antes de iniciar a atividade?
$\operatorname{Sim}$ minutos $\square$ Não

Você realizou essa atividade... (podem ser marcadas várias opções)

$\square$ sozinho $\square$ marido/esposa $\quad \square$ com crianças $\quad \square$ pessoas de fora do domicílio $\square$ pessoas do domicílio

Esta manhã, você já sabia que teria que realizar a atividade mencionada acima?

$\square \operatorname{Sim} \quad \square$ Não

\section{Essa atividade poderia ser realizada em outro horário?}
Não
$\square$ Sim,
hs
min mais cedo
$\square$ Sim, hs
min mais tarde

Essa atividade poderia ter sido realizada por outra pessoa de seu domicílio?

$\checkmark \operatorname{Sim}$

$\square$ Não

\section{Com que freqüência você realiza essa atividade?}
1 a 2 vezes na semana
2 a 3 vezes na semana
mais de 3 vezes na semana 
Eu estava em... (endereço completo do local de origem ou ponto de referência mais próximo)

Horário de saída da origem:

hs $\min$

Com quem/acompanhante (podem ser marcadas várias opções)

$\square$ sozinho $\square$ marido/esposa $\quad \square$ com crianças $\quad \square$ pessoas de fora do domicílio $\square$ pessoas do domicílio

Fui para... (endereço completo do local de destino, ou ponto de referência mais próximo)

Principal motivo da viagem (ver tabela no final do diário)

Horário de chegada no destino: hs $\min$

Como você chegou até seu local de destino?
automóvel (motorista)
automóvel (carona)
ônibus
a pé
bicicleta

outros

Caso o ônibus tenha sido usado, especificar o tempo de espera no ponto de embarque, e o local do ponto de ônibus em que foi efetuado o desembarque (rua, local de referência ou cruzamento mais próximo, etc.).

Tempo de espera no ponto de ônibus:

Local do ponto de ônibus onde foi feito o desembarque:

Horário de chegada ao ponto de desembarque:

Obs: Lembre-se que sua próxima atividade tem como origem o local de desembarque do ponto de ônibus!

Após chegar ao local de destino, você esperou algum tempo antes de iniciar a atividade?

Sim, minutos $\square$ Não

Você realizou essa atividade... (podem ser marcadas várias opções)

$\checkmark$ sozinho $\square$ marido/esposa $\square$ com crianças $\square$ pessoas de fora do domicílio $\square$ pessoas do domicílio

Esta manhã, você já sabia que teria que realizar a atividade mencionada acima?

Sim $\quad \square$ Não

Essa atividade poderia ser realizada em outro horário?
Não
$\square \operatorname{Sim}$,
hs
min mais cedo
$\square$ Sim, hs
min mais tarde

Essa atividade poderia ter sido realizada por outra pessoa de seu domicílio?

Sim

$\square$ Não

\section{Com que freqüência você realiza essa atividade?}
1 a 2 vezes na semana
2 a 3 vezes na semana
mais de 3 vezes na semana 
Eu estava em... (endereço completo do local de origem ou ponto de referência mais próximo)

Horário de saída da origem:

hs $\min$

Com quem/acompanhante (podem ser marcadas várias opções)

$\square$ sozinho $\square$ marido/esposa $\quad \square$ com crianças $\quad \square$ pessoas de fora do domicílio $\square$ pessoas do domicílio

Fui para... (endereço completo do local de destino, ou ponto de referência mais próximo)

Principal motivo da viagem (ver tabela no final do diário)

Horário de chegada no destino: hs $\min$

Como você chegou até seu local de destino?
automóvel (motorista)
automóvel (carona)
ônibus
a pé
bicicleta

outros

Caso o ônibus tenha sido usado, especificar o tempo de espera no ponto de embarque, e o local do ponto de ônibus em que foi efetuado o desembarque (rua, local de referência ou cruzamento mais próximo, etc.).

Tempo de espera no ponto de ônibus:

Local do ponto de ônibus onde foi feito o desembarque:

Horário de chegada ao ponto de desembarque:

Obs: Lembre-se que sua próxima atividade tem como origem o local de desembarque do ponto de ônibus!

Após chegar ao local de destino, você esperou algum tempo antes de iniciar a atividade?

Sim, minutos $\square$ Não

Você realizou essa atividade... (podem ser marcadas várias opções)

$\square$ sozinho $\square$ marido/esposa $\quad \square$ com crianças $\quad \square$ pessoas de fora do domicílio $\square$ pessoas do domicílio

Esta manhã, você já sabia que teria que realizar a atividade mencionada acima?

Sim $\quad \square$ Não

Essa atividade poderia ser realizada em outro horário?
Não
$\square \operatorname{Sim}$,
hs
min mais cedo
$\square$ Sim, hs
min mais tarde

Essa atividade poderia ter sido realizada por outra pessoa de seu domicílio?

Sim

$\square$ Não

\section{Com que freqüência você realiza essa atividade?}
1 a 2 vezes na semana
2 a 3 vezes na semana
mais de 3 vezes na semana 
Eu estava em... (endereço completo do local de origem ou ponto de referência mais próximo)

Horário de saída da origem:

hs $\min$

Com quem/acompanhante (podem ser marcadas várias opções)

$\square$ sozinho $\square$ marido/esposa $\quad \square$ com crianças $\quad \square$ pessoas de fora do domicílio $\square$ pessoas do domicílio

Fui para... (endereço completo do local de destino, ou ponto de referência mais próximo)

Principal motivo da viagem (ver tabela no final do diário)

Horário de chegada no destino: hs $\min$

Como você chegou até seu local de destino?
automóvel (motorista)
automóvel (carona)
ônibus
a pé
bicicleta

outros

Caso o ônibus tenha sido usado, especificar o tempo de espera no ponto de embarque, e o local do ponto de ônibus em que foi efetuado o desembarque (rua, local de referência ou cruzamento mais próximo, etc.).

Tempo de espera no ponto de ônibus:

Local do ponto de ônibus onde foi feito o desembarque:

Horário de chegada ao ponto de desembarque:

Obs: Lembre-se que sua próxima atividade tem como origem o local de desembarque do ponto de ônibus!

Após chegar ao local de destino, você esperou algum tempo antes de iniciar a atividade?

Sim, minutos $\square$ Não

Você realizou essa atividade... (podem ser marcadas várias opções)

$\square$ sozinho $\square$ marido/esposa $\quad \square$ com crianças $\quad \square$ pessoas de fora do domicílio $\square$ pessoas do domicílio

Esta manhã, você já sabia que teria que realizar a atividade mencionada acima?

Sim $\square$ Não

Essa atividade poderia ser realizada em outro horário?
Não
$\square \operatorname{Sim}$,
hs
min mais cedo
$\square$ Sim, hs
min mais tarde

Essa atividade poderia ter sido realizada por outra pessoa de seu domicílio?

Sim

$\square$ Não

\section{Com que freqüência você realiza essa atividade?}
1 a 2 vezes na semana
2 a 3 vezes na semana
mais de 3 vezes na semana 
Eu estava em... (endereço completo do local de origem ou ponto de referência mais próximo)

Horário de saída da origem:

hs $\min$

Com quem/acompanhante (podem ser marcadas várias opções)

$\square$ sozinho $\square$ marido/esposa $\quad \square$ com crianças $\quad \square$ pessoas de fora do domicílio $\square$ pessoas do domicílio

Fui para... (endereço completo do local de destino, ou ponto de referência mais próximo)

Principal motivo da viagem (ver tabela no final do diário)

Horário de chegada no destino: hs $\min$

Como você chegou até seu local de destino?
automóvel (motorista)
automóvel (carona)
ônibus
a pé
bicicleta

outros

Caso o ônibus tenha sido usado, especificar o tempo de espera no ponto de embarque, e o local do ponto de ônibus em que foi efetuado o desembarque (rua, local de referência ou cruzamento mais próximo, etc.).

Tempo de espera no ponto de ônibus:

Local do ponto de ônibus onde foi feito o desembarque:

Horário de chegada ao ponto de desembarque:

Obs: Lembre-se que sua próxima atividade tem como origem o local de desembarque do ponto de ônibus!

Após chegar ao local de destino, você esperou algum tempo antes de iniciar a atividade?

Sim, minutos $\square$ Não

Você realizou essa atividade... (podem ser marcadas várias opções)

$\square$ sozinho $\square$ marido/esposa $\quad \square$ com crianças $\quad \square$ pessoas de fora do domicílio $\square$ pessoas do domicílio

Esta manhã, você já sabia que teria que realizar a atividade mencionada acima?

Sim $\quad \square$ Não

Essa atividade poderia ser realizada em outro horário?
Não
$\square \operatorname{Sim}$,
hs
min mais cedo
$\square$ Sim, hs
min mais tarde

Essa atividade poderia ter sido realizada por outra pessoa de seu domicílio?

Sim

$\square$ Não

\section{Com que freqüência você realiza essa atividade?}
1 a 2 vezes na semana
2 a 3 vezes na semana
mais de 3 vezes na semana 
Eu estava em... (endereço completo do local de origem ou ponto de referência mais próximo)

Horário de saída da origem:

hs $\min$

Com quem/acompanhante (podem ser marcadas várias opções)

$\square$ sozinho $\square$ marido/esposa $\quad \square$ com crianças $\quad \square$ pessoas de fora do domicílio $\square$ pessoas do domicílio

Fui para... (endereço completo do local de destino, ou ponto de referência mais próximo)

Principal motivo da viagem (ver tabela no final do diário)

Horário de chegada no destino: hs $\min$

Como você chegou até seu local de destino?
automóvel (motorista)
automóvel (carona)
ônibus
a pé
bicicleta

outros

Caso o ônibus tenha sido usado, especificar o tempo de espera no ponto de embarque, e o local do ponto de ônibus em que foi efetuado o desembarque (rua, local de referência ou cruzamento mais próximo, etc.).

Tempo de espera no ponto de ônibus:

Local do ponto de ônibus onde foi feito o desembarque:

Horário de chegada ao ponto de desembarque:

Obs: Lembre-se que sua próxima atividade tem como origem o local de desembarque do ponto de ônibus!

Após chegar ao local de destino, você esperou algum tempo antes de iniciar a atividade?

Sim, minutos $\square$ Não

Você realizou essa atividade... (podem ser marcadas várias opções)

$\square$ sozinho $\square$ marido/esposa $\quad \square$ com crianças $\quad \square$ pessoas de fora do domicílio $\square$ pessoas do domicílio

Esta manhã, você já sabia que teria que realizar a atividade mencionada acima?

Sim $\quad \square$ Não

Essa atividade poderia ser realizada em outro horário?
Não
$\square \operatorname{Sim}$,
hs
min mais cedo
$\square$ Sim, hs
min mais tarde

Essa atividade poderia ter sido realizada por outra pessoa de seu domicílio?

Sim

$\square$ Não

\section{Com que freqüência você realiza essa atividade?}
1 a 2 vezes na semana
2 a 3 vezes na semana
mais de 3 vezes na semana 
Eu estava em... (endereço completo do local de origem ou ponto de referência mais próximo)

Horário de saída da origem:

hs $\min$

Com quem/acompanhante (podem ser marcadas várias opções)

$\square$ sozinho $\square$ marido/esposa $\quad \square$ com crianças $\quad \square$ pessoas de fora do domicílio $\square$ pessoas do domicílio

Fui para... (endereço completo do local de destino, ou ponto de referência mais próximo)

Principal motivo da viagem (ver tabela no final do diário)

Horário de chegada no destino: hs $\min$

Como você chegou até seu local de destino?
automóvel (motorista)
automóvel (carona)
ônibus
a pé
bicicleta

outros

Caso o ônibus tenha sido usado, especificar o tempo de espera no ponto de embarque, e o local do ponto de ônibus em que foi efetuado o desembarque (rua, local de referência ou cruzamento mais próximo, etc.).

Tempo de espera no ponto de ônibus:

Local do ponto de ônibus onde foi feito o desembarque:

Horário de chegada ao ponto de desembarque:

Obs: Lembre-se que sua próxima atividade tem como origem o local de desembarque do ponto de ônibus!

Após chegar ao local de destino, você esperou algum tempo antes de iniciar a atividade?

Sim, minutos $\square$ Não

Você realizou essa atividade... (podem ser marcadas várias opções)

$\square$ sozinho $\square$ marido/esposa $\quad \square$ com crianças $\quad \square$ pessoas de fora do domicílio $\square$ pessoas do domicílio

Esta manhã, você já sabia que teria que realizar a atividade mencionada acima?

Sim $\quad \square$ Não

Essa atividade poderia ser realizada em outro horário?
Não
$\square \operatorname{Sim}$,
hs
min mais cedo
$\square$ Sim, hs
min mais tarde

Essa atividade poderia ter sido realizada por outra pessoa de seu domicílio?

Sim

$\square$ Não

\section{Com que freqüência você realiza essa atividade?}
1 a 2 vezes na semana
2 a 3 vezes na semana
mais de 3 vezes na semana 
Eu estava em... (endereço completo do local de origem ou ponto de referência mais próximo)

Horário de saída da origem:

hs $\min$

Com quem/acompanhante (podem ser marcadas várias opções)

$\square$ sozinho $\square$ marido/esposa $\quad \square$ com crianças $\quad \square$ pessoas de fora do domicílio $\square$ pessoas do domicílio

Fui para... (endereço completo do local de destino, ou ponto de referência mais próximo)

Principal motivo da viagem (ver tabela no final do diário)

Horário de chegada no destino: hs $\min$

Como você chegou até seu local de destino?
automóvel (motorista)
automóvel (carona)
ônibus
a pé
bicicleta

outros

Caso o ônibus tenha sido usado, especificar o tempo de espera no ponto de embarque, e o local do ponto de ônibus em que foi efetuado o desembarque (rua, local de referência ou cruzamento mais próximo, etc.).

Tempo de espera no ponto de ônibus:

Local do ponto de ônibus onde foi feito o desembarque:

Horário de chegada ao ponto de desembarque:

Obs: Lembre-se que sua próxima atividade tem como origem o local de desembarque do ponto de ônibus!

Após chegar ao local de destino, você esperou algum tempo antes de iniciar a atividade?

Sim, minutos $\square$ Não

Você realizou essa atividade... (podem ser marcadas várias opções)

$\square$ sozinho $\square$ marido/esposa $\quad \square$ com crianças $\quad \square$ pessoas de fora do domicílio $\square$ pessoas do domicílio

Esta manhã, você já sabia que teria que realizar a atividade mencionada acima?

Sim $\square$ Não

Essa atividade poderia ser realizada em outro horário?
Não
$\square \operatorname{Sim}$,
hs
min mais cedo
$\square$ Sim, hs
min mais tarde

Essa atividade poderia ter sido realizada por outra pessoa de seu domicílio?

Sim

$\square$ Não

\section{Com que freqüência você realiza essa atividade?}
1 a 2 vezes na semana
2 a 3 vezes na semana
mais de 3 vezes na semana 
Eu estava em... (endereço completo do local de origem ou ponto de referência mais próximo)

Horário de saída da origem:

hs $\min$

Com quem/acompanhante (podem ser marcadas várias opções)

$\square$ sozinho $\square$ marido/esposa $\quad \square$ com crianças $\quad \square$ pessoas de fora do domicílio $\square$ pessoas do domicílio

Fui para... (endereço completo do local de destino, ou ponto de referência mais próximo)

Principal motivo da viagem (ver tabela no final do diário)

Horário de chegada no destino: hs $\min$

Como você chegou até seu local de destino?
automóvel (motorista)
automóvel (carona)
ônibus
a pé
bicicleta

outros

Caso o ônibus tenha sido usado, especificar o tempo de espera no ponto de embarque, e o local do ponto de ônibus em que foi efetuado o desembarque (rua, local de referência ou cruzamento mais próximo, etc.).

Tempo de espera no ponto de ônibus:

Local do ponto de ônibus onde foi feito o desembarque:

Horário de chegada ao ponto de desembarque:

Obs: Lembre-se que sua próxima atividade tem como origem o local de desembarque do ponto de ônibus!

Após chegar ao local de destino, você esperou algum tempo antes de iniciar a atividade?

Sim, minutos $\square$ Não

Você realizou essa atividade... (podem ser marcadas várias opções)

$\square$ sozinho $\square$ marido/esposa $\quad \square$ com crianças $\quad \square$ pessoas de fora do domicílio $\square$ pessoas do domicílio

Esta manhã, você já sabia que teria que realizar a atividade mencionada acima?

Sim $\square$ Não

Essa atividade poderia ser realizada em outro horário?
Não
$\square \operatorname{Sim}$,
hs
min mais cedo
$\square$ Sim, hs
min mais tarde

Essa atividade poderia ter sido realizada por outra pessoa de seu domicílio?

Sim

$\square$ Não

\section{Com que freqüência você realiza essa atividade?}
1 a 2 vezes na semana
2 a 3 vezes na semana
mais de 3 vezes na semana 


\title{
DIÁRIO DE ATIVIDADES
}

\author{
$2^{\circ}$ DIA
}

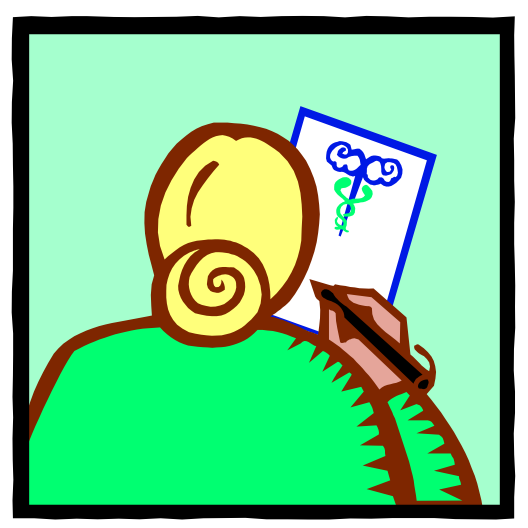

Data de preenchimento

20 Dia: 1 
Eu estava em... (endereço completo do local de origem ou ponto de referência mais próximo)

Horário de saída da origem:

hs $\min$

Com quem/acompanhante (podem ser marcadas várias opções)

sozinho

$\square$ marido/esposa

$\square$ com crianças

pessoas de fora do domicílio

pessoas do domicílio

Fui para... (endereço completo do local de destino, ou ponto de referência mais próximo)

Principal motivo da viagem (ver tabela no final do diário)

Horário de chegada no destino:

hs $\min$

\section{Como você chegou até seu local de destino?}
automóvel (motorista)
automóvel (carona)
ônibus
a pé
bicicleta
outros

Caso o ônibus tenha sido usado, especificar o tempo de espera no ponto de embarque, e o local do ponto de ônibus em que foi efetuado o desembarque (rua, local de referência ou cruzamento mais próximo, etc.).

Tempo de espera no ponto de ônibus:

Local do ponto de ônibus onde foi feito o desembarque:

Horário de chegada ao ponto de desembarque:

Obs: Lembre-se que sua próxima atividade tem como origem o local de desembarque do ponto de ônibus!

Após chegar ao local de destino, você esperou algum tempo antes de iniciar a atividade?

Sim, minutos $\square$ Não

Você realizou essa atividade... (podem ser marcadas várias opções)

$\square$ sozinho $\square$ marido/esposa $\quad \square$ com crianças $\quad \square$ pessoas de fora do domicílio $\square$ pessoas do domicílio

Esta manhã, você já sabia que teria que realizar a atividade mencionada acima?

$\operatorname{Sim}$ $\square$ Não

Essa atividade poderia ser realizada em outro horário?
Não
$\square \operatorname{Sim}$
hs
min mais cedo
$\checkmark$ Sim, hs min mais tarde

Essa atividade poderia ter sido realizada por outra pessoa de seu domicílio?

Sim $\square$ Não

\section{Com que freqüência você realiza essa atividade?}
1 a 2 vezes na semana
2 a 3 vezes na semana
mais de 3 vezes na semana 
Eu estava em... (endereço completo do local de origem ou ponto de referência mais próximo)

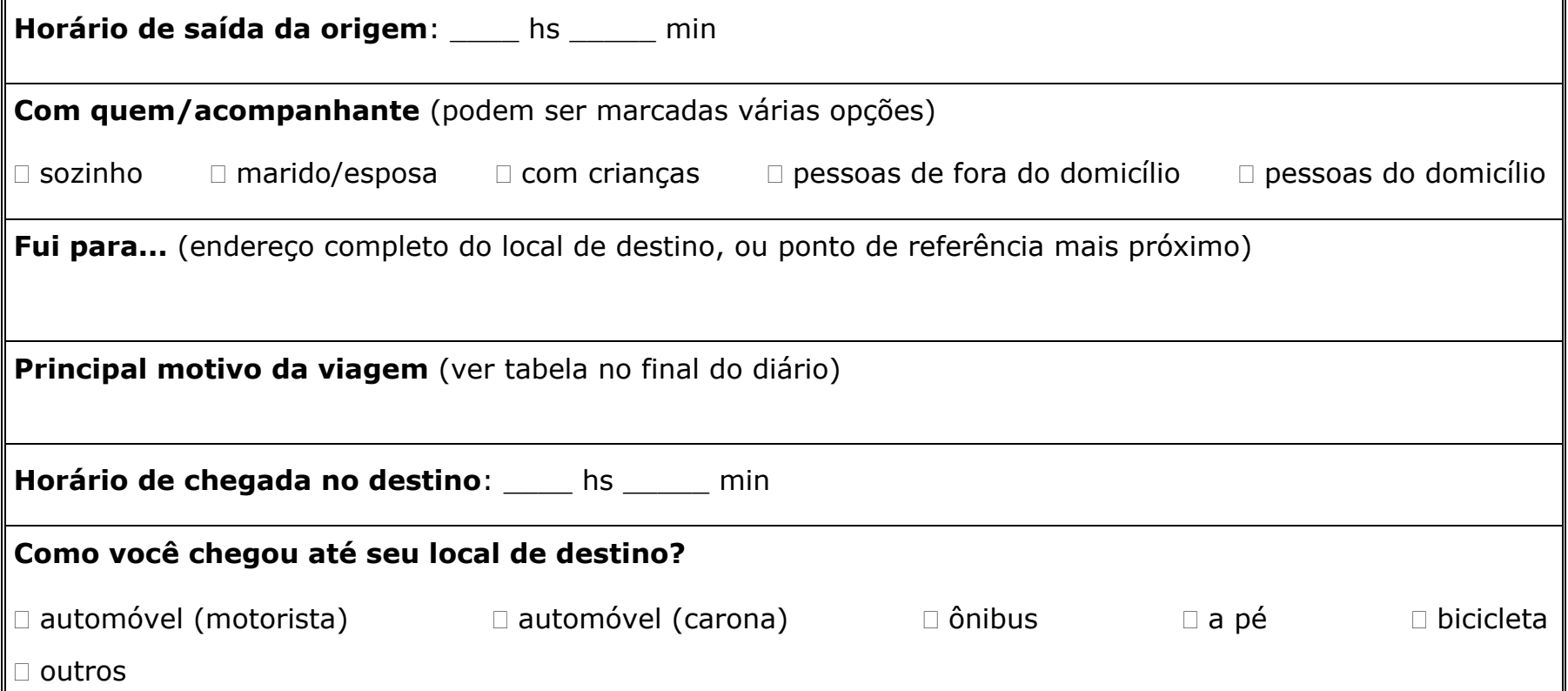

Caso o ônibus tenha sido usado, especificar o tempo de espera no ponto de embarque, e o local do ponto de ônibus em que foi efetuado o desembarque (rua, local de referência ou cruzamento mais próximo, etc.).

Tempo de espera no ponto de ônibus:

Local do ponto de ônibus onde foi feito o desembarque:

Horário de chegada ao ponto de desembarque:

Obs: Lembre-se que sua próxima atividade tem como origem o local de desembarque do ponto de ônibus!

Após chegar ao local de destino, você esperou algum tempo antes de iniciar a atividade?
$\operatorname{Sim}$ minutos $\square$ Não

Você realizou essa atividade... (podem ser marcadas várias opções)

$\square$ sozinho $\square$ marido/esposa $\quad \square$ com crianças $\quad \square$ pessoas de fora do domicílio $\square$ pessoas do domicílio

Esta manhã, você já sabia que teria que realizar a atividade mencionada acima?

$\square$ Sim $\square$ Não

Essa atividade poderia ser realizada em outro horário?
Não
$\square \operatorname{Sim}$,
hs
min mais cedo
$\square$ Sim, hs
min mais tarde

Essa atividade poderia ter sido realizada por outra pessoa de seu domicílio?

Sim

$\square$ Não

Com que freqüência você realiza essa atividade?
1 a 2 vezes na semana
2 a 3 vezes na semana
mais de 3 vezes na semana 
Eu estava em... (endereço completo do local de origem ou ponto de referência mais próximo)

Horário de saída da origem:

hs $\min$

Com quem/acompanhante (podem ser marcadas várias opções)

sozinho

$\square$ marido/esposa

$\checkmark$ com crianças

pessoas de fora do domicílio

pessoas do domicílio

Fui para... (endereço completo do local de destino, ou ponto de referência mais próximo)

Principal motivo da viagem (ver tabela no final do diário)

Horário de chegada no destino:

hs $\min$

\section{Como você chegou até seu local de destino?}
automóvel (motorista)
automóvel (carona)
ônibus
a pé
bicicleta
outros

Caso o ônibus tenha sido usado, especificar o tempo de espera no ponto de embarque, e o local do ponto de ônibus em que foi efetuado o desembarque (rua, local de referência ou cruzamento mais próximo, etc.).

Tempo de espera no ponto de ônibus:

Local do ponto de ônibus onde foi feito o desembarque:

Horário de chegada ao ponto de desembarque:

Obs: Lembre-se que sua próxima atividade tem como origem o local de desembarque do ponto de ônibus!

Após chegar ao local de destino, você esperou algum tempo antes de iniciar a atividade?

Sim, minutos $\square$ Não

Você realizou essa atividade... (podem ser marcadas várias opções)

$\square$ sozinho $\square$ marido/esposa $\quad \square$ com crianças $\quad \square$ pessoas de fora do domicílio $\square$ pessoas do domicílio

Esta manhã, você já sabia que teria que realizar a atividade mencionada acima?

$\operatorname{Sim}$ $\square$ Não

Essa atividade poderia ser realizada em outro horário?
Não
$\square \operatorname{Sim}$
hs
min mais cedo
$\checkmark$ Sim, hs min mais tarde

Essa atividade poderia ter sido realizada por outra pessoa de seu domicílio?

Sim $\square$ Não

\section{Com que freqüência você realiza essa atividade?}
1 a 2 vezes na semana
2 a 3 vezes na semana
mais de 3 vezes na semana 


\section{Atividade 4 - Dia 2}

Eu estava em... (endereço completo do local de origem ou ponto de referência mais próximo)

Horário de saída da origem:

hs $\min$

Com quem/acompanhante (podem ser marcadas várias opções)

sozinho

$\square$ marido/esposa

$\square$ com crianças

pessoas de fora do domicílio

pessoas do domicílio

Fui para... (endereço completo do local de destino, ou ponto de referência mais próximo)

Principal motivo da viagem (ver tabela no final do diário)

Horário de chegada no destino: hs $\min$

\section{Como você chegou até seu local de destino?}
automóvel (motorista)
automóvel (carona)
ônibus
a pé
bicicleta
outros

Caso o ônibus tenha sido usado, especificar o tempo de espera no ponto de embarque, e o local do ponto de ônibus em que foi efetuado o desembarque (rua, local de referência ou cruzamento mais próximo, etc.).

Tempo de espera no ponto de ônibus:

Local do ponto de ônibus onde foi feito o desembarque:

Horário de chegada ao ponto de desembarque:

Obs: Lembre-se que sua próxima atividade tem como origem o local de desembarque do ponto de ônibus!

Após chegar ao local de destino, você esperou algum tempo antes de iniciar a atividade?

Sim, minutos $\neg$ Não

Você realizou essa atividade... (podem ser marcadas várias opções)

$\neg$ sozinho $\square$ marido/esposa $\square$ com crianças $\square$ pessoas de fora do domicílio $\square$ pessoas do domicílio

Esta manhã, você já sabia que teria que realizar a atividade mencionada acima?

$\operatorname{Sim}$ $\square$ Não

Essa atividade poderia ser realizada em outro horário?
Não
$\square \operatorname{Sim}$,
hs
min mais cedo
$\neg \operatorname{Sim}$, hs min mais tarde

Essa atividade poderia ter sido realizada por outra pessoa de seu domicílio?

$\operatorname{Sim}$ $\square$ Não

Com que freqüência você realiza essa atividade?
1 a 2 vezes na semana
2 a 3 vezes na semana
mais de 3 vezes na semana 


\section{Atividade 5 - Dia 2}

Eu estava em... (endereço completo do local de origem ou ponto de referência mais próximo)

Horário de saída da origem:

hs $\min$

Com quem/acompanhante (podem ser marcadas várias opções)

sozinho

$\square$ marido/esposa

$\square$ com crianças

pessoas de fora do domicílio

pessoas do domicílio

Fui para... (endereço completo do local de destino, ou ponto de referência mais próximo)

Principal motivo da viagem (ver tabela no final do diário)

Horário de chegada no destino:

hs $\min$

\section{Como você chegou até seu local de destino?}
automóvel (motorista)
automóvel (carona)
ônibus
a pé
bicicleta

outros

Caso o ônibus tenha sido usado, especificar o tempo de espera no ponto de embarque, e o local do ponto de ônibus em que foi efetuado o desembarque (rua, local de referência ou cruzamento mais próximo, etc.).

Tempo de espera no ponto de ônibus:

Local do ponto de ônibus onde foi feito o desembarque:

Horário de chegada ao ponto de desembarque:

Obs: Lembre-se que sua próxima atividade tem como origem o local de desembarque do ponto de ônibus!

Após chegar ao local de destino, você esperou algum tempo antes de iniciar a atividade?

Sim, minutos $\square$ Não

Você realizou essa atividade... (podem ser marcadas várias opções)

$\neg$ sozinho $\square$ marido/esposa $\square$ com crianças $\square$ pessoas de fora do domicílio $\square$ pessoas do domicílio

Esta manhã, você já sabia que teria que realizar a atividade mencionada acima?

$\operatorname{Sim}$ $\square$ Não

Essa atividade poderia ser realizada em outro horário?
Não
$\square \operatorname{Sim}$,
hs
min mais cedo
$\neg \operatorname{Sim}$, hs min mais tarde

Essa atividade poderia ter sido realizada por outra pessoa de seu domicílio?

$\operatorname{Sim}$ $\square$ Não

Com que freqüência você realiza essa atividade?
1 a 2 vezes na semana
2 a 3 vezes na semana
mais de 3 vezes na semana 


\section{Atividade 6 - Dia 2}

Eu estava em... (endereço completo do local de origem ou ponto de referência mais próximo)

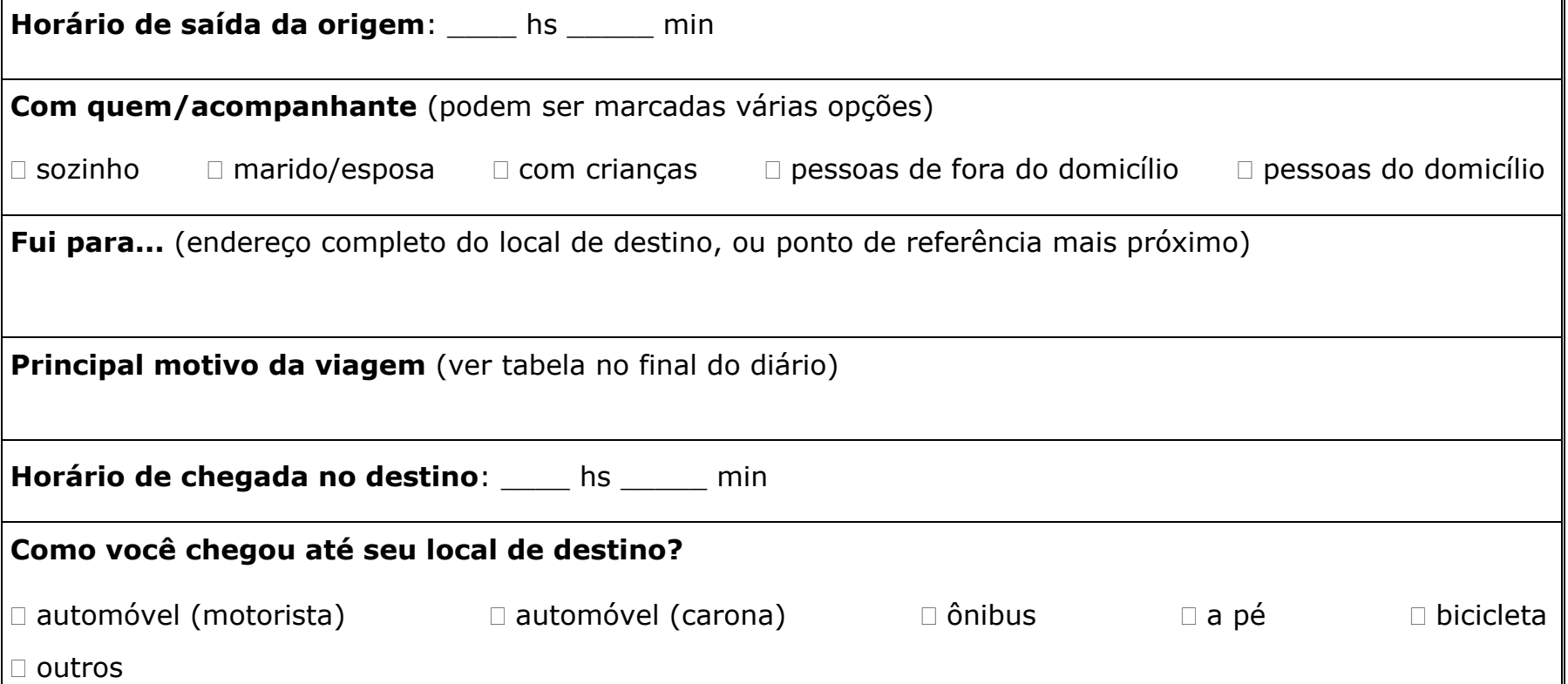

Caso o ônibus tenha sido usado, especificar o tempo de espera no ponto de embarque, e o local do ponto de ônibus em que foi efetuado o desembarque (rua, local de referência ou cruzamento mais próximo, etc.).

Tempo de espera no ponto de ônibus:

Local do ponto de ônibus onde foi feito o desembarque:

Horário de chegada ao ponto de desembarque:

Obs: Lembre-se que sua próxima atividade tem como origem o local de desembarque do ponto de ônibus!

\section{Após chegar ao local de destino, você esperou algum tempo antes de iniciar a atividade?}

Sim, minutos $\square$ Não

Você realizou essa atividade... (podem ser marcadas várias opções)

$\square$ sozinho $\square$ marido/esposa $\quad \square$ com crianças $\quad \square$ pessoas de fora do domicílio $\square$ pessoas do domicílio

Esta manhã, você já sabia que teria que realizar a atividade mencionada acima?

Sim $\square$ Não

\section{Essa atividade poderia ser realizada em outro horário?}
Não
$\square \operatorname{Sim}$,
hs
min mais cedo
$\square \operatorname{Sim}$, hs
min mais tarde

Essa atividade poderia ter sido realizada por outra pessoa de seu domicílio?

Sim

$\square$ Não

\section{Com que freqüência você realiza essa atividade?}
1 a 2 vezes na semana
2 a 3 vezes na semana
mais de 3 vezes na semana 


\section{Atividade 7 - Dia 2}

Eu estava em... (endereço completo do local de origem ou ponto de referência mais próximo)

Horário de saída da origem:

hs $\min$

Com quem/acompanhante (podem ser marcadas várias opções)

sozinho

$\square$ marido/esposa

$\square$ com crianças

pessoas de fora do domicílio

pessoas do domicílio

Fui para... (endereço completo do local de destino, ou ponto de referência mais próximo)

Principal motivo da viagem (ver tabela no final do diário)

Horário de chegada no destino:

hs $\min$

\section{Como você chegou até seu local de destino?}
automóvel (motorista)
automóvel (carona)
ônibus
a pé
bicicleta

outros

Caso o ônibus tenha sido usado, especificar o tempo de espera no ponto de embarque, e o local do ponto de ônibus em que foi efetuado o desembarque (rua, local de referência ou cruzamento mais próximo, etc.).

Tempo de espera no ponto de ônibus:

Local do ponto de ônibus onde foi feito o desembarque:

Horário de chegada ao ponto de desembarque:

Obs: Lembre-se que sua próxima atividade tem como origem o local de desembarque do ponto de ônibus!

Após chegar ao local de destino, você esperou algum tempo antes de iniciar a atividade?

Sim, minutos $\square$ Não

Você realizou essa atividade... (podem ser marcadas várias opções)

$\neg$ sozinho $\square$ marido/esposa $\square$ com crianças $\square$ pessoas de fora do domicílio $\square$ pessoas do domicílio

Esta manhã, você já sabia que teria que realizar a atividade mencionada acima?

$\operatorname{Sim}$ $\square$ Não

Essa atividade poderia ser realizada em outro horário?
Não
$\square \operatorname{Sim}$,
hs
min mais cedo
$\neg \operatorname{Sim}$, hs min mais tarde

Essa atividade poderia ter sido realizada por outra pessoa de seu domicílio?

$\operatorname{Sim}$ $\square$ Não

Com que freqüência você realiza essa atividade?
1 a 2 vezes na semana
2 a 3 vezes na semana
mais de 3 vezes na semana 
Eu estava em... (endereço completo do local de origem ou ponto de referência mais próximo)

Horário de saída da origem:

hs $\min$

Com quem/acompanhante (podem ser marcadas várias opções)

$\square$ sozinho $\square$ marido/esposa $\quad \square$ com crianças $\quad \square$ pessoas de fora do domicílio $\square$ pessoas do domicílio

Fui para... (endereço completo do local de destino, ou ponto de referência mais próximo)

Principal motivo da viagem (ver tabela no final do diário)

Horário de chegada no destino: hs $\min$

Como você chegou até seu local de destino?
automóvel (motorista)
automóvel (carona)
ônibus
a pé
bicicleta

outros

Caso o ônibus tenha sido usado, especificar o tempo de espera no ponto de embarque, e o local do ponto de ônibus em que foi efetuado o desembarque (rua, local de referência ou cruzamento mais próximo, etc.).

Tempo de espera no ponto de ônibus:

Local do ponto de ônibus onde foi feito o desembarque:

Horário de chegada ao ponto de desembarque:

Obs: Lembre-se que sua próxima atividade tem como origem o local de desembarque do ponto de ônibus!

Após chegar ao local de destino, você esperou algum tempo antes de iniciar a atividade?

Sim, minutos $\square$ Não

Você realizou essa atividade... (podem ser marcadas várias opções)

$\square$ sozinho $\square$ marido/esposa $\quad \square$ com crianças $\quad \square$ pessoas de fora do domicílio $\square$ pessoas do domicílio

Esta manhã, você já sabia que teria que realizar a atividade mencionada acima?

Sim $\square$ Não

Essa atividade poderia ser realizada em outro horário?
Não
$\square \operatorname{Sim}$,
hs
min mais cedo
$\square$ Sim, hs
min mais tarde

Essa atividade poderia ter sido realizada por outra pessoa de seu domicílio?

Sim

$\square$ Não

\section{Com que freqüência você realiza essa atividade?}
1 a 2 vezes na semana
2 a 3 vezes na semana
mais de 3 vezes na semana 


\section{Atividade 9 - Dia 2}

Eu estava em... (endereço completo do local de origem ou ponto de referência mais próximo)

Horário de saída da origem:

hs $\min$

Com quem/acompanhante (podem ser marcadas várias opções)

sozinho

$\square$ marido/esposa

$\square$ com crianças

pessoas de fora do domicílio

pessoas do domicílio

Fui para... (endereço completo do local de destino, ou ponto de referência mais próximo)

Principal motivo da viagem (ver tabela no final do diário)

Horário de chegada no destino:

hs $\min$

\section{Como você chegou até seu local de destino?}
automóvel (motorista)
automóvel (carona)
ônibus
a pé
bicicleta

outros

Caso o ônibus tenha sido usado, especificar o tempo de espera no ponto de embarque, e o local do ponto de ônibus em que foi efetuado o desembarque (rua, local de referência ou cruzamento mais próximo, etc.).

Tempo de espera no ponto de ônibus:

Local do ponto de ônibus onde foi feito o desembarque:

Horário de chegada ao ponto de desembarque:

Obs: Lembre-se que sua próxima atividade tem como origem o local de desembarque do ponto de ônibus!

Após chegar ao local de destino, você esperou algum tempo antes de iniciar a atividade?

Sim, minutos $\square$ Não

Você realizou essa atividade... (podem ser marcadas várias opções)

$\neg$ sozinho $\square$ marido/esposa $\square$ com crianças $\square$ pessoas de fora do domicílio $\square$ pessoas do domicílio

Esta manhã, você já sabia que teria que realizar a atividade mencionada acima?

$\operatorname{Sim}$ $\square$ Não

Essa atividade poderia ser realizada em outro horário?
Não
$\square \operatorname{Sim}$,
hs
min mais cedo
$\neg \operatorname{Sim}$, hs min mais tarde

Essa atividade poderia ter sido realizada por outra pessoa de seu domicílio?

$\operatorname{Sim}$ $\square$ Não

Com que freqüência você realiza essa atividade?
1 a 2 vezes na semana
2 a 3 vezes na semana
mais de 3 vezes na semana 
Eu estava em... (endereço completo do local de origem ou ponto de referência mais próximo)

Horário de saída da origem:

hs $\min$

Com quem/acompanhante (podem ser marcadas várias opções)

$\square$ sozinho $\square$ marido/esposa $\quad \square$ com crianças $\quad \square$ pessoas de fora do domicílio $\square$ pessoas do domicílio

Fui para... (endereço completo do local de destino, ou ponto de referência mais próximo)

Principal motivo da viagem (ver tabela no final do diário)

Horário de chegada no destino: hs $\min$

Como você chegou até seu local de destino?
automóvel (motorista)
automóvel (carona)
ônibus
a pé
bicicleta

outros

Caso o ônibus tenha sido usado, especificar o tempo de espera no ponto de embarque, e o local do ponto de ônibus em que foi efetuado o desembarque (rua, local de referência ou cruzamento mais próximo, etc.).

Tempo de espera no ponto de ônibus:

Local do ponto de ônibus onde foi feito o desembarque:

Horário de chegada ao ponto de desembarque:

Obs: Lembre-se que sua próxima atividade tem como origem o local de desembarque do ponto de ônibus!

Após chegar ao local de destino, você esperou algum tempo antes de iniciar a atividade?

Sim, minutos $\square$ Não

Você realizou essa atividade... (podem ser marcadas várias opções)

$\square$ sozinho $\square$ marido/esposa $\quad \square$ com crianças $\quad \square$ pessoas de fora do domicílio $\square$ pessoas do domicílio

Esta manhã, você já sabia que teria que realizar a atividade mencionada acima?

Sim $\square$ Não

Essa atividade poderia ser realizada em outro horário?
Não
$\square \operatorname{Sim}$,
hs
min mais cedo
$\square$ Sim, hs
min mais tarde

Essa atividade poderia ter sido realizada por outra pessoa de seu domicílio?

Sim

$\square$ Não

\section{Com que freqüência você realiza essa atividade?}
1 a 2 vezes na semana
2 a 3 vezes na semana
mais de 3 vezes na semana 
OBRIGADA POR SUA PARTICIPAÇÃO!

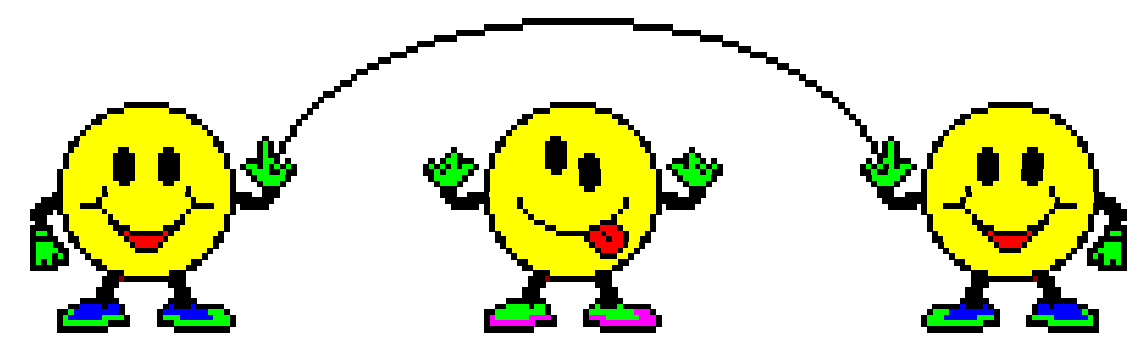

